\title{
3D Seismic Traveltime Tomography of the Central South Island, New Zealand
}

Nicolas Eduard Alype Brikke

\author{
A thesis submitted in fulfilment of \\ the requirements for the degree of \\ Masters in Science \\ in Geophysics
}

\author{
Institute of Geophysics \\ School of Geography, Environment and Earth Sciences \\ Victoria University of Wellington \\ Te Whare Wānanga o te Upoko o te Ika a Māui \\ Wellington, New Zealand
}

November 2010 


\section{Frontispiece}

In many religions and traditional beliefs around the world, the Earth is worshipped and personified as a feminine divinity because of the life she gives birth to. Like a drop of poetry, humanism and creativity in an ocean of science, numbers and pragmatism, here follows an ode to the Earth and its strength, symbolised by "Wrickta Scale", the English Creole term for Richter scale:

She sight up the most high In conversation all the while But I have seen a form of godliness

And a conscious style

She is humble, she is gentle

She is such and such

But can she find the mental toughness

When things get rough

Wrickta scale, Wrickta scale

We never gonna fail I know

Never gonna fail

Visit her body

With the frequency

Visit her mind

With the frequency

Come enhance her earth cell

Come enhance her creativity

She rocking the world from antiquity

Wrickta scale, Wrickta scale

We never gonna fail I know

Never gonna fail

Extract of "Wrickta Scale", Vaughn Benjamin, Midnite. 


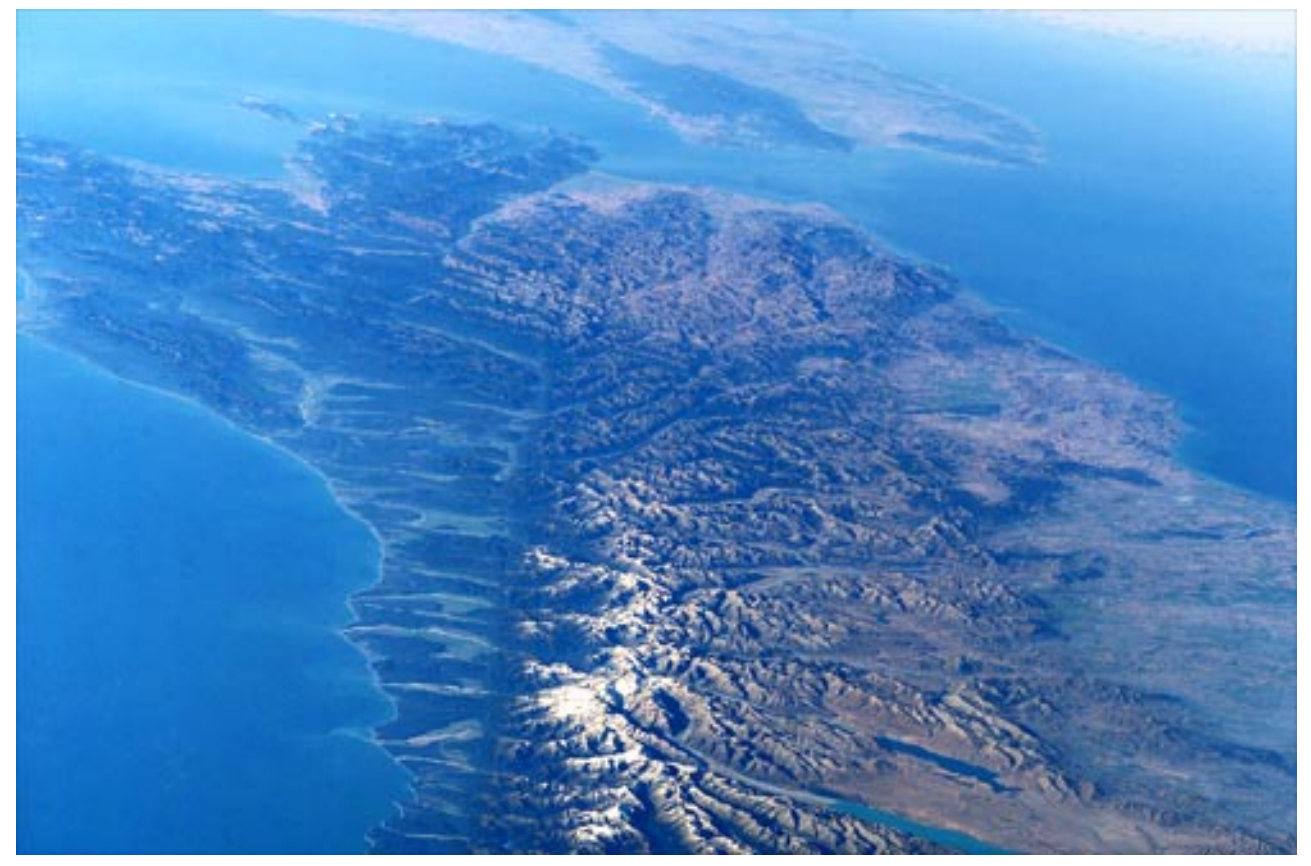

Figure 1: Picture from the NASA looking NNE along the Alpine fault. 


\section{Acknowledgements}

I would like to express my greatest gratitude to my primary supervisor Tim Stern for guiding me throughout this project which has proven, on more than one occasion, to be longer than expected. My second supervisor, Nick Rawlinson (Australian National University), is greatly thanked for his precious and constructive assistance regarding FMTOMO and for an enjoyable stay in Canberra. This project also benefited from the input and advice of Stephen Bannister (GNS Science).

I acknowledge the help of the following researchers:

- Harm van Avendonk (University of Texas Institute of Geophysics)

- Martin Scherwath (University of Kiel)

- Geoffroy Lamarche and Arne Pallentin (National Institute for Weather and Atmosphere)

The input of Mark Henderson (Victoria University of Wellington (VUW)) to this project has been invaluable and his patience and support were greatly appreciated. Adrian Benson and Yannik Behr are thanked for their script-writing assistance and general helpfulness and good vibes. I thank Mark Henderson, Susi Woelz and Sandra Bourguignon for proof-reading my thesis.

Thanks to the co-students of the department of Geophysics at VUW. Special Big Ups to Erik Ewig, Jan Baur, Anya Seward, Syuhada, Dan Bassett.

I am infinitely grateful to my parents that allowed me to study without worrying about financial issues. I am ever-thankful for my parents' and my sister's trust and support, the completion of this project wouldn't have been possible without it. Thank you Kirsten for assisting me in the last run towards completion. 


\section{Abstract}

The three-dimensional (3D) evolution of the Australian-Pacific late boundary in the central South Island of New Zealand is investigated by analysing seismic data from the South Island GeopHysical Transect (SIGHT) project and by using a novel 3D tomography inversion method, FMTOMO. A $380 \mathrm{~km}$-long, $350 \mathrm{~km}$-wide and $56 \mathrm{~km}$-deep 3D tomography image of the P-wave velocity structure and interface geometry of the crust and upper-mantle is constructed by inverting for 164,048 traveltime picks. The picks are both coincident (in-line) and oblique (cross-line) to the survey geometry. The traveltime picks and station elevations were static corrected and reduced to basement level, respectively, to eliminate the highly variable sedimentary component of the inversion process. Synthetic testing of the model space was carried out to help the interpretation of the solution model features.

Some model features are consistent with previous results. Usual crustal velocities $(5.5 \mathrm{~km} / \mathrm{s}$ close to the surface and $6.3 \mathrm{~km} / \mathrm{s}$ at the bottom of the crust) are found at distal ends of the collision zone. Lower velocities $(5.7 \mathrm{~km} / \mathrm{s})$ intrude the mid-crust of the Australian plate to depths of about $20 \mathrm{~km}$, which is consistent with the downward flexure of the Australian plate. A low velocity zone $(5.9-6.1 \mathrm{~km} / \mathrm{s})$ is situated to the southeast of the Alpine fault, which is consistent with the Alpine fault low velocity zone. Furthermore, a high-velocity body $(6.3 \mathrm{~km} / \mathrm{s})$ is observed in the top $10 \mathrm{~km}$ of the upper-crust immediately above the thickened crust between the west coast of the South Island and the Main Divide of the Southern Alps. This body is interpreted as a drier, more rigid body of schist. A zone of low velocity $(5.8 \mathrm{~km} / \mathrm{s}$ reaching $8 \mathrm{~km}$ depth) is observed immediately to the southeast of the aforementioned high velocity body. The feature is interpreted as a back-shearing faulting structure through which fluid escape towards the surface. A flexural analysis of an apparent flexure profile of the Australian Plate along SIGHT line 01 yielded a flexural parameter, $\alpha$, of $89 \mathrm{~km}$, an elastic thickness, Te, of $14 \mathrm{~km}$ and a flexural rigidity, $D$, of $1.5 .10^{23} \mathrm{~N} . \mathrm{m}$. These results are consistent with results of a flexural analysis of SIGHT line 02W [Harrison 1999].

The following features are derived from the solution model. An apparent gradient in uppermantle anisotropy is observed with seismic velocities increasing towards the south of the model. Also, the geometry of the Mohorovičić discontinuity is apparently smooth between the two main SIGHT transects. The tomography method used in this project proves to be complementary to other coarser-scale and finer-scale seismic studies of the region in that it brings out features that were not seen by them. Notwithstanding that the interface inversion process remains to be perfected in the software, the velocity inversion produced a satisfactory solution model. 


\section{Contents}

$\begin{array}{ll}\text { Frontispiece } & \text { i }\end{array}$

Acknowledgements $\quad$ iii

Abstract $\quad$ v

Table of Contents vi vi

List of Figures $\quad$ xi

List of Tables $\quad$ xiv

List of Abbreviations $\quad$ xvii

1 Introduction $\quad 1$

1.1 Motivation and objectives . . . . . . . . . . . . . . . . . 1

1.1 .1 Motivation . . . . . . . . . . . . . . . . . . 1

1.1 .2 Objectives . . . . . . . . . . . . . . . . 3

1.2 Tectonic setting of the study area . . . . . . . . . . . . . . . . . 4

1.2.1 Plate motion . . . . . . . . . . . . . . . . . 4

1.2.2 Rotation pole . . . . . . . . . . . . . . . . 5 5

1.3 Geophysical features . . . . . . . . . . . . . . . . . . 5

1.3.1 Main faults in the study area . . . . . . . . . . . . . . . 6

1.3.2 Accommodation of convergence . . . . . . . . . . . . . . . 7

1.4 Geological setting . . . . . . . . . . . . . . . . . . 8

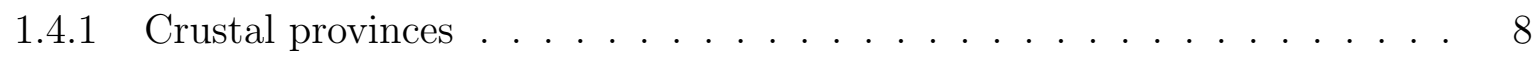

1.4.2 Fault-related rocks . . . . . . . . . . . . . . . . 10

1.4.3 Sediments and surface geology . . . . . . . . . . . . 10

1.5 Structure of the document . . . . . . . . . . . . . . . . . . 12 
2 Data used for this study $\quad 13$

2.1 The SIGHT project . . . . . . . . . . . . . . . . . 13

2.1 .1 Introduction . . . . . . . . . . . . . . . . . . 13

2.1 .2 Survey geometry . . . . . . . . . . . . . . . . . . 13

2.1.3 Seismic acquisition campaigns . . . . . . . . . . . . . . . 15

2.1.4 Related published work . . . . . . . . . . . . . . . . . 16

2.2 Seismic data . . . . . . . . . . . . . . . . . . . 18

2.2.1 West Coast cross-line dataset . . . . . . . . . . . . . . . . . . . 18

2.2 .2 Seismic processing . . . . . . . . . . . . . . . . 20

2.2 .3 Phase picking . . . . . . . . . . . . . . . 22

2.3 Pick dataset . . . . . . . . . . . . . . . . . . . . . . . . . 27

2.4 Summary . . . . . . . . . . . . . . . . . . . . 28

3 Shallow structure static correction $\quad 29$

3.1 Preparation for static corrections . . . . . . . . . . . . . . . . . . . 29

3.1 .1 Justification . . . . . . . . . . . . . . . . . . . . . . . 29

3.1 .2 Assumptions . . . . . . . . . . . . . . . . 30

3.1 .3 Correction strategy . . . . . . . . . . . . . . . . 32

3.2 Seismic velocity of sediment . . . . . . . . . . . . . . . . 32

3.2.1 Velocity misinterpretation . . . . . . . . . . . . . . 32

3.2 .2 Sediment velocity estimation . . . . . . . . . . . . . . 34

3.3 Estimation of the offshore sedimentary structures . . . . . . . . . . . . . 34

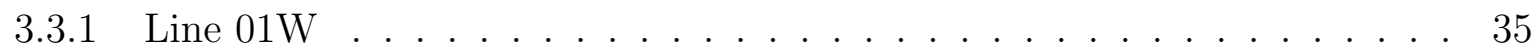

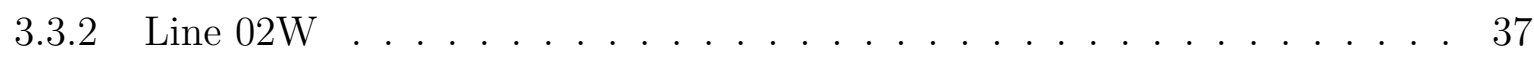

3.3 .3 Line $03 \mathrm{~W} \ldots \ldots \ldots \ldots \ldots \ldots \ldots$

3.4 Estimation of the onshore sedimentary structures . . . . . . . . . . . 37

3.4 .1 Individual basins . . . . . . . . . . . . . . . . . . . . . 40

3.4 .2 Total onshore statics . . . . . . . . . . . . . . . . . . 42

3.5 Summary of the static corrections . . . . . . . . . . . . . . 43

4 Method and synthetic tests $\quad 45$

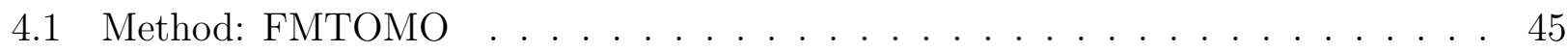

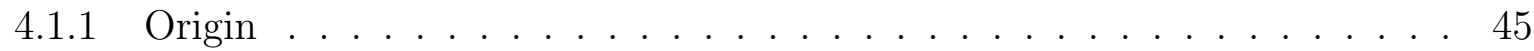

4.1 .2 Grids, nodes and interfaces . . . . . . . . . . . . . . 45

4.1 .3 Hierarchy of the software package . . . . . . . . . . . . . . . 46 
4.1 .4 Applications of FMTOMO . . . . . . . . . . . . . . . . 47

4.2 Preparation of synthetic tests . . . . . . . . . . . . . . . . 48

4.2 .1 Model domain parameterisation . . . . . . . . . . . . . . . 48

4.2 .2 Slicing of the model domain . . . . . . . . . . . . . . . . 50

4.2 .3 Reference model . . . . . . . . . . . . . . . . . . . . . 50

4.3 Checkerboard test . . . . . . . . . . . . . . . . . . 52

4.3 .1 Modelling parameters . . . . . . . . . . . . . 52

4.3 .2 Solution model's recovery f. . . . . . . . . . . . . . . . 52

4.4 Spike tests . . . . . . . . . . . . . . . . . . . . . 58

4.4 .1 Positive anomalies . . . . . . . . . . . . . . . . . 59

4.4 Negative anomalies . . . . . . . . . . . . . . . . . . . . 59

4.5 Summary of synthetic tests . . . . . . . . . . . . . . . . . 62

4.5.1 Checkerboard test . . . . . . . . . . . . . . 62

4.5 .2 Spike tests . . . . . . . . . . . . . . . . 62

5 Tomography inversion $\quad 63$

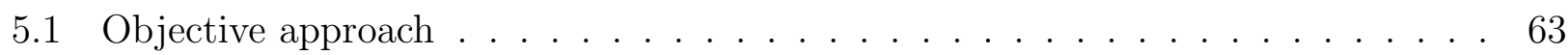

5.1 .1 Objective features . . . . . . . . . . . . . 63

5.1 .2 Results of the objective approach . . . . . . . . . . . . . . . 64

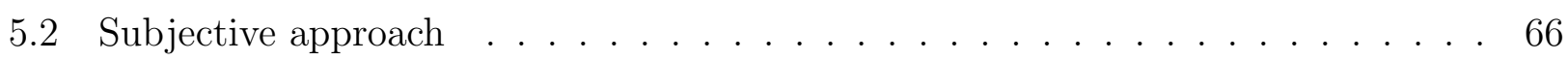

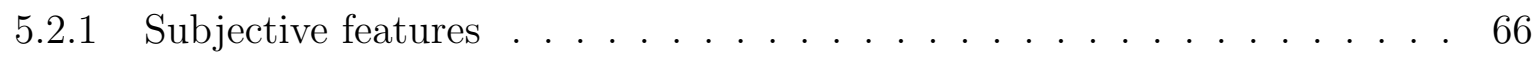

5.2 .2 Reference model . . . . . . . . . . . . . . . . . . . 67

5.2 .3 Inversion strategy . . . . . . . . . . . . . . . . . . . . . 68

5.2 .4 Solution model . . . . . . . . . . . . . . . . . . . . . . 69

5.2.5 Statistical analysis of the solution model . . . . . . . . . . . . 70

5.2 .6 Raypath coverage . . . . . . . . . . . . . . . . 73

5.3 Summary of the tomography inversion . . . . . . . . . . . . . . 74

5.3 .1 Objective approach . . . . . . . . . . . . . . . . 74

5.3 .2 Subjective approach . . . . . . . . . . . . . . . . 74

$\begin{array}{lll}6 & \text { Discussion } & 77\end{array}$

6.1 Interpretation of the solution model . . . . . . . . . . . . . . . 77

6.1 .1 Uncertainty estimation . . . . . . . . . . . . . . . 77

6.1 .2 Interpretation of model features . . . . . . . . . . . . . 80

6.2 Inversion tomography versus forward modelling . . . . . . . . . . . . 86 
6.3 Summary of the findings - conclusions . . . . . . . . . . . . 87

$\begin{array}{ll}\text { A Traveltime picks datasets breakdown } & 89\end{array}$

A.1 Author's picks, cross-line West Coast . . . . . . . . . . . . . . . . 89

A.1.1 Traveltime picks . . . . . . . . . . . . . . . . . . 89

A.2 Additional picks . . . . . . . . . . . . . . . . . . . 90

A.2.1 van Avendonk et al. [2004], in-line T1 . . . . . . . . . . . . . . . 90

A.2.2 Scherwath et al. [2003], in-line T2 . . . . . . . . . . . . . . . 90

A.3 Total pick dataset . . . . . . . . . . . . . . . . . . . 91

A.3.1 Pick uncertainties . . . . . . . . . . . . . . . . 91

$\begin{array}{ll}\text { B Dataset consistency } & 97\end{array}$

B.1 Offshore sources and receivers . . . . . . . . . . . . . . . 97

B.2 Land sources and receivers . . . . . . . . . . . . . . . . . . . 98

B.3 MCS stack offset . . . . . . . . . . . . . . . . . . . . . . 99

$\begin{array}{ll}\text { C Model parameters calibration } & 101\end{array}$

C.1 Damping and smoothing factors . . . . . . . . . . . . . . . . . 101

C.2 Amplitude and node spacing . . . . . . . . . . . . . . . 103

C.3 Traveltime uncertainty and number of iterations . . . . . . . . . . . 103

$\begin{array}{ll}\text { D Final inversion schemes } & 107\end{array}$

D.1 Reference model interpolation . . . . . . . . . . . . . . . . . 107

D.1.1 Interface boundaries . . . . . . . . . . . . . . . . . 107

D.1.2 Velocity structure . . . . . . . . . . . . . . 107

D.2 Additional inversion features . . . . . . . . . . . . . . . 108

D.2.1 Down-weighting scheme . . . . . . . . . . . . . . 108

D.2.2 Station term estimation f . . . . . . . . . . . . . . 109

D.2.3 Down-weighting strategy . . . . . . . . . . . . . 110

$\begin{array}{ll}\text { E Solution model input files } & 111\end{array}$

$\begin{array}{llr}\text { F } & \text { Participatory software development } & 117\end{array}$

$\begin{array}{ll}\text { References } & 119\end{array}$ 


\section{List of Figures}

1 Alpine fault seen from space . . . . . . . . . . . . . . ii

1.1 New Zealand in the southwest Pacific region . . . . . . . . . . . . . . . 2

1.2 Comparison of South Island's elevation, deep seismicity, strain and rainfall . . . 3

1.3 Palinspastic map of Franz Josef . . . . . . . . . . . . . . . . . . . 5

1.4 Satellite view of the Alpine fault . . . . . . . . . . . . . . . . . 6

1.5 Sketch of crustal root . . . . . . . . . . . . . . . . 7

1.6 Map of crustal terranes . . . . . . . . . . . . . . . . . . . . . . . . 9

1.7 Map of surface geology . . . . . . . . . . . . . . . . . . . 10

1.8 Photograph of the Gates of Haast . . . . . . . . . . . . . . . . . 11

2.1 Map of the SIGHT Project . . . . . . . . . . . . . . . . . . . 14

2.2 West Coast cross-line dataset and raypath azimuthal range . . . . . . . . . . . 19

2.3 Sketch of frequency filter . . . . . . . . . . . . . . . . . . . . 20

2.4 Effect of seismic processing data . . . . . . . . . . . . . . . . 21

2.5 Sketch of seismic phases . . . . . . . . . . . . . . . . . 22

2.6 Synthetic MacRay phase plots . . . . . . . . . . . . . . . . . . 24

2.7 Seismic gather of $01 \mathrm{~W}$ into $\mathrm{T} 2 \ldots \ldots \ldots \ldots \ldots$

2.8 Seismic gather of $02 \mathrm{~W}$ into $\mathrm{T} 1 \ldots \ldots \ldots \ldots$

2.9 Seismic gather of $03 \mathrm{~W}$ into $\mathrm{T} 1$ and $\mathrm{T} 2 \ldots \ldots \ldots \ldots$

3.1 Traveltime static due to layer thickness variation . . . . . . . . . . . . . 29

3.2 Snell's Law . . . . . . . . . . . . . . . . . . . . . . . 31

3.3 Delay times plot after Stern et al. $[2010] \ldots \ldots \ldots$. . . . . . . . . . 33

3.4 Stack and statics of line $01 \mathrm{~W} \ldots \ldots \ldots \ldots$

3.5 Stack and statics of line $02 \mathrm{~W} \ldots \ldots \ldots \ldots$

3.6 Stack and statics of line $03 \mathrm{~W} \ldots \ldots \ldots \ldots \ldots$

3.7 Onshore basins . . . . . . . . . . . . . . . . . . . . . . 40 
3.8 Statics of the SIGHT land transects . . . . . . . . . . . . . . . . . 42

3.9 Full statics along lines 01 and $02 \ldots \ldots \ldots$. . . . . . . . . . . . 44

4.1 Cubic B-splines . . . . . . . . . . . . . . . . . . 46

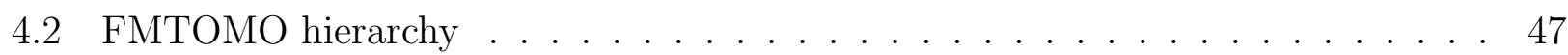

4.3 Map of the velocity nodes . . . . . . . . . . . . . . . . . . . 49

4.4 Maps of cross section of model domain . . . . . . . . . . . . . . . 51

4.5 Reference model of first inversion test . . . . . . . . . . . . . . . 51

4.6 Result of full checkerboard test of slices A, B, C and D . . . . . . . . . . 53

4.7 Result of full checkerboard test of slices E, F, G and H . . . . . . . . . . . 54

4.8 Result of full checkerboard test of slices $1,2,3,4$ and $5 \ldots \ldots \ldots$

4.9 Result of full checkerboard test of slices $6,7,8,9$ and $10 \ldots \ldots 6$

4.10 Result of full checkerboard test of all depth slices . . . . . . . . . . . . 57

4.11 Map of location of spikes . . . . . . . . . . . . . . . . . 58

4.12 Results of positive spike test . . . . . . . . . . . . . . . 60

4.13 Results of negative spike test . . . . . . . . . . . . . . . . 61

5.1 Objective approach solution models . . . . . . . . . . . . . . . 65

5.2 Objective approach traveltime residuals distribution . . . . . . . . . . . . 66

5.3 Subjective reference model . . . . . . . . . . . . . . . . 67

5.4 Subjective approach solution model - slices A to H . . . . . . . . . . . . 71

5.5 Subjective approach solution model - slices 1 to $10 \ldots \ldots$. . . . . . . 72

5.6 Subjective approach traveltime residuals distribution $\ldots \ldots \ldots$. . . . . . . 73

5.7 Ray diagram along Line $02 \ldots \ldots \ldots \ldots$. . . . . . . . . . . . . . . . . . . . . . . .

6.1 Crustal features . . . . . . . . . . . . . . . . . . 81

6.2 Upper-mantle velocity structure . . . . . . . . . . . . . . . . . . . 82

6.3 Moho geometry between line 01 and line $02 \ldots \ldots$. . . . . . . . . 83

6.4 Australian Plate flexure along line $01 \ldots \ldots$. . . . . . . . . . . . . 84

C.1 Damping and smoothing checkerboard test . . . . . . . . . . . . 102

C.2 Amplitude and node spacing checkerboard tests . . . . . . . . . . . . 104

C.3 Standard deviation checkerboard tests . . . . . . . . . . . . . 105

D.1 Down-weighting function . . . . . . . . . . . . . . . 109

D.2 Station terms evolution . . . . . . . . . . . . . . . . 110 
E.1 Detail of input file grid3dg.in $1 / 4 \ldots \ldots \ldots$. . . . . . . . . . . 112

E.1 Detail of input file grid3dg.in $2 / 4 \ldots \ldots \ldots \ldots$

E.1 Detail of input file grid3dg.in $3 / 4 \ldots \ldots$. . . . . . . . . . . 114

E.1 Detail of input file grid3dg.in $4 / 4 \ldots \ldots$. . . . . . . . . . . . . . . . . . . . . .

E.2 Detail of input file obsdata.in . . . . . . . . . . . . . . 116 


\section{List of Tables}

2.1 Offshore shot lines details $\ldots \ldots \ldots \ldots$

2.2 Total pick dataset . . . . . . . . . . . . . . . . . . . . . . . . . 28

3.1 Correction sediment velocity for additional picks . . . . . . . . . . . . . 34

3.2 Sediments velocity estimation $\ldots \ldots \ldots \ldots \ldots \ldots \ldots$

4.1 Model bounds of reference model . . . . . . . . . . . . . . . . . 48

4.2 Parameterisation of model grids . . . . . . . . . . . . . . . . . . 49

4.3 Coordinates of slices $\ldots \ldots \ldots \ldots \ldots \ldots$

4.4 Model parameters for full checkerboard test $\ldots \ldots \ldots \ldots$. . . . . . . 52

5.1 Statistics of objective solution model . . . . . . . . . . . . . . 65

$5.2 \quad$ Inversion scheme $\ldots \ldots \ldots \ldots$

5.3 Statistics of subjective solution model . . . . . . . . . . . . . . . 73

6.1 Comparative flexural calculation . . . . . . . . . . . . . . . . 85

A.1 Author's pick dataset . . . . . . . . . . . . . . . . . . . . . . . . 89

A.2 Additional pick datasets $\ldots \ldots \ldots \ldots \ldots$

A.3 Pick dataset . . . . . . . . . . . . . . . . . . . . . . . . . . . 91

A.4 Travel time pick uncertainties, 1 of $5 \ldots \ldots \ldots \ldots$. . . . . . . . 92

A.4 Travel time pick uncertainties, 2 of $5 \ldots \ldots \ldots$

A.4 Travel time pick uncertainties, 3 of $5 \ldots \ldots \ldots$. . . . . . . . . 94

A.4 Travel time pick uncertainties, 4 of $5 \ldots \ldots \ldots$. . . . . . . . 95

A.4 Travel time pick uncertainties, 5 of $5 \ldots \ldots \ldots \ldots$

B.1 Offshore bathymetry check . . . . . . . . . . . . . . . . . . 98

B.2 Land positioning check $\ldots \ldots \ldots \ldots \ldots$

B.3 Bathymetry difference . . . . . . . . . . . . . . . . . . . . . . . 99 
D.1 Interface interpolation parameters . . . . . . . . . . . . . . 108

D.2 Velocity interpolation parameters . . . . . . . . . . . . . . 108 


\section{List of Abbreviations}

01W Offshore West Coast shot line 01

02W Offshore West Coast shot line 02

03W Offshore West Coast shot line 03

12W Offshore West Coast shot line 12

23W Offshore West Coast shot line 23

2D Two-dimensional

3D Three-dimensional

AF Alpine fault

AFZ Alpine Fault Zone

ACT Australian Capital Territory

AGC Amplitude Gain Control

ANU Australian National University

BDT Brittle-Ductile Transition

CDP Common Depth Point

DSIR Department of Scientific and Industrial Research (now GNS Science)

FMTOMO Fast Marching TOMOgraphy method

GeoNet New Zealand's national seismograph network

GMT Generic Mapping Tools [Wessel and Smith 1998]

GNS Geological and Nuclear Sciences (now GNS Science)

GPS Global Positioning System

Hz Hertz, frequency unit

IMCF Irish Man Creek fault

Ka Thousand years

LGM Last Glacial Maximum

Line 01 Combination of $01 \mathrm{~W}$ and $\mathrm{T} 1$ 
Line 02 Combination of $02 \mathrm{~W}$ and $\mathrm{T} 2$

LVZ Low Velocity Zone

Ma Million years

MAD Median Absolute Deviator

MCS Multi-Channel Seismics

Moho Mohorovičić discontinuity

NASA National Aeronautics and Space Administration

NIWA National Institute for Weather and Atmosphere

NUVEL-1A Model of current worldwide plate motion [DeMets et al. 1994]

NZGD49 New Zealand Grid Datum of 1949, geodetic datum used for NZMG

NZMG New Zealand Map Grid, metric mapping grid of New Zealand's territory

NZNSN New Zealand National Seismograph Network

OB Ocean Bottom

OBH Ocean Bottom Hydrophone

OBS Ocean Bottom Seismometer

ON Onshore

OO Onshore-Offshore

Pa Pascal, pressure unit

Pg Upper-crustal refraction

PIP Crustal reflection

PmP Moho reflection

Pn Upper-mantle refraction

PSN Previous Shot Noise

RG Receiver Gather

RMS Root Mean Square

SAMBA Southern Alps Microearthquake Borehole Array

SAPSE Southern Alps Passive Seismic Experiment

SEG-Y Society of Exploration Geophysicists' format 'Y' for seismic data

SIGHT South Island GeopHysical Transect project

SNR Signal-to-Noise Ratio

SRTM Shuttle Radar Topography Mission 
SWB South Westland Basin

SWBF South Westland Basin Fault

T1 Transect 1, the northern land transect

T2 Transect 2, the southern land transect

T3 Transect 3, parallel to the East coast and crossing the Otago region

T3W Transect 3W, parallel to the west coast

TWTT Two Way Travel Time

UTIG University of Texas Institute of Geophysics

VUW Victoria University of Wellington

WGS84 World Geodetic System of 1984 


\section{Chapter 1}

\section{Introduction}

\subsection{Motivation and objectives}

\subsubsection{Motivation}

In the current tectonic setting, New Zealand (Figure 1.1) is located in the southwest Pacific, about $1400 \mathrm{~km}$ southeast of Noumea, New Caledonia; some $2000 \mathrm{~km}$ southeast of Sydney, Australia and $2200 \mathrm{~km}$ south of Suva, Fiji. It is astride the tectonically active Pacific-Australian Plate boundary. Ongoing tectonic processes, such as bipolar subduction and oblique continental collision, are thought to generate geological and geophysical features including volcanism, rapidly growing orogenic belts, crustal extension as well as shortening and mantle down-welling. Due to tectonic convergence and high rates of exhumation, the central South Island shows the highest rate of rock uplift in New Zealand, comparable with rates measured in the Himalayas [Blythe 1998, Tippett and Kamp 1993]. This is materialised by the uplift of the orogen of the Southern Alps. The continental juxtaposition shown in Figure 1.2 highlights the superimposition of striking features in the central part of the South Island.

The highest topography (Figure 1.2 a) in New Zealand, high shear strain rates (Figure $1.2 \mathrm{c}$ ), and some of the highest annual rainfalls in the world (Figure $1.2 \mathrm{~d}$ ), up to $13 \mathrm{~m} / \mathrm{yr}$ [Henderson 1998], occur in the central South Island. This enhances and accelerates erosion and generates large amounts of sediments off the Southern Alps. As a result, strain release is expected in the region. However, kinematic modelling indicates that the Alpine fault to $12 \mathrm{~km}$ depth is not slipping significantly [Beavan et al. 2007]. Furthermore, the Evison wall [Evison 1971], built across the Alpine fault in May 1964, is still intact. There is a zone of unusually muted seismicity in the central part of the South Island (Figure $1.2 \mathrm{~b}$ ) where large paleo-earthquakes have been reported [Scholz et al. 1973, Sutherland et al. 2007, Wells et al. 1999]. Although there is growing consensus among scientists that it is "realistic to expect some great earthquakes" in the central section of the Alpine fault [Sutherland et al. 2007], there are two schools of thought about its apparent lack of seismicity:

1. The central section of the Alpine fault is locked and is currently accumulating stress with a large earthquake overdue [Beavan et al. 2007; 1999, Eberhart-Phillips 1995, Evison 1971, Leitner et al. 2001].

2. Weak rocks, high temperatures at shallow depths and high fluid pressures impede the brittle behaviour of rocks. Hence, the strain is distributed over the region as it accumulates [Stern et al. 2001; 2007, Walcott 1998]. 


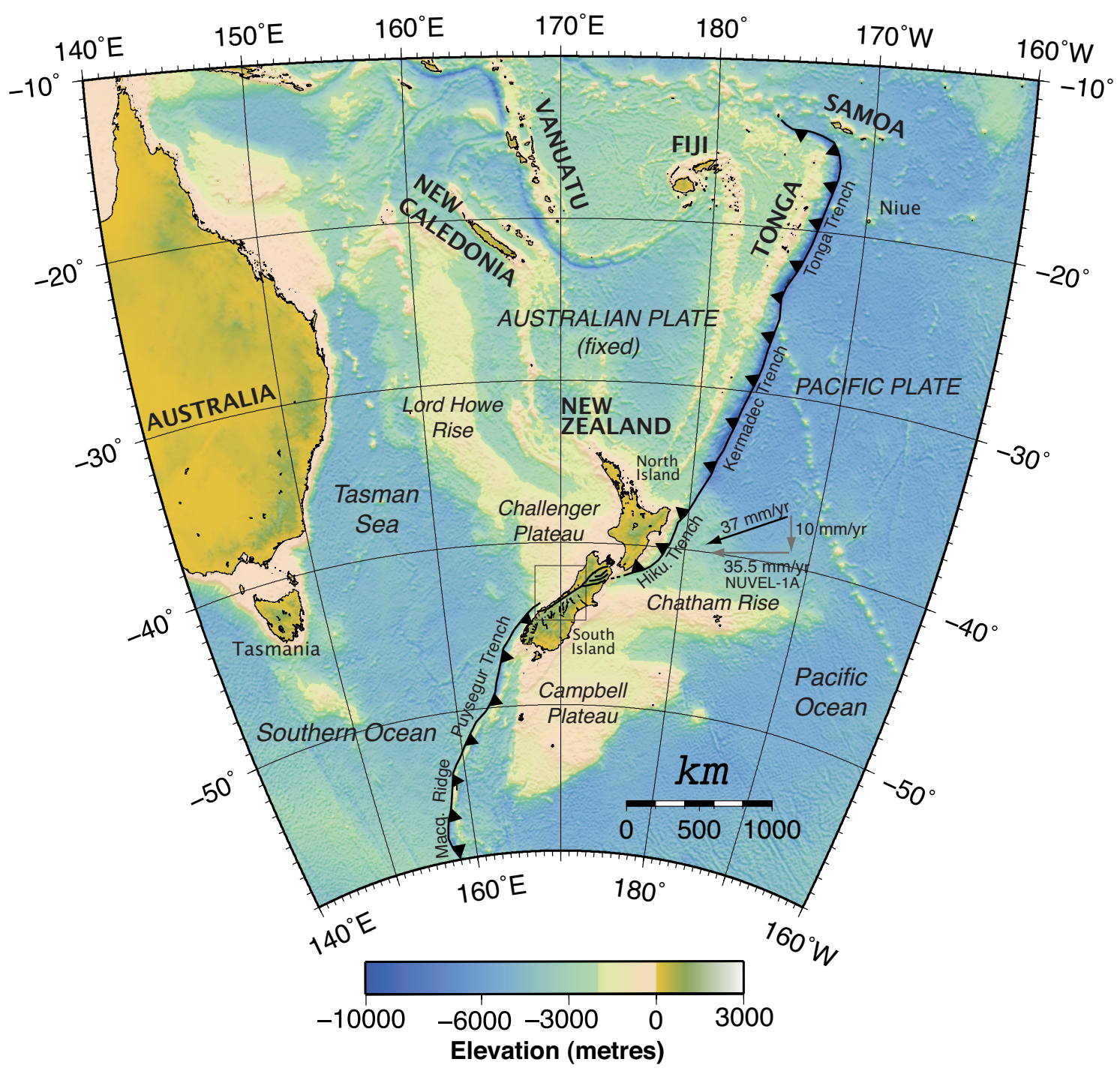

Figure 1.1: Regional map showing the location of New Zealand in the southwest Pacific and the regional tectonic settings. The Pacific plate's oceanic lithosphere subducts under the Australian along the Tonga, Kermadec and Hikurangi trenches along the east of the North Island of New Zealand. Strike-slip and continental collision is taken up near the Alpine fault in the South Island. To the south of the South Island, the Australian oceanic lithosphere subducts under the Pacific plate's continental lithosphere along the Puysegur trench and the Macquarie ridge. The NUVEL-1A model relative plate motion vector (black arrow) is of $37 \mathrm{~mm} / \mathrm{yr}$, and its north and east components (grey arrows) are of 10 and $35.5 \mathrm{~mm} / \mathrm{yr}$, respectively [DeMets et al. 1990]. The black rectangle shows the focus area of this study, the South Island of New Zealand. Hiku. Trench

Hikurangi Trench. Macq. Ridge Macquarie Ridge.

Two dimensional high-resolution tomographic images have been produced along the South Island Geophysical Transect (SIGHT) project's main transects (black lines in Figure 1.2 a) [Godfrey et al. 2001, Melhuish et al. 2005, Scherwath 2002, van Avendonk et al. 2004] and threedimensional (3D) tomographic studies of the South Island have been undertaken [Baldock and Stern 2005, Eberhart-Phillips and Bannister 2002, Henrys et al. 2004, Kohler and EberhartPhillips 2002, Scherwath et al. 2006, Stern et al. 2000]. However, the 3D tomographic studies of the South Island either have a coarse local resolution and/or do not include interfaces boundaries in the models. As a result no relfection data has been used to constrain interface geometry. Furthermore, a high-resolution 3D tomographic model of the East Coast of the South Island has 


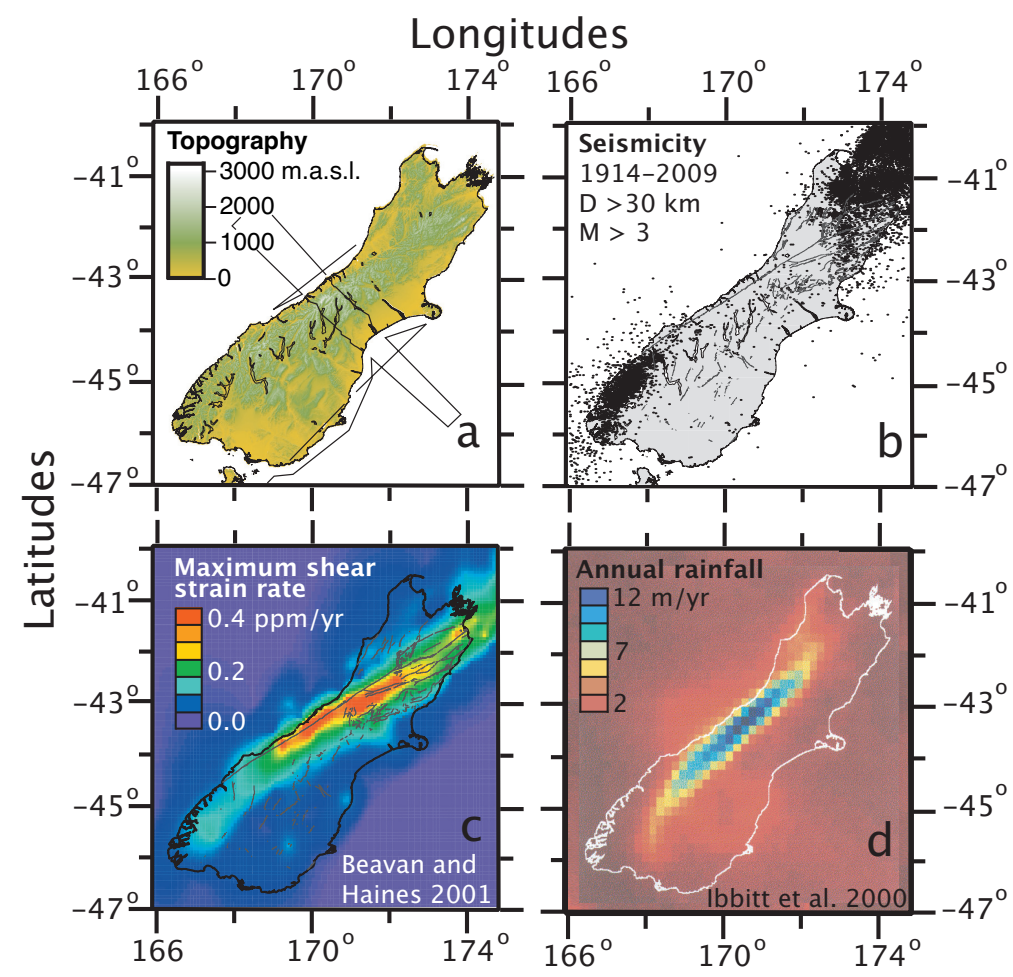

Figure 1.2: Figure showing the correlation between the topography (a.), the seismicity deeper than $30 \mathrm{~km}$ depth (b.), the maximum shear strain rate (c.) and the annual rainfall in the South Island (d.). High elevation, low seismicity, high shear strain rate and high rainfall occur along-strike of the Alpine fault and reach their maximum in the centre section of it. Plot a. uses the Shuttle Radar Topography Mission (SRTM) data. The black lines represent the survey geometry of the SIGHT project. Plot $\boldsymbol{b}$. uses data from GeoNet. The earthquakes plotted (dots) are from 1914 to 2009, of a minimum focal depth of $30 \mathrm{~km}$ and of minimum magnitude of 3. The black lines represent active faults. Plot c., after Beavan and Haines [2001], shows the distribution of the maximum shear strain rate across the island. The axis of maximum strain is sub-parallel to the collision zone and to the surface trace of the Alpine fault. Plot d., after Ibbitt et al. [2000], shows the annual rainfall across the South Island.

been produced using the SIGHT data [Baldock 2004] and this project is its western equivalent. So there is no high-resolution $\mathrm{P}$-wave $3 \mathrm{D}$ tomography of the velocity structure and the interface boundaries of the West Coast of the South Island, where structures of interest have been reported (e.g. Stern et al. [2001]).

\subsubsection{Objectives}

This project is a continuation of geophysical studies focused on the Alpine fault and its seismogenesis along its central section in the South Island of New Zealand. A new automated tomography method developed by Rawlinson [2005] is used to invert a high-density seismic traveltime dataset to produce a three-dimensional tomographic model of the central part of the South Island focussed on the central section of the Alpine fault. Active onshore-offshore seismic data from the cross-line West Coast dataset of the SIGHT are processed and used alongside additional in-line data. After a static correction step for the traveltimes, and synthetic testing of the model space, the solution model will bring insight to the following questions: Can the crustal and upper-mantle velocity structures presented in the literature be recovered by using 
this tomography code and method? How do the velocity structure and the lower-crustal/Moho interface geometry evolve between the main SIGHT transects? A flexure signature of the Australian Plate has been observed along the southern transect, is a similar feature observable along the northern one? Furthermore, as the tomography software is still in development, this project will test its ability to model such a dataset and it will also participate in improving the code.

\subsection{Tectonic setting of the study area}

The consideration of the region's tectonic history and current day state is useful for the appreciation of the crustal and mantle processes discussed in Chapter 6.

\subsubsection{Plate motion}

The NUVEL-1A model estimates a dominant oblique convergent plate motion of $37 \mathrm{~mm} / \mathrm{yr}$ at an angle of $071^{\circ} \pm 2$ (Australian plate fixed). In the South Island, this rate includes a dextral slip component of $35.5 \mathrm{~mm} / \mathrm{yr}$ and a convergent one of $10 \mathrm{~mm} / \mathrm{yr}$ [DeMets et al. 1990; 1994] (Figure 1.1). High strain and surface deformation rates (Figure $1.2 \mathrm{c}$ ) are focussed on the central part of the South Island [Beavan and Haines 2001] and decrease on the northern and southern ends of the Alpine fault [Beavan et al. 1999, Kamp and Tippett 1993, Little et al. 2005, Norris 1979, Walcott 1998, Wellman 1979].

The plate motion since the mid-late Eocene resulted in $860 \mathrm{~km}$ of dextral slip in the South Island, with $460 \mathrm{~km}$ occurring along the Alpine fault (Figure 1.3 and 1.4). On the surface, this is observable by the separation and displacement of the Median batholiths in Southland and in northwest Nelson (Figure 1.6) [Kamp 1986, Wellman 1953]. Since the inception of convergence in the late Miocene - early Pliocene a suggested $14-19 \mathrm{~km}$ of crustal material has been uplifted to the surface [Grapes 1995, Tippett and Kamp 1993], along with $90 \mathrm{~km}$ of shortening of the South Island and $230 \mathrm{~km}$ of dextral slip along the Alpine fault [Walcott 1998].

The current plate motion is accommodated in four different ways along the plate boundary in the South Island (Figure 1.1):

1. Subduction towards the northwest of the Pacific plate's oceanic lithosphere under the Australian plate's continental lithosphere (Challenger Plateau) along the Hikurangi Trench to the east of the North Island.

2. Strike-slip motion is accommodated by four major faults in the Marlborough region in the north of the South Island (from north to south the Wairau, Awatere, Clarence and Hope faults; a, b, c and d in Figure 1.3, respectively).

3. Continent-continent collision between the Pacific and Australian plates' lithosphere (Chatham Rise and Challenger Plateau, respectively) with strike-slip and convergent motions focussed near the Alpine fault.

4. Subduction towards the southeast of the Australian plate's oceanic lithosphere under the Pacific plate's continental lithosphere (Campbell Plateau) offshore to the south of the South Island along the Puysegur Trench [Davey et al. 1998, Suggate 1963]. 


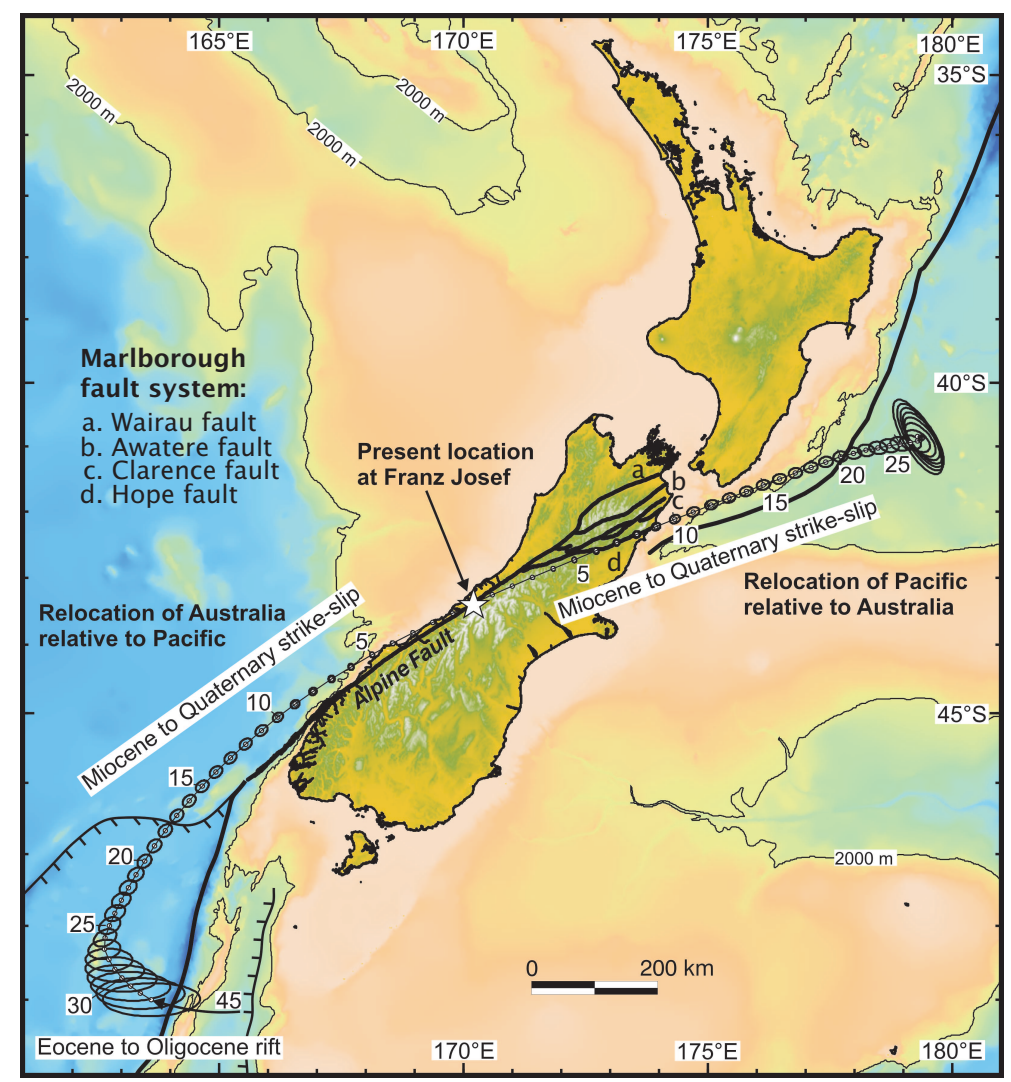

Figure 1.3: Palinspastic map showing the location of Franz Josef. The ellipses represent the location uncertainty margin at different time intervals. After Cox and Sutherland [2007]. a Wairau fault. b Awatere fault. c Clarence fault. c Hope fault.

\subsubsection{Rotation pole}

Since mid-late Eocene, the Pacific plate rotation pole has migrated southeastwards at an average rate of $1^{\circ}$ per million years (Ma) [Sutherland 1995]. The veering of the migration direction of the rotation pole towards the southwest at about $5 \mathrm{Ma}$ induced a significant change in plate motion that is suggested to have instigated the Kaikoura orogeny [Adams 1979, Stock and Molnar 1987, Sutherland 1995, Walcott 1984]. Strike-slip and east-west compressive motion were accommodated by the Marlborough Fault System and the Alpine fault, respectively [King 2000]. A late Pliocene - early Pleistocene increase in westward component in the Pacific plate motion resulted in an accelerated convergence and associated uplift of the Southern Alps [King 2000, Tippett and Kamp 1993, Walcott 1979]. However, Cande and Stock [2004] suggest small changes in relative displacement along the Alpine Fault over the last 20 Myr.

\subsection{Geophysical features}

The tomographic model produced in Chapter 5 intends to image crustal and mantle features in the study region. Some of the investigated features, including the faults in the study area, the main crustal and mantle features underneath the central South Island, are described hereafter. 


\subsubsection{Main faults in the study area}

\section{Alpine fault and Southern Alps}

The Alpine fault is a dextral continental transform located along the western foothills of the Southern Alps and striking sub-parallel to the Main Divide [Wellman 1953]. It is thought to have started developing at around $21 \mathrm{Ma}$ [King 2000]. About $70 \%$ of the plate motion is accommodated along the Alpine fault [Norris and Cooper 1995]. The dextral slip component is responsible for the offset of the Matai terrane and Median batholith between Nelson and Southland regions. Convergence is by the obduction of the metasediments of the Pacific continental crust along the ramp of the Alpine fault into the Southern Alps [Wellman 1953] materialised, culminating at Aoraki/Mount Cook (3754 m.a.s.l, Figure 1.4).

The Alpine fault is continuous for about $460 \mathrm{~km}$ and is one of the straightest natural features seen from space (Figure 1.4). However, on the scale of tens of kilometres, the Alpine fault is thought to be composed of north- and east-orientated segments dominated by oblique thrusting and strike-slip motions, respectively [Norris and Cooper 1995]. The ramp of the Alpine fault dips approximately 30-55 at depth [Davey et al. 1995, Kleffmann 1999, Sibson et al. 1979]; however, dip measurements of schist and mylonite foliations suggest that the fault is near vertical at the surface [Little et al. 2002]. The orogenic setting of the Southern Alps is often compared to the Himalayan ranges in northern India and Tibet [Jiracek et al. 2007] and the Hsueshan and Backbone ranges in western Taiwan [Wu et al. 2007]; the Alpine fault has been compared to the San Andreas fault in California, North America [Fuis et al. 2007, Hatherton 1969, Stern and McBride 1998] and the Lishen fault in Taiwan [Upton et al. 2003].

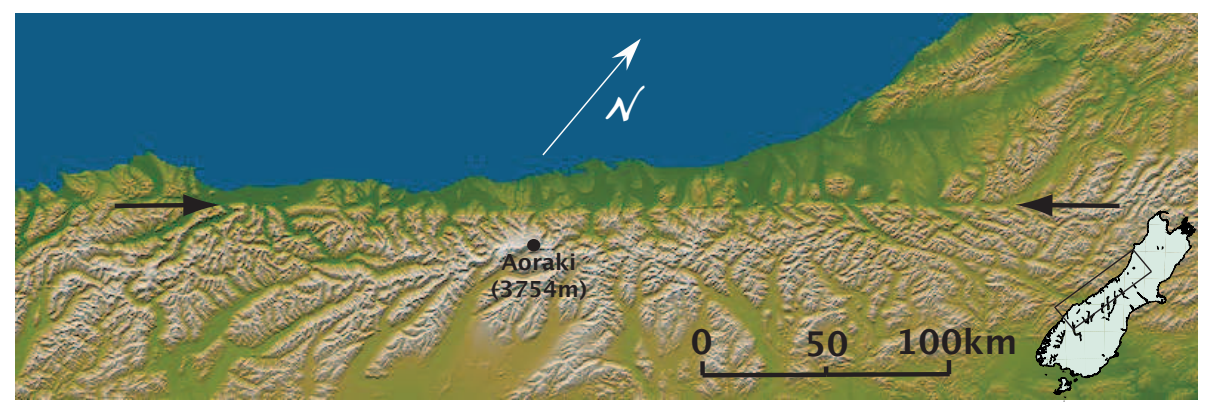

Figure 1.4: Image of the West Coast South Island from NASA's Shuttle Radar Topography Mission (SRTM). The surface trace of the Alpine fault lines out between the two black arrows. Aoraki/Mt Cook (3754 m.a.s.l.) is labelled by a black circle.

\section{Other faults}

The remainder of the plate motion is accommodated by sub-parallel fault structures located both to the northwest and to the southeast of the Alpine fault [Pearson et al. 1995, Tippett and Hovius 2000]. Some of the faults to the northwest of the Alpine fault are the Fraser fault [Jongens 2006, Young 1968], the Bald Hill Ranges Thrust fault [Rattenbury 1986] and the South Westland fault zone [Sircombe and Kamp 1998]. Some of those to the southeast of the Alpine fault are the Main Divide fault zone [Cox et al. 1997, Cox and Findlay 1995], the Irishman Creek fault [Amos et al. 2007], the Ostler fault [Campbell et al. 2010, Ghisetti et al. 2007] and others (e.g. Wallace et al. [2007]). The faults to the southeast of the Alpine fault coincide with the back-sheared escalator-like crustal sub-units proposed by [Little et al. 2002, Wellman 1979, Wightman and Little 2007]. 


\subsubsection{Accommodation of convergence}

The main geophysical features, resulting from oblique continental collision, that the tomography model aims to image, are described hereafter.

\section{Crustal root}

Because of its relative age difference and, thus, strength, the Pacific plate's crust is thought to accommodate more deformation than the Australian plate [Beaumont et al. 1996, van Avendonk et al. 2004]. The sequence of Mesozoic metasediments of the Pacific crust are stripped from a supposed underlying oceanic crust along a décollement surface at the base of the crust. The excess crustal material which is not ramped towards the surface along the Alpine fault is deepened in an asymmetrical crustal root under the Southern Alps (Figure 1.5). The crust is thickened by $17 \mathrm{~km}$ to thicknesses of 39 to $44 \mathrm{~km}$ under the central South Island [Davey et al. 1998, Kleffmann et al. 1998, Scherwath et al. 2003, van Avendonk et al. 2004, Woodward 1979], and reaches a maximum depth of $48 \pm 4 \mathrm{~km}$ underneath Wanaka [Bourguignon et al. 2006]. The deepest point of the lithospheric root is displaced by $20 \mathrm{~km}$ to the southeast of the Main Divide [Scherwath et al. 2003, van Avendonk et al. 2004]. The old oceanic crust is thought to thicken with the mantle lithosphere [Stern 1995, Walcott 1998, Wellman 1979]. However, gravity studies show that the crustal root is excessively compensating for the topography of the Southern Alps and, hence, the area is in an Airy isostatic disequilibrium [Bourguignon 2009].

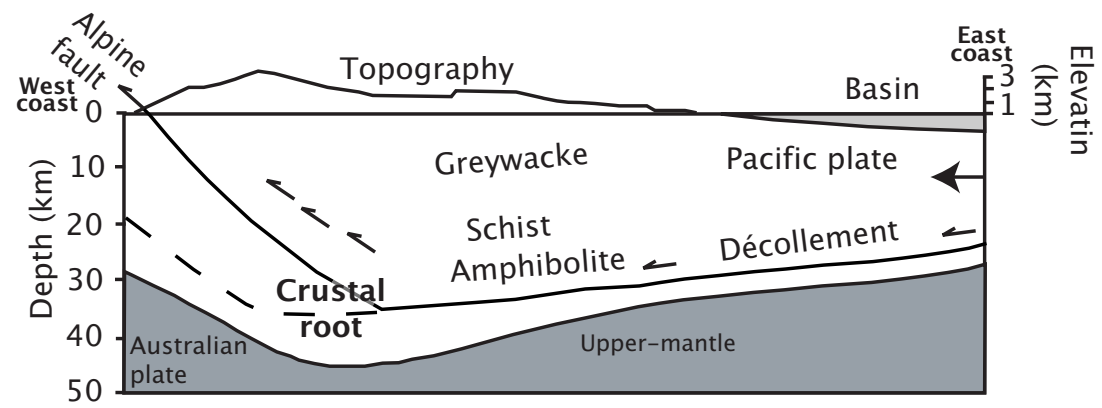

Figure 1.5: Sketch of crustal thickening and crustal root underneath the South Island. After Vry et al. [2010].

\section{Alpine Fault Zone (AFZ)}

The Alpine Fault Zone (AFZ) is a Low Velocity Zone (LVZ) for seismic P-waves located in the thickened crust to the southeast of the Alpine fault ramp [Scherwath et al. 2003, Stern et al. 2001]. The rapid uplift of the crustal rocks shoaled the $350^{\circ} \mathrm{C}$ isotherm, termed the Brittle-Ductile Transition (BDT), from $15 \mathrm{~km}$ to $6-8 \mathrm{~km}$ depth [Allis et al. 1979, Allis and Shi 1995, Norris and Cooper 1995, O'Keefe 2008, Walcott 1998]. Magneto-telluric studies show that the LVZ is roughly coincident with a region of low resistivity - high conductivity, indicating the presence of fluids at depth [Ingham 1995, Wannamaker et al. 2002]. The reduction in seismic velocity at depths greater than $15 \mathrm{~km}$ is thought to be caused by over-pressured fluids originating from the deepening marine metasediments of the Pacific crust [Cox et al. 1997, Stern et al. 2001, Vry et al. 2001], whereas mechanical processes are suggested to reduce seismic velocities closer to the surface [Smith et al. 1995]. Stern et al. [2007] describes this LVZ as a "profoundly hot, wet and weak region of the continental crust". Seismic velocity reductions of 
up to 10\%, compared to that of the protolyth, are observed [Davey et al. 1998, Kleffmann 1999, Leitner et al. 2001, Scherwath et al. 2003, Stern et al. 2001, Stern and McBride 1998] as well as closer to the surface [Brikke 2007, Garrick and Hatherton 1973, Taylor 1997]. There is evidence of crustal anisotropy in Haast schist and mylonites, whose foliations cause a preferential velocity direction [Okaya et al. 1995, Savage et al. 2007].

\section{Mantle down-welling}

A symmetrical zone of cold, high density and high velocity upper-mantle material is argued to lie immediately under the crustal root [Stern et al. 2001]. This 'Mantle-Blob' is $80-100 \mathrm{~km}$ wide, $100 \mathrm{~km}$ long and presents a speed increase of $7 \%$ compared to the surrounding mantle [Stern et al. 2000]. This structure is thought to have occurred from the downward deflection of the mantle isotherms due to lithospheric shortening and continuous mantle thickening [Bourguignon 2009, Stern et al. 2001]. Teleseismic P-wave traveltime delay data suggest a uniform thickening of the mantle lithosphere and a homogeneous strain distribution [Molnar et al. 1999, Scherwath et al. 2002, Stern et al. 2000]. This would not be the case if the oceanic lithosphere intrudes into the mantle lithosphere as proposed by Beaumont et al. [1996]. Anisotropy of $7-13 \%$ is observed in the uppermost mantled exactly underneath and along the base of the crustal root as a result of shearing due to transcurrent plate motion with the fast direction parallel to the plate boundary zone [Baldock and Stern 2005, Bourguignon et al. 2007, Savage et al. 2007]. Recent studies show that such a setting of anisotropy can be caused by the presence of fluids in the plate boundary [Jung et al. 2009].

\subsection{Geological setting}

The velocities of the rocks of the area, both sedimentary and basement rocks, are estimated as part of a static traveltime correction (Chapter 3) and so the consideration of the geological variety is crucial.

\subsubsection{Crustal provinces}

The basement rocks in the study area are classified into two rock provinces and granitic intrusions. They are described hereafter and shown in Figure 1.6.

\section{Western province}

This zone consists of Pre-Cambrian to Mesozoic crystalline rocks of up to $600 \mathrm{Ma}$ in age that were once part of Gondwanaland. These rocks can be found in Fiordland, West Coast and Nelson regions of the South Island [Nathan et al. 1986]. The Western Province rocks are older and, hence, resistant.

\section{Eastern province}

Rocks of this province can be divided into two groups that both originated from deposits off the east coast of Gondwanaland. The Arc Rocks, which are Carboniferous to Cretaceous in age, are 


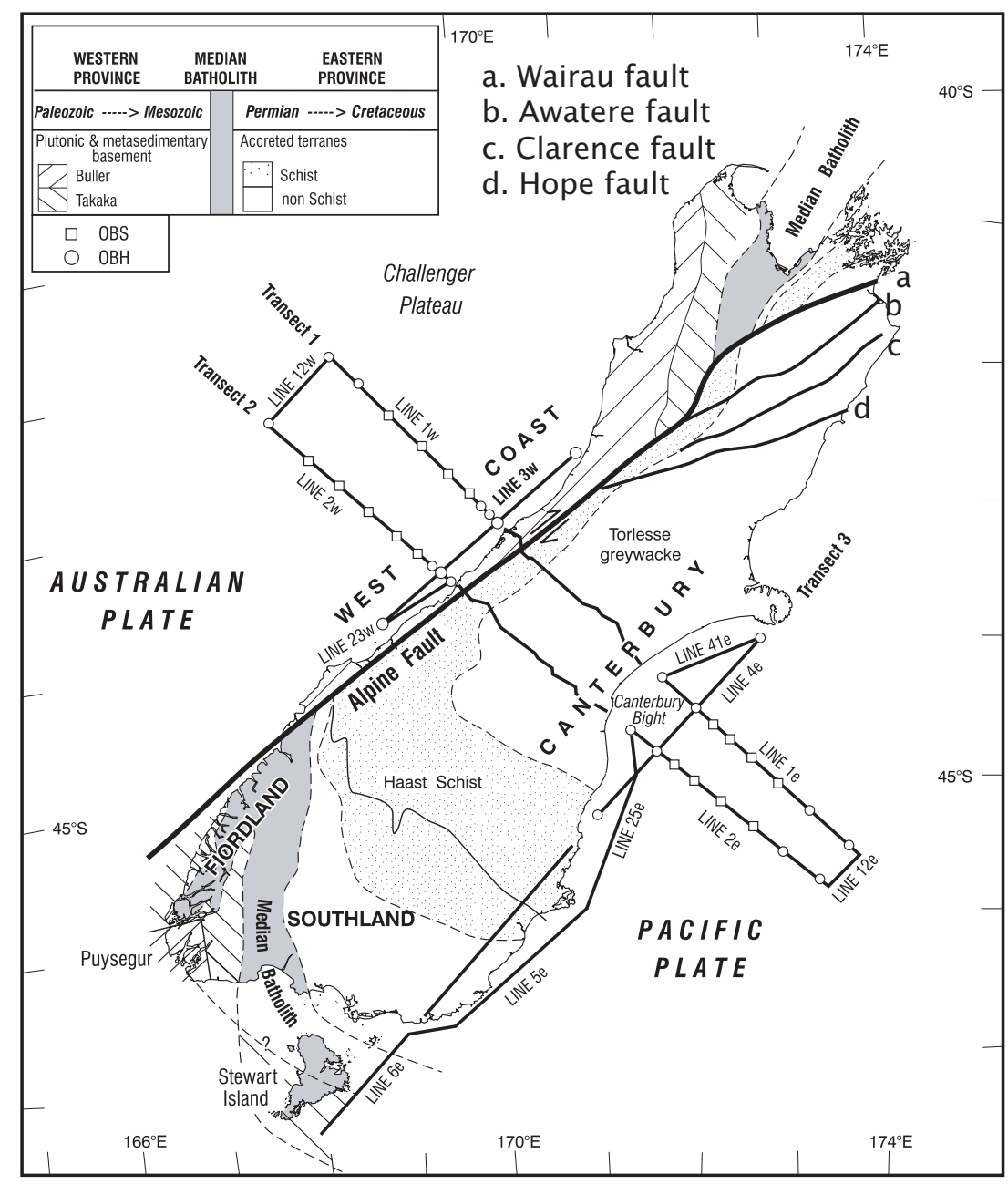

Figure 1.6: Map of the crustal terrane and basement rock in the South Island. The map shows the Western and Eastern provinces, the Torlesse greywackes and Haast schists. The labelled black solid lines represent the arrays of the SIGHT project, white squares and circles represent $O B S$ and $O B H$, respectively. After Davey et al. [200\%]. a

Wairau fault. $\boldsymbol{b}$ Awatere fault. $\boldsymbol{c}$ Clarence fault. $\boldsymbol{c}$ Hope fault.

derived from a volcanic arc material. The Torlesse rocks, mainly consisting of low metamorphicgrade greywackes of Permian to Jurassic in age, are derived from turbidity currents deposited on the sea floor. Crustal collision in the Jurassic (Rangitata orogeny) pushed the Torlesse greywackes to depths of $25-30 \mathrm{~km}$ [Adams 1979], where the high temperature and pressure conditions metamorphosed Torlesse greywackes into Haast schists. These are being uplifted into the Southern Alps (Kaikoura orogeny) and their metamorphic grade increases as a function of crustal depth and closeness to the Alpine fault.

\section{Granitic intrusions}

Granitic gneisses from the Fraser Formation [Rattenbury 1991, Young 1968] appear immediately to the west of the Alpine fault. Fission track studies show that they are coincident with the onset of convergent plate motion 5 Ma ago [White and Green 1986]. 


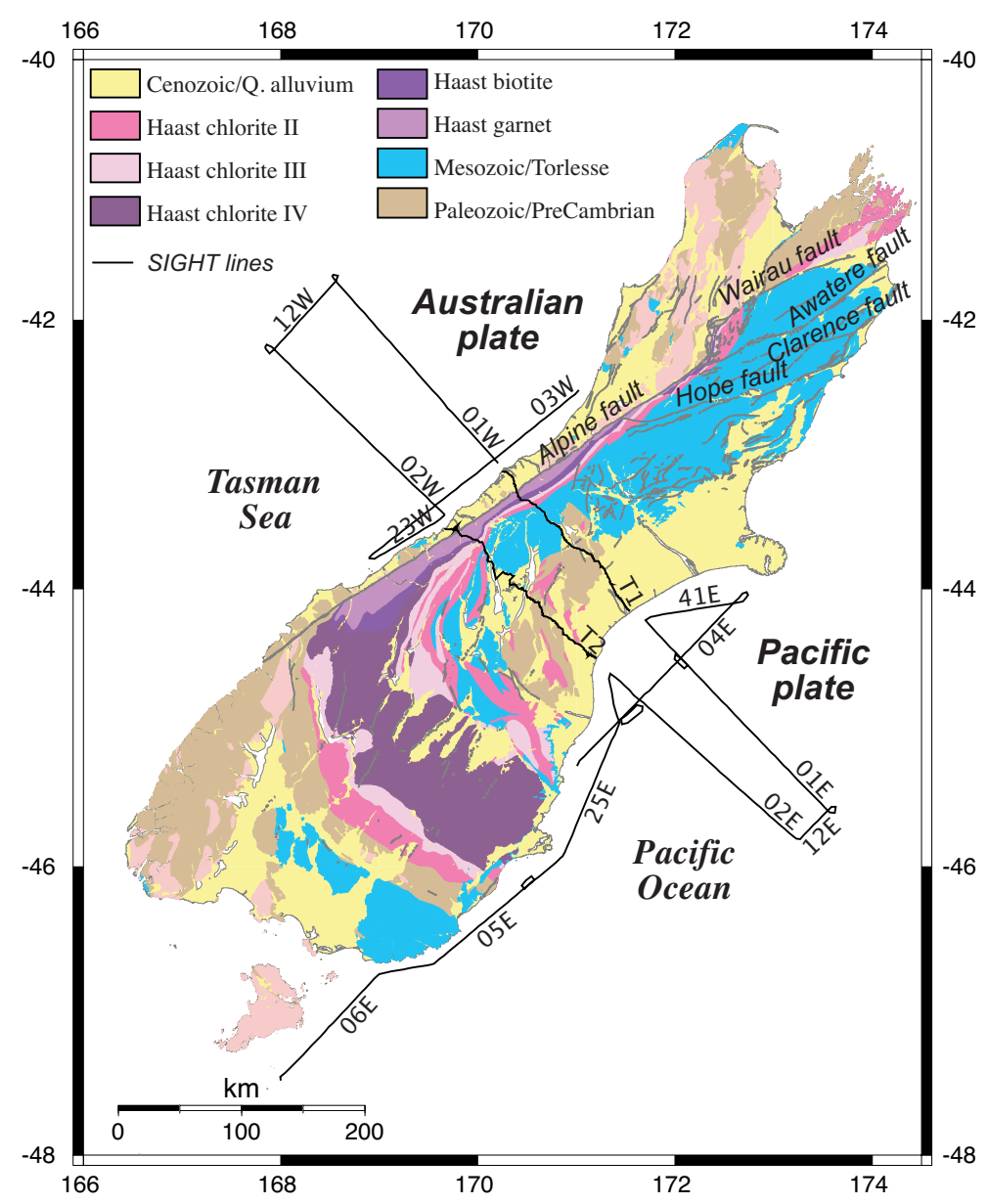

Figure 1.7: Map of the surface geology in the South Island. The labelled black solid lines represent the arrays of the SIGHT project. After Christensen and Okaya [2007].

\subsubsection{Fault-related rocks}

As for major faults, a complex of fault-related rocks is observed in the close vicinity of the Alpine fault. Adjacent to the Alpine fault surface ramp, is a $1 \mathrm{~km}$ thick band of highly foliated amphibolite grade ultra-mylonites [Sibson 1977]. This band is thought to thicken with depth to about $7.5 \mathrm{~km}$ thick [Brikke 2007, Kleffmann 1999, Stern et al. 2002]. The foliation and lineation of the mylonites are consistent with the strike-slip motion on the Alpine fault [Rattenbury 1987]. To the east of the mylonite band is a zone of cataclasites that result from elastico-frictional deformation at shallow depths. Adjacent to the cataclasites is a zone of fault gouge, or 'rock flour', that formed close to the surface. Another such complex associated with the Fraser fault is suggested to exist immediately to the west of the Alpine fault [Young 1968].

\subsubsection{Sediments and surface geology}

\section{Glacial outwash and till}

Large amounts of glacial and fluvioglacial till and outwash have been generated [Forsyth 2001, Sutherland et al. 1995] as a result of New Zealand's glacial history in the Holocene (Otira glaciation [100 - $18 \mathrm{Ka}$ ], New Zealand's Last Glacial Maximum (LGM), and the Waimea glaciation [180 - $140 \mathrm{Ka}$ ) [Petit et al. 1999, Suggate 1990, Sutherland et al. 2006]). Glacial 


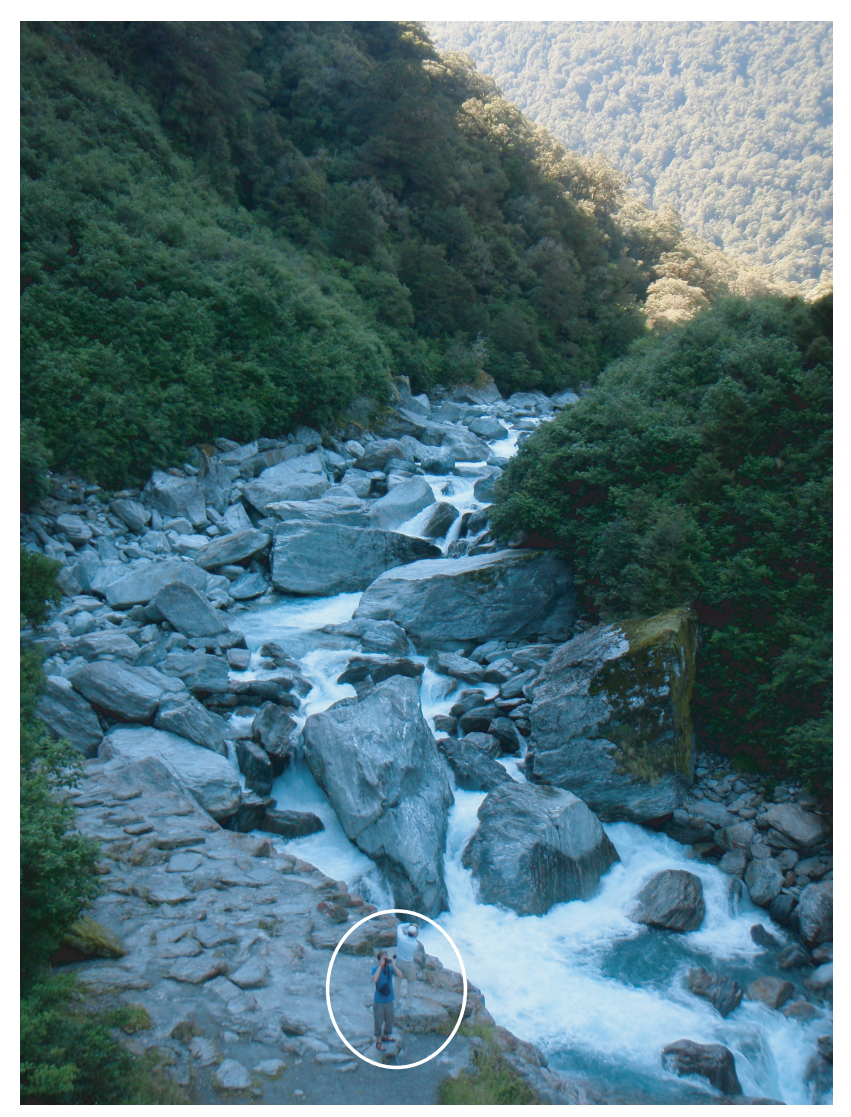

Figure 1.8: Picture showing the size of boulders broken off the flanks of the Haast River. Picture taken at the gates of Haast in late January 2009. Tourists in white circle for scale.

outwash and till generally include extremely heterogeneous grain sizes and are coarse grained. Some sedimentary basins in the South Island, such as the McKenzie Basin and the West Coast of the South Island [Cox and Barrell 2007, Suggate and Almond 2005], were notably affected by glacial activity whereas others, such as the Cannington Basin, have had limited glacial influence [Cox and Barrell 2007].

\section{Clastic and alluvial sediments}

High rainfall focussed on the Southern Alps generates approximately $0.35 .10^{6} \mathrm{~km}^{3}$ of clastic sediments per year on the West Coast of the South Island [Ibbitt et al. 2000]. The scale of the erosion can be seen on Figure 1.8 taken at the Gates of Haast. Sediments are channelled down towards both coasts of the South Island, with grain size decreasing towards the coast. Eocene to Holocene alluvial gravels in the Canterbury Plains form a sequence of sub-horizontal beds.

\section{Other sediments}

A 80 - $100 \mathrm{~m}$ layer Oligocene limestone, the Awarua limestone, is found in basins on both sides of the Alpine fault as well as in sedimentary sequences in the Taranaki region [Katz and Kliewer 1970, Nathan et al. 1986, Sutherland 1996]. Cretaceous and Miocene coal measures are also observed in the region [Cox and Barrell 2007]. 


\subsection{Structure of the document}

The present document is organised in the following way:

Chapter 1 contains the motivation and objectives of this research project along with the geophysical and geological description of the study area.

Chapter 2 presents the seismic data used for this project, the SIGHT West Coast cross-line dataset. Their seismic processing, picking and resulting traveltime dataset are described here.

Chapter 3 details the estimation of sediment thickness and velocity along the SIGHT main transects. This leads to the calculation of individual static corrections.

Chapter 4 describes the synthetic testing step to assess the tomography software and the model space. The tomography method, FMTOMO, is also presented here.

Chapter 5 presents the results of the tomography approach. The latter consists of an objective and subjective approach to the inversion modelling of the data. The final preferred tomography model is shown here.

Chapter 6 deals with assessing the model uncertainties and discussing the solution model and results. A discussion on the advantages and disadvantages of tomography versus forward modelling is provided here.

Appendix A includes the breakdown of the traveltime pick datasets used for this project with respect to its source and seismic phases.

Appendix B describes the dataset consistency checks taken to ensure the coherency of geometry of the different components of the dataset.

Appendix $\mathbf{C}$ presents the synthetic calibration tests used to determine the preferred values for the model and inversion parameters for the synthetic modelling approach.

Appendix D details the interpolation schemes used to construct the 3D reference model for the final inversion. This Appendix also includes the description of additional downweighting and station term calculation schemes that were used during the final inversion.

Appendix $\mathbf{E}$ presents the main input files used for the final inversion to create the preferred tomography model.

Appendix F lists suggestions for possible future software improvement for FMTOMO.

Abbreviations are spelled out the first time they are used in the text. For further referral, a list of abbreviations is supplied before Chapter 1. 


\section{Chapter 2}

\section{Data used for this study}

\subsection{The SIGHT project}

\subsubsection{Introduction}

The South Island GeopHysical Transect (SIGHT) project was a joint research initiative led by United States and New Zealand scientists. Its aim was to investigate at depth the plate boundary zone between the Australian and Pacific plates in the South Island. The data acquisition campaigns were realised between 1995 and 1998 and included active [Holbrook and Davey 1996, Kleffmann 1999, Scherwath et al. 1996], passive [Leitner et al. 2001] and teleseismic datasets [Stern et al. 2000], as well as magneto-telluric [Wannamaker et al. 2002] and gravity ones [Scherwath et al. 2006]. The narrowness of the South Island in the southeast - northwest direction (down to $160 \mathrm{~km}$ ) is highly favourable for the acquisition of an onshore-offshore seismic dataset across the plate boundary [Okaya et al. 2002]. The onshore and onshore-offshore seismic gathers are combined to form "Super-Gathers" of over $500 \mathrm{~km}$ in offset [Okaya et al. 2002]. The entire seismic dataset amounts to almost 110 billion seismic traces. Although the data collection campaigns span the whole of the South Island, the main area of focus is its central part.

\subsubsection{Survey geometry}

The SIGHT project consisted of two sub-parallel transects across the central South Island perpendicular to the plate boundary in a southeast - northwest direction (Figure 2.1):

- Transect 1 (T1), known as the northern transect, follows the Whataroa and Perth Rivers from the West Coast, crosses the Main Divide, then follows the Havelock and Rangitata River to the east coast.

- Transect 2 (T2), known as the southern or Mt Cook transect, is $50 \mathrm{~km}$ to the south of T1. It follows the Karangarua River from the West Coast, crosses the Main Divide at Mt Sefton, through Mt Cook Village, along Lake Pukaki, through the MacKenzie and Cannington basins and to Pareora, $20 \mathrm{~km}$ to the south of Timaru on the east coast. It also intersects with the location of the osffhore well Clipper-1. 


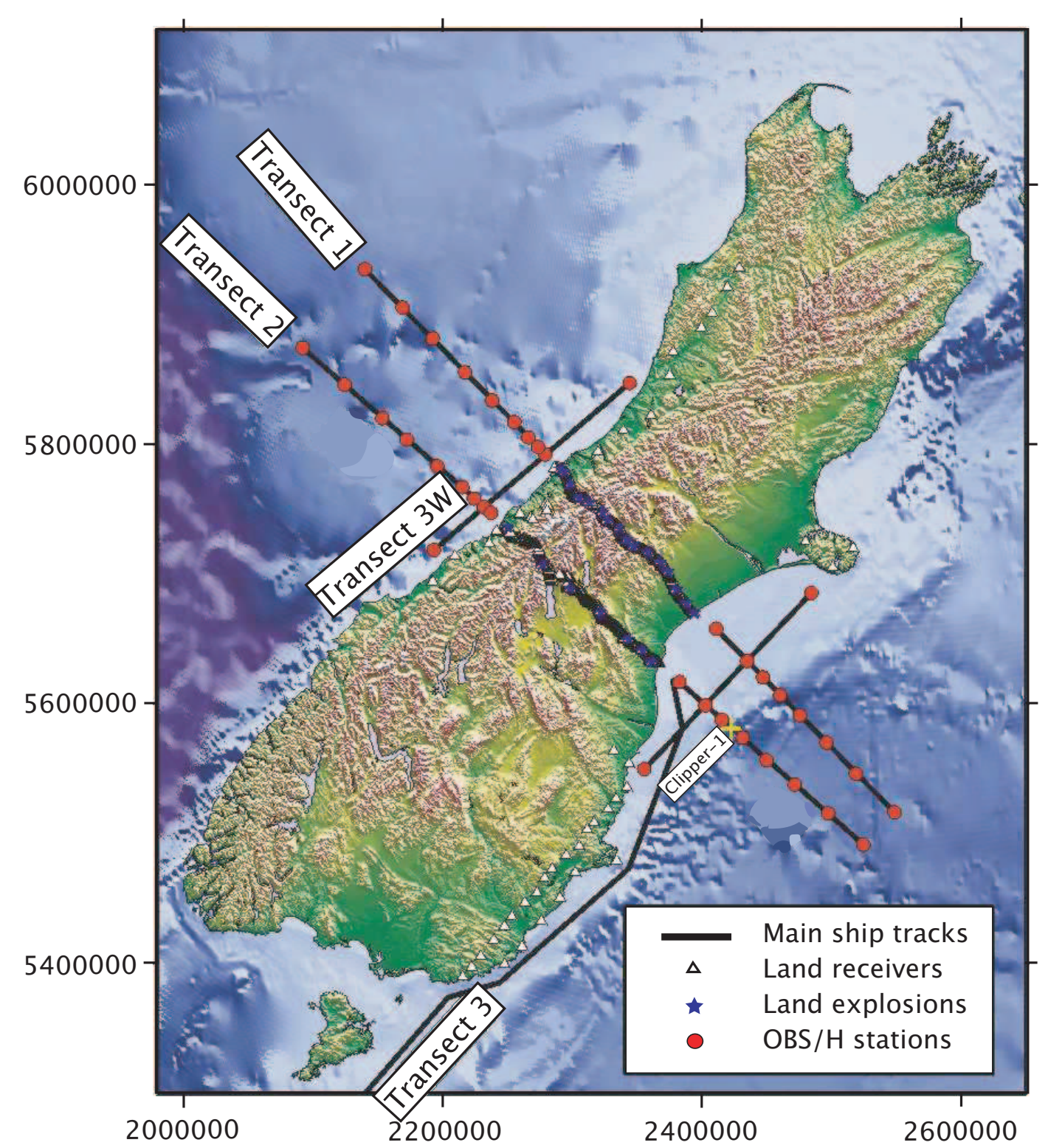

Figure 2.1: The SIGHT project's seismic acquisition campaigns. The ocean bottom instruments in red circles, the land shots in stars, the land receivers are shown in triangles (under blue stars) and the offshore shot lines are shown in solid black lines. Map after Scherwath [2002]. Units are in metres, New Zealand Map Grid (NZMG). The location of the Clipper-1 borehole is represented by a yellow cross. 
There were also two secondary transects sub-parallel to the east and west coasts that intersect $\mathrm{T} 1$ and $\mathrm{T} 2$ : transect 3 (T3) on the east coast and transect $3 \mathrm{~W}$ (T3W) on the West Coast. The offshore transects extended for almost $200 \mathrm{~km}$ off the coast. This was designed to investigate both the Pacific and Australian Plates at some distance from the collision zone and to carry out possible flexural studies.

\subsubsection{Seismic acquisition campaigns}

The SIGHT project had three active seismic campaigns: the onshore, the offshore and onshoreoffshore campaign.

\section{The onshore campaign}

The dataset consists of shot gathers along $\mathrm{T} 1$ and $\mathrm{T} 2$. The receiver array along each transect consisted of 400, one-to-three component instruments with a nominal spacing of about $400 \mathrm{~m}$ (triangles in Figure 2.1). The source array (stars on Figure 2.1) included 23 chemical explosions (sixteen along T1 and seven along T2) with detonation charges ranging from 50 to over $1200 \mathrm{~kg}$ of Powergel [Scherwath et al. 1996]. Two types of instruments were used to record the ground motion:

1. REFTEKs have a natural frequency of either $4.5 \mathrm{~Hz}$ or $2 \mathrm{~Hz}$ with a sampling rate of $4 \mathrm{~ms}$ and have their three component motion sensors lodged in the same casing.

2. EDAs are only used for land shot data collection. They have a natural frequency of $2 \mathrm{~Hz}$, a sampling rate of $8.3 \mathrm{~ms}$ and have a separate housing for each sensor.

Each instrument was buried at a depth of about $30-50 \mathrm{~cm}$ or at least covered with soil to maximise the coupling. The instruments were synchronised either by integrated Global Positioning System (GPS) clock, by time "pulsing" with programmable palm-top computers or by integrated synchronised clocks.

\section{The offshore campaign}

This dataset consists of ocean-bottom receiver gathers and conventional CDP reflection data along the main and secondary transects. The scientific vessel R/V Maurice Ewing, operated by the Lamont-Doherty Earth Observatory of Columbia University, shot along the extension of the main and secondary transects in the Pacific Ocean and Tasman Sea. An array of 20 tuned airguns (total volume of $139 \mathrm{~L}$ ) fired every 20 seconds, (approximately $51.8 \mathrm{~m}$ spacing) at a towing depth of $8 \mathrm{~m}$.

A total of 44,000 shots were fired along thirteen ship track lines (five on the west coast and eight on the east coast; black solid lines on Figures 2.1 and 2.2) [Holbrook and Davey 1996]. There were two offshore receiver arrays:

1. Ocean Bottom Seismometers and Hydrophones (OBS/H). A contingent of twenty Woodshole OBS/H were deployed along the ship tracks (red circles on Figures 2.1).

2. Multi-Channel Seismic (MCS) array. For technical reasons, two streamers were used: a streamer with 26 (2,600 m length) and 38 (3,800 m length) active sections were towed in conjunction with the airgun array on the west coast and east coast, respectively. 


\section{The onshore-offshore campaign}

The location of the South Island (between the Tasman Sea and the Pacific Ocean), the geometrical simplicity and young age of the orogen of the Southern Alps and the relatively low level of human activity are factors that make it a successful focus for onshore-offshore investigations [Okaya et al. 2002]. This dataset consists of receiver gathers along the main and secondary transects. The airgun shots were simultaneously recorded by more than 200 land receivers (triangles on Figure 2.2), approximately spaced every $1.5 \mathrm{~km}$ along the main transects, and much sparser parallel to lines T3 and T3W. The terms 'line 01' is used in the text to represent the combination of offshore shot line $01 \mathrm{~W}$ and $\mathrm{T} 1$. The same is applicable to the term 'line 02 '.

\subsubsection{Related published work}

In the past decade, the datasets from the SIGHT project have been used for numerous crustal studies and have widely contributed to expand the geophysical understanding of the plate boundary in the South Island. Hereafter is a summary of the most significant results published using data from the SIGHT project:

\section{Along T1}

van Avendonk et al. [2004] processed a two-dimensional (2D) crustal tomography under line 01 from $\mathrm{P}$-wave travel times. Convergence induced an asymmetrical thickening of the crust by $9 \mathrm{~km}$ underneath the Southern Alps to a thickness of $37 \mathrm{~km}$. The deepest point of the crustal root is offset by $20 \mathrm{~km}$ to the southeast of the main divide of the Southern Alps. A zone of reduced velocities $(5.9 \mathrm{~km} / \mathrm{s})$ is observed in the crust to the southeast of the Alpine fault. Reduced upper-mantle velocities of $7.8 \mathrm{~km} / \mathrm{s}$ are observed under the West Coast.

Pulford [2002] used the onshore-offshore S-wave data of line 01 and identified a broad region of low Poisson ratio $(\sigma=0.15)$ for a $V_{p} / V_{s}$ ratio of 1.56 at $10-20 \mathrm{~km}$ depth under the Southern Alps, indicating low pore fluid pressure, which contrasts with previous interpretation of high pore fluid pressure at this depth.

Wannamaker et al. [2002] modelled electrical resistivity data acquired during the SIGHT project. The proposed model shows a low resistivity anomaly $(30-300 \mathrm{ohm} . \mathrm{m})$ which indicates presence of fluid.

\section{Along T2}

Scherwath et al. [2003] processed a 2D crustal tomography under line 02 using P-wave traveltimes from the onshore, offshore and onshore-offshore campaigns. An asymmetrical crustal thickening of $17 \mathrm{~km}$ forms a $44 \mathrm{~km}$ thick root, whose base is offset $10-20 \mathrm{~km}$ to the southeast of the main divide of the Southern Alps. Reduced upper-mantle velocities of $7.8 \mathrm{~km} / \mathrm{s}$ were observed beneath the West Coast. Flexural bending of the Australian Plate and high fluid pressure immediately to the east of the Alpine fault are proposed sources for the zone of P-wave velocity reduction.

Harrison [1999] produced and interpreted a migrated and depth converted stack under line $02 \mathrm{~W}$ using the MCS data. Results from flexural modelling show that the Westland 
sedimentary basin is regionally compensated and controlled by flexure. The Australian Plate appears to support a significant proportion of the Southern Alps.

Kleffmann et al. [1998] interpreted deep reflections as originating from the Alpine fault zone. They suggest that the fault zone is dipping by $33 \pm 5^{\circ}$ and has a thickness of about $7.5 \mathrm{~km}$ wide.

\section{Along T3 and T3W}

Godfrey et al. [2001] produced a $600 \mathrm{~km}$ long crustal image under T3. The model suggests a low velocity mantle and an extremely low velocity, highly reflective lower crust. They proposed the presence of a buoyant load in the mantle and a high heat flow.

Melhuish et al. [2005] processed a 2D crustal tomography under T3W. Partial melting is suggested to cause an increase in reflectivity and seismic velocity in the lower crust. The depth of the Mohorovičić discontinuity (Moho) is reasonably stable at $30 \mathrm{~km}$ and upper-mantle velocities are of $8.3 \mathrm{~km} / \mathrm{s}$.

\section{Three-dimensional composite studies}

Kohler and Eberhart-Phillips [2002] used teleseismic P-wave arrival times from the New Zealand National Seismograph Network (NZNSN) and from the Southern Alps Passive Seismic Experiment (SAPSE) to invert for three-dimensional (3D) velocity structure of the uppermost mantle under the Southern Alps. The model shows a near-vertical $2-4 \%$ high velocity zone steeply dipping westwards in the uppermost mantle directly underneath the thickened crust under the Southern Alps. However, the resolution tests of the proposed model indicate a maximum velocity recovery of $40 \%$ and a westward smearing in this part of the model.

Eberhart-Phillips and Bannister [2002] simultaneously inverted active and passive seismic travel times to process $3 \mathrm{D} \mathrm{Vp}$ and $\mathrm{Vp} / \mathrm{Vs}$ models of the crust under the Southern Alps region. A LVZ is observed to the southeast of the Alpine fault up to $14 \mathrm{~km}$ depth. This is coincident with the presence of fluids and high fracture density from active deformation and faulting.

Baldock and Stern [2005] present a high-resolution 3D P-wave velocity tomography model under the eastern South Island. The model shows a mid-crustal LVZ with a $4 \%$ reduction in velocity. The proposed pattern of lithospheric deformation suggests a pervasive and widespread deformation zone.

Scherwath et al. [2006] processed a joint inversion of seismic and gravity data to yield a $3 \mathrm{D}$ image the lithospheric deformation in the collision zone. They propose that the obliqueness of the compression allows lower lithospheric material to escape and creep south during shortening.

Stern et al. [2000] propose that P-wave teleseismic delay times observed underneath the Southern Alps are caused by a symmetric, high-density (density contrast of $40 \pm 5 \mathrm{~kg} / \mathrm{m}^{3}$ ) and high-velocity (up to $8.6 \mathrm{~km} / \mathrm{s}$ ) mantle body, colloquially known as the "Mantle-Blob".

Henrys et al. [2004] processed all onshore-offshore and onshore seismic data to produce a 3D image of the Moho below the continental collision zone. The crustal root is proposed to reach a maximum depth of $45 \mathrm{~km}$, coinciding with a regional ( $80 \mathrm{mGal}$ ) Bouguer gravity low. On both end of the collision zone, shallower Moho underlies a 20km-thick crust. 


\section{Synthesis of findings}

In summary, these studies coincide in the following points:

- There is a crustal root underlying the Southern Alps, it is thought to deepen towards the south (thickness increasing from $37 \mathrm{~km}$ under T1 to $44 \mathrm{~km}$ under T2) and is sub-parallel and displaced $20 \mathrm{~km}$ to the southeast of the Main Divide.

- On either side of the collision zone, the crust reaches usual thicknesses of the order of $20 \mathrm{~km}$.

- There is evidence of metamorphic fluids within the thickened crust, which are thought to reduce the seismic velocity of the rocks in the crustal root to the southeast of the Alpine fault; this zone is termed the Alpine fault Zone (AFZ).

- The Moho geometry follows the geometry of the thickened crust.

- Immediately underneath the crustal root is a high-velocity, high-density body of mantle material, that is termed the "Mantle Blob".

- Furthermore, a flexure signature of the Australian Plate was observed along line 02W.

\subsection{Seismic data}

Data from all four seismic campaigns of the SIGHT project are used here: reflection and refraction traveltime picks from the onshore, offshore and onshore-offshore campaigns are used for the inversion; the MCS stacks are used to estimate the offshore sedimentary structures. The in-line datasets are provided by Martin Scherwath and Harm van Avendonk. However, only the cross-line onshore-offshore datasets of the West Coast of the South Island are processed and picked and the MCS stacks sampled for this study. A detailed account of this dataset is undertaken here.

\subsubsection{West Coast cross-line dataset}

The dataset used for this study includes sources from the offshore ship track and receivers onshore (black solid lines and orange triangles in Figure $2.2 \mathrm{a}$, respectively). The seismic raypaths covers a wide azimuthal range. The area of highest raypath density is located close to the coastal region and in between the main SIGHT transects (Figure $2.2 \mathrm{~b}$ ). However, all the seismic rays are incoming from the northwest, there are no back shooting rays.

\section{West Coast shooting campaign}

A total of 15891 airgun shots were fired along the 5 ship track lines in the Tasman Sea. These lines are $01 \mathrm{~W}, 12 \mathrm{~W}, 02 \mathrm{~W}, 23 \mathrm{~W}$ and $03 \mathrm{~W}$ (black solid lines in Figure and 2.2). However, due to large offsets and low Signal-to-Noise Ratio (SNR), the data of the tie lines $12 \mathrm{~W}$ and $23 \mathrm{~W}$ have been discarded. Details of the shot lines are summarised in Table 2.1. 

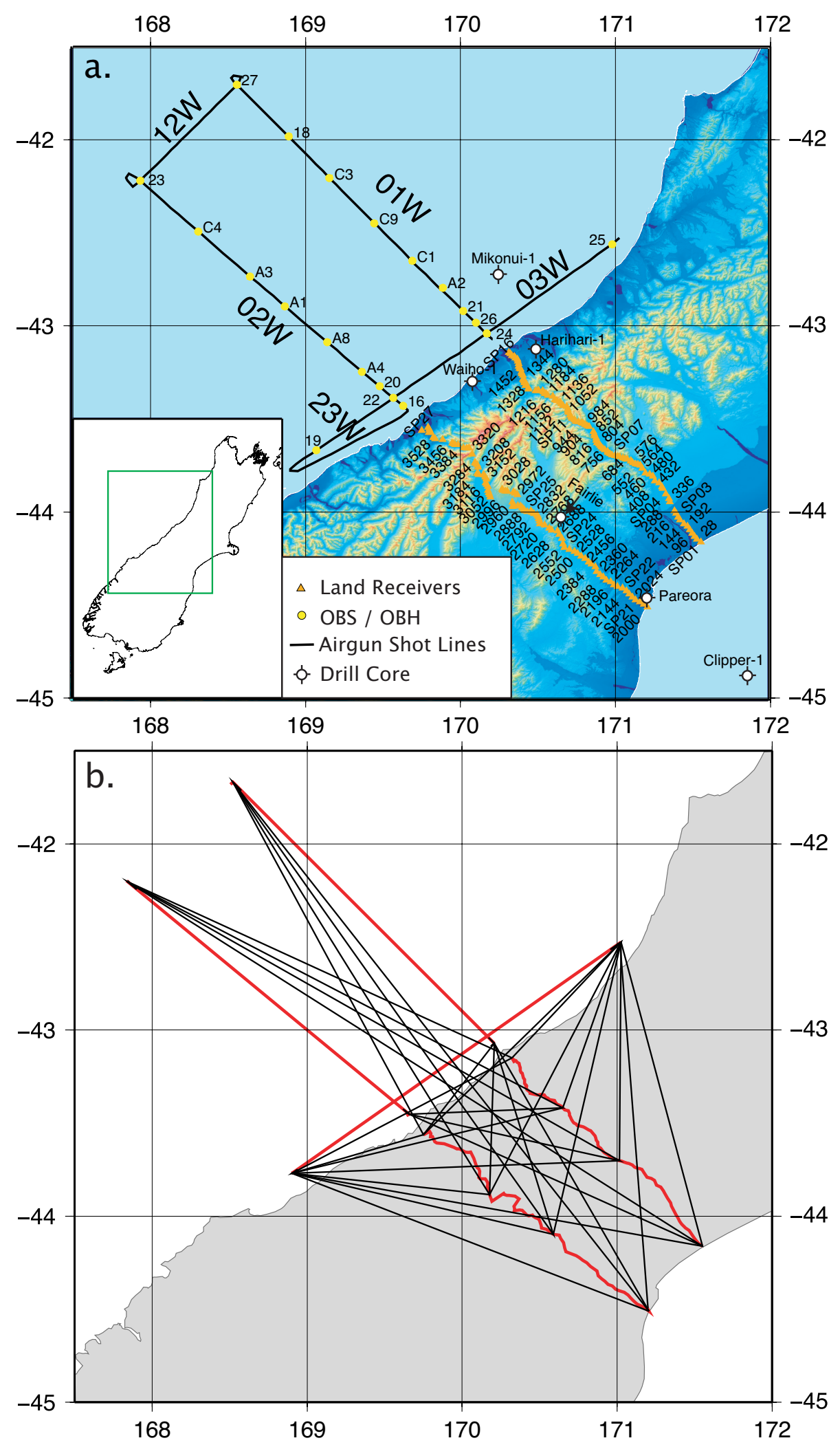

Figure 2.2: $\quad \boldsymbol{a}$. The West Coast cross-line dataset with the land and offshore receivers (orange triangles and yellow circles, respectively), and offshore sources (black solid lines). The location of the drill core used in this study are marked, they are Mikonui-1 [Diamond 1981], Harihari-1 [NZ Petroleum Exploration Co. 1971], Waiho-1 [NZ Petroleum Exploration Co. 1972], Clipper-1 [Hawkes and Mound 1984], Pareora and Fairlie [Gair 1978]. b. Schematic view of the density of the raypaths and the azimuthal range of the dataset. The red solid lines indicate the sources and receivers array; the black solid lines indicate the raypath azimuths from different combinations of source-receiver pairs. 


\begin{tabular}{cccc} 
Shot Line & $01 \mathrm{~W}$ & $02 \mathrm{~W}$ & $03 \mathrm{~W}$ \\
\hline \hline First shot number & 995 & 7235 & 12615 \\
Last shot number & 5052 & 11185 & 16885 \\
\hline Effective number of shots & 4058 & 3951 & 4271
\end{tabular}

Table 2.1: Table of details of the West Coast offshore shot lines used for this study.

\section{Receivers}

The data from the vertical component data of land receivers along both main transects (orange triangles on Figure 2.2 a) are used for this study. A total of 274 Receiver Gathers (RG) are processed and picked. Some receiver gathers have been discarded due to too low SNR. The amount of available data and its exceptionally good quality means that the discarding of receiver gathers will not deteriorate the raypath coverage of the model area. The dataset is divided into three sub-datasets:

1. Line $01 \mathrm{~W}$ into T2: $70 \mathrm{RG}$ (Figure 2.7)

2. Line 02W into T1: 79 RG (Figure 2.8)

3. Line 03W into T1 and T2: 125 RG (Figure 2.9)

\subsubsection{Seismic processing}

The seismic data were processed with Globe Claritas [Ravens 1999]. The data are in SEG-Y format (IBM floating point [Meissinger 2004]). The main objective of processing the seismic gathers is to facilitate the phase identification and picking processes by improving the look and coherency of the seismic gather. The effect of processing on the seismic data is illustrated in Figure 2.4. Five main processing modules are used, they are described hereafter:

Frequency filters are designed to segregate certain frequencies from the seismic gather. A band-pass filter (Figure 2.3) is applied to the data to remove environmental noise $(0.6 \mathrm{~Hz}$ and below) and the high frequency noise (13 Hz and above), yet to retain the seismic events $(6-8 \mathrm{~Hz})$ as well as low frequency events from large offsets $(4 \mathrm{~Hz})$.

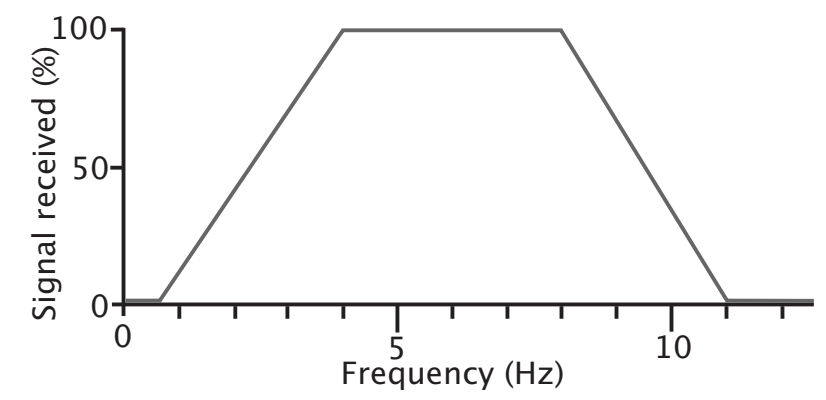

Figure 2.3: Sketch of the frequency band-pass filter applied to the seismic data. Its defining points are 0.7, 4, 8 and $11 \mathrm{~Hz}$. 
Automatic Gain Control (AGC) normalises the seismic trace over a set time length and effectively enhances the coherency of later arrivals. A time window of $990 \mathrm{~ms}$ is used on the data. This value results in a better overall look of the amplitudes of the seismic gather.

Balancing scales an individual trace with respect to the average amplitude over a set time window. A window of $5,000 \mathrm{~ms}$ is used on the data because the seismic events of interest fit within such a time window.

Partial stacking sums the amplitude of adjacent seismic traces. This allows to improve, or even recover, the coherency of an event where the SNR is inferior to 1. Three adjacent traces are stacked together in these data. Notwithstanding that it significantly improves the whole receiver gathers, this processing step is predominantly meant to enhance the coherency of seismic events at large offsets (>250 km and up to $350 \mathrm{~km}$ ), such as uppermantle refractions (Pn). In order to optimise the constructive interference of the stacking, the seismic events of interest are individually flattened, by applying a reduction velocity of $8 \mathrm{~km} / \mathrm{s}$ (as opposed to $6 \mathrm{~km} / \mathrm{s}$ as it is originally) for the Pn phases.

Predictive deconvolution aims to retrieve the original seismic source wavelet from its convolution along the raypath by cross correlating seismic traces. This method is used to get rid of ringing in a seismic gather. A filter length of $570 \mathrm{~ms}$ and a gap length of $112 \mathrm{~ms}$ are found to reduce the majority of the ringing while not significantly degrading the frequency content (thus coherency) of the events of interest.

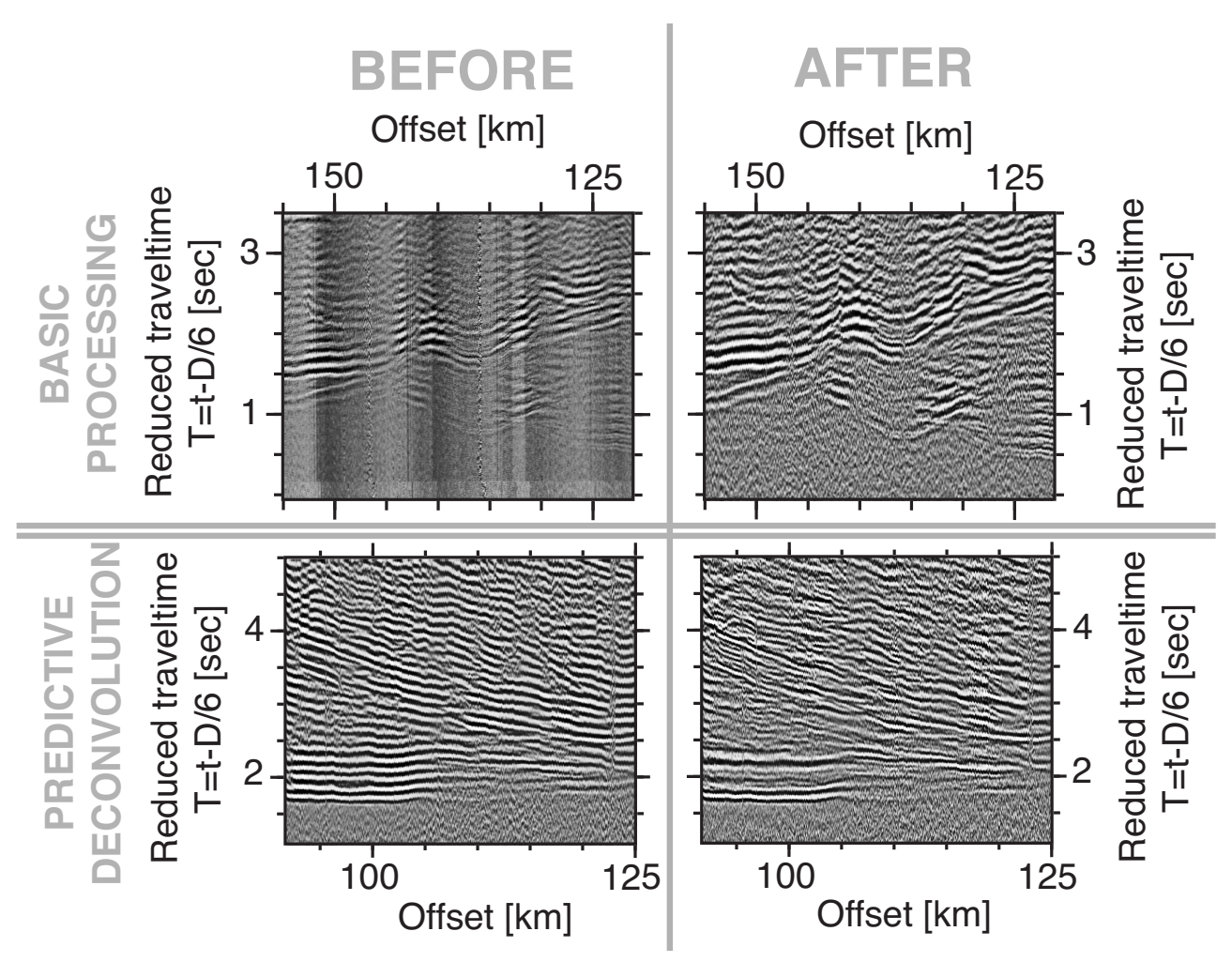

Figure 2.4: Plots showing seismic data before (left plots) and after (right plots) basic processing (top plots) and predictive deconvolution (bottom plots). The basic processing removes spurious frequency and normalises the seismic trace. The predictive deconvolution eliminates the ringing of the data. 


\subsubsection{Phase picking}

The phase identification is done by eye and the picking is done manually on the Statics/First Break module of Globe Claritas [Ravens 1999]. Many seismic events are observable on the gather; however only four phases are picked and later used for modelling, as only these could be confidently identified [Zelt 1999]. These are the crustal reflection (PlP), the crustal refraction $(\mathrm{Pg})$, the upper-mantle/Moho reflection $(\mathrm{PmP})$, and the upper-mantle refraction $(\mathrm{Pn})$ (Figure 2.5). Examples of phase identification can be seen alongside the processed seismic gathers in Figures $2.7-2.9$.

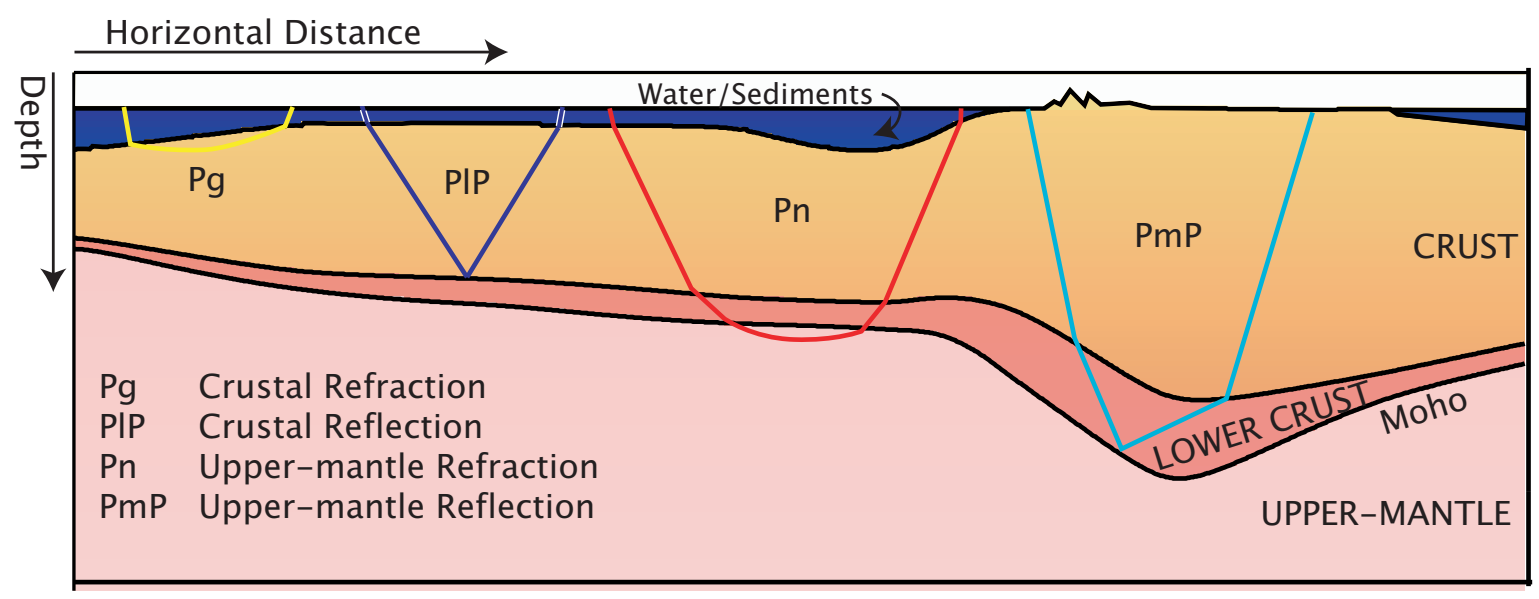

Figure 2.5: Schematic drawing showing the raypath of the crustal refraction, $P g$ in yellow, the crustal reflection, PlP in blue, the upper-mantle refraction, Pn in red, and the upper-mantle reflection, PmP in light blue.

\section{Synthetic receiver gather}

To serve as a guideline for the phase identification, a 2D synthetic ray tracing plot (Figure 2.6) based on the model of SIGHT's Line 01 [van Avendonk et al. 2004] is produced with MacRay [Luetgert, J.H. 1992]. To simulate a receiver gather, a shot gather was produced. One artefact of the software (Figure 2.6) is that the northwest flank of the crustal root does not appear to be sampled by seismic rays. However, the continuous coherency of the PmP and Pn phases in the seismic gathers (Figures $2.7-2.9$ ) indicate that there is no shadow zone in this region.

The Pg phase (light blue lines in Figure 2.6) appears flat (with a reduction velocity of $6 \mathrm{~km} / \mathrm{s}$ ) and is observed throughout the seismic gather. The other linear event is the upper-mantle refraction, Pn (black lines in Figure 2.6), that emerges from the Moho reflection, PmP (red lines in Figure 2.6). The other curved event is the lower-crustal reflection, PlP (dark blue lines in Figure 2.6).

The cross-over distance between $\mathrm{Pg}$ and $\mathrm{Pn}$ (feature 1 in Figure $2.6 \mathrm{~b}$ ) is located at about $150 \mathrm{~km}$ offset from the receiver. A characteristic zone of high amplitudes marks the critical distance between Pn and PmP (feature 2 in Figure $2.6 \mathrm{~b}$ ), and the former emerges from the latter between $90-120 \mathrm{~km}$ offset. At $150-200 \mathrm{~km}$ offset, a high amplitude zone results from the overlapping and summing of Pg, PlP and PmP energies. At larger offset $(230 \mathrm{~km}) \mathrm{PlP}$ and $\mathrm{Pg}$ become asymptotic (feature 3 in Figure $2.6 \mathrm{~b}$ ) as PlP's raypath is similar to a refraction bottoming at the base of the crust. 
The refraction inside the supposed oceanic lower-crust (green line in Figure 2.6) is shadowed by the overlapping energy of the latter high amplitude zone. In the seismic data, this zone of high amplitude will result in a difficult phase identification procedure as four phases are virtually on top of each other. In the same fashion as for Pg and PlP, PmP becomes asymptotic to the oceanic lower-crustal refraction at offset larger than $160 \mathrm{~km}$ (feature 4 in Figure $2.6 \mathrm{~b}$ ).

\section{Manual picking}

The dataset is scrutinised prior to picking to ensure the phases are correctly being identified. Furthermore, the receiver gathers are picked using the snapping pick tool ensuring the consistent picking of the same part of the waveform. The flattening tool was used to verify that the picks are effectively from the same event and not a later arrival. At large offsets $(>250 \mathrm{~km})$, because of the low SNR, the identification of an event relies on its coherency rather than its amplitude. To further enhance the coherency of low SNR events at larger offsets, a sharp frequency filter was used on the data to generate Gibb's phenomena and, hence, allow the recognition of a previously-muted continuation of a seismic event.

Only seismic phases that are confidently identified are picked. Picking uncertainties vary from $50 \mathrm{~ms}$ to $300 \mathrm{~ms}$ depending on the quality of the receiver gather and the continuity of the event. A detailed breakdown of the seismic phases and a table of picking uncertainties are provided in Appendix A. Hereafter is a summary of the picking of each sub-datasets:

1. 01W into T2: All four phases are picked in this dataset. The PlP phase is underrepresented compared to the other phases and there is limited Pg energy at offsets greater than $170 \mathrm{~km}$. PmP phases are generally strong and are confidently picked from short to large offsets. Some Pn phases are traced up to $350 \mathrm{~km}$ offset. A duplication of Pn is observed at an offset of around $240 \mathrm{~km}$ (white arrows in Figure 2.7)as well as a series of multiple reflections (e.g. PmP2 and PmP3 in Figure 2.7). These events have been noted previously by Scherwath et al. [2003] and Melhuish et al. [2005] and may originate from discontinuities in the upper-mantle.

2. 02W into T1: All four phases are also picked in this dataset. PlP and Pg phases at shorter offsets are less represented than in the previous sub-dataset. Again, PmP and Pn phases can be traced confidently throughout the gather. Pn duplications are also observable (white arrows in Figure 2.8). A jump in apparent velocity of $P g$ appears to originate from two different events (wobbles on the yellow line in Figure 2.8). This feature is also observed by Scherwath [2002], and is suggested to be due to local shallow structure offshore.

3. 03W into T1 and T2: Due to the out-of-plane geometry of this dataset, the 2D synthetic receiver gather could not be used for the identification of the phases. Only the first breaks are picked with confidence as Pg. Therefore, this dataset provides most of the $\mathrm{Pg}$ traveltime picks. Some deeper high-amplitude events are observed (white dashed lines in Figure 2.9) but are not picked to prevent misinterpretation. 


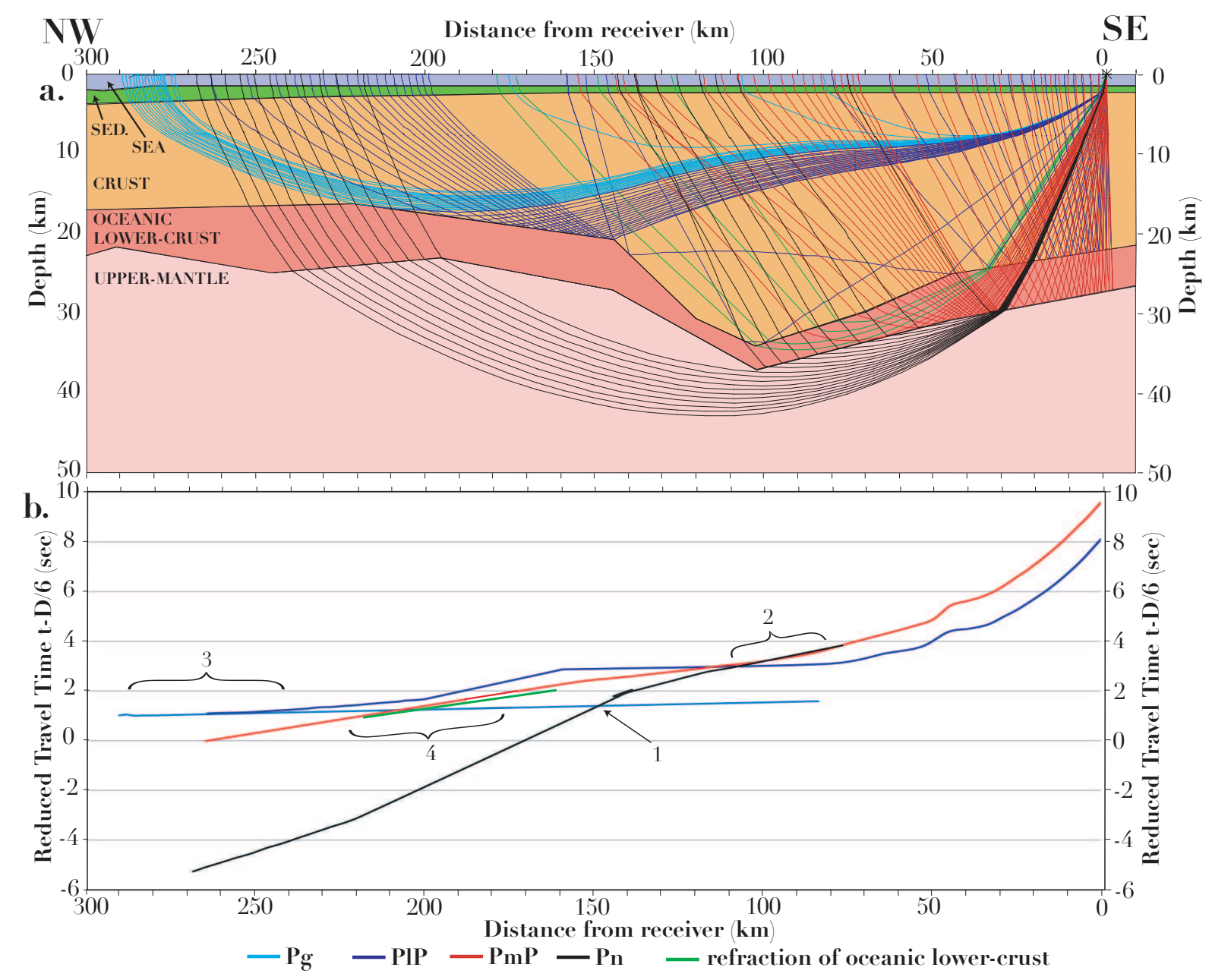

Figure 2.6: Synthetic seismic gather produced by MacRay [Luetgert, J.H. 1992]. a. The velocity and boundary structure used to calculate the seismic rays is based on the model from van Avendonk et al. [2004]. Five phases are calculated: the crustal refractions, Pg (light blue lines), the lowercrustal reflections, PlP (dark blue lines), the Moho reflections, PmP (red lines), the refractions from the oceanic lower-rust (green lines) and the upper-mantle refractions, Pn (black lines). $\boldsymbol{b}$. The resulting traveltime plot of the calculated seismic rays in plot a. A reduction velocity of $6 \mathrm{~km} / \mathrm{s}$ is applied to the traveltimes. Feature 1 shows the cross-over between $\mathrm{Pg}$ and $P n$, feature 2 indicates the critical distance between Pn and PmP, feature 3 shows that $P g$ and $P l P$ are becoming asymptotic and feature 4 shows that PmP and the refractions from the oceanic lower-crust are becoming asymptotic. 


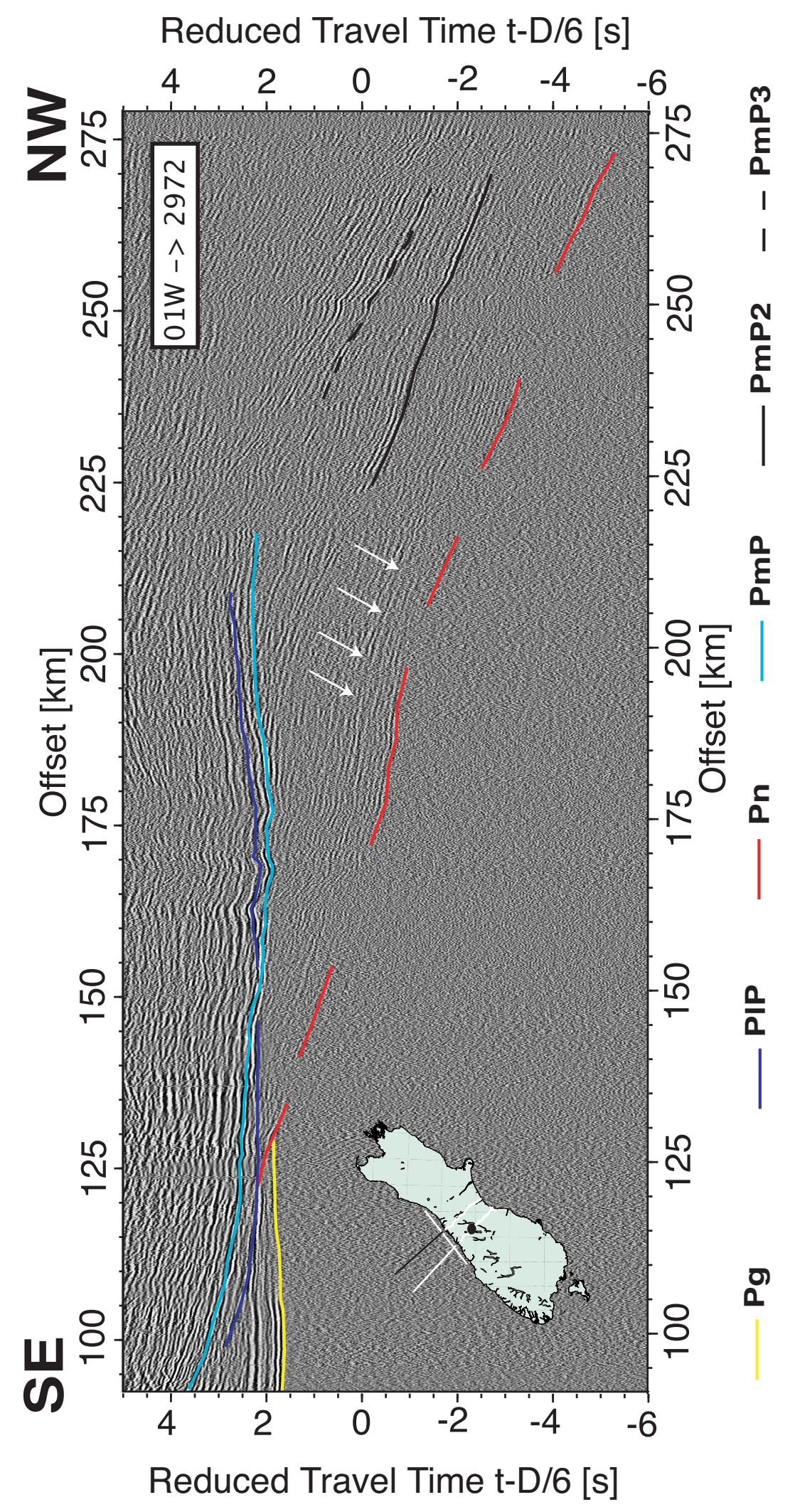

Figure 2.7: Example of an onshore-offshore receiver gather from the West Coast cross-line dataset. Land receiver 2972 along T2 receiving the offshore shots of Line $01 \mathrm{~W}$, they are represented by the blue dot and line, respectively, in the map inset. The seismic gather has a reduction velocity of $6 \mathrm{~km} / \mathrm{s}(T=t-D / 6)$. The seismic phases interpreted include the crustal reflection (PlP, in dark blue) and refraction (Pg, in yellow), the uppermantle reflection (PmP, in light blue) and refraction $(P n$, in red). White arrows show the Pn duplication. Multiple upper-mantle reflections (PmP2 and PmP3, solid and dotted black lines, respectively) are also observed in this receiver gather. 


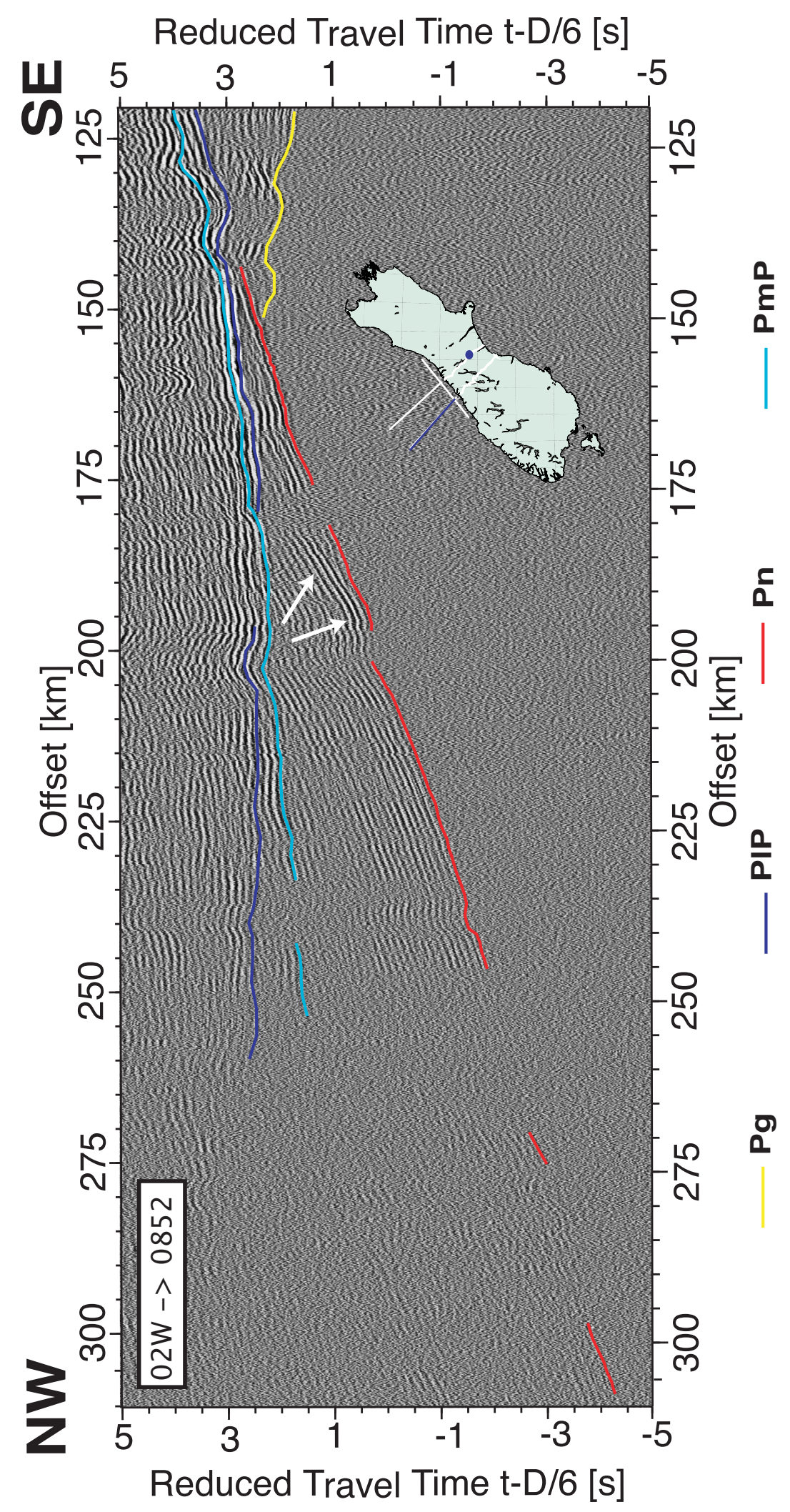

Figure 2.8: Example of an onshore-offshore receiver gather from the West Coast cross-line dataset. Land receiver 852 along $T 1$ receiving the offshore shots of line $02 \mathrm{~W}$, they are represented by the blue dot and line, respectively, in the map inset. The seismic gather has a reduction velocity of $6 \mathrm{~km} / \mathrm{s}(T=t-D / 6)$. The seismic phases interpreted include the crustal reflection (PlP, in dark blue) and refraction (Pg, in yellow), the uppermantle reflection (PmP, in light blue) and refraction (Pn, in red). White arrows show the Pn duplication. 


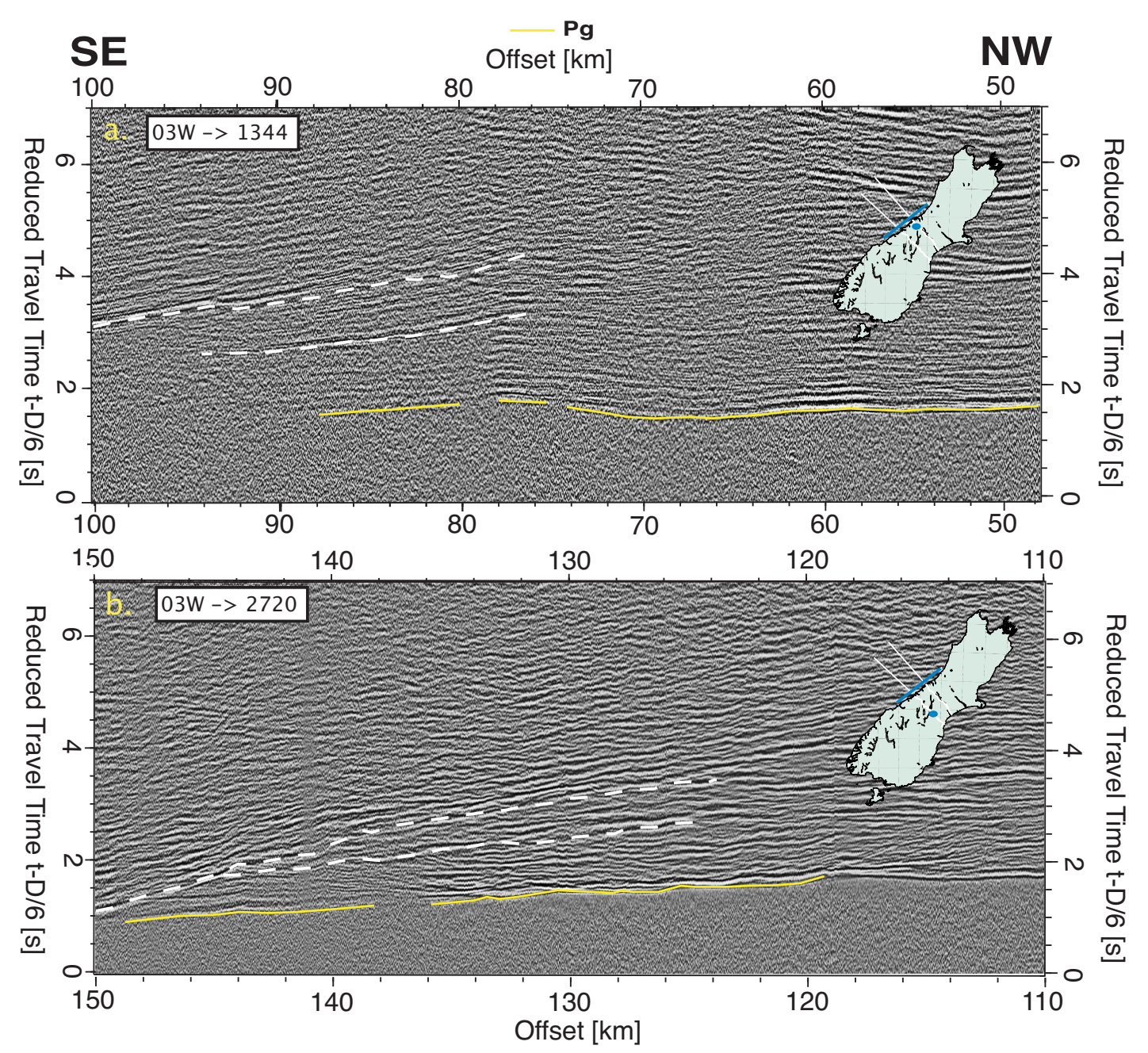

Figure 2.9: Example of an onshore-offshore receiver gather from the West Coast cross-line dataset. Shots of Line $03 \mathrm{~W}$ recorded by land receivers 1344 along $T 1$ (a.) and 2720 along T2 (b.), they are represented by the blue dots and lines, respectively, in the map insets. The plots have a reduction velocity of $6 \mathrm{~km} / \mathrm{s}(T=t-D / 6)$. The crustal refractions ( $P g$, in yellow) are interpreted. Later arrivals are observed but not interpreted (white dashed lines).

\subsection{Pick dataset}

The manual picking done for this project resulted in a total of 98,884 traveltime picks. An additional 65,164 traveltime picks are received from the in-line datasets of the SIGHT line 01 [van Avendonk et al. 2004] and line 02 [Scherwath et al. 2003]. Hence, the total pick dataset is composed of 164,048 picks as summarised in Table 2.2. Again, a detailed breakdown of each dataset is presented in Appendix A. Furthermore, because of the different geometry conventions used to process each dataset, several consistency steps are taken to limit any possible inconsistencies, they are summarised in Appendix B.

Apart from $\mathrm{Pn}$ (17\% of the dataset), all phases are reasonably evenly represented (34\% of $\mathrm{Pg}$, $21 \%$ of PlP and $28 \%$ of PmP). This enables the sampling of the crustal velocity structure as well as the lower-crustal and Moho boundary geometry. However, the coverage of the upper-mantle velocity structure is more limited. 


\begin{tabular}{c|c|c|c|c||c} 
Phases & $\mathrm{Pg}$ & $\mathrm{PlP}$ & $\mathrm{PmP}$ & $\mathrm{Pn}$ & Total \\
\hline Picks & 56,637 & 34,406 & 45,320 & 27,685 & 164,048
\end{tabular}

Table 2.2: Table of the phase breakdown of the total traveltime pick dataset used for the study.

\subsection{Summary}

Some 274 receiver gathers from the West Coast cross-line dataset from the SIGHT project are processed and manually picked for this study. Only four phases (crustal and upper-mantle refractions and lower-crustal and Moho reflections), which could be confidently identified, have been picked. The total traveltime pick dataset for this study includes 164,048 traveltimes from three different sources. The dataset is divided into $34 \%$ of $\mathrm{Pg}, 21 \%$ of $\mathrm{PlP}, 28 \%$ of $\mathrm{PmP}$ and $17 \%$ of Pn picks. The better covered area are the crust and the upper-mantle located in between the two main SIGHT transects, and the least well covered ones are the lower-crust and upper-mantle boundary geometry and velocity structure along the main SIGHT transects. 


\section{Chapter 3}

\section{Shallow structure static correction}

\subsection{Preparation for static corrections}

\subsubsection{Justification}

A seismic ray samples the velocity properties of the rocks it encounters along its raypath, and the relatively low sedimentary velocities increase noticeably the proportion of traveltime spent in the sedimentary layers. Figure 3.1 illustrates how the lateral thickness variation affects a seismic gather and, hence, the traveltime picks.

Static time corrections, or statics, are defined as seismic traveltime variations caused by the heterogeneous velocity field and layer thickness in the near-surface. Statics are difficult to adequately estimate as the structural irregularities of the near surface are often unknown and/or complex. Therefore, over the last decades, geophysical exploration companies have pushed the development of accurate statics estimation algorithms. Numerous automated procedures have been developed for this purpose (e.g. Bevc [1997], Chang et al. [2002], de Vel [1984], Li et al. [2009], Rajasekaran and McMechan [1996], Schuster and Zhou [2006], Zhou [2006], Zhu et al. [2008]).

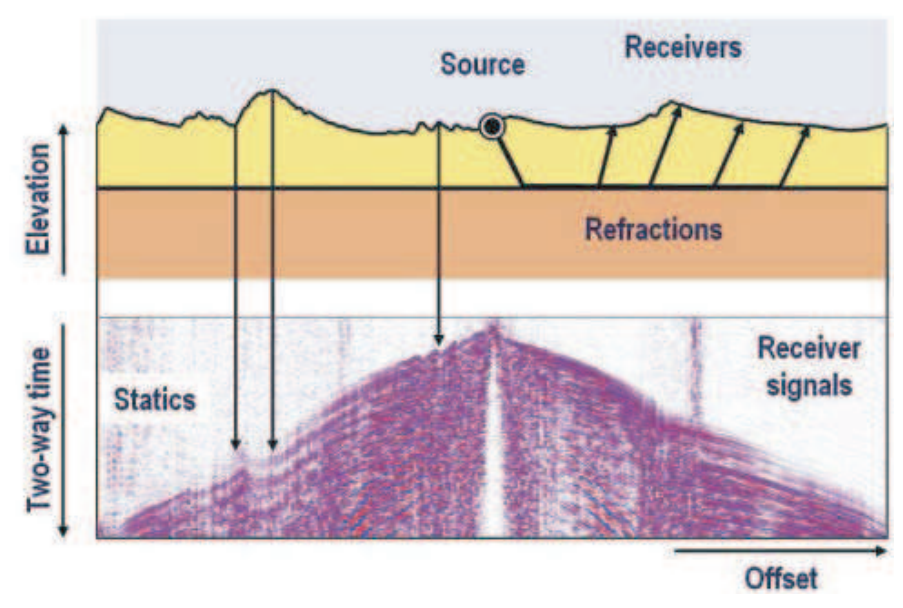

Figure 3.1: Schematic drawing of the time shifts and other spurious effects on the seismic gather caused by a layer of varying thickness, after Laake and Zaghloul [2009]. Picking phases without taking account of layer thickness will lead to error in modelling. 
In the case of tomography, time delays will cause a localised velocity anomaly that will be balanced by a velocity anomaly of opposite sign elsewhere along a raypath [Stern et al. 2010]. Hence, sediment layers and their corresponding delays need to be determined. In some past studies only a superficial knowledge of the uppermost crust has been taken into account (e.g. Kohler and Eberhart-Phillips [2002], Rawlinson et al. [2006a]). Some inversion methods allow the input of the sedimentary structures as part of the model space [van Avendonk et al. 2001, Zelt and Smith 1992]. However, the smoothness of the interface definition function of the method used for this study, FMTOMO [Rawlinson 2005] (described in Section 4.1), does not allow their input. Therefore, the calculation of static corrections for the traveltime related to the sedimentary structures is undertaken to eliminate the effect of such delays. The careful estimation of sediment thickness and velocity can significantly reduce depth misinterpretation of modelled structures and eliminate spurious model artefacts [Cox 1999].

These corrections are only carried out for the sediments because the basement rocks have better constrained velocities. If the traveltime contribution of sediments is corrected (i.e. removed), then the sediment thickness under the station also needs to be corrected for. Effectively, the traveltime and station elevation are stripped to basement level. Therefore, this elimination is carried out in two complementary ways:

1. Traveltime correction: This step implies the removal of the portion of the traveltime corresponding to the transit of the seismic raypath in the sediments.

2. Elevation correction: The sediment thickness under each station is subtracted from the station's elevation down to basement level.

Seismic velocity (Section 3.2) and stratigraphic information (Section 3.3 and 3.4) about the sedimentary basin of the study area has been gathered from a variety of sources including active seismic, gravity and petroleum industry well data, as discussed below.

\subsubsection{Assumptions}

The assumptions made to facilitate the static corrections of the traveltime picks are described hereafter:

Geometric ray theory: The behaviour of a seismic wave is treated as a seismic ray as opposed to a wave front. This approach is better when dealing with traveltimes, as it simplifies the analysis while yielding a reasonably good approximation [Stein and Wysession 2003].

Surface consistency: The path length and emergence angle of an incoming seismic ray will be affected by the sharp velocity contrast between crustal material and sediments. Snell's Law, based on Fermat's Principle of propagation of light, states that the angle of emergence, $i_{1}$, is dependent on the angle of incidence, $i_{2}$, and on the velocities on either side of the interface, $v_{1}$ and $v_{2}$ (Figure 3.2) as follows:

$$
\begin{aligned}
& \frac{v_{1}}{\sin \left(i_{1}\right)}=\frac{v_{2}}{\sin \left(i_{2}\right)} \\
& i_{1}=\sin ^{-1}\left(\frac{v_{1} \cdot \sin \left(i_{2}\right)}{v_{2}}\right)
\end{aligned}
$$


So, from equation 3.2, the greater the difference between $v_{1}$ and $v_{2}$, the smaller the ratio $v_{1} / v_{2}$ and the smaller $i_{1}$ is, and the more vertically the ray will emerge from the interface towards the surface. Therefore, it is assumed that the seismic ray travels vertically through the sedimentary fill.

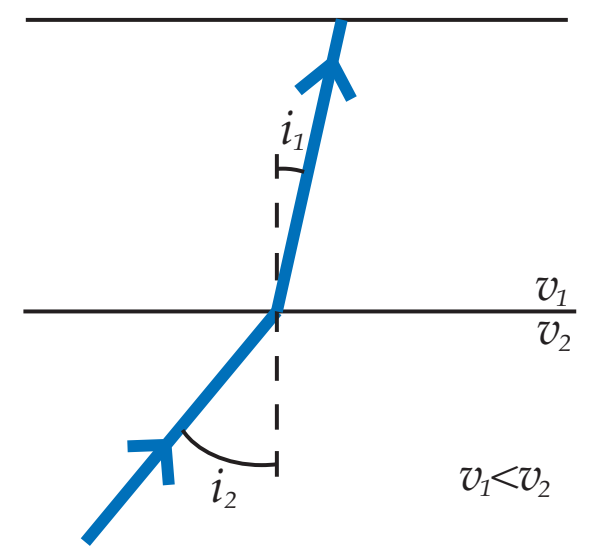

Figure 3.2: Illustrative sketch of the variables involved in Snell's Law.

For example, the angle of incidence, $i_{1}$, for a ray incoming at $i_{2}=30^{\circ}$, with $v_{1}=2.5 \mathrm{~km} / \mathrm{s}$ and $v_{2}=5.3 \mathrm{~km} / \mathrm{s}$ is of $13.6^{\circ}$. Hence the error in horizontal distance, $X_{\text {err }}$ over a thickness of $6 \mathrm{~km}$ (maximum expected sedimentary fill, see Section 3.4.2) of material of $v_{1}$ is:

$$
X_{\text {err }}=6 . \tan \left(i_{1}\right)=1.451 \mathrm{~km}
$$

And the difference in traveltime, $t_{d i f f}$, will be:

$$
t_{d i f f}=\frac{6}{v_{1} \cdot \cos \left(i_{1}\right)}-\frac{6}{v_{1}}=0.069 \mathrm{~s}
$$

The error in horizontal distance $(1.451 \mathrm{~km})$ represents $18 \%$ of the node spacing of the inversion grid (see Section 4.2.1) and the time difference between the vertical and slant raypaths $(0.069 \mathrm{~s})$ represents a traveltime error of less than $3 \%$. For upper-crustal velocity of $6 \mathrm{~km} / \mathrm{s}$, this traveltime error is of the order of $2 \%$. Hence, the surface consistency assumption will have minimal effect on the resolution of the inversion.

This approximation fails for short raypaths where refractions only travel through the sediments. However, the earliest refractions, as discussed in Section 2.2.3, are picked at offsets greater than $90 \mathrm{~km}$ and have an apparent velocity of $6 \mathrm{~km} / \mathrm{s}$ (flatness of $\mathrm{Pg}$ in Figure $2.7-2.9$ ). Hence, they have sampled crustal velocities and this assumption is applicable to them.

Other assumptions: Each event is assumed to produce one single arrival - no multipathing or scattered arrivals are modelled. Also, the static correction of emerging or incident ray is considered the same for all events, regardless of their arrival time. Finally, each sedimentary units are modelled with one uniform value of seismic velocity. 


\subsubsection{Correction strategy}

A layer stripping approach is implemented to estimate the static and elevation correction in the model area along the main SIGHT transects. The correction is done in four steps:

1. Sediment velocity estimation. The velocities used to model each sediment body, $v_{i}$, are estimated from a compilation of velocity estimates of the area from other studies (Section 3.2).

2. Sediment thickness estimation. The thickness of each sediment body, $d_{i}$, for the onshore and offshore sedimentary structures is estimated from seismic stratigraphy studies, gravity models, borehole data and geological maps (Sections 3.3 and 3.4).

3. Corrections computation. The sediment thickness below the datum, $D_{j}$, and the individual time correction for each source, $t_{S_{j}}$, and receiver, $t_{R_{j}}$, are computed as follows:

$$
\begin{aligned}
& D_{j}=\sum_{i=1, n} d_{i} \\
& t_{R_{j} / S_{j}}=\sum_{i=1, n} \frac{d_{i}}{v_{i}}
\end{aligned}
$$

4. Application of corrections. The initial elevation, $H$, and traveltime, $T$, of the picks (including the additional data) are corrected $\left(H_{\text {corr }}\right.$ and $T_{\text {corr }}$, respectively). The time correction value is the sum of the static correction of its corresponding source and receiver $\left(t_{S_{j}}\right.$ and $t_{R_{j}}$, respectively) as follows:

$$
T_{\text {corr }_{j}}=T_{j}-\left(t_{S_{j}}+t_{R_{j}}\right)
$$

The elevation correction is effectively a vertical projection of the stations. The correction value for each station, $D_{j}$, is subtracted as follows:

$$
H_{\text {corr }_{j}}=H_{j}-D_{j}
$$

Once the static and elevation corrections are applied, the traveltimes correspond to the raypath travelling exclusively through crustal and upper-mantle material and all stations effectively lie on basement rock. Thus, the irregular topography of the basement horizon (seabed and mountains) is not corrected for, which is preferable for the purpose of inversion modelling [Zelt 1999].

Although it has been done with care, velocity misinterpretations and sediment thickness misestimations may have intruded the static correction estimation process. Given that sediment velocity errors can amount to significant traveltime delays (as discussed in Section 3.2), a supplementary $300 \mathrm{~ms}$ is added onto the traveltime pick uncertainties.

\subsection{Seismic velocity of sediment}

\subsubsection{Velocity misinterpretation}

The transit time of a raypath in a medium of a certain thickness is inversely proportional to the seismic velocity of the medium. The misinterpretation of the sediment velocity can cause 
delay times that will permeate through the model in the form of a velocity-depth trade-off [Zelt 1999]. This is illustrated by considering the vertical delay time, $\Delta t$, as follows (after Sherriff and Geldart [1995]):

$$
\Delta t=h\left|\left(\frac{1}{V_{1}}-\frac{1}{V_{2}}\right)\right|
$$

Consider a rock unit of thickness $h=2 \mathrm{~km}$, and replacing its seismic velocity, $V_{1}$, by $V_{2}=$ $V_{1}+1 \mathrm{~km} / \mathrm{s}$. As seen on Figure $3.3 \mathrm{a}$, for $V_{1}=6.5 \mathrm{~km} / \mathrm{s}$ (typical crustal velocity), $\Delta t=0.04 \mathrm{~s}$. However, for $V_{1}=2.1 \mathrm{~km} / \mathrm{s}$ (typical sediment velocity), $\Delta t=0.3 \mathrm{~s}$, which is over seven times greater than for crustal velocities. Therefore, the use of an incorrect velocity to model the near surface sediments results in a significant traveltime error, and errors in sediment velocity of the order of $50-100 \%$ occur easily. As seen on Figure $3.3 \mathrm{~b}$, a $1.3 \mathrm{~km} / \mathrm{s}$ error in velocity in a $2 \mathrm{~km}$-thick sediment section will result in the misinterpretation pf the Moho's depth by up to $10 \mathrm{~km}$.

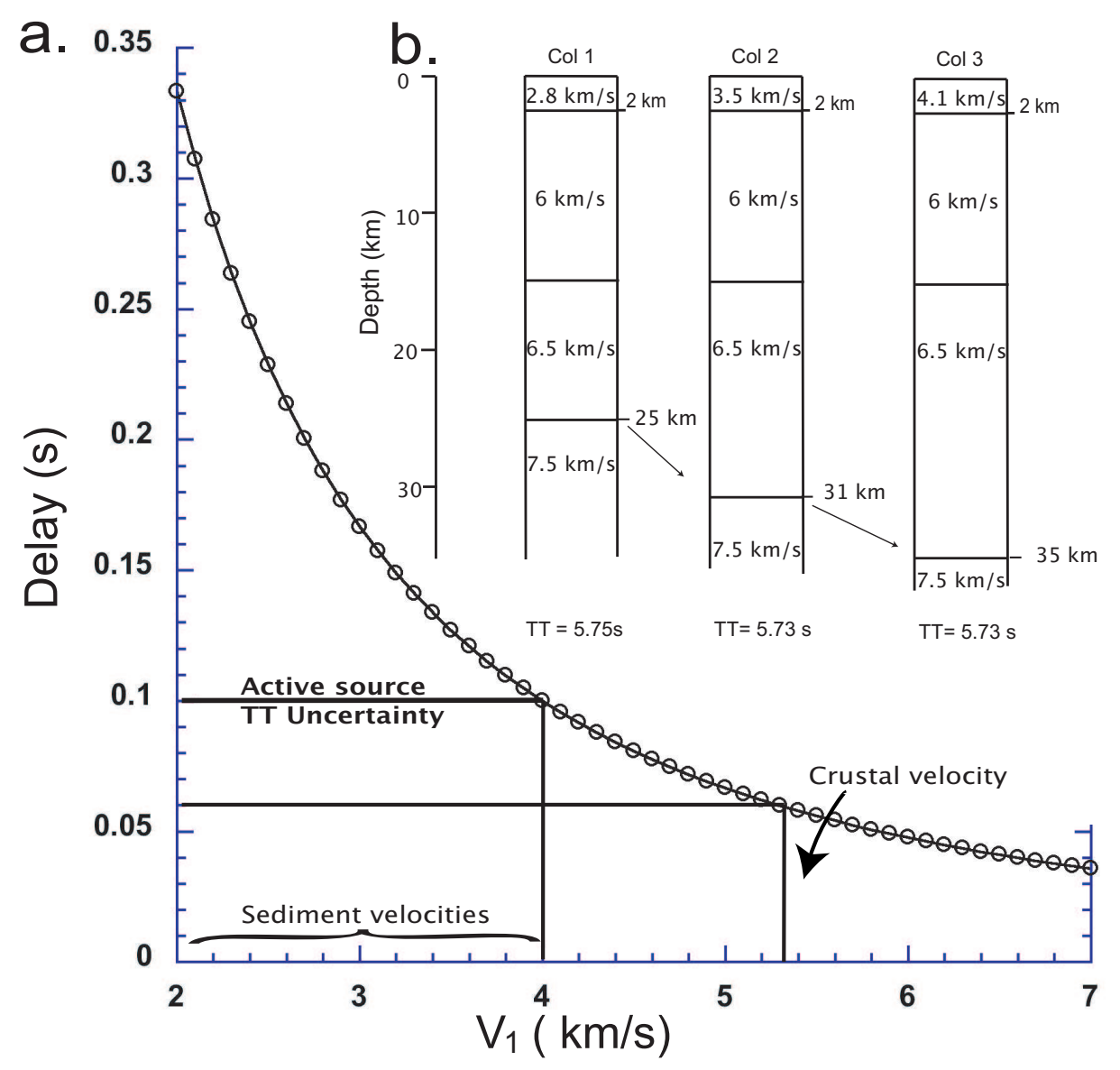

Figure 3.3: $\boldsymbol{a}$. Plot of the non-linear relation between the velocities of rock, $V_{1}$, and the resulting delay time, if their velocity is mis-estimated by $1 \mathrm{~km} / \mathrm{s}\left(V=V_{1}+1 \mathrm{~km} / \mathrm{s}\right)$, in a $2 \mathrm{~km}$ thick section. $\boldsymbol{b}$. Diagrams showing Moho depth modification by $10 \mathrm{~km}$ as a result of a difference of velocity in the top $2 \mathrm{~km}$ of sediments. After Stern et al. [2010]. 


\subsubsection{Sediment velocity estimation}

\section{Velocities from additional studies}

The authors of the additional picks [Scherwath et al. 2003, van Avendonk et al. 2004] have taken account of the sediments in the near surface by using layer stripping methods, refraction statics and MCS stacks [Davey et al. 1998, Harrison 1999]. The sediment structure is included into the reference model and the traveltimes remained uncorrected. However, the velocities used to model the sediments are averaged from the near surface velocity field. van Avendonk et al. [2004] modelled the sediments as one body of velocities varying between 2 and $4 \mathrm{~km} / \mathrm{s}$. The sediment body modelled by Scherwath [2002] allows for three layers of sediments offshore, and only one body of coarse velocity gradient onshore as indicated in Table 3.1. These are not accurate representations of the underlying sediment structure.

\begin{tabular}{r||c|c|c|c|c|c}
\multicolumn{1}{c||}{ Author } & \multicolumn{2}{c|}{ Offshore Sediments $(\mathrm{km} / \mathrm{s})$} & \multicolumn{3}{c}{ Onshore Sediments $(\mathrm{km} / \mathrm{s})$} \\
\hline \hline Scherwath [2002] & $1.7-2.5$ & $3.3-3.6$ & $4.2-4.3$ & $1.6-4.4$ & $1.4-3.9$ & $1.9-4.3$ \\
\hline van Avendonk et al. [2004] & \multicolumn{3}{|c|}{$2.0-4.0$} & \multicolumn{3}{c}{$2.0-4.0$} \\
\hline
\end{tabular}

Table 3.1: Table showing the velocities used to model the sedimentary structures offshore and onshore by Scherwath [2002] and van Avendonk et al. [2004].

\section{Velocities for this study}

High velocity contrasts are expected in the near surface region of the model due to the presence of sediments of varying age, thickness and coarseness. Cretaceous to Holocene sediments cause a heterogeneous velocity field in the near surface of the study area. The velocities of ten sediment bodies, summarised in Table 3.2 are compiled from the literature to yield an individual velocity estimate.

The variation in the sediment velocity in the literature is of $\pm 50 \%$ or more, hence, velocity mis-estimation is expected. The glacial tills are modelled with a velocity of $0.9 \mathrm{~km} / \mathrm{s}$, dry and wet Pleistocene gravels with velocities of $1.54 \mathrm{~km} / \mathrm{s}$ and $2.5 \mathrm{~km} / \mathrm{s}$, respectively. Pliocene and Miocene marine sediments are modelled with velocities of $2.63 \mathrm{~km} / \mathrm{s}$ and $3.07 \mathrm{~km} / \mathrm{s}$, respectively, and Oligocene limestone with a velocity of $4.00 \mathrm{~km} / \mathrm{s}$. Eocene sediments are modelled with a velocity of $3.8 \mathrm{~km} / \mathrm{s}$ [Stagpoole 1997], White Rock and Cretaceous coal measures with velocities of $1.90 \mathrm{~km} / \mathrm{s}$ and $4.00 \mathrm{~km} / \mathrm{s}$, respectively [Langdale 1996, Taylor 1997], which are coincident with measurements from Greenhalgh and Emerson [1986]. Finally, offshore West Coast, the top sediment layer, Pleistocene in age, is modelled with a velocity of $2.5 \mathrm{~km} / \mathrm{s}$ [Sircombe and Kamp 1998].

\subsection{Estimation of the offshore sedimentary structures}

The migrated stacks of offshore lines $01 \mathrm{~W}, 02 \mathrm{~W}$ and $03 \mathrm{~W}$ (plots a and b in Figures 3.4 3.6), processed by Greenroyd et al. [2003] from the University of Texas Institute of Geophysics (UTIG), are used to estimate the sediment thickness offshore of the West Coast of the South Island. Previous studies and stack interpretations were used as a guide for the interpretation 


\begin{tabular}{c||c|c|c|c|c|c}
\multicolumn{1}{c||}{ Authors } & Glacial & \multicolumn{2}{|c|}{ Quat Fl-Grvl } & Plio & Mio & Oligo \\
$\Downarrow$ & Till & Dry & Wet & Sed & Sed & Cret \\
\hline \hline Langdale [1996] & 0.50 & 2.07 & 2.30 & - & 2.90 & 4.40 \\
Woodward [1989] & - & 1.25 & 2.76 & 2.94 & - & - \\
Woodward and Kicinski [1987] & - & 0.80 & 2.86 & - & - & - \\
Woodward [1987] & - & - & 2.59 & - & - & - \\
Taylor [1997] & - & 1.05 & 2.88 & - & 2.90 & 3.50 \\
Brikke [2007] & 1.80 & 2.18 & 2.25 & - & 3.40 & - \\
Kleffmann et al. [1998] & 1.80 & - & 2.6 & - & 3.70 & - \\
Scherwath et al. [2003] & - & 1.90 & - & - & 2.60 & 3.20 \\
Stagpoole [1997] & - & 1.65 & 2.60 & 2.40 & 3.40 & 4.10 \\
Sircombe and Kamp [1998] & - & - & 2.11 & 2.53 & 3.12 & 3.91 \\
Chetwin [1998] & - & - & - & 2.40 & 2.90 & 4.50 \\
\hline \hline Used for this study & 0.90 & 1.54 & 2.5 & 2.63 & 3.07 & 4.00
\end{tabular}

Table 3.2: Literature summary table of the sediment's seismic velocities (in $\mathrm{km} / \mathrm{s}$ ) and the velocities that were used for this study. Quat $\boldsymbol{F l - G r v l}$ Quaternary fluvial gravels. Plio Sed Pliocene marine sediments. Mio Sed Miocene sediments. Oligo Cret Oligocene limestone and Cretaceous coal measures.

of the seismic horizons [Davey et al. 1998, Harrison 1999, Sircombe and Kamp 1998]. A consistency check of the offset of the stack is described in Appendix B.3. The stacks are plotted in Two Way Travel Time (TWTT). The stratigraphic sequence (plots a and b in Figures $3.4-3.6$ ) corresponds to that of the South Westland Basin (SWB) [Sircombe and Kamp 1998, Sutherland 1996]. A total of five horizons are traced throughout the stack, delimiting rock units of Pleistocene, Pliocene, Miocene and Oligocene in age, and the basement interface. Each horizon is sampled every fiftieth shot (approx. $2.5 \mathrm{~km}$ ), interpolated and converted to one way traveltime (plot c of Figures $3.4-3.6$ ), the vertical accuracy is of about $50 \mathrm{~ms}$. The thickness of each layer is computed considering the velocities mentioned in Section 3.2 (Figures $3.4-3.6 \mathrm{~d}$ ). The thickness of sediments has a direct influence on the depth of the interface and this is why the basement horizon in the MCS lines and that of the depth converted plots (plots a \& b, and plot c in Figures $3.4-3.6$ ) seem not to match.

\subsubsection{Line $01 \mathrm{~W}$}

The horizons are correlated with borehole data of the Waiho-1 drillhole [Sutherland 1996] (see Figure 2.2 for the location of the borehole) and the interpretation of line is consistent with that of Sircombe [1993] from the MCS line, NZ-102, parallel to the main SIGHT offshore shot lines, aligned with the borehole. The basement horizon is irregular (Figure $3.4 \mathrm{a}$ and b), fluctuating from $2 \mathrm{~s}$ TWTT close to the West Coast $(8 \mathrm{~km}$ offset) to $3.6 \mathrm{~s}$ at the centre of the line $(133 \mathrm{~km}$ offset) and back to $2.3 \mathrm{~s}$ at the northwest end of the line (208 $\mathrm{km}$ offset). The sea water is responsible for the maximal traveltime static $(0.8 \mathrm{~s}$ ) (Figure $3.4 \mathrm{c}$ ) followed by the Oligocene sediments (maximum of $0.5 \mathrm{~s}$ ). The basement remains reasonably stable $(2-3 \mathrm{~km}$ depth) but drops down to $4.5 \mathrm{~km}$ at $147 \mathrm{~km}$ offset (Figure $3.4 \mathrm{~b}$ ). The Pleistocene and Pliocene sediment isopach increases towards the coast and reaches a thickness of about $3 \mathrm{~km}$ at $10 \mathrm{~km}$ offset from the coast. The maximum static $(1.82 \mathrm{~s})$ coincides with the maximum thickness of sediment $(3.5 \mathrm{~km})$ and the maximum depth to basement $(4.5 \mathrm{~km})$ at an offset of about $140 \mathrm{~km}$. 


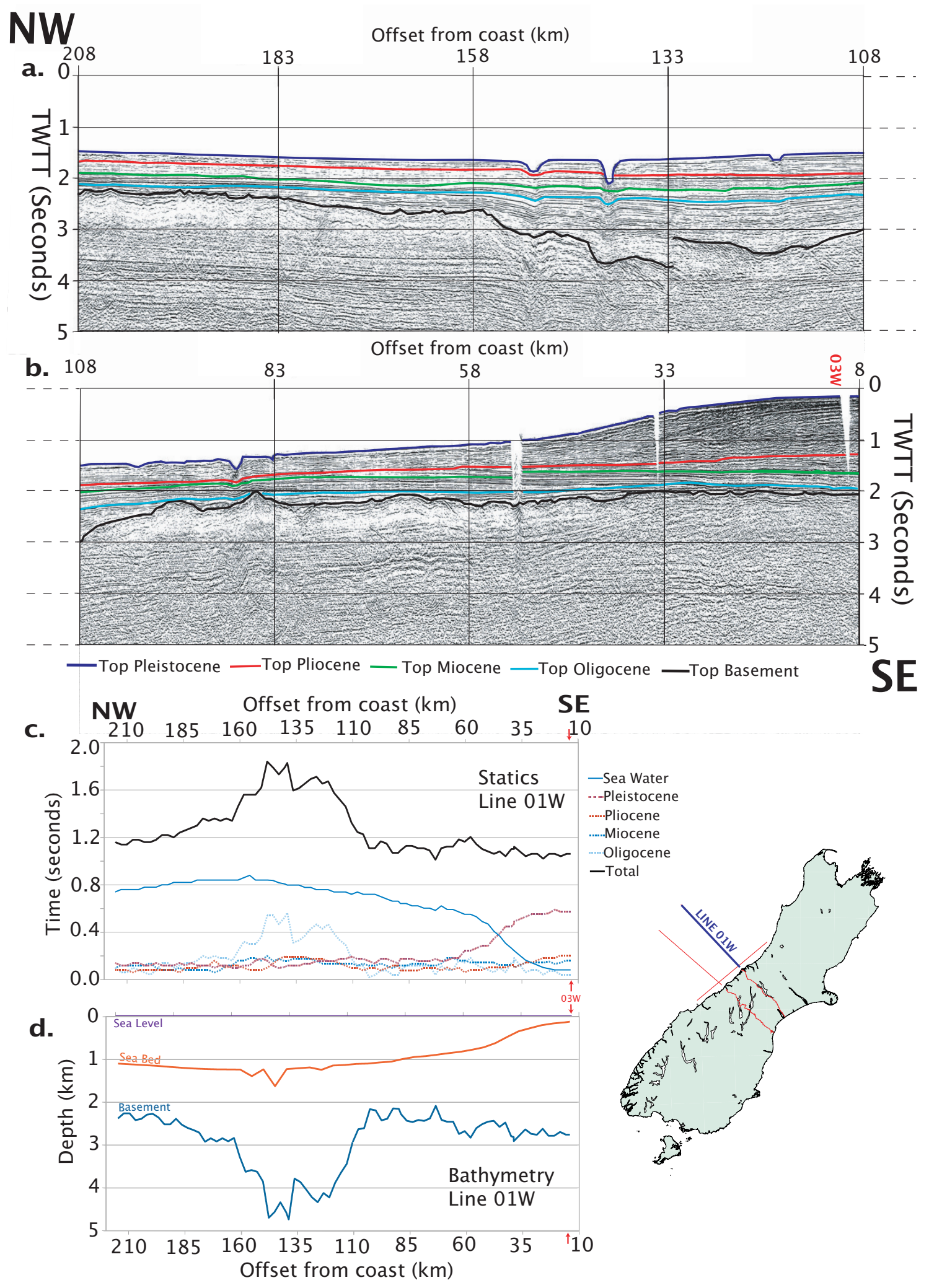

Figure 3.4: $\boldsymbol{a}$. and b. MCS migrated stack section of line $01 \mathrm{~W}$ with interpretation of the seismic horizons representing sediment layers of different ages. c. Plot of the contribution of each sedimentary layer to the total traveltime statics. $\boldsymbol{d}$. Plot of the bathymetry of the sea bed and that of the basement considering the sediments' thicknesses and velocities. $03 \mathbf{W}$ and red arrows Intersection with line $03 \mathrm{~W}$. 


\subsubsection{Line $02 \mathrm{~W}$}

The interpretation of line $02 \mathrm{~W}$ is based on that of Harrison [1999]. The horizons appear unfaulted and the basement remains under $2 \mathrm{~s}$ TWTT along the whole length of the stack reaching $4.5 \mathrm{~s}$ at the northwest end the line (Figure 3.5). The sea bed horizon is reasonably smooth except for two submarine channels at $124 \mathrm{~km}$ and $169 \mathrm{~km}$ offset. The sea water contributes most to the static correction, with delays of up to $1.5 \mathrm{~s}$ (more than $2 \mathrm{~km}$ thickness of water column), followed by the Pleistocene and Pliocene sediments with $0.5 \mathrm{~s}$ and $0.75 \mathrm{~s}$ maximum delay, respectively (Figure 3.5 a).

The basement is at $4 \mathrm{~km}$ depth $10 \mathrm{~km}$ from to the coast, it stabilises at depths shallower than $3 \mathrm{~km}$ between 25 and $130 \mathrm{~km}$ offset and then deepens to over $5 \mathrm{~km}$ depth at $200 \mathrm{~km}$ offset (Figure $3.5 \mathrm{~b})$. The greatest static $(2.25 \mathrm{~s})$ coincides with the greatest sediment thickness $(3.5 \mathrm{~km})$ at the northwest end of the line.

The shape and size of a half-graben (at $85 \mathrm{~km}$ offset in Figure $3.5 \mathrm{~b}$ ), interpreted by Harrison [1999], are reconsidered. This seismic event is associated (dotted black line on Figure 3.5 b) with a scattering edge effect. Bishop [1992] observed similar structures in North Westland, but these structures are not filled with the overlying material rather they have a lid of material that fills the gap between the subsided horizon and the overlying bed. Hence, the straight horizon traced is thought to be the extent of the subsidence of this half-graben, and the bounding faults are interpreted to have a throw of $0.2 \mathrm{~s}$ TWTT, rather than $1 \mathrm{~s}$ as suggested by Harrison [1999].

\subsubsection{Line $03 \mathrm{~W}$}

The interpretation of the horizons along this line is consistent with that of Melhuish et al. [2005]. All horizons appear flat and unfaulted in the northeast half of the stack (Figure $3.6 \mathrm{~b}$ ), and more uneven on the southwest half of the stack (Figure 3.6 a) with sharp changes in reflectivity. The basement horizon deepens from $1.6 \mathrm{~s}$ (Figure $3.6 \mathrm{~b}$ ) to 2.7 - $3 \mathrm{~s}$ (Figure $3.6 \mathrm{a}$ ) to the northeast and the southeast end of the line, respectively. In contrast with the two other stacks, line $03 \mathrm{~W}$ is shot in shallow waters close to the coast. The sea water only contributes a maximum static of $0.5 \mathrm{~s}$. The Pleistocene, Pliocene and Miocene sediments contribute to statics of $0.5 \mathrm{~s}, 0.45 \mathrm{~s}$ and $0.65 \mathrm{~s}$, respectively (Figure $3.6 \mathrm{c}$ ).

The basement steadily increases in depth from $2.5 \mathrm{~km}$, close to the coast, to over $4 \mathrm{~km}$ depth at the southwest end of the line (Figure $3.6 \mathrm{~d}$ ). The maximum static of $1.58 \mathrm{~s}$ coincides with the greatest depth to basement $(4.2 \mathrm{~km})$ at the southwest end of the line.

\subsection{Estimation of the onshore sedimentary structures}

Petroleum well data, gravity and seismic studies of the near-surface in areas overlapping with the SIGHT project's main transects are used to estimate the sedimentary structures onshore on the South Island. These studies were done prior [Davey et al. 1998, Kleffmann et al. 1998], during [Taylor 1997] and after the acquisition campaigns [Brikke 2007, Harrison 1999, Langdale 1996, Langdale and Stern 1998]. Furthermore, borehole data [Gair 1978, NZ Petroleum Exploration Co. 1971; 1972, Sutherland 1996] and geological maps [Cox and Barrell 2007, Forsyth 2001] are also consulted to build stratigraphic models of the sedimentary basins along the main transects. 
NW

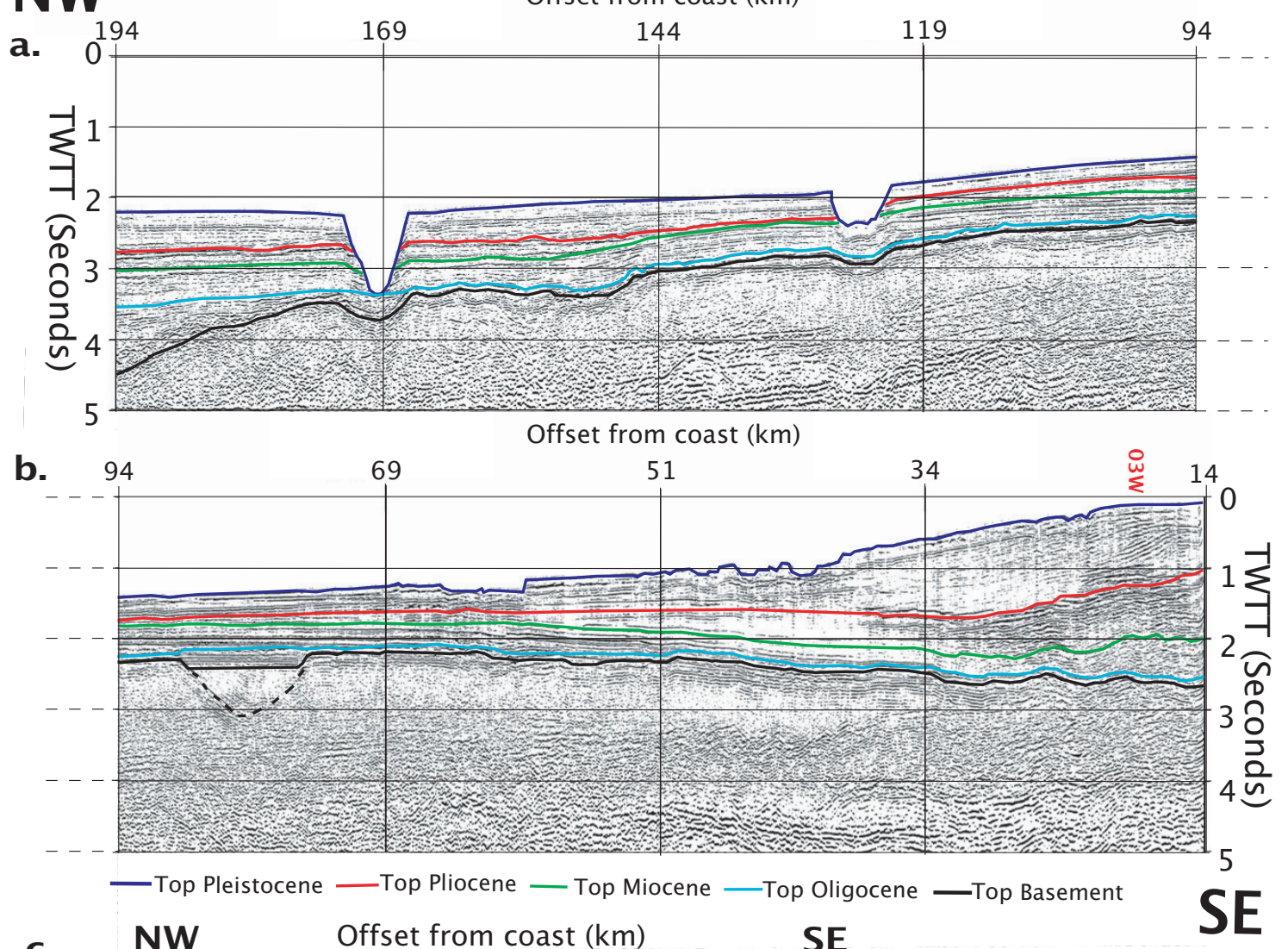

C.

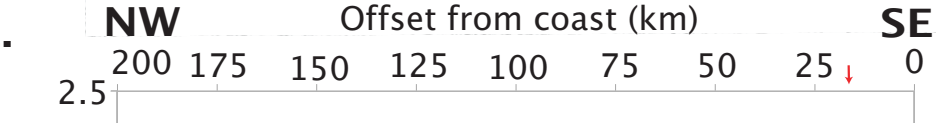

0

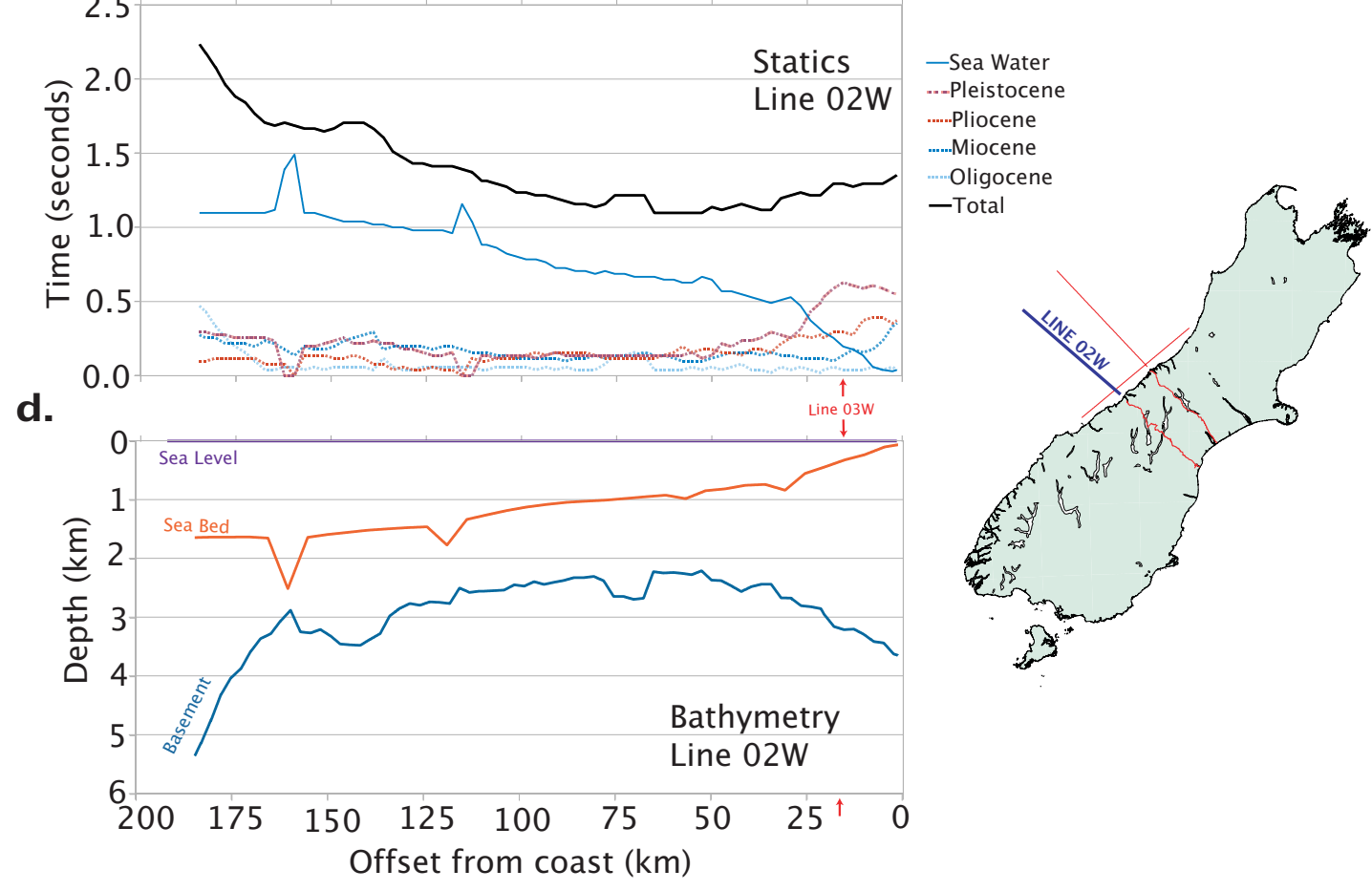

Figure 3.5: $\boldsymbol{a}$. and $\boldsymbol{b}$. MCS migrated stack section of line 02W with the interpretation of the seismic horizons representing sediment layers of different ages. The location of the half-graben interpreted by Harrison [1999] is marked in a dotted black line. $c$. Plot of the contribution of each sedimentary layer to the total traveltime statics. $\boldsymbol{d}$. Plot of the bathymetry of the sea bed and that of the basement considering the sediments' thickness and velocities. 03Wand red arrows Intersection with line $03 \mathrm{~W}$. 


\section{a. SW}

Offset from SW end of line 03W $(\mathrm{km})$

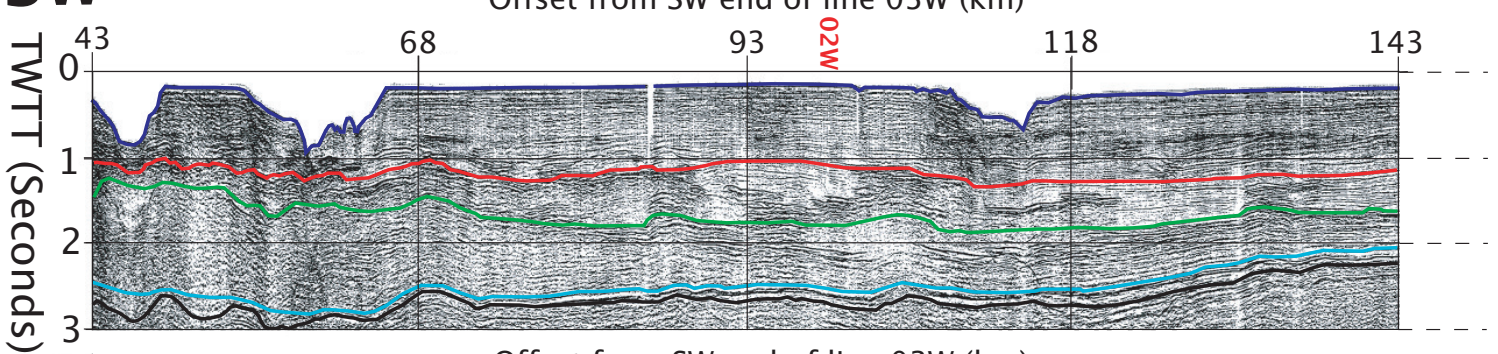

Offset from SW end of line 03W $(\mathrm{km})$

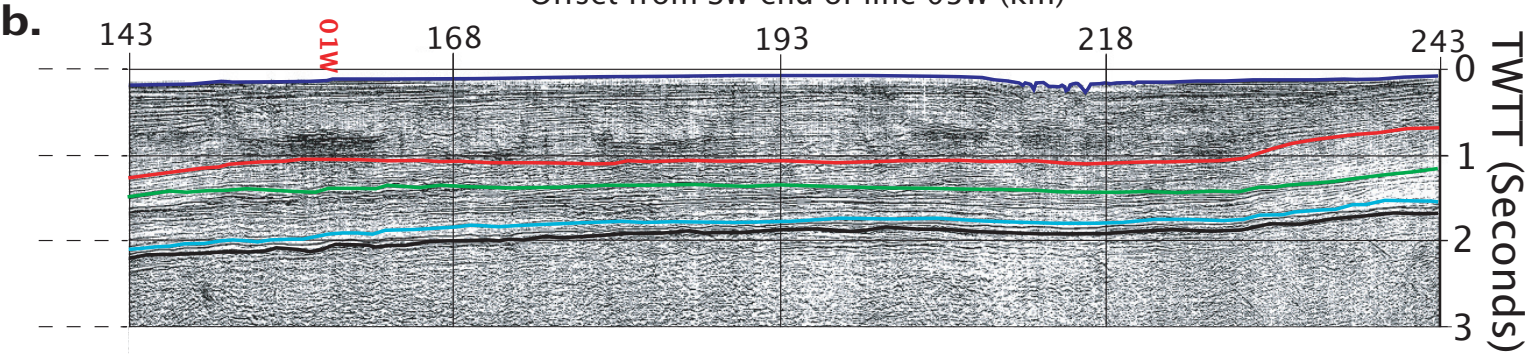

—Top Pleistocene —Top Pliocene — Top Miocene —Top Oligocene —Top Basement

C. SW Offset from SW end of line $03 \mathrm{~W}(\mathrm{~km})$ NE

\section{$\begin{array}{llllllllll}35 & 60 & 85 & 110 & 135 & 160 & 185, & 210 & 235 & 260\end{array}$}

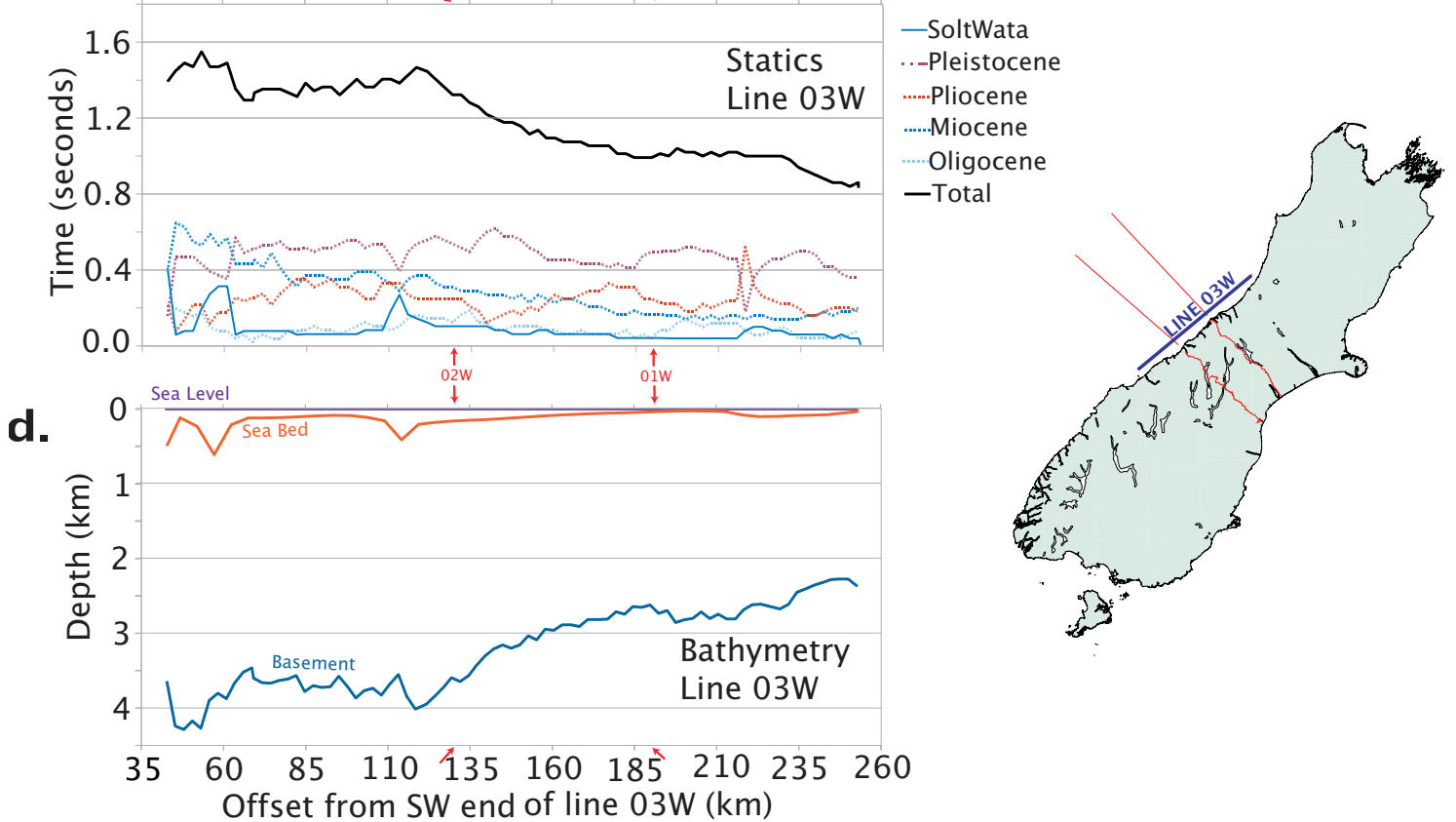

Figure 3.6: $\boldsymbol{a}$. and b. MCS migrated stack section of line $03 W$ with the interpretation of the seismic horizons representing sediment layers of different ages. c. Plot of the ontribution of each sedimentary layerc to the total traveltime statics. $\boldsymbol{d}$. Plot of the bathymetry of the sea bed and that of the basement considering the sediments' thickness and velocities. $01 \mathbf{W}$ Intersection with line $01 \mathrm{~W}$. 02 $\mathbf{W}$ Intersection with line 02W. 


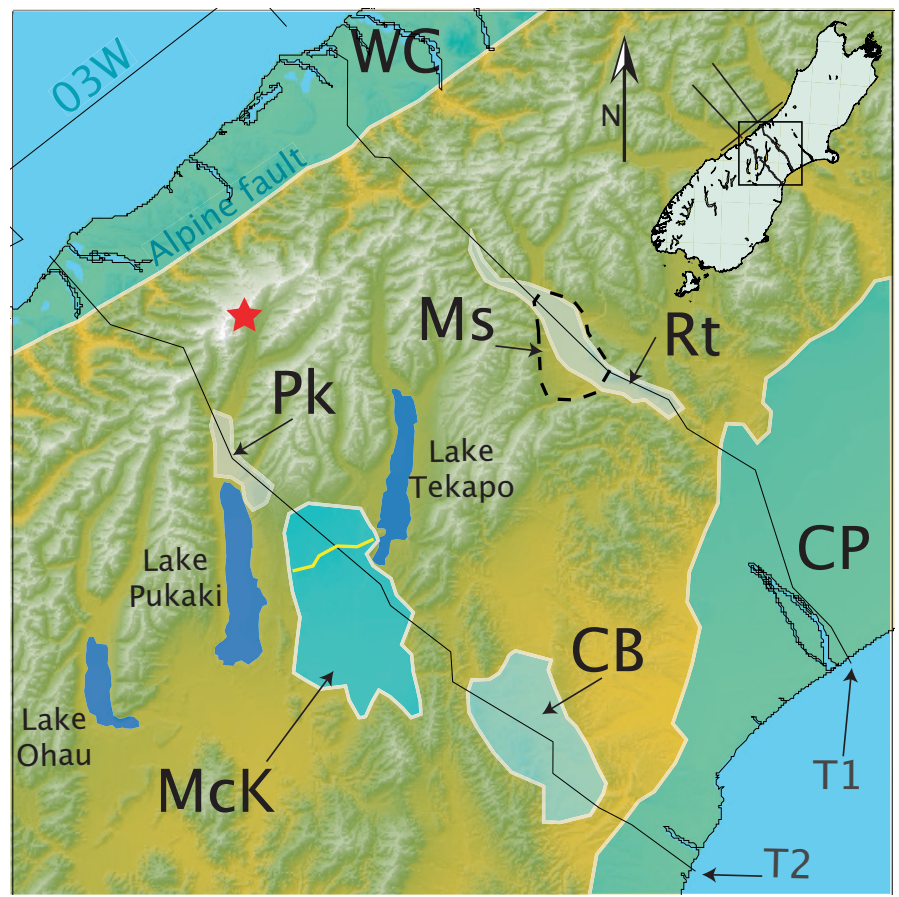

Figure 3.7: Map showing the location of the onshore sedimentary basins with respect to the SIGHT land transect (labelled T1 and T2). The offshore line $03 \mathrm{~W}$ and the surface trace of the Alpine fault are also labelled. The red star indicates the location of Aoraki/Mt Cook and the yellow line in the MacKenzie Basin is the Irish Man Creek Fault. The Mesopotamia Basin (Ms) is outlined in black dashed lines. $\boldsymbol{C P}$ Canterbury Plains. $\boldsymbol{C B}$ Cannington Basin. McK MacKenzie Basin. Ms Mesopotamia Basin.

$\boldsymbol{P k}$ Pukaki Basin. Rt Rangitata River valley. WC West Coast Basin.

The basins modelled along T1 are the Canterbury Plains, and the West Coast (CP and WC in Figure 3.7). No stratigraphic data are available for the Mesopotamia Basin in the literature. The latter was not modelled and the traveltime picks from the stations in the basin were discarded. The basin modelled along T2 are the Canterbury Plains, the Cannington Basin, the McKenzie Basin (CP, CB and McK in Figure 3.7) and the West Coast/South Westland Basin.

\subsubsection{Individual basins}

\section{Canterbury Plains}

The Canterbury Plains are bounded by the foothills of the Southern Alps to the northwest, by the Banks Peninsula to the east, by the Pacific Ocean to the northeast and southeast along Pegasus Bay and the Canterbury Bight, respectively. The sedimentary sequence consists of Late Cretaceous and Eocene sandstones and mudstones, Oligocene limestones and Miocene sandstones and mudstones [Field and Browne 1993]. This sequence is overlain by up to $2 \mathrm{~km}$ of unconsolidated Quaternary alluvial gravels [Atkins and Hicks 1979, Brown and Wilson 1988, Cox and Barrell 2007, Leckie 1994, Taylor 1997, Wellman 1956, Woodward 1989]. The Canterbury Plains are a relic glacial outwash surface but there are no significant glacial deposits [Cox and Barrell 2007]. The sediment thickness decreases towards the east and the depth to basement decreases towards the southwest [Hicks 1989, Woodward 1989, Woodward and Kicinski 1987]. 


\section{Cannington Basin}

The Cannington Basin is located to the northwest of the Canterbury Basin on T2, to the southeast of the McKenzie Basin and to the south of the Fairlie Basin. It is bounded by the Hunter's fault to the west [Gair 1959] and by the Brothers fault complex to the east [Langdale and Stern 1998]. The Neogene uplift of the Canterbury Ranges induced subsidence due to faulting and folding in the Cannington/Fairlie region [Langdale 1996] and separated the Cannington Basin from the Canterbury Plains. Therefore, the sedimentary sequence is similar to that of the Canterbury Plains with sediments thickness of up to $1 \mathrm{~km}[\mathrm{Cox}$ and Barrell 2007, Forsyth 2001, Langdale 1996]. The thickness of individual rock units are not expected to correlatese, however, due to the nearby faulting systems [Langdale and Stern 1998]. Furthermore, the Cannington Basin has not been directly affected by glaciers [Cox and Barrell 2007].

\section{McKenzie Basin}

The McKenzie Basin is located to the northwest of Burkes Pass to the south of the Gammack and Hall Ranges and to the east of the Ohau Range. It includes back-shearing faults such as the Ostler fault and the Irishman Creek fault (IMCF, yellow line in Figure 3.7), as well as the post-glacial lakes Pukaki and Tekapo. There are less than $2 \mathrm{~km}$ of Cenozoic sediments as well as glacial till and fluvioglacial outwash in the stratigraphic sequence of the McKenzie Basin [Cox and Barrell 2007, Forsyth 2001, Long et al. 2003]. Due to the highly heterogeneous lateral and vertical near-surface structure, the McKenzie Basin is modelled as three sub-basins:

1. Southeast of Irish Man Creek fault. The stratigraphic column is dominated by Holocene and Pleistocene alluvial gravels, Pliocene and Miocene sediments (up to $1.5 \mathrm{~km}$ thick) and glacial till immediately to the southeast of IMCF [Chetwin 1998, Cox and Barrell 2007].

2. Between Irish Man Creek fault and Lake Pukaki. The thickness of the main units (Pleistocene to Miocene) have a thickness of $600 \mathrm{~m}$ and the glacial till reach thicknesses of $500 \mathrm{~m}$ [Chetwin 1998, Cox and Barrell 2007].

3. Pukaki Lake area. A maximum thickness of $400 \mathrm{~m}$ of coarse and highly heterogeneous glacial deposits are overlain by up to $300 \mathrm{~m}$ of Quaternary river gravels and up to $1.2 \mathrm{~km}$ of Pliocene sediments [Cox and Barrell 2007, Kleffmann 1999].

\section{West Coast}

The western coast of the South Island is divided into two sub-basins which are on either side of the South Westland Basin fault (SWBF). Firstly, the West Coast Basin is bounded to the southeast by the Alpine fault, to the northwest by the South Westland Basin (SWB) fault and extends from Hokitika to the north to Fiordland to the south. The stratigraphy sequence is characterised by Miocene and Pliocene sediments overlain by Quaternary fluvioglacial gravels and outwash due to recent glacial activity. Secondly, the South Westland Basin is limited to the southeast by the SWBF and thins offshore onto the Challenger Plateau [Cotton 1956, Nathan 1977]. The sequence for this basin is similar to that used for the offshore part of the basin described in Section 3.3. The thickness of sediments increase to over $3 \mathrm{~km}$ to the northwest of the South Westland Basin fault [Sircombe and Kamp 1998]. The latter goes onshore between $\mathrm{T} 1$ and $\mathrm{T} 2$, and therefore the correction only applies to T1. 

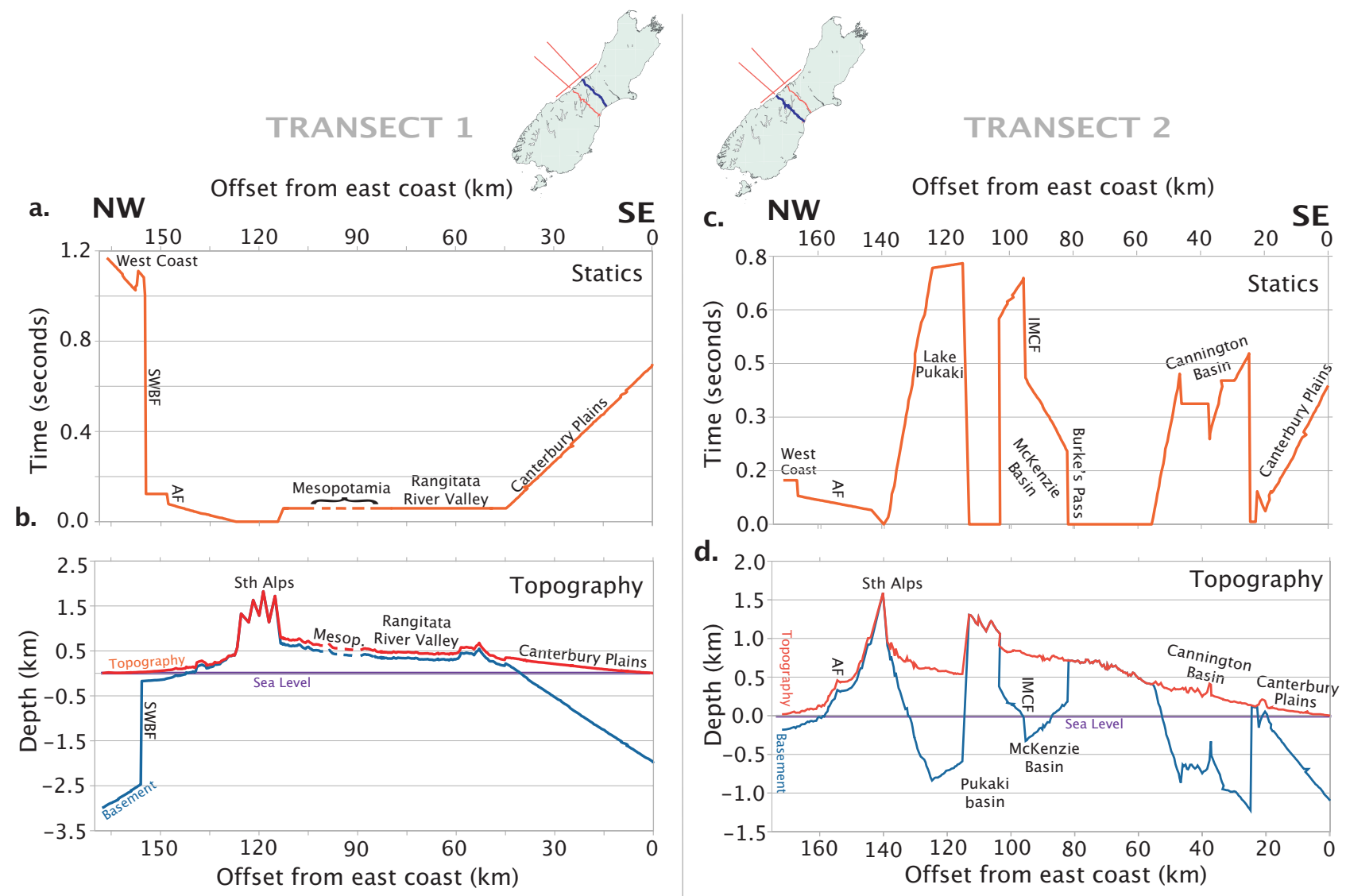

Figure 3.8: $\boldsymbol{a}$. Plot of the static corrections along T1. b. Plot showing the relative elevation of the topography (red line) and estimated basement horizon (blue line) along T1. c. Plot of the static corrections along T2. d. Plot showing the relative elevation of the topography (red line) and estimated basement horizon (blue line) along T2. $\boldsymbol{S} \boldsymbol{W B F}$ South Westland Basin fault. AF Alpine fault. IMCF Irishman Creek fault.

\subsubsection{Total onshore statics}

Along T1, the statics observed are summarised in Figure 3.8 a and b. To the northwest of the Canterbury Plains, which has statics of $0.1-0.5 \mathrm{~s}$, the receivers follow the Rangitata River valley, which is bounded by greywacke hills on either side with shallow depth to basement and delay times of about $0.05 \mathrm{~s}$ [Cox and Barrell 2007]. The greatest traveltime statics, with delays of $1-1.4 \mathrm{~s}$, originate from the West Coast (Figure $3.8 \mathrm{a}$ ) due to the presence of glacial till and an abrupt increase in sediment thickness to the northwest of the SWBF (Figure $3.8 \mathrm{~b}$ ). At an offset of about $120 \mathrm{~km}$, the statics are nil. This is because the station are on basement rock, and so no static correction is needed. Similarly, the height of these stations were not modified.

Along T2, the largest traveltime statics are of about $1.4 \mathrm{~s}$ are located in the area of Lake Pukaki and MacKenzie Basin due to the presence of glacial till and heterogeneous river gravels (Figure $3.8 \mathrm{c}$ ). The maximum sediment thickness is found in the east end of the Canterbury Plains and in the Cannington Basin (Figure $3.8 \mathrm{~d}$ ) with traveltime static of the order of $0.5 \mathrm{~s}$. The West Coast has relatively low traveltime statics as it is on the hanging wall of the SWB and has a depth to basement of $200 \mathrm{~m}$ (0.17 s delay). As for before, at offsets of $60-80 \mathrm{~km}$, $105-115 \mathrm{~km}$ and $140 \mathrm{~km}$, the statics are nil. This is because the stations are on basement rock; so no static corrections are needed and the stations' elevation are not modified. 


\subsection{Summary of the static corrections}

MCS stacks of the SIGHT project source lines are sampled to estimate the offshore sedimentary structures. Results from stratigraphy, seismic and gravity studies are used to estimate the onshore sedimentary structures. The sediment thickness, and associated traveltime fraction, is estimated for each source and receiver. The sedimentary basin statics are then removed from the station's traveltimes and its elevation is reduced to that of basement rocks. The purpose of this correction step is to account for and remove all contributions (time and vertical position) of the sediments. Therefore, when a station is on basement rock, this correction does not apply. A summary plot of the composite static correction along SIGHT line 01 and 02 is presented in Figure 3.9 a and b, respectively. An extra $300 \mathrm{~ms}$ of uncertainty is added to the traveltime picks to account for mis-estimation of sediments thicknesses and velocities.

The largest contribution to static correction in the onshore part of line 01 (Figure 3.9 a) is the Canterbury Basin and the SWB $(0.7-1.15 \mathrm{~s})$. The column of water and the Oligocene limestone contribute most to the static correction in the offshore part of line 01. The maximum static along line 01 is of $1.7-1.9 \mathrm{~s}$ at an offset of $60-100 \mathrm{~km}$ corresponding to the greatest depth to basement (about $4.8 \mathrm{~km}$ thick, including a water column of $1.5 \mathrm{~km}$ ), but generally, most of the offshore static corrections oscillate between $1-1.5 \mathrm{~s}$.

The Canterbury Plains along line 02 have a lesser static footprint $(0.5 \mathrm{~s})$ as the basin gets narrower and shallower southwards (Figure $3.9 \mathrm{~b}$ ). The Cannington Basin is thicker than the former, yet has a similar statics (0.6 s). The McKenzie Basin and Pukaki Basin have more sediment thickness and glacial till. The latter have the largest statics of the order of $0.8 \mathrm{~s}$. The water column and the Pleisto-Pliocene sediments contribute to the greatest amount of static offshore of line 02 . Offshore statics increase from $1-1.3 \mathrm{~s}$ to $2.6 \mathrm{~s}$ to the northwest of the SWBF as depth to basement reaches $6 \mathrm{~km}$. 


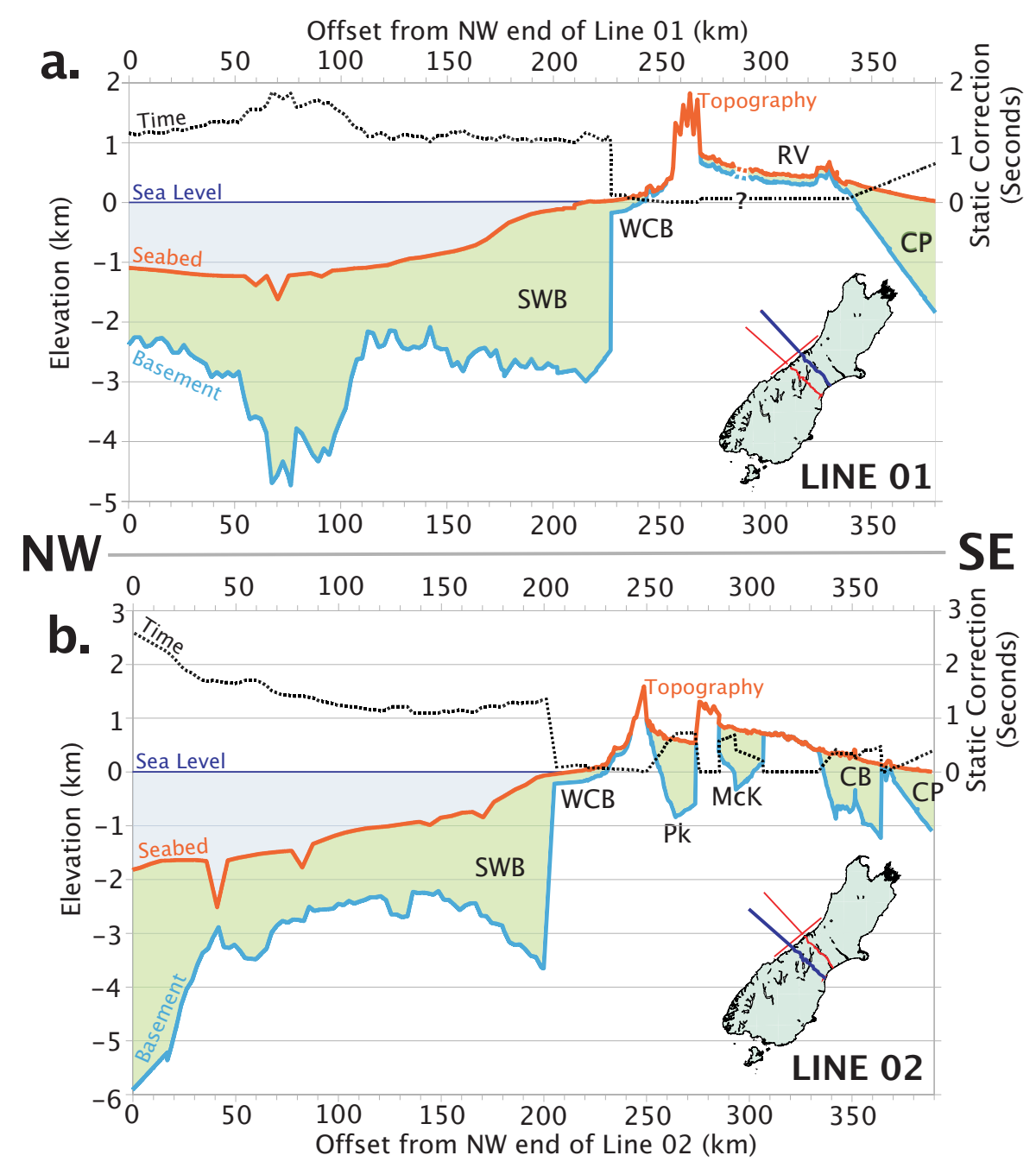

Figure 3.9: Composite static correction plots showing the combination of the onshore and offshore statics of line 01 (a.) and line $02(\boldsymbol{b}$.). The plots show the sediment thickness (in green) between the topography (red line) and the basement horizon (blue line) and the resulting traveltime static (dotted black line). $\boldsymbol{S} \boldsymbol{W B}$ South Westland Basin. WCB West Coast Basin. $\boldsymbol{R} \boldsymbol{V}$ Rangitata river valley. $\boldsymbol{C P}$ Canterbury plains. Pk Pukaki Basin. McK McKenzie basin. CB Cannington Basin. 


\section{Chapter 4}

\section{Method and synthetic tests}

\subsection{Method: FMTOMO}

\subsubsection{Origin}

FMTOMO [Rawlinson 2005], which stands for Fast Marching TOMOgraphy, is the free tomography software package used for this project (http://rses.anu.edu.au/ nick/fmtomo.html). The code is written and developed at the Australian National University (ANU), Canberra, Australian Capital Territory (ACT) [de Kool et al. 2006, Rawlinson 2005, Rawlinson and Kennett 2008, Rawlinson and Sambridge 2005, Sambridge and Gudmundsson 1998, Sambridge et al. 2007].

FMTOMO has been designed to deal with complex velocity and interface structures in three dimensions allowing the modelling of a wide range of tectonic settings (subducting slab, mantle wedge, variable thickness sedimentary fills) [Rawlinson 2005]. However, azimuthal anisotropy, which is present in the study region [Baldock 2004, Kleffmann 1999, Melhuish et al. 2005, Pulford 2002, Scherwath et al. 2002], cannot be modelled.

The Fast Marching Method [Sethian 1996] (FMM) is implemented for the forward modelling part of the tomography. FMM is a computationally efficient and robust grid-based eikonal solver that implicitly tracks the evolution of wavefronts in 3D layered media. A subspace inversion scheme is used for the inverse part of the tomography.

\subsubsection{Grids, nodes and interfaces}

Two independent grids are used in the method, the propagation and the inversion grid. The propagation grid, which does not influence the model itself, is used for the wavefront tracking step of the forward modelling. A refined propagation grid can be added around the seismic sources to account for the spherical spreading of the emanating seismic energy. The inversion grid, which describes and influences the model, is composed of the velocity and interface grids that define the velocity and interface fields, respectively. Additional cushion nodes are added onto the extremities in each dimension of each grid for all the user-specified nodes to be defined and modelled.

The velocity and interface nodes control a mosaic of cubic B-spline functions that define the continuum. These functions are used because of the continuity of their second derivatives, their rapid evaluation and their local control (changing one node only affects the nodes in the 
vicinity of it, unlike natural cubic-splines). Two consecutive interfaces are allowed to overlap each other causing the bounded layer to become horizontally discontinuous, hence, creating a layer pinch-out, or an isolated body [Rawlinson 2005].

Cubic B-spline functions are piecewise cubic polynomials that are continuous in curvature where they suture together. Four nodes are required to define a single segment (Figure 4.1). As a result, the interfaces and velocity nodes are not interpolated as the function may not pass through them. The non-interpolating nature of the cubic B-splines implies that the interfaces will not truthfully represent the node field.

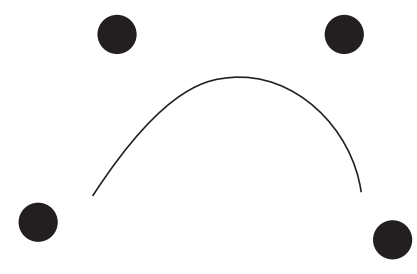

Figure 4.1: Schematic drawing illustrating the non-interpolating nature of the cubic Bspline function. The black dots are the defined nodes and the solid line is the function obtained by the cubic B-spline's interpretation of the node field. After Rawlinson [2005].

\subsubsection{Hierarchy of the software package}

The software package sequentially runs a range of programs, which all play a specific part in the production of the tomography image; their interaction is summarised in Figure 4.2. A brief description of the role of the programs is given hereafter:

OBSDATA converts the observed data (traveltimes, source and receiver locations, seismic phases and path signatures) into a readable format for the following programs.

GRID3DG creates the propagation and inversion grids in three dimensions with the userspecified node parameters. This will define the reference model for inversion or for synthetic tests.

SYNTHDATA creates synthetic traveltime dataset.

FRECHGEN calculates the Frechet derivatives used in the forward modelling step.

FM3D solves the forward problem of traveltime prediction by applying the Fast Marching Method.

INVERT3D carries out the subspace inversion, adjusts the model parameters and calculates the Root Mean Square (RMS) traveltime residual, the variance and the $\chi^{2}$ traveltime misfit.

TOMO3D Sequentially runs FM3D and INVERT3D for $x$ iterations. 


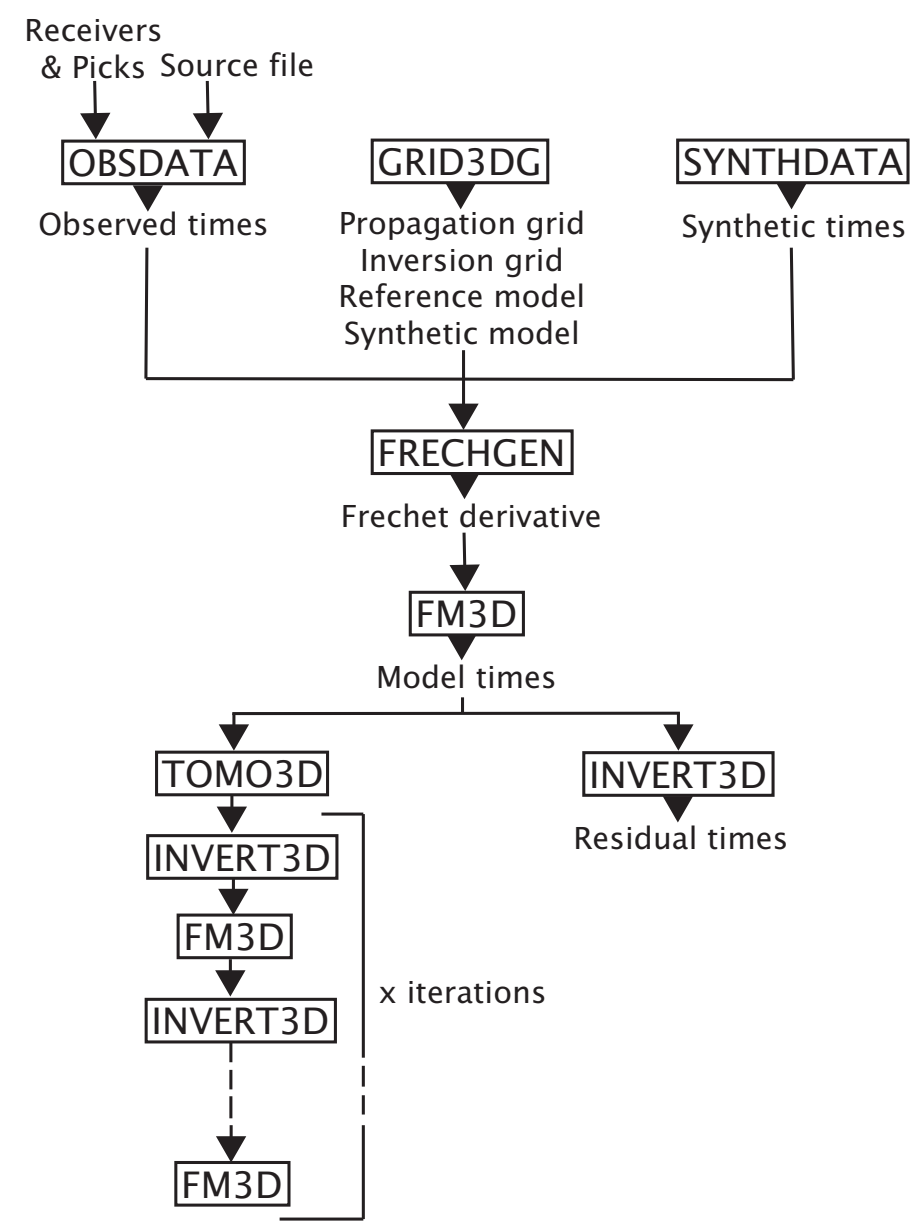

Figure 4.2: Flow chart of the interaction and hierarchy of the programs involved in the tomography inversion process in FMTOMO.

\subsubsection{Applications of FMTOMO}

FMTOMO has been used for investigating the crustal and upper mantle structure of Australia and Tasmania using teleseismic data [Rawlinson and Kennett 2008, Rawlinson et al. 2006a;b] and simultaneous active and passive seismic data [Rawlinson and Urvoy 2006]. It has also been used for crustal structure studies in Finland [Hyvönen et al. 2007], Taiwan [Lee et al. 2008, Mouyen et al. 2008], Philippines [Doo et al. 2008] and New Zealand [Bassett et al. 2010, Bourguignon 2009].

The methods that have been used to produce 3D models of the South Island region [Baldock 2004, Eberhart-Phillips and Bannister 2002, Kohler and Eberhart-Phillips 2002] were limited by the use of first-breaks to derive the velocity structure and had a coarse local scale and upper-crustal definition. FMTOMO is mainly chosen for its ability to define and invert for interfaces in 3D and its novel use of the FMM. This allows the modelling of reflection data, both near-offset and wide-angle, and the joint inversion of both velocity and interface structure in 3D, which is not commonplace for 3D inversion algorithms [Rawlinson and Sambridge 2003].

Furthermore, this project has contributed to the development of FMTOMO as this was the first datasets of this density to have been tested on the code. Comments and feedback to the writer of the tomography code are given in Appendix F. 


\subsection{Preparation of synthetic tests}

Active seismic traveltime datasets usually include large quantities of observations while there are only a handful of model parameters. This outlines the under-determined nature of the inverse problem, materialised by an imbalance between the unknowns (data) and variables (model parameters). Thus, a range of solution models will fit the observed data to a satisfactory level. This non-uniqueness is addressed by performing synthetic modelling tests that directly assess the solution's robustness and/or quality [Rawlinson and Sambridge 2003, Zelt 1999].

Synthetic tests assess the resolution potential of the dataset as well as the resolution thresholds of different parts of the model [Rawlinson et al. 2006b, Zelt 1999]. Effectively, a synthetic structure and dataset are generated and inverted for starting from a homogeneous reference model while using the same source and receiver geometry as the real experiment [Rawlinson and Sambridge 2003]. Areas where the synthetic patterns are well recovered are considered well resolved, and vice-versa. Modelling artefacts, such as raypath effect or smearing, can be localised in the model space to be account for during the interpretation. Synthetic tests are also used to weight the effects of varying model parameters on the solution model. Two methods of synthetic tests are implemented here: the checkerboard test (Section 4.3) and the spike test (Section 4.4).

\subsubsection{Model domain parameterisation}

\section{Model bounds}

The model space (Figure 4.3) is defined to include all arrays (onshore T1 and T2, and offshore lines $01 \mathrm{~W}, 02 \mathrm{~W}$ and $03 \mathrm{~W}$ ) and its area is, therefore, much bigger than that sampled by seismic rays. FMTOMO does not allow referential rotation to minimise the model space area. This is, however, not important as an increased amount of inactive nodes does not slow down the calculations; FMTOMO only calculates and modifies nodes that are hit by seismic rays. The model domain, whose bounds are summarised in Table 4.1, is about $370 \mathrm{~km}$-long in the eastwest direction and $340 \mathrm{~km}$-long in the north-south direction. The orientation of the grid is defined by the software.

\begin{tabular}{c|c|c} 
Dimensions & \multicolumn{2}{|c}{ Model Bounds } \\
$\Downarrow$ & Start & Finish \\
\hline Latitude $\left({ }^{\circ} \mathrm{S}\right)$ & 41.5 & 44.54 \\
\hline Longitude $\left({ }^{\circ} \mathrm{E}\right)$ & 167.5 & 172.06 \\
\hline Elevation $(\mathrm{km})$ & 4 & -56
\end{tabular}

Table 4.1: Table of the bounds of the model space.

\section{Node grids}

The node spacing of the propagation grid is set to about $6 \mathrm{~km}$, as it needs to be slightly finer than that of the inversion grid for the wavefront tracking step to sample the velocity field adequately. The refined grid has 10 extra nodes between the source node and its neighbouring node in all three dimensions equalling to 1000 extra nodes per source. Hence, the node spacing in the vicinity of the source is of about $400 \mathrm{~m}$. 


\begin{tabular}{r||ccc|c} 
Grids & Latitude & Longitude & Depth & Total Nodes \\
\hline \hline Propagation nodes & 57 & 63 & 20 & 71820 \\
node spacing $(\mathrm{km})$ & 6.1 & 6.0 & 3.2 & - \\
\hline Velocity nodes & 43 & 47 & 15 & 30315 \\
node spacing $(\mathrm{km})$ & 7.7 & 7.9 & 4.3 & - \\
\hline Interface nodes & 39 & 58 & - & 2262 \\
node spacing $(\mathrm{km})$ & 8.5 & 6.4 & - & -
\end{tabular}

Table 4.2: Table showing the details of the parameterisation of the propagation, velocity and interface grids in terms of their number of nodes, approximate node spacing and total number of nodes, excluding the cushion nodes.

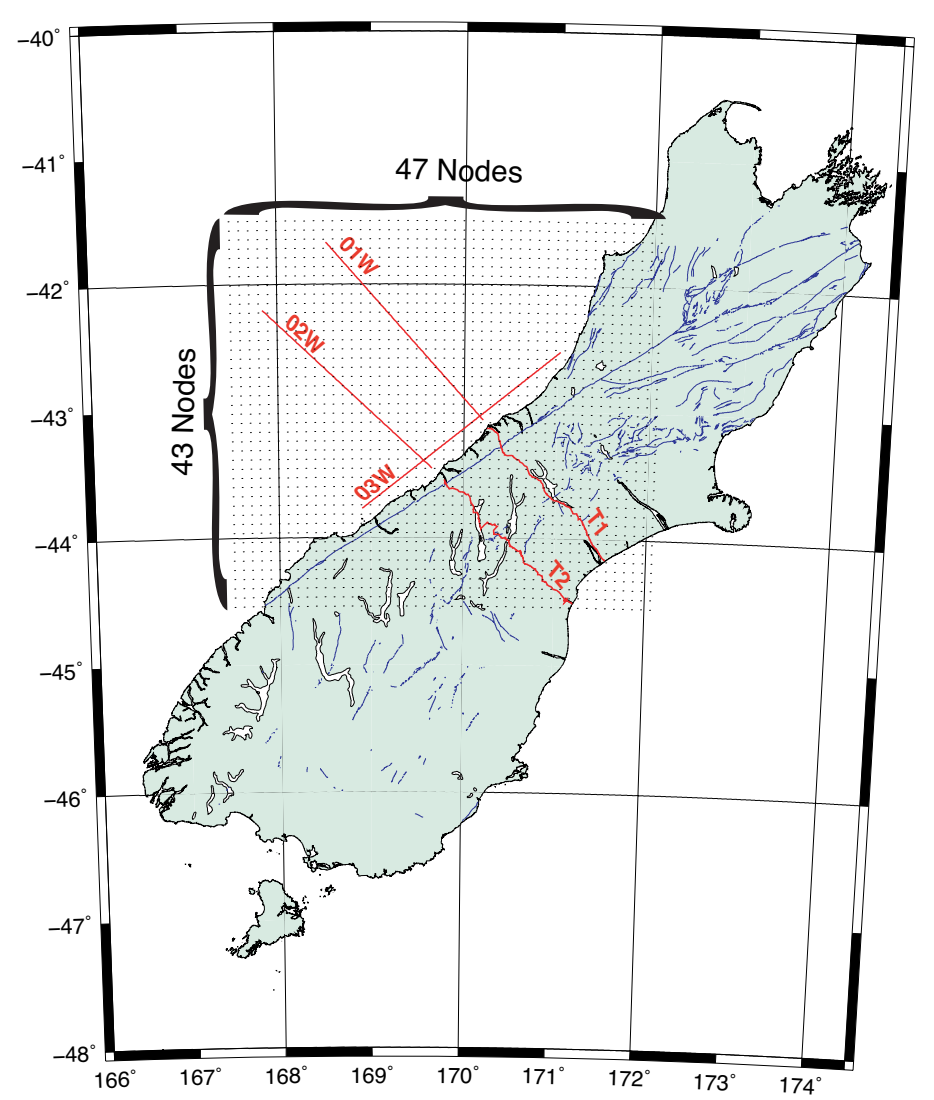

Figure 4.3: Map showing the grid of the velocity nodes of the model area. There are 47 velocity nodes in the east-west direction and 43 in the north-south direction. This equates to a node spacing of about $8 \mathrm{~km}$. The blue lines represent active faults. The red labelled lines show the SIGHT project's seismic arrays and shot lines.

The velocity grid, illustrated in Figure 4.3, is set as close as possible to $8 \mathrm{~km}$ spacing. The grids that extend in depth (propagation and velocity grid) have a finer grid spacing in the depth direction to enhance the resolution of crustal structures. The detailed number of nodes for different grids is summarised in Table 4.2 . 


\subsubsection{Slicing of the model domain}

The model domain is divided into eighteen cross sectional slices (Table 4.3). Eight cross sections sample the model along the longitude axis (cross sections A, B, C and D on Figure $4.4 \mathrm{~b}$ ) and along the latitudes axis (cross sections E, F, G and $\mathrm{H}$ on Figure $4.4 \mathrm{~b}$ ). Five cross sections sample the model parallel to lines 01 and 02 (cross sections 1 to 5 on Figure 4.4 a), with slices 1 and 5 sampling along lines 02 and 01, respectively. Five other cross sections sample the model parallel to line 03W (cross sections 6 to 10 on Figure 4.4 a), with slices 6 and 8 sampling along line $03 \mathrm{~W}$ and the Alpine fault surface trace, respectively.

\begin{tabular}{r||cc|cc|c}
\multicolumn{1}{r||}{ Slices } & \multicolumn{2}{c}{ Start (dec. degrees) } & \multicolumn{2}{c}{ End (dec. degrees) } & Feature \\
$\Downarrow$ & Latitude & Longitude & Latitude & Longitude & of interest \\
\hline \hline Slice A & -44.54 & 170.0 & -41.5 & 170.0 & $170.0^{\circ} \mathrm{E}$ \\
Slice B & -44.54 & 170.2 & -41.5 & 170.2 & $170.2^{\circ} \mathrm{E}$ \\
Slice C & -44.54 & 170.4 & -41.5 & 170.4 & $170.4^{\circ} \mathrm{E}$ \\
Slice D & -44.54 & 170.6 & -41.5 & 170.6 & $170.6^{\circ} \mathrm{E}$ \\
\hline Slice E & -43.20 & 167.50 & -43.20 & 172.06 & $-43.20^{\circ} \mathrm{S}$ \\
Slice F & -43.35 & 167.50 & -43.35 & 172.06 & $-43.35^{\circ} \mathrm{S}$ \\
Slice G & -43.50 & 167.50 & -43.50 & 172.06 & $-43.50^{\circ} \mathrm{S}$ \\
Slice H & -43.65 & 167.50 & -43.65 & 172.06 & $-43.65^{\circ} \mathrm{S}$ \\
\hline \hline Slice 1 & -42.20 & 167.84 & -44.50 & 171.21 & Line 02 \\
Slice 2 & -42.04 & 168.00 & -44.38 & 171.23 & - \\
Slice 3 & -41.92 & 168.15 & -44.30 & 171.35 & - \\
Slice 4 & -41.79 & 168.28 & -44.21 & 171.47 & - \\
Slice 5 & -41.67 & 168.52 & -44.15 & 171.55 & Line 01 \\
\hline Slice 6 & -43.77 & 168.90 & -42.53 & 171.02 & Line 03W \\
Slice 7 & -43.83 & 169.00 & -42.68 & 171.16 & - \\
Slice 8 & -43.91 & 169.12 & -42.81 & 171.27 & AFST \\
Slice 9 & -44.02 & 169.29 & -42.94 & 171.36 & M. Div. \\
Slice 10 & -44.13 & 169.47 & -43.15 & 171.45 & Cr. Rt.
\end{tabular}

Table 4.3: Table of details of the latitudes and longitudes of the cross sections, or slices, through the model domain. dec. degrees decimal degrees. AFST Alpine fault surface trace. M. Div. Main Divide. Cr. Rt. Crustal root.

\subsubsection{Reference model}

The reference model used for the synthetic tests has a laterally homogeneous velocity structure. However, an approximation of the the lower-crustal and Moho interfaces is added so as to include the reflection phases into the modelling. The cubic B-Spline function could not fit adequately the basement rock topography and so the crust was divided into two layers (Layer 1 and 2) at $6 \mathrm{~km}$ depth. The reference model is therefore formed of four layers, as seen in Figure 4.5:

Layer 1 extends from $2 \mathrm{~km}$ above mean sea level to $6 \mathrm{~km}$ depth. Velocities vary homogeneously from 5.1 to $5.8 \mathrm{~km} / \mathrm{s}$ at the top and at the bottom of the layer, respectively. The purpose of this layer is to mimic the top $6 \mathrm{~km}$ of crustal material within which the sources and receivers are located. The velocity structure of this layer is not inverted for. 


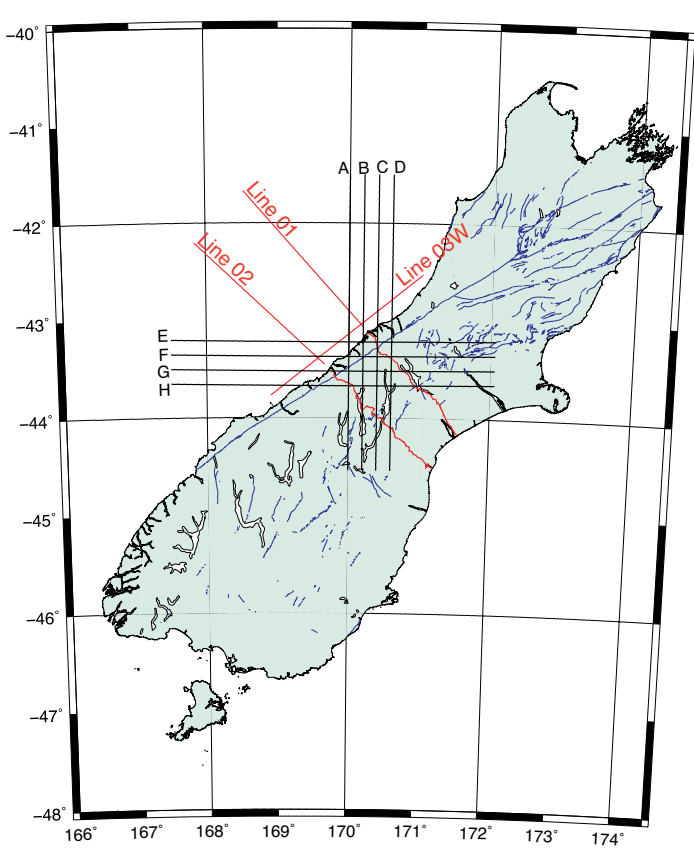

(a)

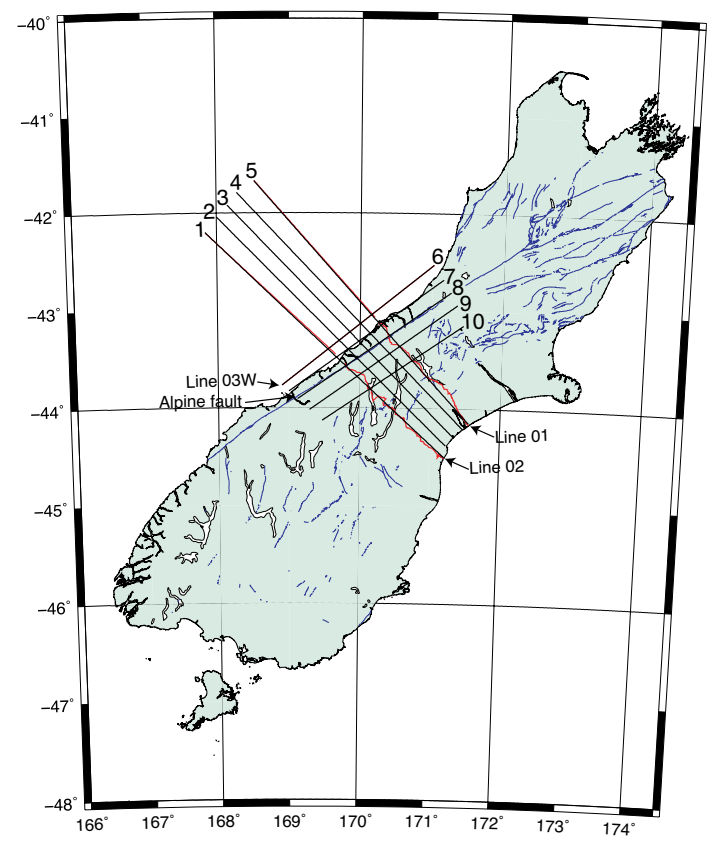

(b)

Figure 4.4: a. Maps of the slices along longitudes (slices $A-D$ ) and latitudes (slices $E-H)$. The blue lines represent the active faults. $\boldsymbol{b}$. Maps of the cross-sectional slices (or slices) through the model domain parallel to lines 01 and 02 (slices 1 - 5), and parallel to line $03 \mathrm{~W}$ and the Alpine fault surface trace (slices 6 - 10).

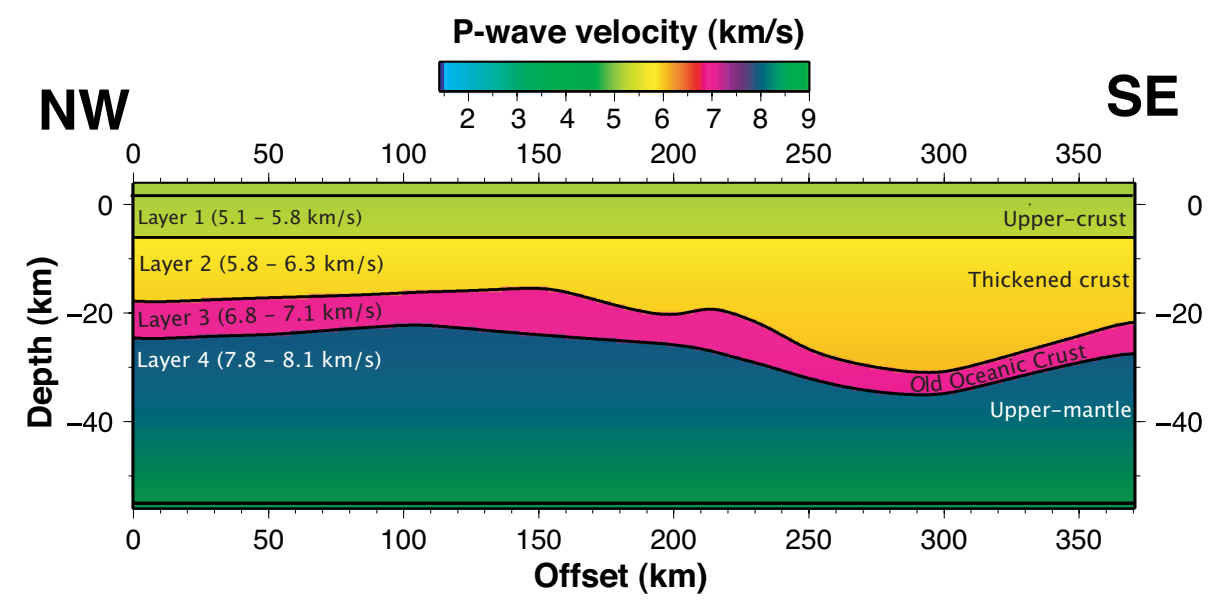

Figure 4.5: Plot of the reference model used for the two types of synthetic tests: the checkerboard tests and spike tests.

Layer $\mathbf{2}$ is the crustal layer with a uniform, laterally-homogeneous velocity gradient from $5.8 \mathrm{~km} / \mathrm{s}$ at the top to $6.3 \mathrm{~km} / \mathrm{s}$ at the bottom of the layer. Its thickness varies between $10 \mathrm{~km}$ to $25 \mathrm{~km}$.

Layer 3 represents the supposed old oceanic crust. It is between 5 and $7 \mathrm{~km}$ thick and its velocity varies between $6.8 \mathrm{~km} / \mathrm{s}$ at the top and $7.1 \mathrm{~km} / \mathrm{s}$ and bottom of the layer.

Layer 4 represents the upper-mantle with velocities varying from $7.8 \mathrm{~km} / \mathrm{s}$ at the top to $8.1 \mathrm{~km} / \mathrm{s}$ at bottom of the layer. 


\subsection{Checkerboard test}

\subsubsection{Modelling parameters}

The checkerboard tests are termed this way because of the patterns of alternating regions of high and low velocities of the synthetic reference model which resembles a (left plots in Figure $4.8-4.10 \mathrm{a}$ ). The preferred values of the model parameters, which are determined from a set of calibration tests (Appendix C), are summarised in Table 4.4. These parameters are used for the inversion of the full checkerboard test; they include damping, smoothing, checkerboard pattern velocity amplitude, velocity grid node spacing, standard deviation of added Gaussian noise and number of iterations.

\begin{tabular}{r|cccccc} 
Parameter & Damping & Smoothing & Iterations & Veloc. Ampl. & Node Sp. & Std. Dev. \\
\hline Value & 35 & 30 & 11 & $1.0 \mathrm{~km} / \mathrm{s}$ & $8 \mathrm{~km}$ & $100 \mathrm{~ms}$
\end{tabular}

Table 4.4: Table of the modelling parameters used for the inversion of the full checkerboard test. Veloc. Ampl. Velocity Amplitude. Node Sp. Node Spacing. Std. Dev. Standard Deviation of the Gaussian noise.

\subsubsection{Solution model's recovery}

The plots of eighteen cross-sectional slices and ten depth slices through the solution models of the full checkerboard test are displayed in Figures $4.6-4.10$. The checkerboard tests are aligned in the north-south and east-west directions, so the patterns in Figures 4.6, 4.7 and 4.10 are evenly spaced and regularly proportioned. However, the checkerboard patterns in Figures 4.8 and 4.9 are derived from the aforementioned ones, and because of the obliqueness of the slices, they appear irregular and unevenly spaced.

\section{Crust}

The checkerboard pattern is well recovered throughout the crust with a recovery of the velocity amplitude of up to $75 \%$ along the main SIGHT lines (slices 1 and 5 in Figure 4.8 and slice 6 in Figure 4.9) where the raypaths cover the whole length of the profile. A velocity amplitude recovery of $50-60 \%$ is observed in the coastal region between the main SIGHT lines (slices $2-$ 4 in Figure 4.8) and to the south east of line 03W (slices $7-10$ in Figure 4.9). Some smearing is observed both in the upper-crust and lower-crust. The area of best recovery is, as expected, in the coastal areas between the SIGHT lines where the seismic rays of the onshore-offshore survey of many different azimuths overlap (slices of 10, 15 and $20 \mathrm{~km}$ depth in Figure 4.10).

\section{Supposed old oceanic lithosphere}

Velocity recovery in the old oceanic lithosphere is generally more than $50 \%$, especially in areas between the SIGHT lines (slice of $25 \mathrm{~km}$ depth in Figure 4.10). The size of the patterns is overestimated due to horizontal smearing (slices 1 and 4 in Figure 4.8, slice 10 in Figure 4.9 and slice $\mathrm{H}$ in Figure 4.7). 


\section{Upper-mantle}

In the upper-mantle, the velocity amplitude recovery is generally less than $30 \%$. Significant horizontal smearing is observed. Outlined checkerboard patterns are, nevertheless, recovered (slice 3 in Figure 4.8, slice 7 in Figure 4.9, slice C in Figure 4.6 and slice F in Figure 4.7).

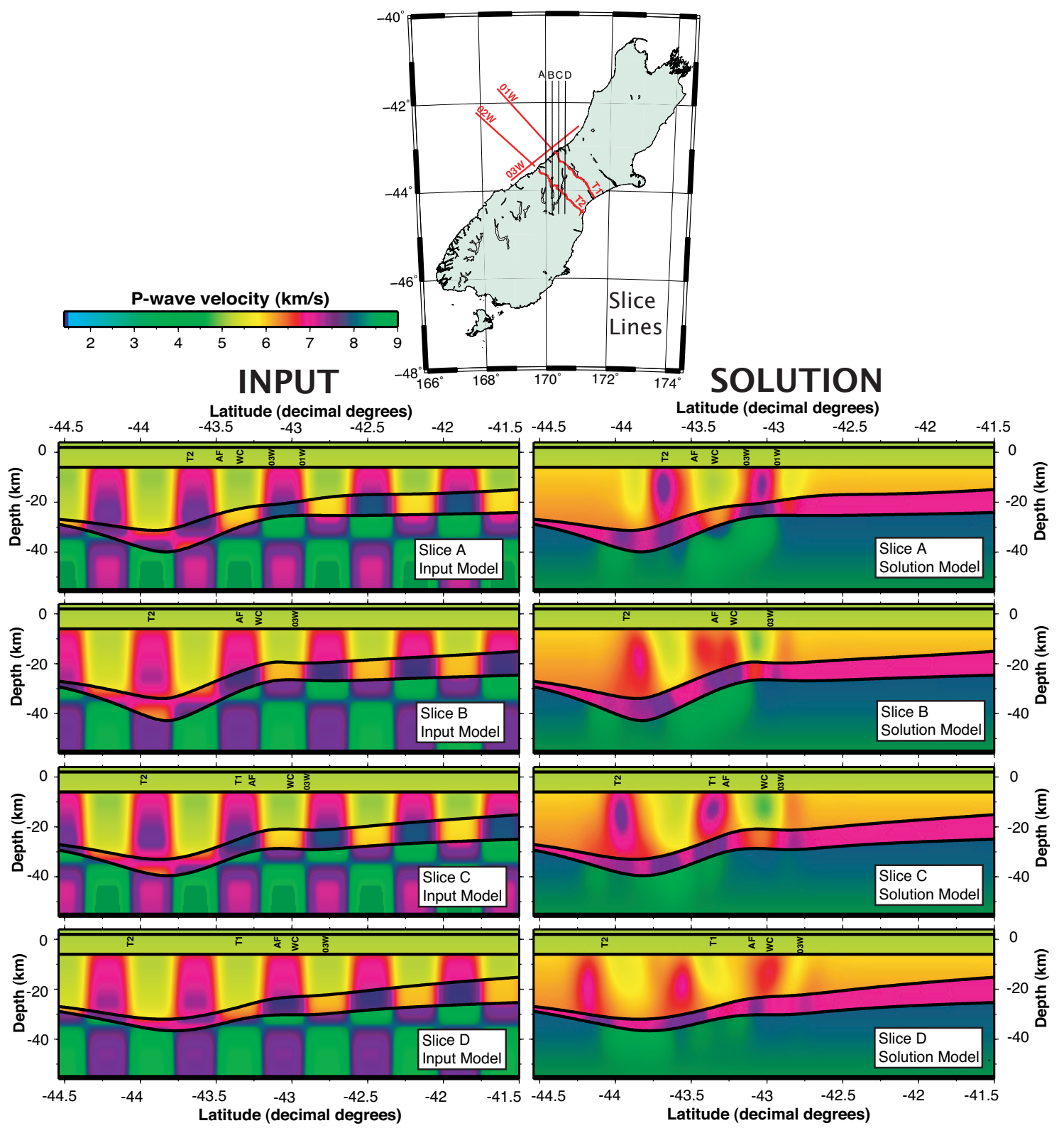

Figure 4.6: Plots of the input (left plots) and solution models (right plots) of the inversion of the full checkerboard tests through cross-sectional slices $A, B, C$ and $D$. Values for damping and smoothing of 35 and 30, respectively, velocity amplitude of $1 \mathrm{~km} / \mathrm{s}$, node spacing of $8 \mathrm{~km}$ and standard deviation of Gaussian noise of $100 \mathrm{~ms}$ are used for this model. Eleven inversion iterations are computed. WC West Coast. $\boldsymbol{A F}$ Alpine fault surface trace. $01 \mathrm{~W}$ Line $01 \mathrm{~W}$. 03W Line 03W. T1 Land transect 1. T2 Land transect 2. 


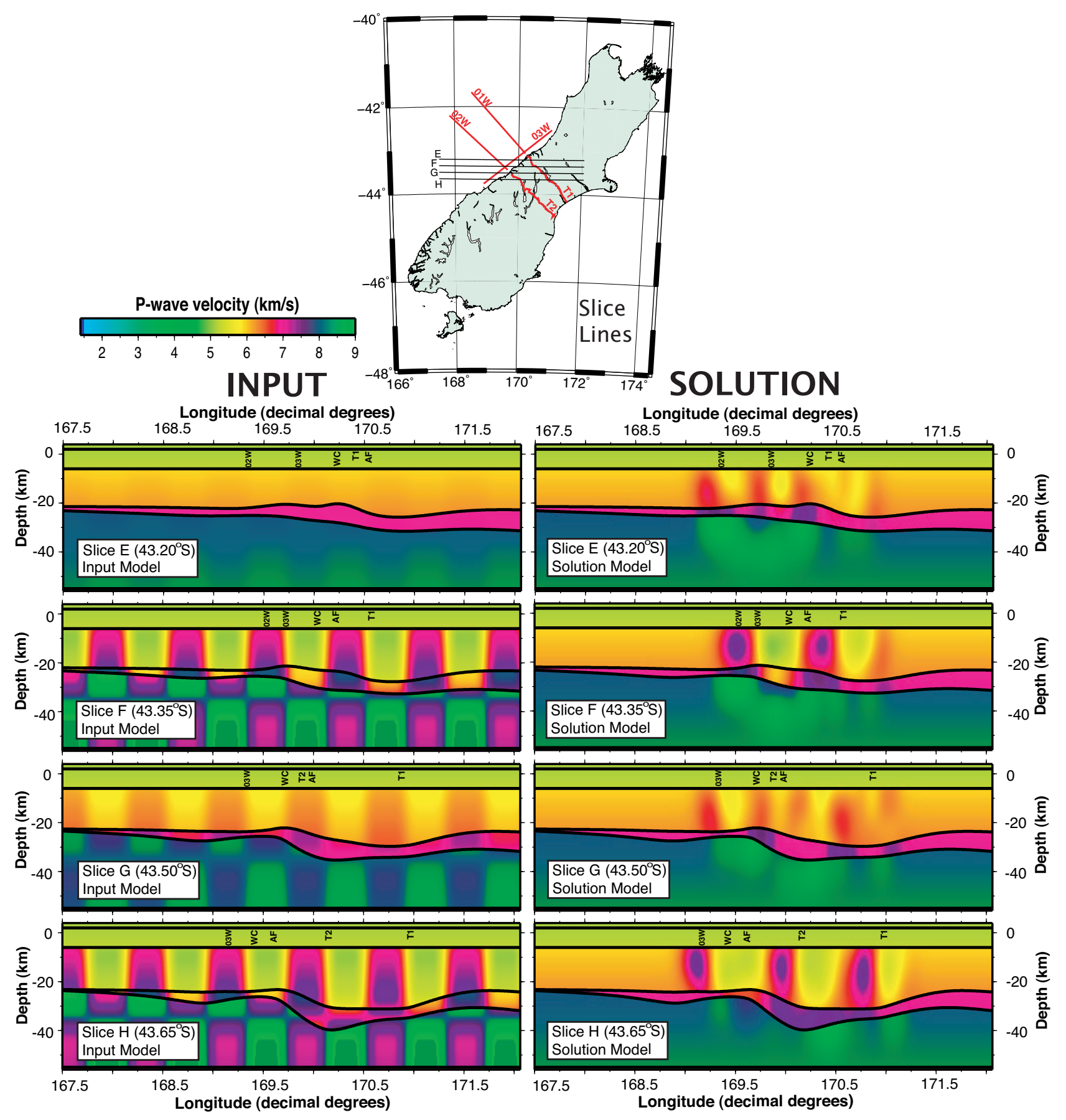

Figure 4.7: Plots of the input (left plots) and solution models (right plots) of the inversion of the full checkerboard tests through cross-sectional slices $E, F, G$ and $H$. Values for damping and smoothing of 35 and 30, respectively, velocity amplitude of $1 \mathrm{~km} / \mathrm{s}$, node spacing of $8 \mathrm{~km}$ and standard deviation of Gaussian noise of $100 \mathrm{~ms}$ are used for this model. Eleven inversion iterations are computed. WC West Coast. $\boldsymbol{A F}$ Alpine fault surface trace. 02W Line 02W. 03W Line 03W. T1 Land transect 1. T2 Land transect 2. 


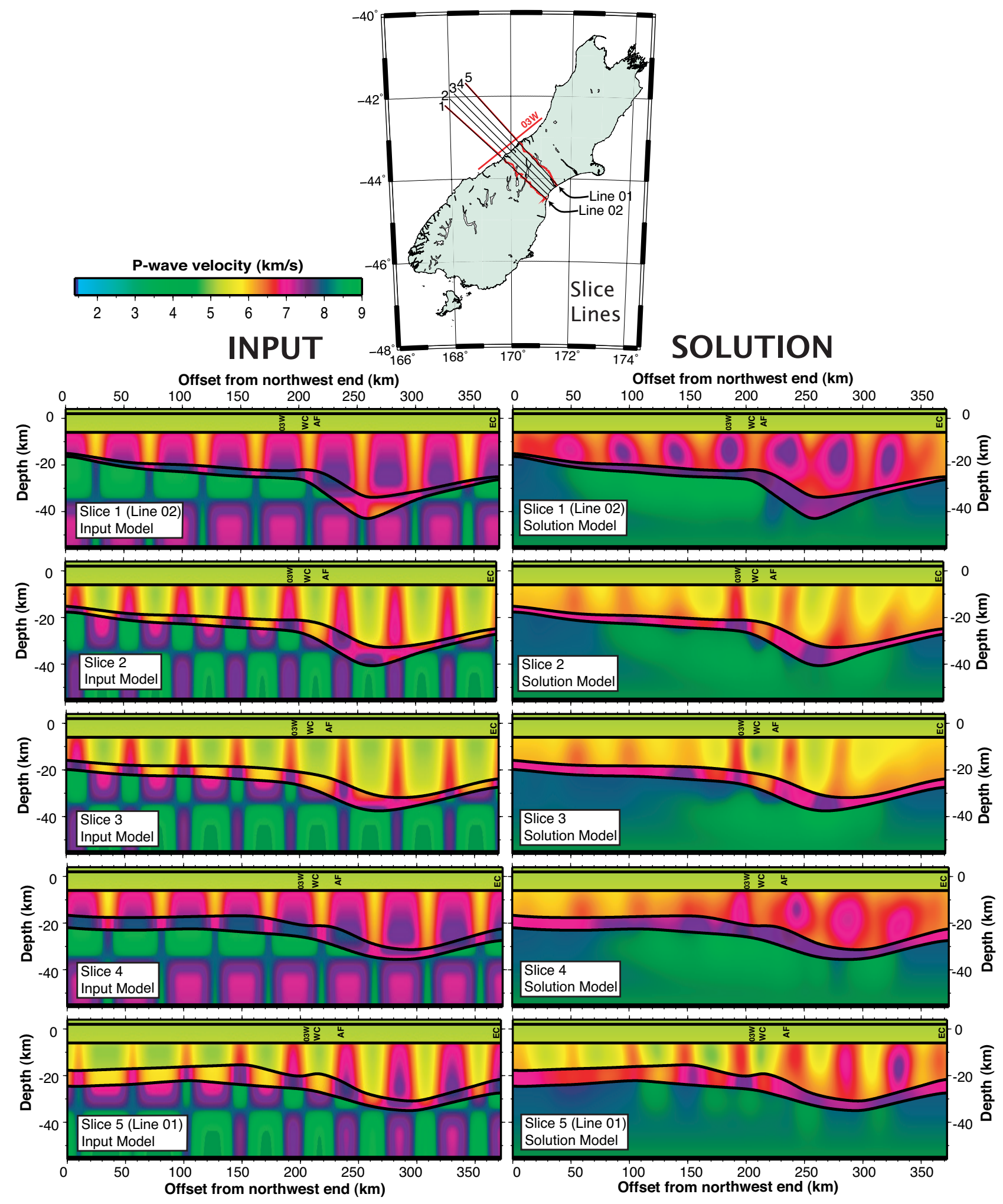

Figure 4.8: Plots of the input (left plots) and solution models (right plots) of the inversion of the full checkerboard tests through cross-sectional slices 1, 2, 3, 4 and 5. Values for damping and smoothing of 35 and 30, respectively, velocity amplitude of $1 \mathrm{~km} / \mathrm{s}$, node spacing of $8 \mathrm{~km}$ and standard deviation of Gaussian noise of $100 \mathrm{~ms}$ are used for this model. Eleven inversion iterations are computed. $03 \boldsymbol{W}$ Line 03W. WC West Coast. AF Alpine fault surface trace. EC East coast. 


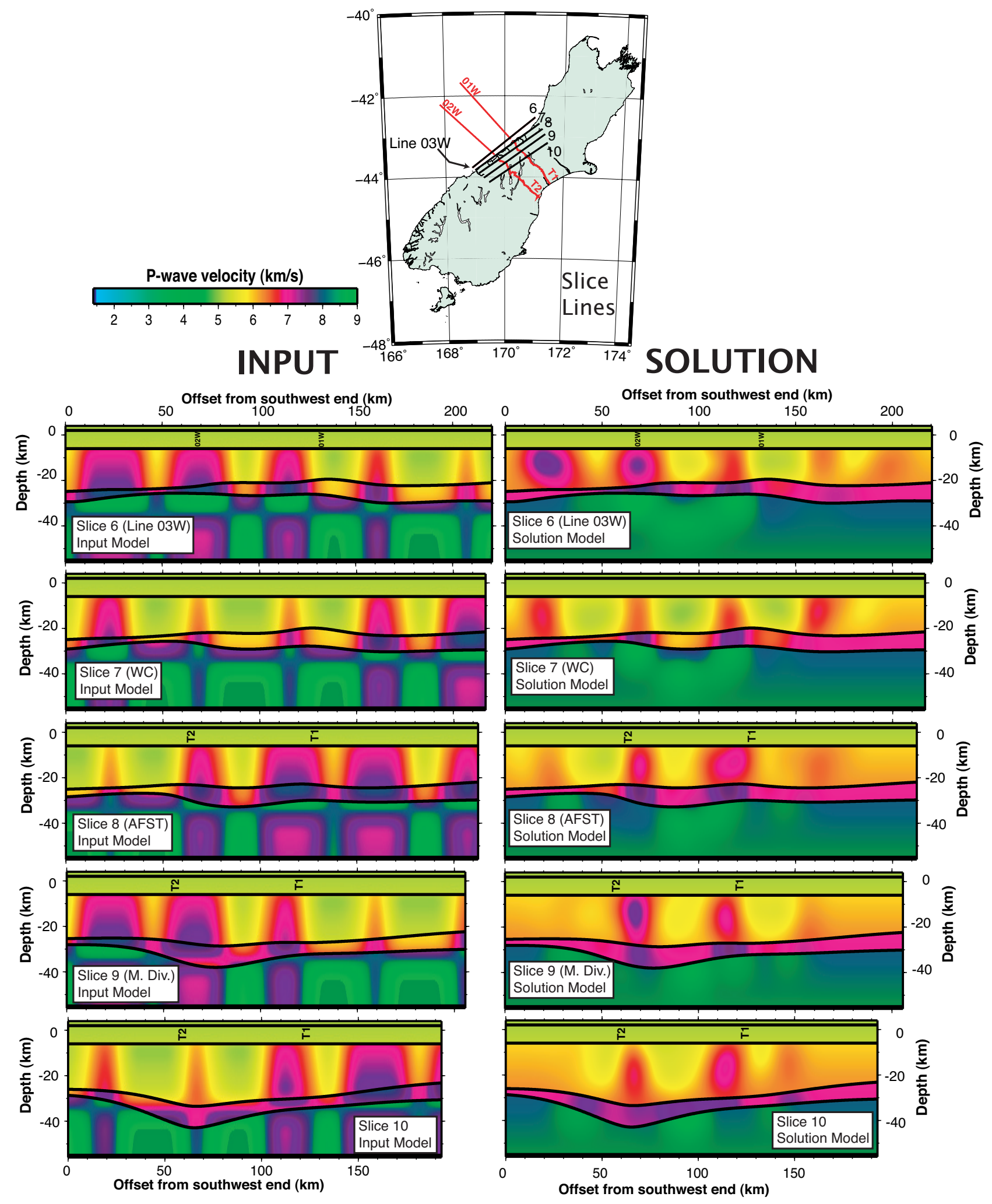

Figure 4.9: Plots of the input (left plots) and solution models (right plots) of the inversion of the full checkerboard tests through cross-sectional slices 6, 7, 8, 9 and 10. Values for damping and smoothing of 35 and 30, respectively, velocity amplitude of $1 \mathrm{~km} / \mathrm{s}$, node spacing of $8 \mathrm{~km}$ and standard deviation of Gaussian noise of $100 \mathrm{~ms}$ are used for this model. Eleven inversion iterations are computed. WC West Coast. AFST Alpine fault surface trace. M. Div. Main Divide. 01 W Line 01W. 02W Line 02W. T1 Land transect 1. T2 Land transect 2. 


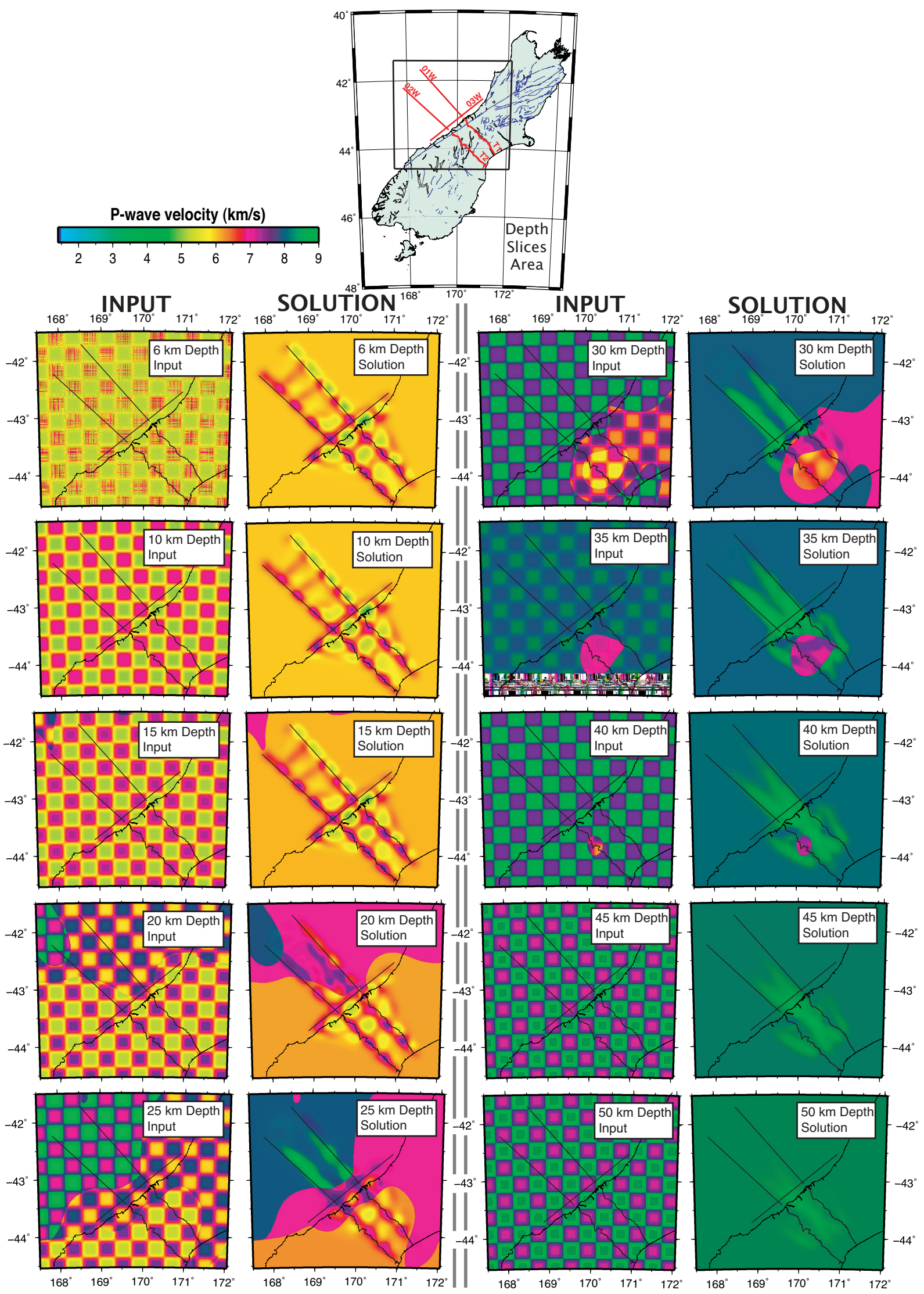

Figure 4.10: Plots of the input (first and third plots column) and solution models (second and fourth plots column) of the inversion of the full checkerboard tests through depth slices at 6, 10, 15, 20, 25, 30, 35, 40, 45 and $50 \mathrm{~km}$ depth. Values for damping and smoothing of 35 and 30, respectively, velocity amplitude of $1 \mathrm{~km} / \mathrm{s}$, node spacing of $8 \mathrm{~km}$ and standard deviation of Gaussian noise of $100 \mathrm{~ms}$ are used for this model. Eleven inversion iterations are computed. 


\subsection{Spike tests}

The second synthetic test method used here, the spike tests, enables the assessment of the recovery of more realistic and localised structures than the ones generated for the checkerboard tests [Rawlinson and Sambridge 2003]. A velocity anomaly, or spike, of specified size and velocity amplitude is introduced in a homogeneous model and an associated synthetic traveltime dataset is generated. The spike is then inverted for and the resolution threshold of the solution model can be assessed.

The area of most interest is the AFZ, located in the thickened crustal root to the southeast of the Alpine fault ramp. To assess the resolution threshold of this area, two spikes are introduced into the region of the thickened crust region (blue dots in Figure 4.11). One spike is aligned along line 01 , the second one between lines 01 and 02 along the meridian $170.35^{\circ} \mathrm{E}$. Spikes of different velocity amplitude, polarity and depth in the crust are tested. Damping and smoothing of 35 and 30, respectively, are used here; a node spacing is $8 \mathrm{~km}$ and a Gaussian noise of $100 \mathrm{~ms}$ are introduced to the synthetic dataset. Since the perturbation of the initial model is minimal, four inversion iterations are sufficient to reduce the global traveltime residuals to the value of added noise (100 ms).

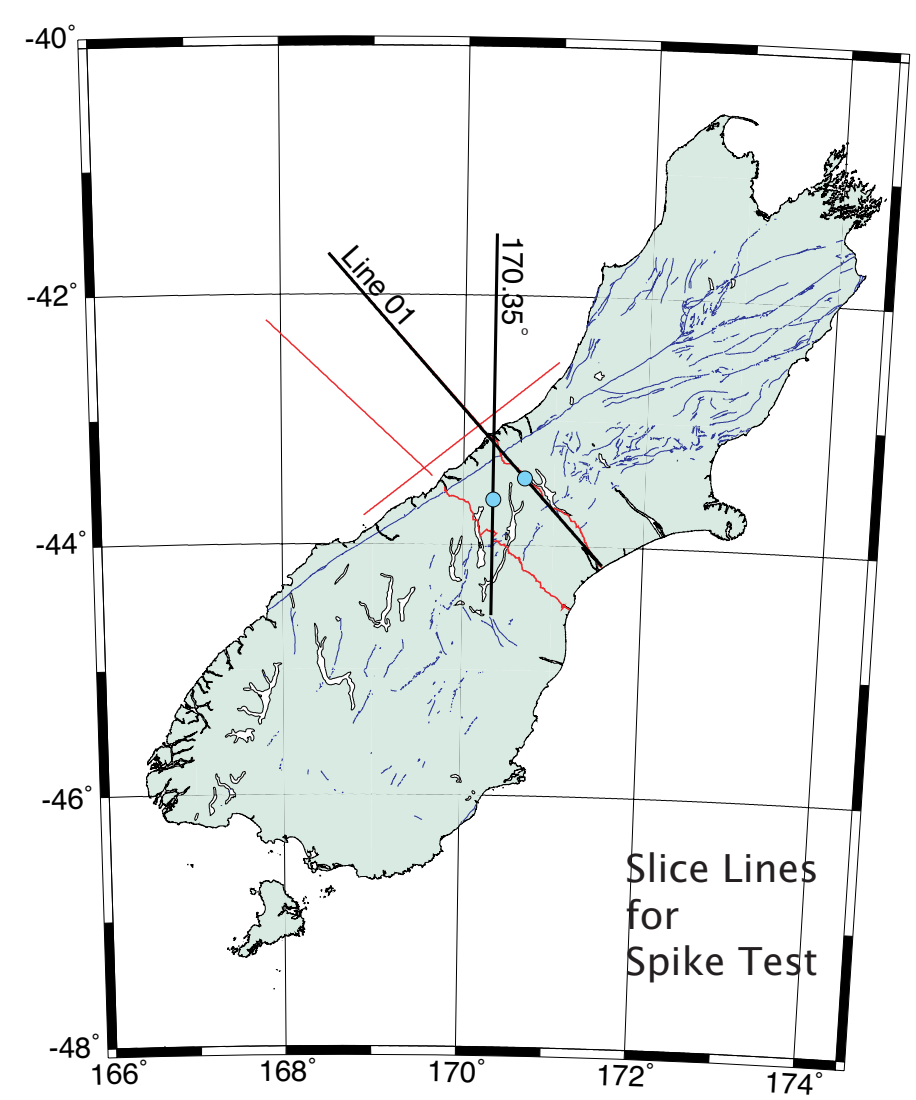

Figure 4.11: Map showing the location of the two velocity spikes (light blue dots) and the two cross sections through the solution model (black lines along line 01 and along the meridian $\left.170.35^{\circ} \mathrm{E}\right)$. The blue lines represent active faults. 


\subsubsection{Positive anomalies}

Twenty-five models with different combinations of velocity amplitudes (0.2 to $1.0 \mathrm{~km} / \mathrm{s})$ and crustal depths $(10$ to $30 \mathrm{~km}$ ) were computed. The results of four models are shown in Figure 4.12 .

\section{Along line 01}

The velocity recovery threshold in the upper-crust is $0.6 \mathrm{~km} / \mathrm{s}$ with an amplitude recovery of $80 \%$ (Figure $4.12 \mathrm{a}$ ). In the lower-crust the threshold is $0.4 \mathrm{~km} / \mathrm{s}$ with a $60 \%$ recovery of the amplitude (Figure $4.12 \mathrm{~b}$ ). A horizontal smearing in the lower crust apparently increases the dimension of the bottom edge of the spike by a factor of 2 (right plot of Figure $4.12 \mathrm{~b}$ ).

\section{Between lines}

Between the SIGHT lines, the velocity threshold is of 0.6 and $0.4 \mathrm{~km} / \mathrm{s}$ in the upper-crust (Figure 4.12 c) and lower-crust (Figure 4.12 d), respectively, with $80 \%$ amplitude recovery throughout the crust. The threshold is greater in the upper-crust due to the paucity of rays arriving to the surface, as there are few receivers in the area. Horizontal smearing in the lower crust is observed, apparently increasing the dimensions of the bottom edge of the spike by a factor of 1.5 (right plot of Figure $4.12 \mathrm{~d}$ ).

\subsubsection{Negative anomalies}

Ten models were computed with velocity spikes of -0.6 and $-0.8 \mathrm{~km} / \mathrm{s}$ and varying crustal depth (10 to $30 \mathrm{~km}$ depth). The results of four of the models are shown in Figure 4.13.

\section{Along line 01}

The negative anomalies are harder to recover than the positive ones. The velocity recovery threshold is $-0.6 \mathrm{~km} / \mathrm{s}$ in the upper-crust and mid-crust (Figure $4.13 \mathrm{a}$ ) and $-0.8 \mathrm{~km} / \mathrm{s}$ in the lower crust (Figure $4.13 \mathrm{~b}$ ). Unlike the positive spike test, the amplitude recovery decreases with depth from $75 \%$ in the upper-crust to $20 \%$ in the lower crust. This may be due to the fact that rays will tend to diverge from low velocity zones unless forced to through the proximity of the start and end points of raypaths.

\section{Between lines}

The velocity threshold and amplitude recovery are similar to that along line 01 although the recovery is reduced, from $60 \%$ in the upper-crust to $15 \%$ in the lower crust (Figure $4.13 \mathrm{c}$ ). 

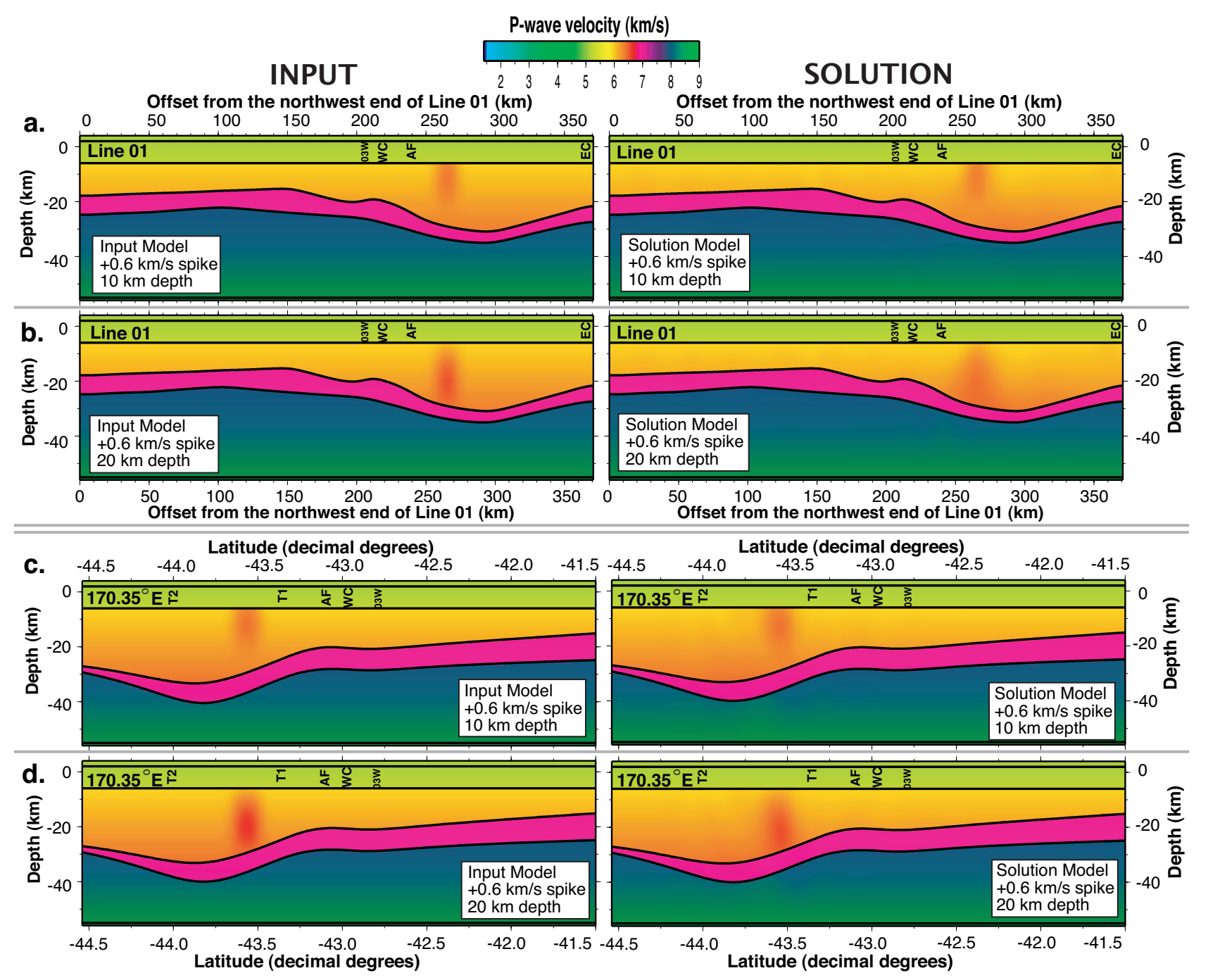

Figure 4.12: Results of the positive spike tests with velocity anomaly of $+0.6 \mathrm{~km} / \mathrm{s}$. Values for damping and smoothing of 35 and 30, respectively, node spacing of $8 \mathrm{~km}$ and standard deviation of Gaussian noise of $100 \mathrm{~ms}$ are used for this model. Four inversion iterations are computed. a. Plots along line 01 of the input (left plot) and solution model for the spike at $10 \mathrm{~km}$ depth (right plot). $\boldsymbol{b}$. Plots along line 01 of the input (left plot) and solution model for the spike at $20 \mathrm{~km}$ depth (right plot). $c$. Plots along the meridian $170.35^{\circ} \mathrm{E}$ of the input (left plot) and solution model for the spike at $10 \mathrm{~km}$ depth (right plot). $\boldsymbol{d}$. Plots along the meridian $170.35^{\circ} \mathrm{E}$ of the input (left plot) and solution model for the spike at $20 \mathrm{~km}$ depth (right plot). WC West Coast. EC East coast. AF Alpine fault surface trace. 03W Line 03W. T2 Land transect 2. 

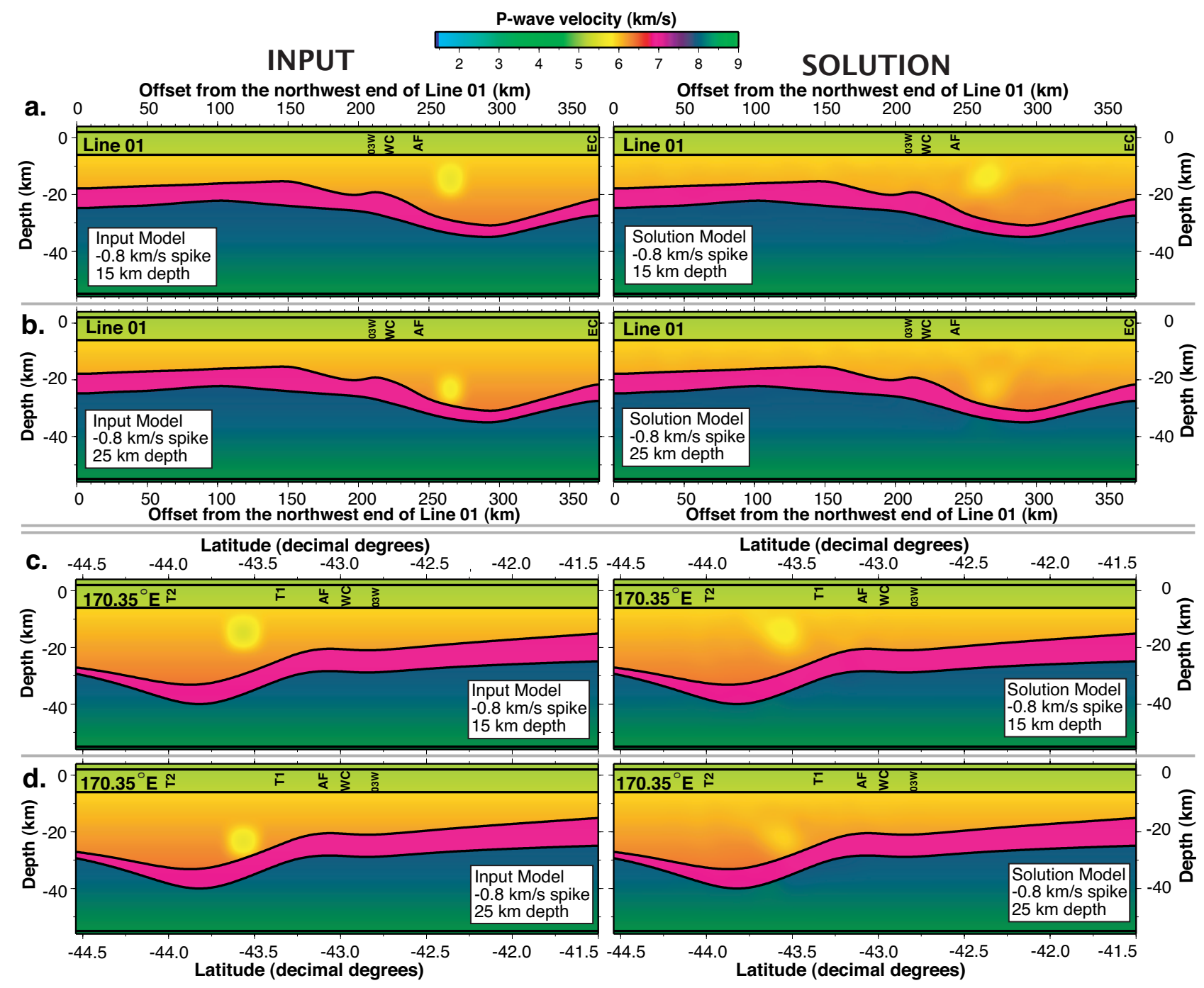

Figure 4.13: Results of the negative spike tests with velocity anomaly of $-0.8 \mathrm{~km} / \mathrm{s}$. Values for damping and smoothing of 35 and 30, respectively, node spacing of $8 \mathrm{~km}$ and standard deviation of Gaussian noise of $100 \mathrm{~ms}$ are used for this model. Four inversion iterations are computed. a. Plots along line 01 of the input (left plot) and solution model for the spike at $10 \mathrm{~km}$ depth (right plot). $\boldsymbol{b}$. Plots along line 01 of the input (left plot) and solution model for the spike at $20 \mathrm{~km}$ depth (right plot). $c$. Plots along the meridian $170.35^{\circ} \mathrm{E}$ of the input (left plot) and solution model for the spike at $10 \mathrm{~km}$ depth (right plot). $\boldsymbol{d}$. Plots along the meridian $170.35^{\circ} \mathrm{E}$ of the input (left plot) and solution model for the spike at $20 \mathrm{~km}$ depth (right plot). WC West Coast. EC East coast. AF Alpine fault surface trace. 03W Line 03W. T2 Land transect 2. 


\subsection{Summary of synthetic tests}

The checkerboard and spike tests are processed to gain insight on the resolution capabilities of the modelling software and the dataset.

\subsubsection{Checkerboard test}

Structures between the surface and the lower-crust interface are considered well resolved with a velocity recovery of up to $75 \%$. Horizontal smearing by a factor of up to 2 is observed in the lower part of the crust. The area of best recovery coincides with the area where the raypath coverage is denser: along the main transect and in between them around the coastal region. This is the region sampled by the onshore-offshore dataset.

The resolution is less in the upper-crust in between the main survey lines, than along them as there are few rays that propagate to the surface. Resolution in the lower part of the crust is found to be increased between the main survey lines, as more raypath travel through this region. However, regardless of the resolution, negative velocity disturbances are recovered to a lesser extent than positive ones, especially in the lower part of the crust.

The supposed oceanic lower-crust is considered well resolved with up to $50 \%$ recovery of velocity amplitude. Structures below the Moho, in the upper-mantle, are not well resolved due to small recovery (less than $30 \%$ ) and to horizontal smearing. A zone of velocity disturbances along the raypaths does testify of the presence of structure recovery.

\subsubsection{Spike tests}

There is $80 \%$ and $60 \%$ of recovery of $0.6 \mathrm{~km} / \mathrm{s}$ and $0.4 \mathrm{~km} / \mathrm{s}$ velocity disturbances in the uppercrust and lower-crust, respectively. There is smearing by a factor of 2 in the lower-crust. There is better resolution at the base of the crust in between the main SIGHT transects than along them, however, and lesser upper-crustal resolution.

Negative anomalies are harder to resolve than positive ones. Only $75 \%$ in the upper-crust and $20 \%$ in the lower-crust along line 01 . The resolution is reduced to $60 \%$ and $15 \%$, respectively, in between the SIGHT transects. 


\section{Chapter 5}

\section{Tomography inversion}

A tomographic assessment method [Zelt 1999] is carried out to yield a preferred solution model for this dataset. This approach includes an objective, or tomographic, approach and a complementary subjective approach. The reason to implement this assessment method is to gain understanding on the credibility of the preferred solution model, by assessing the structures that are required by the data. This method indirectly justifies the subjective steps taken to produce the preferred model.

\section{$5.1 \quad$ Objective approach}

The first part of the tomographic assessment is the objective approach. The purpose of this unrealistic modelling approach is to understand what structures may be inferred from the data and to assess the resolution of the inversion when using uncorrected data. Effectively, this approach does not consider any prior geological information. Thus, the static corrections are not applied here, as they depend on prior knowledge. Other objective features of the modelling are summarised in the following section.

\subsubsection{Objective features}

This approach is termed 'objective' because of the following modelling features:

- Homogeneous reference model. Minimal prior information is included into the starting model. It is laterally homogeneous and is devoid of interfaces. The starting model is a $1 D$ interpolation from a velocity of $5.5 \mathrm{~km} / \mathrm{s}$ at $3 \mathrm{~km}$ elevation to $8.5 \mathrm{~km} / \mathrm{s}$ at $55 \mathrm{~km}$ depth (top left plot in Figure 5.1).

- Robust phase picks. The picks originate from the most robust and unequivocal seismic phases, the first-break refractions. These include the upper-crustal (Pg) and upper-mantle refractions $(\mathrm{Pn})$.

- Raw traveltime dataset. The dataset is unmodified from its inception. Station elevation and traveltime static corrections estimated in chapter 3 are not applied to the data.

- Unconstrained modelling. Modelling parameters, such as damping and smoothing have not been included in the modelling. 


\subsubsection{Results of the objective approach}

\section{Solution model features}

Eleven velocity inversion iterations, as determined by the calibration tests in Section C.3, were run to yield the solution model. The cross-sectional slices through the solution model of the objective approach are shown in Figure 5.1 (slices $1-5$ ). At first glance, the velocity structure seems chaotic and unrealistic. However, the following observed structures are relevant to this study:

1. Velocities lower than $5.8 \mathrm{~km} / \mathrm{s}$ are found at depths of up to $15-20 \mathrm{~km}$. This is especially clear in slice 1 and 5 where velocities lower than $4.5 \mathrm{~km} / \mathrm{s}$ intrude the top $10 \mathrm{~km}$ of the crust. This is consistent with the presence of thick sedimentary fill along line 01 and 02 , as discussed in Chapter 3, as well as with the LVZ thought to exist to the southeast of the Alpine fault.

2. The downward doming of the velocity field is consistent with the suggested thickened crust under the Southern Alps. The deepest extent of velocity values of $6.5 \mathrm{~km} / \mathrm{s}$, which is the velocity of the bottom of the crust, is located at a distance of $250 \mathrm{~km}$ along slice 1. This is coincident with the location of the base of the thickened crust as suggested by Scherwath et al. [2003] along line 02. On the other hand, it is located at $210 \mathrm{~km}$ distance along slice 5. This is over $50 \mathrm{~km}$ northwest than other results [van Avendonk et al. 2004].

Isolated patches and unrealistically high velocities at depths shallower than $30 \mathrm{~km}$ are attributed to model artefacts, raypath effects and/or errors within the traveltime dataset. These features are not considered significant as the damping and smoothing parameters will mute them in the inversion of the subjective approach (Section 5.2). The raypath coverage can clearly be inferred from the disturbed region of the velocity field. Raypaths reach a maximum depth of $55 \mathrm{~km}$; however this depth will be diminished by the insertion of interfaces described in Section 5.2.

\section{Statistical analysis}

A statistical analysis is carried out in order to qualitatively assess the solution model. The traveltime residual distribution is shown in Figure 5.2 and the values of the Root Mean Square (RMS) traveltime residual, $T_{R M S}$, and the traveltime misfit, $\chi^{2}$, for the initial and solution models are given in Table 5.1. These statistical indicators are calculated as follows:

$$
\begin{aligned}
& T_{R M S}=\left(\frac{\sum\left(t_{o b s}-t_{\text {mod }}\right)^{2}}{n_{o b s}}\right)^{1 / 2} \\
& \chi^{2}=\frac{\sum\left(\frac{t_{o b s}-t_{m o d}}{t_{\text {err }}}\right)^{2}}{n_{\text {obs }}}
\end{aligned}
$$

Where $t_{o b s}$ and $t_{\text {mod }}$ are the observed and estimated traveltimes, respectively, $t_{\text {err }}$ is the traveltime uncertainty and $n_{\text {obs }}$ is the number of observations. As can be seen on Figure 5.2, the 


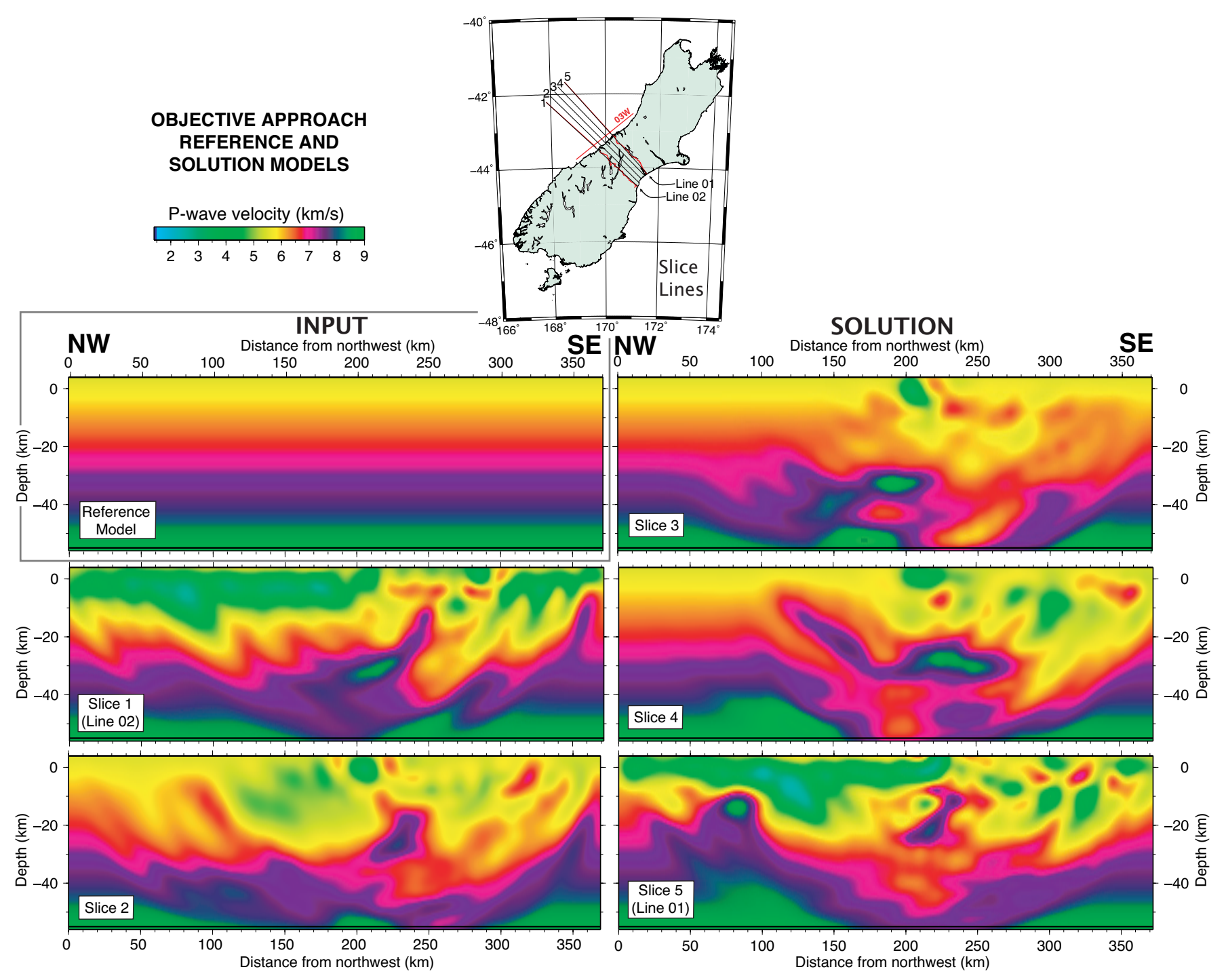

Figure 5.1: Plots of cross-sectional slices through the reference model (top left plot) and the solution model (slices 1 - 5) of the objective tomography approach. The reference model is laterally homogeneous and has no interface. Eleven iterations are run, no damping or smoothing are used and the traveltimes are uncorrected.

inversion process resulted in a clear improvement in the traveltime residual distribution with $55 \%$ of the rays having a traveltime residual of $\pm 0.2 \mathrm{~s}$. Furthermore, reductions of $70 \%$ for $T_{R M S}$ and $93 \%$ for $\chi^{2}$ are observed. Although the model convergence is evident, the final value of RMS traveltime residual of $582 \mathrm{~ms}$ remains unsatisfactory as the level of noise and error in the uncorrected dataset is thought to be of the order of $100-200 \mathrm{~ms}$. Similarly, the final value of traveltime misfit, $\chi^{2}$, of 20.611 is unsatisfactory, as a value close to 1 is preferred [Zelt 1999].

\begin{tabular}{c|c|c} 
Model & $T_{R M S}(\mathrm{~ms})$ & $\chi^{2}$ \\
\hline Initial & 1891.3 & 288.48 \\
Solution & 582.7 & 20.61
\end{tabular}

Table 5.1: Table of statistic indicators reflecting the improvement of the objective solution model after eleven inversion iterations. The indicators are the RMS traveltime residual in $m s, T_{R M S}$, and the dimensionless traveltime misfit, $\chi^{2}$. 


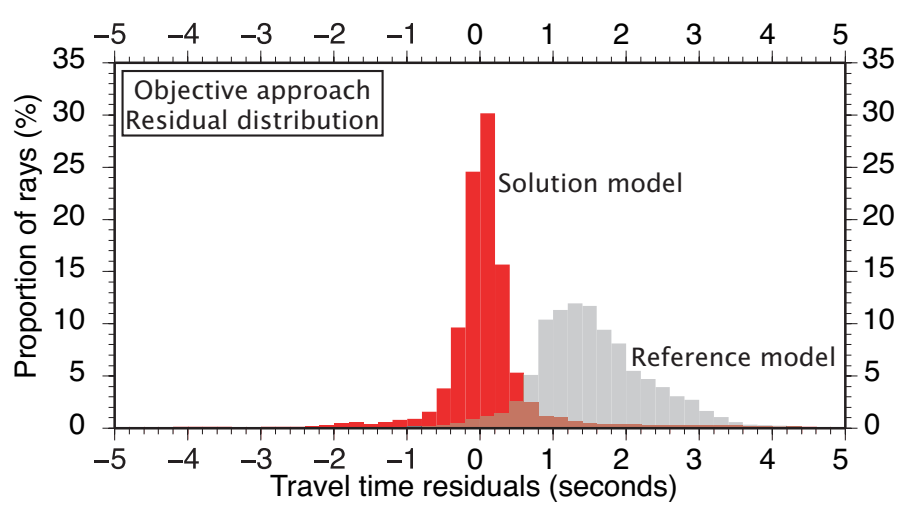

Figure 5.2: Comparative histogram of the traveltime residual distribution between the reference model (grey columns) and the solution model (red columns) of the objective approach. The brown area is the overlapping between the red and grey columns.

\section{$5.2 \quad$ Subjective approach}

The second part of the tomographic assessment is a subjective approach that results in the preferred model presented as the completion of the main objective of this research project. This approach aims to reach a preferred solution, by selecting more realistic local minimum, while reducing the model bias due to features of the dataset that cannot be inverted for-or eliminated-using the tomographic inversion code.

\subsubsection{Subjective features}

This approach is termed 'subjective' because it incorporates the following features:

- 3D varying reference model. The starting model, including geological and geophysical knowledge of the area, is interpolated in 3D. Interfaces are defined to represent seismic discontinuities. The construction of the reference model is detailed below.

- Refractions and reflections dataset. Reflection phases, whose identification and picking are highly subjective, are included in the dataset. The subjectivity lies within the fact that a reflection's onset may be masked by the coda of previous seismic arrivals, notably the refractions.

- Static corrected traveltimes. The stations' elevation is modified to sit on the basement and traveltimes are static-corrected as discussed in Chapter 3.

- Modelling constraints. The modelling parameters, whose values are determined during the synthetic modelling step in Chapter 4, are applied in the inversion process.

- Control over model variations. The detection and segregation of outlying observations are enabled to constrain the behaviour of the solution model during the inversion process. This process is detailed in Appendix D.2. 

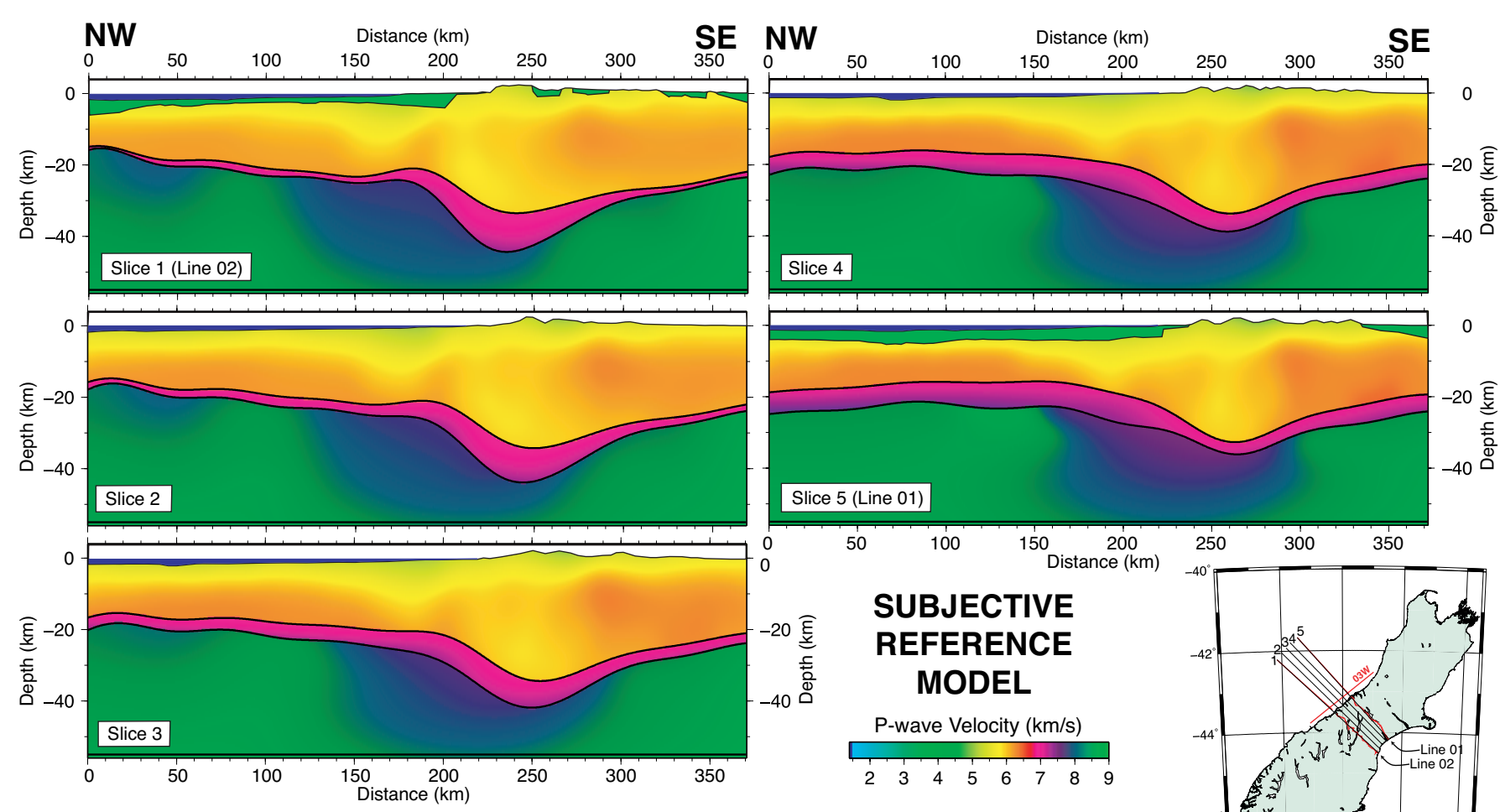

Figure 5.3: Plot of the slices 1 - 5 through the interpolated $3 D$ reference model of the subjective approach. Slice 1 is coincident with line 02, and slice 5 with line 01.

\subsubsection{Reference model}

It is crucial to define a realistic reference model, especially in regions where strong lateral structural variations are expected [Zelt 1999]. The velocity structure and interface geometry of published models for line 01 and 02 [Scherwath et al. 2003, van Avendonk et al. 2004] are used to generate a more realistic reference model. Firstly, the interface boundaries and velocity structure are digitised from paper. Then, an unusual, yet effective, set of interpolation schemes generate a 3D velocity and interface model; they are described in Appendix D.1. The resulting reference model, shown in Figure 5.3, is chosen for its close similarity to the models of line 01 [van Avendonk et al. 2004] and line 02 [Scherwath et al. 2003].

The fast direction of upper-mantle anisotropy is thought to be plate boundary parallel [Baldock and Stern 2005, Scherwath et al. 2002], and so the seismic rays generated along line 03W are likely sample faster velocities than those along lines $01 \mathrm{~W}$ and $02 \mathrm{~W}(8.3 \mathrm{~km} / \mathrm{s}$ as opposed to $7.8 \mathrm{~km} / \mathrm{s}$ along line 01 and 02$)$. Furthermore, crustal isovels at the intersection point between the lines did not match. The joint interpolation of lines $01 \mathrm{~W}, 02 \mathrm{~W}$ and $03 \mathrm{~W}$ would create unrealistic velocity structures and, since the solution model is dependent on the reference model, the model under line 03W [Melhuish et al. 2005] was, therefore, not used. Structural information from other 3D tomography models of the area [Baldock 2004, Eberhart-Phillips and Bannister 2002, Kohler and Eberhart-Phillips 2002] are not considered, because of their coarse local scale, and the limited upper-crustal resolution inherent to earthquake tomography [Okaya 2009]. 


\subsubsection{Inversion strategy}

\section{Sequential inversion}

The inversion of a single phase and/or a single feature (velocity or interface) at a time may affect the final model, also it is desirable for all the model parameters to be determined simultaneously in the case of structural complexity [Zelt 1999]. However, due to an error in the software's source code, this recommendation cannot be followed.

The program bug is associated with insufficient memory allocation during the calculation of the Frechet matrix of the forward modelling step of the interface inversion. Up to the date of submission of this report, no correction for this error has been received. As a result, only three successful interface inversion iterations are possible. Software testing at ANU managed to retrieve the traveltime residuals from the fourth iteration before failing. The traveltime residuals started to rise, suggesting that further iterations will not improve the solution model.

To overcome this software limitation, each phase and associated structural information (velocity structure or interface geometry) is inverted for separately and consecutively in a top-down layerstripping fashion. The inverted model structures are then fixed before inverting for the following phase and/or feature.

\section{Wide-angle reflections as velocity constraint}

At large offsets, wide-angle reflections become asymptotic to a refraction event (offsets $>250 \mathrm{~km}$ for PlP and $>220 \mathrm{~km}$ for PmP; feature 3 and 4 in Figure 2.6, respectively). Hence, a wide-angle reflection can be seen as a refraction bottoming at the base of the layer; thus, the asymptotic part of the wide-angle reflection may potentially be used to obtain velocity information in addition to layer interface geometry information.

Due to the complex geometry of the suggested oceanic lithospheric layer, only the wide-angle PlP are used in this way. The inversion of the wide-angle PlP as refractions gives complementary raypath coverage of the lower part of the crust at depths where Pg phases do not reach (Figure 5.7). On the other hand, there is a total lack of velocity constraint for the suggested oceanic crust; this results in permanent fixture of the velocity structure of this layer.

\section{Modulatory inversion scheme}

To minimise the loss of resolution due to damping and smoothing factors as the solution converges [Zelt 1999] a modulatory inversion scheme was designed. The values of damping and smoothing decreased by a third every third iteration (Table 5.2), as based on the inversion scheme used by Godfrey et al. [2001] and Scherwath et al. [2003].

Additionally, calculations are performed that down-weight aberrant observations and estimate station terms for each iteration; they are detailed in Appendix D.2. The final inversion run is composed of 39 iterations executed over five steps in the following order and for the following features:

1. Pg: Inversion of the velocity structure of the upper-crust during eleven iterations.

2. Wide-angle PIP: Inversion of the velocity structure of the lower part of the crust over the first eleven iterations. 


\begin{tabular}{c|c|c}
$\begin{array}{c}\text { Iteration } \\
\text { Number }\end{array}$ & \multicolumn{2}{|c}{ Values of } \\
Damping & Smoothing \\
\hline 1,2 & 35 & 30 \\
$3,4,5$ & 23 & 20 \\
$6,7,8$ & 15 & 13 \\
$9,10,11$ & 10 & 7
\end{tabular}

Table 5.2: Table of the inversion scheme used in the subjective approach with the values of damping and smoothing decreasing by a third every third iteration.

3. PIP: Inversion of the geometry of the boundary between the crust and the oceanic lowercrust for the next three iterations.

4. PmP: Inversion of the geometry of the Moho for three iterations.

5. Pn: Inversion of the velocity structure of the upper-mantle for the final eleven iterations.

\subsubsection{Solution model}

The velocity structure of the solution model (Figures 5.4-5.5) is much smoother than that of previously published 2D models [Scherwath et al. 2003, van Avendonk et al. 2004]. The interface geometry is only modified lightly as there are only three interface inversion iterations allowed by the software. The solution model as a whole is reasonably conservative in that it resembles the reference model to a greater degree than may be realistic. The most significant features of the final model are described hereafter; they are interpreted and discussed in chapter 6 :

\section{Crustal thinning in the northwest}

An apparent crustal thinning of the Australian plate is observed towards the south: the crust, which is about $20 \mathrm{~km}$ thick (excluding sediments) at the northwest tip of line 01 (feature $1 \mathrm{~b}$ in slice 5 in Figure 5.5), thins to $10 \mathrm{~km}$ at the northwest tip of line 02 (feature 1a in slice 1 in Figure 5.5). This feature is coincident with the western termination of the Challenger Plateau in the Tasman Sea. However, this distal part of the model is coincident with the largest traveltime static corections, corresponding to thick water column and sediments, (over $1 \mathrm{~s}$ for line 01 and up to $2.5 \mathrm{~s}$ for line 02 ). Hence, this result should be interpreted with care.

\section{Velocity reduction in the mid-crust}

Seismic velocities less than to $5.8 \mathrm{~km} / \mathrm{s}$ intrude the mid-crust to the northwest of the collision zone-i.e. the central South Island-at a distance of $130-200 \mathrm{~km}$ (feature 2 in slice 2 in Figure 5.5). This feature is more pronounced to the south (slices 1 and 2 in Figure 5.5) and dissipates towards the north (slices 4 and 5 in Figure 5.5).

\section{Velocity inversion in the upper-crust}

A structure of apparent higher velocity $(6.4 \mathrm{~km} / \mathrm{s})$ than the surrounding material $(5.8 \mathrm{~km} / \mathrm{s})$ is observed in the top $10 \mathrm{~km}$ of the upper-crust to the southeast of the collision zone (feature 3 in slice 3 in Figure 5.5). This body seems to be located in the region between the coast and 
the Main Divide (slice 7 and 9 in Figure 5.5, respectively; between $200-250 \mathrm{~km}$ distance in slice $2-5$ in Figure 5.5; and between $-43.75^{\circ}$ and $-43.00^{\circ}$ latitude in slice B in Figure 5.4).

A narrow zone of reduced velocities of $5.7 \mathrm{~km} / \mathrm{s}$ (feature 4 in slice 3 in Figure 5.5) are observed immediately to the southeast of the aforementioned high velocity body $(270 \mathrm{~km}$ distance in slice 2 and 3 in Figure 5.5; 170.3 longitude in slice H in Figure 5.4).

\section{Low velocity zone in the mid and lower crust: AFZ}

An anomalous zone of reduced velocities $(5.9-6.0 \mathrm{~km} / \mathrm{s})$ in the mid and lower-crust is observed in the crustal root (feature 5 in slice 2 in Figure 5.5), to the southeast of the collision zone (between 230 and $290 \mathrm{~km}$ in slice $1-5$, and between $169.5^{\circ}$ and $171^{\circ}$ longitude in slice $\mathrm{G}$ in Figure 5.4).

\section{Increasing upper-mantle velocity towards the south}

A north-south upper-mantle velocity gradient is observed with increasing velocities towards the south. Under line 01, the upper-mantle velocities of $7.8 \mathrm{~km} / \mathrm{s}$ are observed to the northwest of the western flank of the crustal root (feature $6 \mathrm{~b}$ in slice 5 in Figure 5.5). Under line 02, upper-mantle velocities increase to more usual value of upper-mantle velocity value of $8.3 \mathrm{~km} / \mathrm{s}$ [Seward 2008] (feature 6a in slice 1 in Figure 5.5). This transition occurs smoothly with higher velocities appearing at close proximity of the intersection with line 02 (slice 6 in Figure 5.5).

\section{Apparent flexure profile}

An apparent upward deflection of the lower-crustal and Moho boundaries is observed (feature 7 in slice 5 in Figure 5.5), which resembles a flexure profile [Harrison 1999]. The two high-points observed are at about $165 \mathrm{~km}$ distance on the lower-crustal boundary and at about $90 \mathrm{~km}$ distance on the Moho boundary.

\subsubsection{Statistical analysis of the solution model}

In the same way as was done for the objective approach, a statistical analysis provides quantitative information about the solution model proposed. The traveltime residual distribution is shown in Figure 5.6 and the values of the Root Mean Square (RMS) traveltime residual, $T_{R M S}$, and the traveltime misfit, $\chi^{2}$, for the initial and solution models are given in Table 5.3. The convergence in the traveltime residual distribution is more striking than for the objective approach with $65 \%$ of the rays with a traveltime residual of $\pm 0.2 \mathrm{~s}$. Reductions of $57 \%$ for $T_{R M S}$ and $96.5 \%$ for $\chi^{2}$ are observed. Notwithstanding that the $T_{R M S}$ reduction is less than for the objective approach, its final value, $429 \mathrm{~ms}$ is more compelling. Indeed, it represents the noise content of the corrected dataset, which is $350-450 \mathrm{~ms}$. Furthermore, the final value for the traveltime misfit of 1.04 demonstrates the satisfactory convergence of the solution model [Zelt 1999]. 


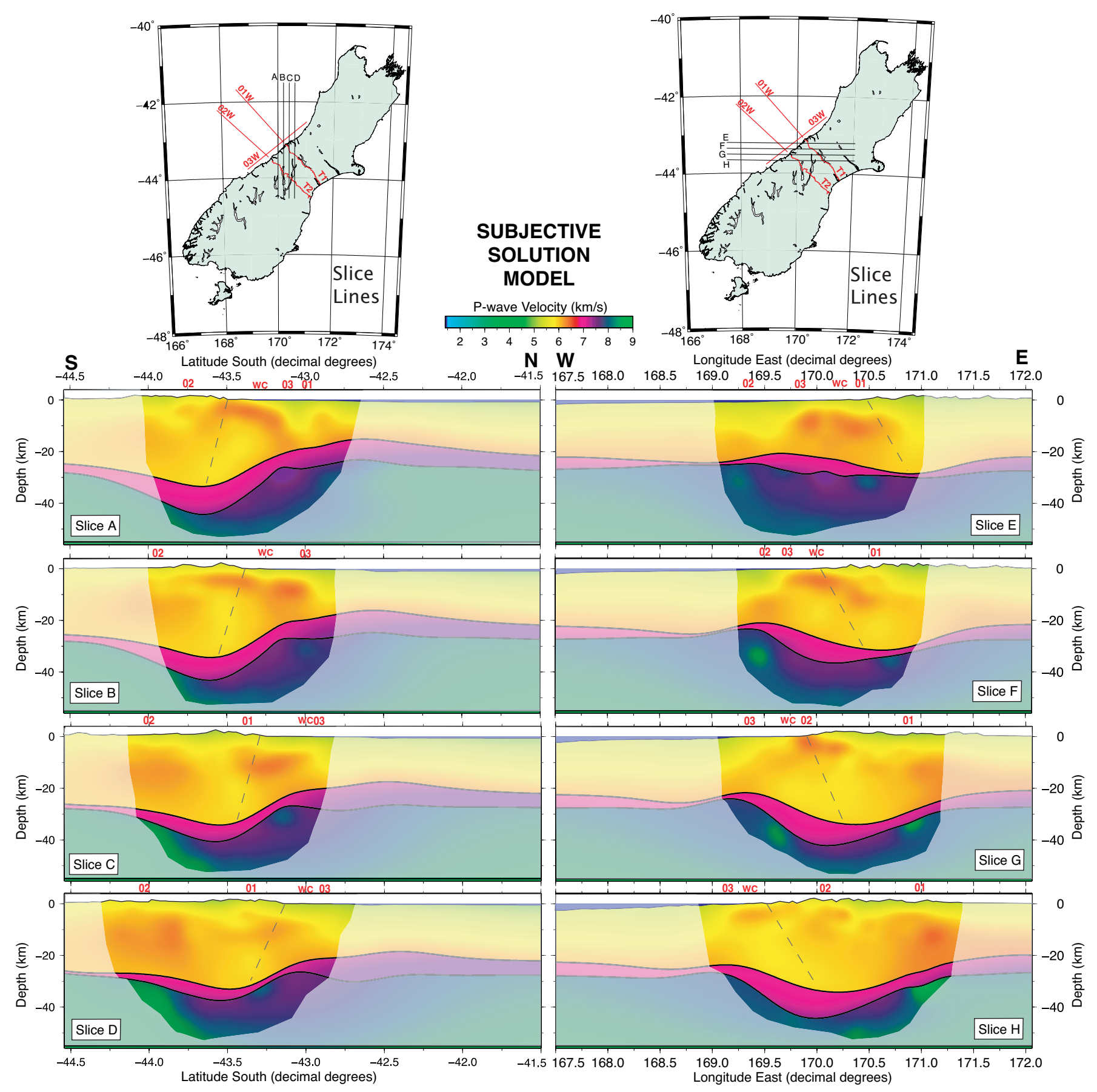

Figure 5.4: Plot of slices $A-H$ through the solution model of the subjective approach. The shaded area represents parts of the model space which are not sampled by seismic rays. The grey dashed line in slices 1 - 5 represents the inferred ramp of Alpine fault dipping at an angle of $45^{\circ}$ to the southeast. The intersection of each slice with line 01 (01), line 02 (02), line $03 W(03)$ and the West Coast (WC) are noted. 


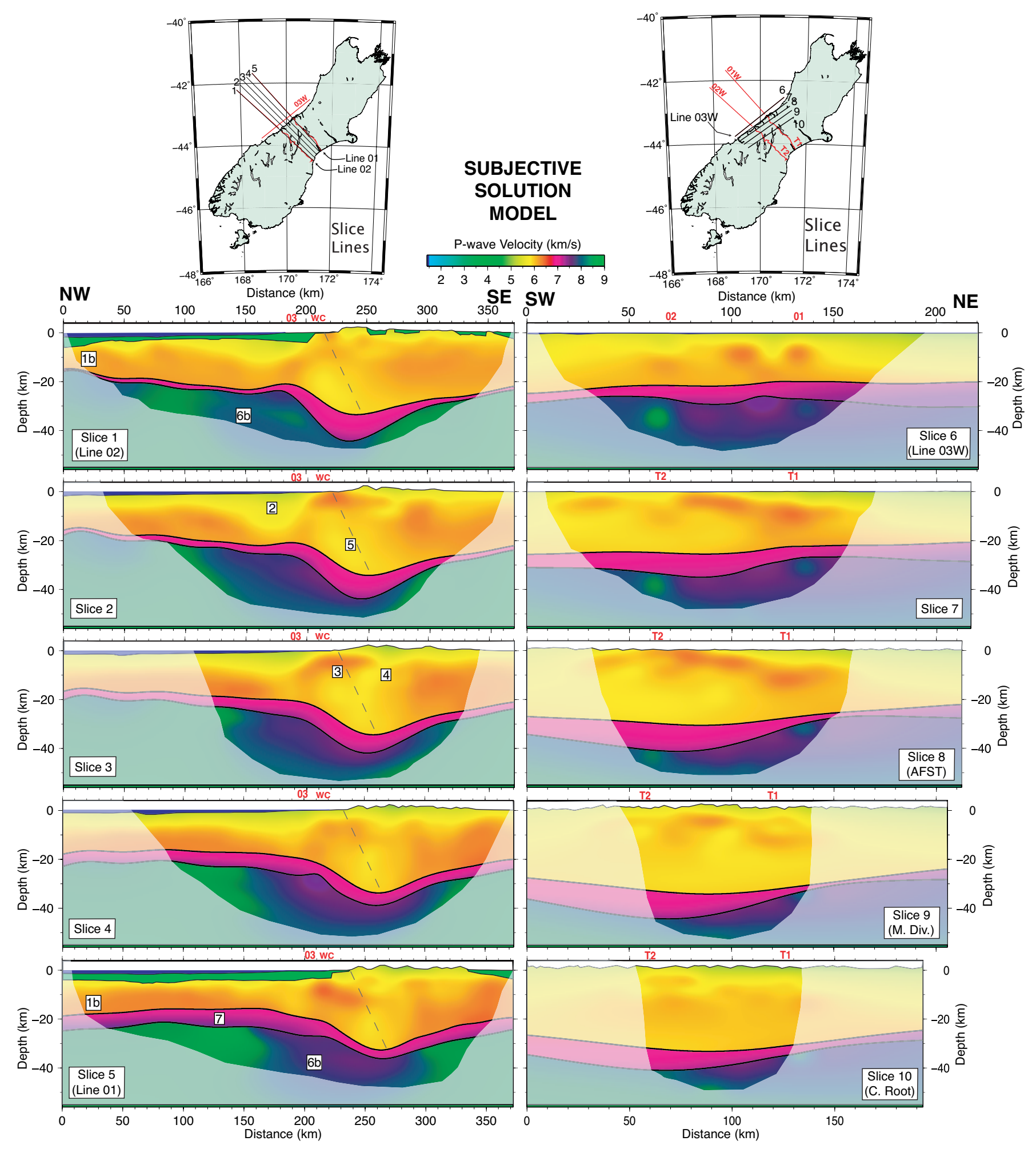

Figure 5.5: Plot of slices 1 - 10 through the solution model of the subjective approach. Slices 1, 5 and 6 are concurrent with lines 02, line 01 and line $03 \mathrm{~W}$, respectively, and slices 8, 9 and 10 are concurrent with the Alpine fault surface trace, the Main Divide and the axis of the crustal root, respectively. The main features of the solution model described in section 5.2.4 are labelled (numbers in white squares). The shaded area represents parts of the model space that is not sampled by seismic rays. The grey dashed line in slices 1 - 5 represents the inferred ramp of Alpine fault dipping at an angle of $45^{\circ}$ to the southeast. The intersection of each slice with land transect 1 (T1), land transect 2 (T2), line $01 \mathrm{~W}$ (01), line 02W (02), line $03 W(03)$ and the West Coast $(W C)$ are noted. 


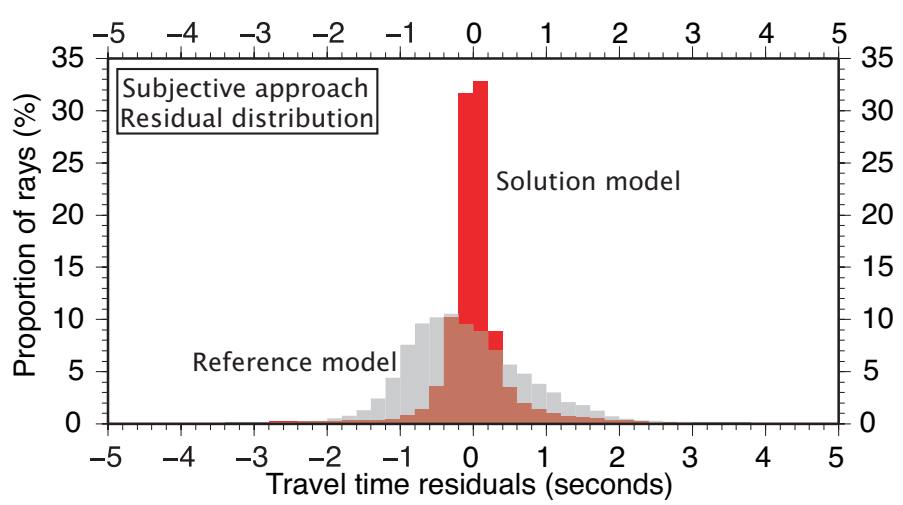

Figure 5.6: Comparative histogram of the traveltime residuals' distribution between the reference model (grey columns) and the solution model (red columns) of the subjective approach. The brown area is the overlapping between the red and grey columns.

\begin{tabular}{c|c|c} 
Model & $T_{R M S}(\mathrm{~ms})$ & $\chi^{2}$ \\
\hline Initial & 1003.3 & 59.29 \\
Solution & 429.1 & 1.04
\end{tabular}

Table 5.3: Table of statistic indicators reflecting the improvement of the subjective solution model after 39 inversion iterations. The indicators are the RMS traveltime residual in $m s, T_{R M S}$, and the dimensionless traveltime misfit, $\chi^{2}$.

\subsubsection{Raypath coverage}

The seismic rays of the least dense dataset (in-line line 02 [Scherwath et al. 2003]) are shown in Figure 5.7. Hence, this raypath coverage is not representative of the total raypath coverage of the model spaces, as the in-line dataset along line 01 [van Avendonk et al. 2004] has substantially more raypaths. Similarly, the cross-line dataset has a wide range of azimuths and large offsets rays that sample the model space at greater depth. However, these datasets would have resulted in an indecipherable raypath diagram, this is why this dataset is plotted. The area sampled by raypaths along each individual model slice can be visualised by the unmasked area in Figures 5.5 and 5.4. The coverage of each phase is described below:

- The crustal refractions, $\mathbf{P g}$, reach a maximum depth of around $15 \mathrm{~km}$ offshore of the South Island. There is dense raypath coverage in the top $10 \mathrm{~km}$ throughout the model.

- The lower-crustal reflections, PIP, do not seem to sample the mid and lower crust in the crustal root along line 02. The wide-angle PlP densely sample the western offshore part of the lower-crust. However, there are scarce near-vertical PIP rays in the offshore and onshore regions.

- The Moho reflections, PmP, sample densely and homogeneously the Moho interface along the thickened crust and to each side of the collision zone. The least dense part, is at the deepest point of the crustal root.

- The upper-mantle refractions, Pn, apparently only sample the upper-mantle to the northwest of the crustal root along line 02 . 


\subsection{Summary of the tomography inversion}

\subsubsection{Objective approach}

No prior information, data correction or modelling constraints are included into the modelling of the objective approach. While resulting in a large reduction of traveltime residuals, most of the resulting structures do not appear realistic. However, the solution model yielded structures that agree with the area's geological knowledge:

- Low velocities intrude into the upper-crust and into mid- to lower-crustal depths. This is coincident with the known velocity structure of the crust and the presence of sediments in the upper-most crust.

- A wide-spread downwards doming of the velocity structure is consistent with the presence of the crustal root.

\subsubsection{Subjective approach}

All available prior information is included in the initial model. Data corrections and modelling constraints are also applied in the subjective approach. This resulted in a $10 \%$ improvement in the traveltime residuals distribution, as well as a significant and satisfactory traveltime misfit reduction. The main observed features are:

- Crustal thinning in the Australian plate in the northwest of the model space.

- A zone of velocity reduction in the mid crust to the northwest of the collision zone.

- A high velocity body in the top $10 \mathrm{~km}$ of the crust, underlying the coastal region and the Southern Alps.

- Low-velocities adjacent to the high velocity body that connect to lower velocities in the mid- and lower-crust.

- Low velocity zone in the mid- to lower-crust underneath the Southern Alps, to the southeast of the Alpine fault.

- Increase in upper-mantle velocities towards the south along the northwestern flank of the crustal root.

- An apparent flexural signature along line 01. 


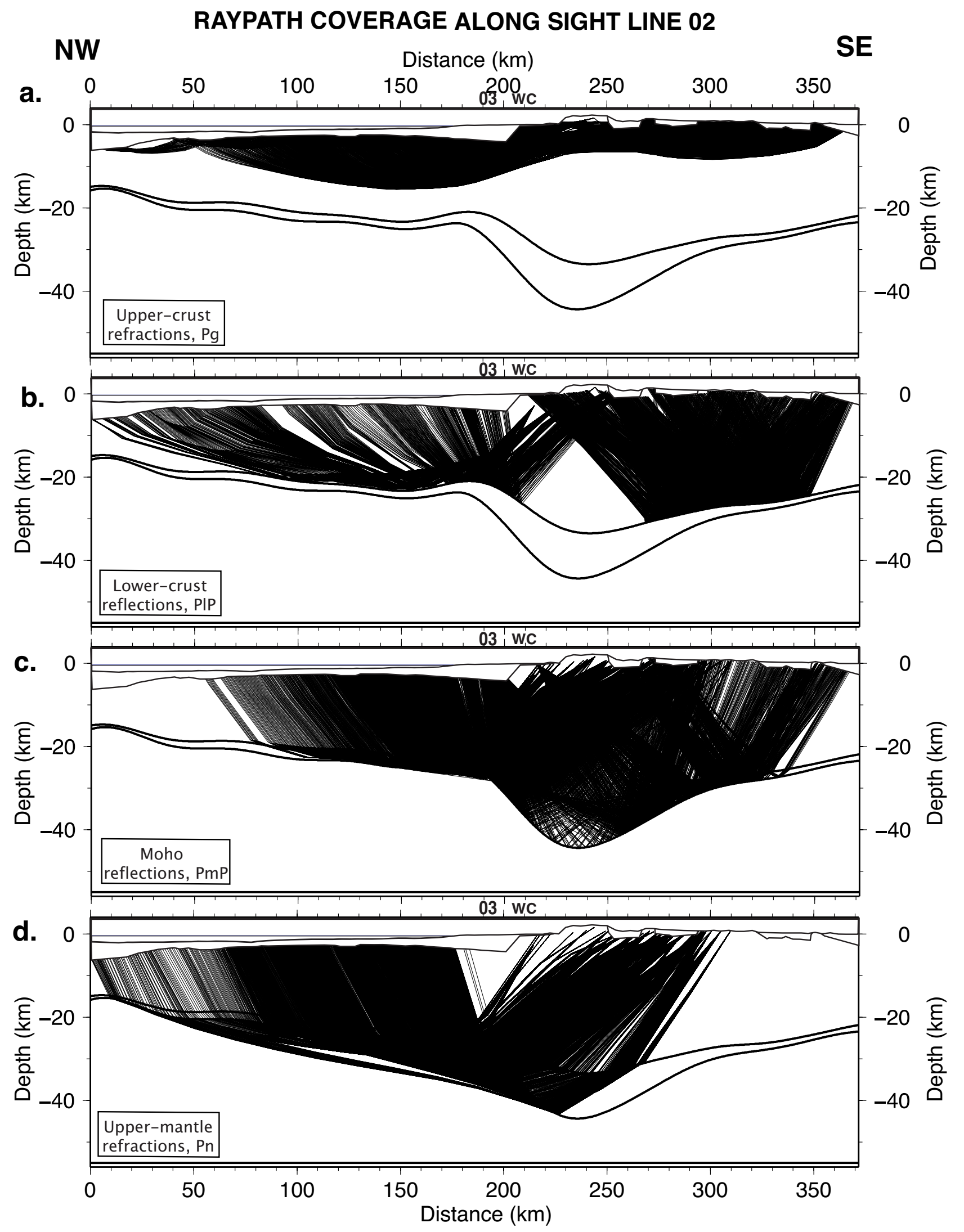

Figure 5.7: Plots of the in-line seismic rays along line 02 of the four phases used in the inversion: (a.) the upper-crustal refractions, $P g,(\boldsymbol{b}$. the lower-crustal reflections, PlP, (c.) the Moho reflections, PmP, and (d.) the upper-mantle refractions, Pn. The intersections with line $03 \mathrm{~W}$ (03) and the West Coast (WC) are noted. 


\section{Chapter 6}

\section{Discussion}

\subsection{Interpretation of the solution model}

\subsubsection{Uncertainty estimation}

\section{Phase identification}

The identification of the refraction first breaks ( $\mathrm{Pg}$ and $\mathrm{Pn}$ ) are unambiguous except for Pn phases at large offsets, where later arrivals may have been picked (cycle skipping). This results in a larger traveltime and, ultimately, it introduces errors into the model in the form of reduced velocities in the upper-mantle.

The onset of the reflection phases (PlP and PmP) may be hidden within the resonating coda of the refractions. The reflection picking is done by eye, hence, there is a possibility of phase misinterpretation. Considering the strong lateral-heterogeneity sampled by the wide-angle reflection raypaths, the accurate picking of those phases is an uncertain task [Rawlinson and Sambridge 2003]. However, only the phases that could be positively identified are picked. The PmP phases are predominant and the PIP ones are more muted in the seismic gather. Hence, there is more uncertainty related to the PIP than for the PmP phases.

\section{Traveltime pick dataset and uncertainty}

There are no back shooting rays in the onshore-offshore dataset. Therefore, no reciprocal traveltime verification is carried out and, as a consequence, any related errors cannot be identified at this point. The resulting errors are minimised by the down-weighting and station term calculation schemes that operate during the tomography inversion. A plot showing the evolution of the station terms as the inversion progresses is presented in Appendix D.2.2. The low values of station terms testify of the accuracy of the static corrections calculated in Chapter 3 and that of the 3D reference model discussed in Section 5.2.

The traveltime dataset of the author has been decimated by a factor of eight to match the density of the least represented dataset. This could result in a loss of resolution, but, in the case of a dense dataset, the decimation of picks does not affect the result [Zelt 1999].

In the pick datasets from other authors [Scherwath et al. 2003, van Avendonk et al. 2004], one value of picking uncertainty is assigned to each phase. However, for the dataset picked for this project (Section 2.2) a common picking uncertainty value is attributed to all the phases of one 
receiver gather. This convention was adopted because, although the onset of reflections maybe shadowed by the coda of earlier arrivals, the quality of a gather was found to be reasonably similar for all its phases. However, this results in an additional picking error of up to $0.1 \mathrm{~s}$. A table of the traveltime uncertainties is presented in Appendix A.3.1.

Any mistake and/or erroneous picking that occurred in other studies [Scherwath et al. 2003, van Avendonk et al. 2004], whose data are included here, permeate through to the solution model. However, the robustness of these studies implies that any such errors are unlikely to be an issue. Nonetheless, uncertainty in coordinate system conversion resulted in $\pm 50 \mathrm{~m}$ of added error in the location of any offshore station, as calculated and discussed in Appendix B.

\section{Sediment thickness estimation}

Offshore The interpretation of the three MCS lines is consistent with previous interpretations [Harrison 1999, Melhuish et al. 2005, Sircombe 1993]. However, there remains a possibility of misinterpreting horizons as, due to time constraints, no amplitude analysis was performed on the stack.

Onshore Basin shape and thickness of sediments were interpolated from seismic stratigraphy and gravity models that are not exactly aligned with the survey geometry. Hence, there is a possibility of over-estimating or under-estimating the sediment thickness.

\section{Velocity estimation}

The chosen values of sediment velocity are averaged from the literature (Section 3.2.2) in which estimate variation are of the order of $50-100 \%$. The resulting errors are difficult to estimate; they will, however, result in a velocity-depth trade-off [Stern et al. 2010, Zelt 1999].

\section{Error of static correction}

Even though manually estimated static corrections are said to be less robust than those gained from ray-tracing methods [Woodward 1991], they are expected to provide a reasonable initial model for shallow structures [Zhu et al. 1992]. Statics are large for stations overlying a thick sediment fill or an extremely low velocity material (maximum of $2.6 \mathrm{~s}$ at the northwest end of line 01 in Figure $3.9 \mathrm{~b}$ ). Quantifying the error originating from the static correction involves combining errors originating from the estimated sediment thickness and the assumed velocities, which is difficult to assess accurately. An additional $300 \mathrm{~ms}$ is, therefore, added onto the traveltime uncertainty of each observations to account for this error source. This error adjustment will result in a smoother solution model as the inversion has a larger uncertainty window within which it can fit the observations. However, the down-weighting and station term calculation schemes effectively reduce the impact upon the solution model of the static correction errors, as is explained above and shown in Appendix D.2.2.

Errors from the surface consistency assumption are estimated to be of the order of less than $3 \%$ (Section 3.1.2) and will, therefore, induce a minor loss of resolution of the final model. The errors linked to water column difference and tidal fluctuations [Lacombe et al. 2009] are estimated and found to be negligible. 


\section{Synthetic tests}

The initial input used for the synthetic modelling has a fixed layer in the top $6 \mathrm{~km}$ of the upper-crust. This layer was originally implemented to overcome the inability to fit a surface through the stations (see Section 4.2.3). Consequently, no inferences can be made for the top $6 \mathrm{~km}$ of the solution model derived from synthetic modelling.

\section{Model parameterisation}

The parameterisation of the nodal field that defines the model $(8 \mathrm{~km}$ horizontally, $4 \mathrm{~km}$ vertically) is sufficient to resolve structures with a horizontal wavelength of about $32 \mathrm{~km}$, as derived from the checkerboard calibration tests (Appendix C.2). Nonetheless, structures of $16 \mathrm{~km}$ horizontally and $8 \mathrm{~km}$ vertically are thought to be resolved by the propagation grid. However, structures of smaller dimensions than the latter are not resolved by the propagation grid. This resolution is satisfactory as the structures of interest are of that size or larger.

\section{Ray path coverage}

Few PIP rays along SIGHT line 02 [Scherwath et al. 2003] can be recovered from within the deepest part of the thickened crust, hence, there is no direct resolution of the LVZ to the southeast of the Alpine fault (see Figure $5.7 \mathrm{a}$ and b). However, the in-line picks of line 01 [van Avendonk et al. 2004] have substantially more PlP phases and thus constrain the thickened crust better than along line 02. Similarly, the cross-line dataset, where ray paths have a wide azimuthal range, is likely to sample the thickened crust.

Near-vertical reflections are primarily sensitive to vertical velocity structures, whereas the wideangle reflections are also sensitive to horizontal velocity structures [Zelt 1999]. Given the proportion of onshore-offshore rays in the dataset, the horizontal velocity structures of the solution model are better constrained than the vertical ones. This is especially true between the main SIGHT lines, where no near-vertical reflection data are available.

The in-line dataset along line 01 has more land shots than line 02 , so near-vertical reflection picks onshore line 02 are limited. As a result, vertical velocity structures are weakly constrained beneath the South Island and are unconstrained offshore west of the South Island (see Figure $5.7 \mathrm{~b}$ and $\mathrm{c}$ ).

\section{Interpolation, down-weighting and station terms schemes}

Polynomials are commonly used to interpolate numerical surfaces. However, the method used to interpolate the 3D reference model (a least square collocation and random walk process) are more complicated to implement but were found to behave better than a polynomial interpolation. These methods were necessary to fit a smooth surface between sparse observations. The preferred values chosen for the parameters were based on visual inspection.

Although there are numerous studies and structural information for this area, the knowledge of the near surface structures cannot be known exactly. The station term calculation and down-weighting schemes reduce the impact of this uncertainty. 


\section{Consideration of wide-angle reflection PIP}

PlP phases are usually used to obtain interface geometry information. However, wide-angle PlP are used in this study to obtain velocity information, as discussed in Section 5.2.3. This is not common practice as the resolution of wide-angle data is generally poorer at greater depths and longer offsets [Zelt 1999]. This approach was, nonetheless, followed in order to gain additional raypath coverage of the lower part of the upper-crust as Pg phases only reach a maximum depth of $15 \mathrm{~km}$.

\section{Interface inversion}

Due to an error in the software code, only three interface inversion iterations could be run. The interfaces were probably not modified as much as was necessary to fit the data optimally. but as was mentioned in Chapter 5, a software test concluded that additional iterations did not modify the interfaces to fit the data better. The geometry of the solution model's interfaces has not departed greatly from these of the reference model and should be interpreted with care.

\subsubsection{Interpretation of model features}

\section{Crustal features}

Several features observed in the solution model confirm findings of previous studies. Common crustal velocity structures on either side of the collision zone (feature 1 in Figure 6.1) are consistent with the findings of van Avendonk et al. [2004] and Scherwath et al. [2003]. Also, low velocities $(5.7 \mathrm{~km} / \mathrm{s})$ intruding into the mid-crust (feature 2 in Figure 6.1) are consistent with the model of line 02 [Scherwath et al. 2003] and are coincident with downward flexure of the Australian plate [Harrison 1999].

A region of reduced velocities $(5.9-6.1 \mathrm{~km} / \mathrm{s})$ in the mid- and lower-crust to the southeast of the Alpine fault is consistent with the AFZ (feature 5 in Figure 6.1), which is thought to be due to high fluid pressures [Scherwath et al. 2003, Stern et al. 2001]. Magneto-telluric and resistivity studies [Ingham and Brown 1998, Ingham 1995, Wannamaker et al. 2002] suggest a zone of low-resistivity, which is indicative of the presence of metamorphic fluids. The presence of pseudotachalytes [Bossiere 1991] and pervasive quartz veining [Upton et al. 2000] in the rocks of the Southern Alps also testify to the high-fluid pressure.

A high velocity body $(6.3 \mathrm{~km} / \mathrm{s})$ in the upper-crust immediately above the thickened crust between the coast and the Main Divide (feature 3 in Figure 6.1) is consistent with findings of the 3D tomography of the Southern Alps [Eberhart-Phillips and Bannister 2002]. The feature is located under the West Coast of the South Island and extends to the western foothills of the Southern Alps. This is about $60 \mathrm{~km}$ northwest from the location of the body suggested by Eberhart-Phillips and Bannister [2002]; they argue the body is coincident with the MacKenzie Basin. The high velocity body is interpreted as a drier and more rigid schist body in between the surrounding greywackes. This body is coincident with a zone of high-resistivity from which can be inferred a depletion of fluid [Wannamaker et al. 2002].

Immediately to the southeast of this high velocity body (feature 3 in Figure 6.1) is an intrusion of lower velocities $(5.8 \mathrm{~km} / \mathrm{s}$ reaching depths of $8 \mathrm{~km})$. This feature appears to connect the AFZ (feature 4 in Figure 6.1) to the surface. This feature is consistent with the findings of Eberhart-Phillips and Bannister [2002] and, furthermore, it correlates with a zone of lowresistivity [Wannamaker et al. 2002] and active faulting, which is indicative of the presence of 


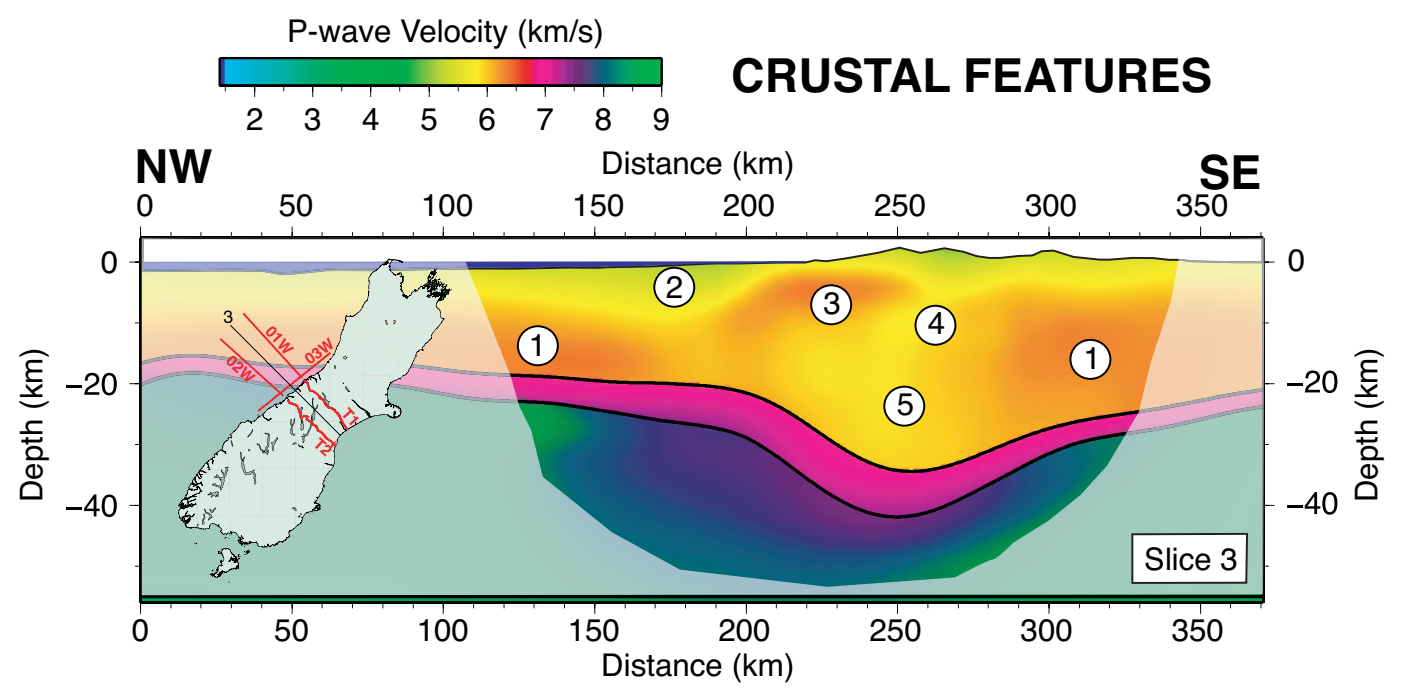

Figure 6.1: Plot of slice 3 through the solution model showing the crustal features of interest. The masked area shows the area not covered by seismic rays.

escaping metamorphic fluids. This feature is argued to be a faulting structure through which metamorphic fluids leak to the surface [Eberhart-Phillips and Bannister 2002, Wannamaker et al. 2002]. However, the resolution of the model presented by Eberhart-Phillips and Bannister [2002] is too coarse to allow a fault-associated LVZ to be detected: only $40 \%$ of velocity recovery in the upper-crust, as opposed to $75 \%$ for this study, as discussed in Section 4.3.2. Higherresolution explosion seismic studies in the region did not recover such a structure [Stern et al. 2001]. The low velocities are clearly visible and are associated as a leakage path of metamorphic fluids to the surface through back-shearing structures from the Alpine fault. Such mechanisms and structures are also suggested by Vry et al. [2010], Wightman and Little [2007].

\section{Distribution of apparent anisotropy}

The fast direction of anisotropy under the West Coast of the South Island, which effectively includes usual upper-mantle velocities of about $8.3 \mathrm{~km} / \mathrm{s}$ [Seward 2008], is estimated to be plate boundary parallel [Baldock and Stern 2005, Scherwath et al. 2002]. Hence, the seismic rays of this study largely sample the slow direction of anisotropy. However, the solution model under line 02 (62 km distance in Figure $6.2 \mathrm{a}$ and right plot in Figure $6.2 \mathrm{~b}$ ) shows velocities similar to that of the fast direction $(8.3 \mathrm{~km} / \mathrm{s})$.

A wide distribution of smaller northeast-southwest striking faults of the Marlborough fault system (grey lines left plot in Figure $6.2 \mathrm{~b}$ ) are accommodating strike-slip motion to the east of the Alpine fault. This broad faulting is no longer apparent at the latitude of Mt Cook, suggesting a focussing of the plate motion onto the Alpine fault. Hence, a wider region of upper-mantle will be affected by strain transfer and the anisotropy may be more pervasive to the north of the model space. The focussing effectively results in the narrowing of the mantle zone affected by the strain transfer from the strike-slip motion in the crust and a localisation of the shear strain transfer of the strike-slip motion to the upper-mantle immediately under the bottom extent of the Alpine fault. This means that more normal upper-mantle velocities $(8.3 \mathrm{~km} / \mathrm{s})$ are expected to the south of line 02 . 

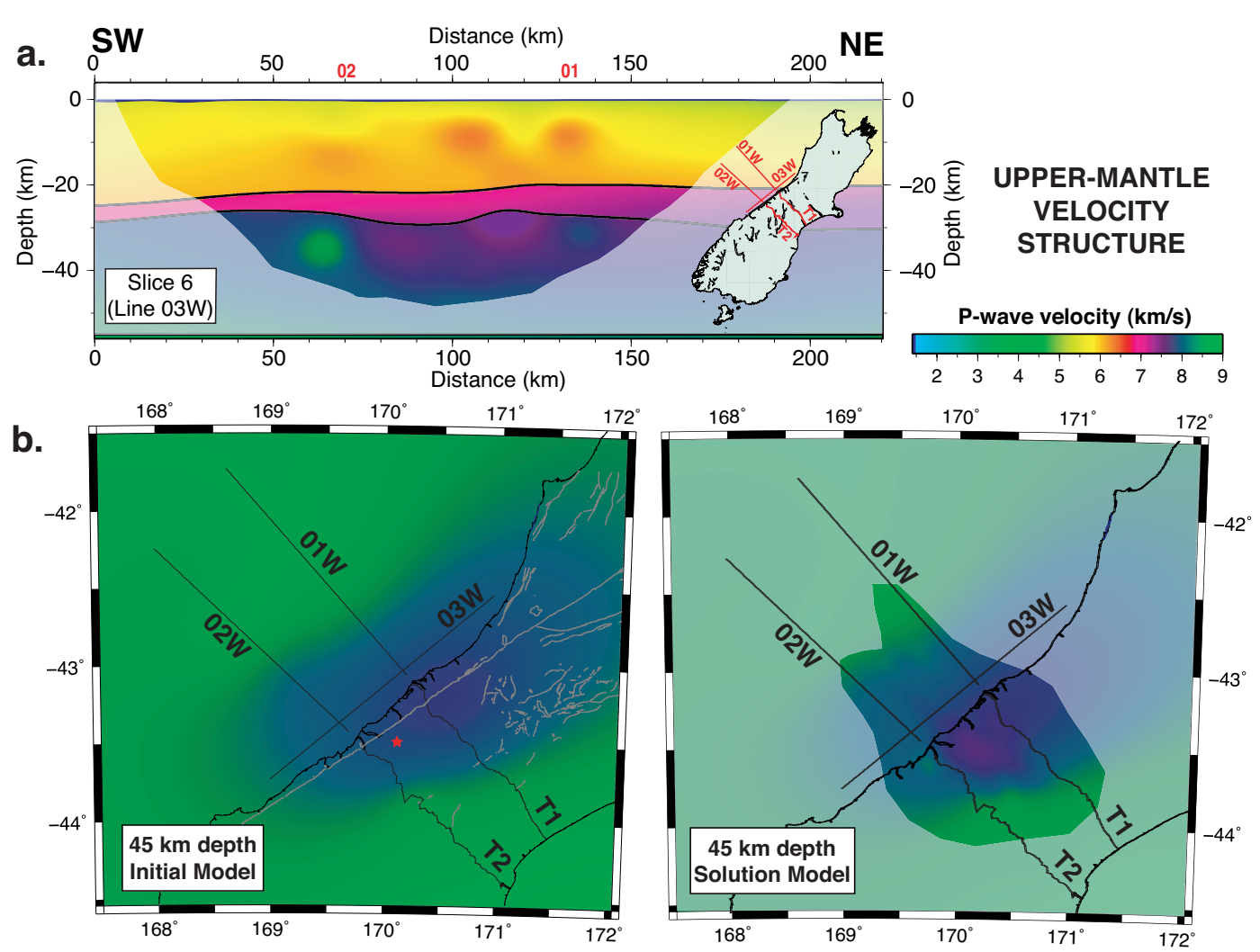

Figure 6.2: $\boldsymbol{a}$. Cross-sectional slice 7 through the solution model showing a spot of increased upper-mantle velocity at $62 \mathrm{~km}$ distance. $\boldsymbol{b}$. Depth slice at $45 \mathrm{~km}$ through the initial (left plot) and solution model (right plot). The masked area in the right plot shows the area not covered by seismic rays and the active faults are marked in grey lines.

Resolution constraints need to be kept in mind for the interpretation of the upper-mantle velocity structure. The checkerboard test shows that less than $30 \%$ of upper-mantle structures are resolved (Section 4.3.2). The shape of a velocity structure is also poorly-resolved due to significant horizontal smearing in the upper-mantle. Furthermore, the patchy nature of the higher mantle velocity (62 km distance in Figure 6.2 a) may be indicative of a model artefact.

\section{Evolution of the crustal root and Moho between lines 01 and 02}

One of the main reasons to use FMTOMO was to invert interfaces in 3D and have insight on the 3D development of the Moho in the central South Island. Along the crustal root, the Moho varies smoothly from a depth of $42 \mathrm{~km}$ under line 02 to $35 \mathrm{~km}$ under line 01 (Figure 6.3). The depth of the Moho is consistent with the findings of Henrys et al. [2004]. Notwithstanding that the input geometry of the Moho is derived from other studies, as discussed in Appendix D.1, most of the geometrical structure of the Moho is similar to that of the reference model. Hence, variations of the geometry of the Moho is the product of the interface interpolation rather than derived from the interface inversion. Therefore, the geometry of the Moho is not well resolved by this tomography inversion.

A bright reflector sequence (up to 4 s thick), the base of which coincides with the PmP modeled Moho, extends throughout most of the lower crust and bends downward asymmetrically beneath the Southern Alps. 


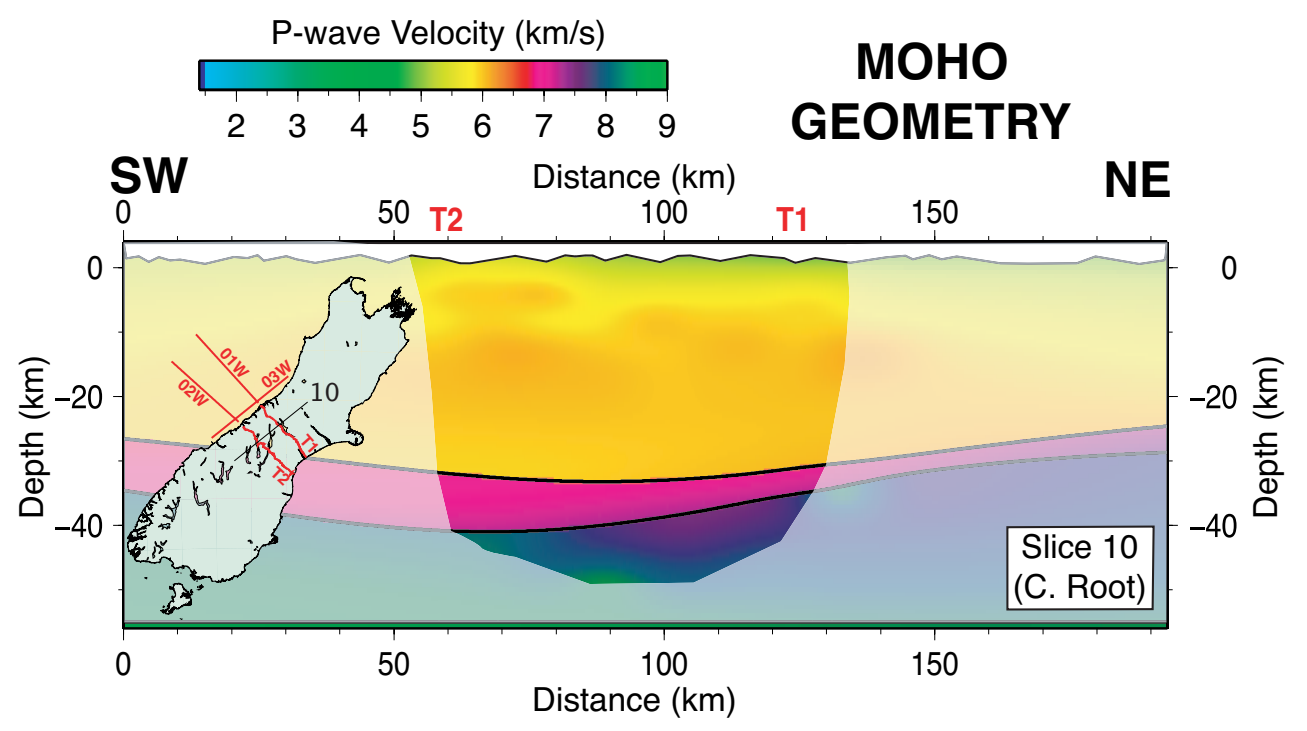

Figure 6.3: Slice through the solution model showing the geometry of the Moho interface. The masked area shows the area not covered by seismic rays. The intersection with $T 1$ and T2 are indicated. C. Root Crustal root.

\section{Apparent flexure of the Australian plate}

An apparently strong flexural signature is observed in the lower-crustal and Moho interfaces along line 01 (Figure $6.4 \mathrm{c}$ ). Flexure is thought to occur in response to the ongoing convergence that initiated in early Pliocene and resulted in the oblique-collision of the Pacific plate against the Australian one [Harrison 1999]. The profile is much more subdued in the south of the solution model due to the increasing gradient in crustal thickness (see slices $1-5$ in Figure 5.5). However, Harrison [1999] suggested evidence of flexure from a seismic stratigraphy study along line $02 \mathrm{~W}$. The interface geometry is different to that proposed by van Avendonk et al. [2004] and Scherwath et al. [2003].

Local high points are located at $170 \mathrm{~km}$ distance on the lower-crustal interface and at $80 \mathrm{~km}$ distance on the Moho interface (Lc and $\mathrm{Mh}$ in Figure 6.4 chowever, respectively). These are coincident with the apparent downward doming towards the southeast of the depth converted basement horizon of line 01 (blue solid line and grey dashed line in Figure 6.4 b, respectively), with a high point located at about $120 \mathrm{~km}$ distance. Furthermore, these apparent flexural high points are coincident with the pinching of the Pliocene sediment body in the seismic stratigraphy sequence of line 01 (between the black arrows in Figure 6.4 a). The sediment body reaches its minimal thickness at a distance of $124 \mathrm{~km}$. The flatness of Oligocene limestone and Miocene mudstone beds suggest that, prior to the onset of convergence, the seafloor would have been reasonably horizontal. Thus the thinning of the Pliocene sediments is attributed to the tilting of the seabed at the time of onset of convergence and, hence, resulting in the flexure of the Australian Plate.

As a first order approximation, the Southern Alps are assumed to act as a line load on top of a broken plate boundary. The variables are the flexural parameter, $\alpha$, the half-width of the bulge, $x_{b}$, the elastic thickness, $T_{e}$, and the flexural rigidity, $D$. The method used here is based on the one used by Stern et al. [1991] for a flexural study in Antarctica. The flexural parameter, $\alpha$, is defined by $\alpha=\left(2 . x_{b}\right) / \pi ; T_{e}$ and $D$ are calculated as follows: 


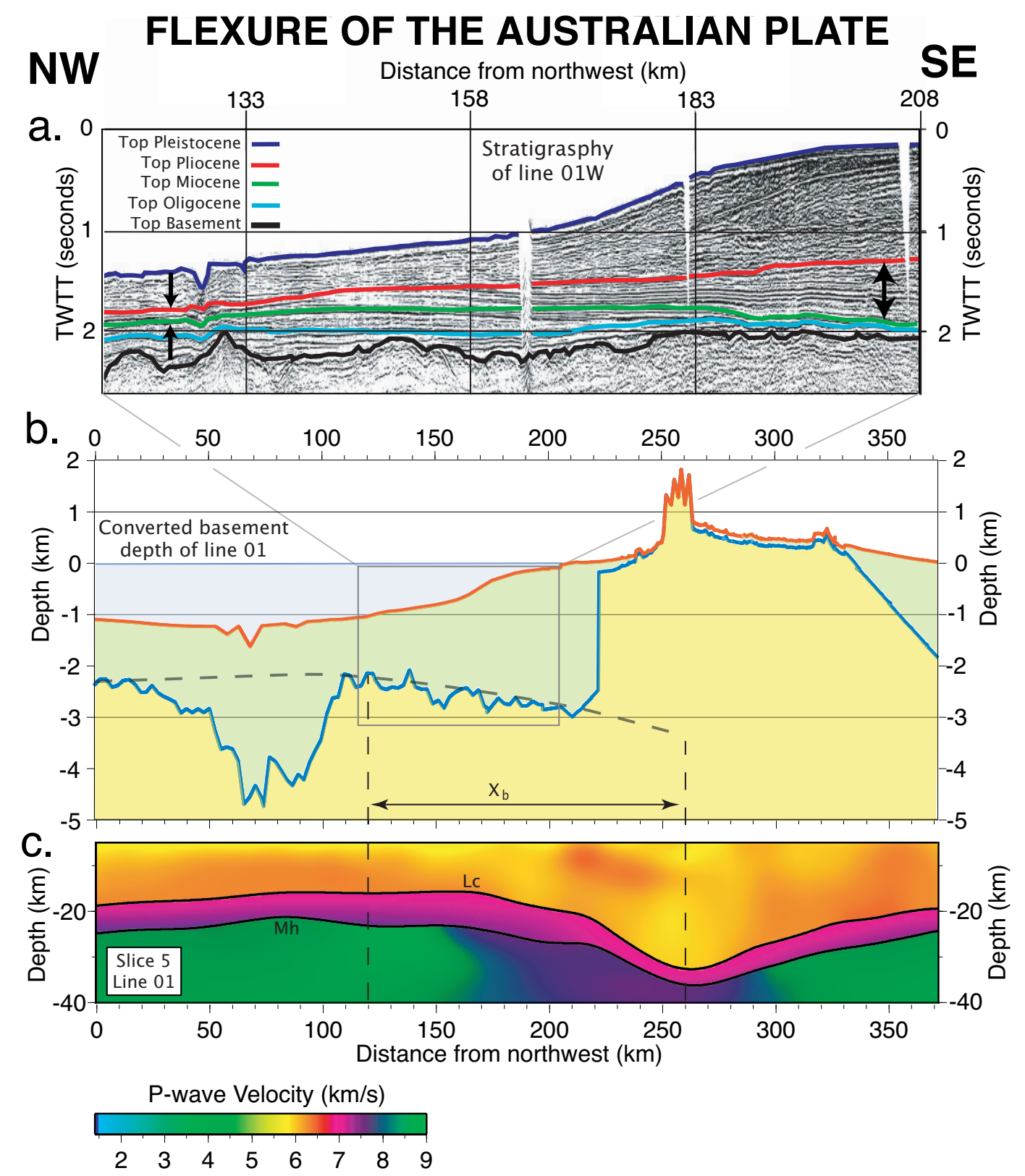

Figure 6.4: Superimposed figures of the flexure profile observable along line 01. a. The interpreted MCS stack of line $01 \mathrm{~W}$. Thinning of Pliocene sediments is shown by the black arrows. $\boldsymbol{b}$. Depth converted profile of the basement horizon (blue) with superimposed apparent flexure profile (grey dashed line). The seabed/topography horizon is in red and the grey square represents the location of plot a. $\boldsymbol{c}$. Slice 5 through the solution model (aligned with line 01) showing the flexure profile in the lower-crustal and Moho interfaces. $x_{b}$ is the half width of the bulge. Lc and $\boldsymbol{M h}$ are high points observed on the lower-crustal and Moho interfaces, respectively. 


$$
\begin{aligned}
& D=\frac{\alpha^{4} \cdot \Delta \rho \cdot g}{4} \\
& T e=\left(\frac{12 D\left(1-\sigma^{2}\right)}{E}\right)^{\frac{1}{3}}
\end{aligned}
$$

Where $\mathrm{E}$ is Young's modulus $\left(\mathrm{E}=6.5 .10^{11} \mathrm{~Pa}\right), \sigma$ is Poisson's ratio $(\sigma=0.25), \Delta \rho$ is the density contrast between the density of the mantle $\left(3300 \mathrm{~kg} / \mathrm{m}^{3}\right)$ and that of the in-filling crustal material $\left(2300 \mathrm{~kg} / \mathrm{m}^{3}\right.$, thus, $\left.\Delta \rho=1,000 \mathrm{~kg} / \mathrm{m}^{3}\right)$ and $g$ is the acceleration due to gravity $\left(g=9.81 \mathrm{~m} / \mathrm{s}^{2}\right)$.

The half width of the bulge, $x_{b}$, (or "flexural outer high" [Watts 2001]) is defined as the distance between the edge of the broken plate, taken here to be the base of the crustal root $(260 \mathrm{~km}$ offset on Figure 6.4 c.), and the highest point of the flexure bulge. There are three options to consider for the high point of the bulge:

1. The high point in the lower-crust interface (at $170 \mathrm{~km}$ offset and labelled Lc on Figure 6.4 c.), $x_{b}=90 \mathrm{~km}$.

2. The pinching point of the Pliocene sediments (black arrows and $120 \mathrm{~km}$ offset on Figure 6.4 a.), which is also the mid point between the two other high points, $x_{b}=140 \mathrm{~km}$.

3. The high point in the Moho interface (at $80 \mathrm{~km}$ offset and labelled Mh on Figure $6.4 \mathrm{c}$.), $x_{b}=180 \mathrm{~km}$.

The results of the flexural calculations are summarised in Table 6.1. Out of the range offered, the flexural values of the mid point are preferred for several reasons. Not only is it the median point between the other high points, but it is also derived from MCS stack, which is the most robust and least biased source of information of the three proposed in Figure 6.4.

\begin{tabular}{r|c||c|c|c}
$\begin{array}{r}\text { High } \\
\text { points }\end{array}$ & $\begin{array}{c}x_{b} \\
(\mathrm{~km})\end{array}$ & $\begin{array}{c}\alpha \\
(\mathrm{km})\end{array}$ & $\begin{array}{c}D \\
(\mathrm{~N} . \mathrm{m})\end{array}$ & $\begin{array}{c}T e \\
(\mathrm{~km})\end{array}$ \\
\hline \hline $\mathrm{Lc}$ & 90 & 57.3 & $2.6 .10^{22}$ & 7.8 \\
Median & 140 & 89.1 & $1.5 .10^{23}$ & 14.1 \\
$\mathrm{Mh}$ & 180 & 114.6 & $4.2 .10^{23}$ & 19.7
\end{tabular}

Table 6.1: Table of the results of the flexural calculation considering three different half width of the bulge, $x_{b}$ : Lc, Median and Mh. The variables are the flexural parameter, $\alpha$, the flexural rigidity, $D$, and the elastic thickness, $T_{e}$.

Consequently, a flexural parameter, $\alpha$, of $89.1 \mathrm{~km}$, an elastic thickness, Te, of $14.1 \mathrm{~km}$ and a flexural rigidity, $D$, of $1.5 .10^{23}$ N.m are proposed for the Australian Plate. The value of elastic thickness, $T e=14.1 \mathrm{~km}$, is consistent with the results of Harrison [1999] who estimated $T e=15 \pm 5 \mathrm{~km}$ for the Australian plate along line $02 \mathrm{~W}$. 


\subsection{Inversion tomography versus forward modelling}

Seismic data are valuable resources for investigating the internal structure and composition of the Earth. Traveltime inversion methods are increasingly popular as a means to image the subsurface structures at all length scales [Rawlinson and Sambridge 2003]. One of their main advantages is their ability to deal with a large amount of observations and their capacity to produce solutions relatively rapidly. Many algorithms have been developed to produce tomographic sections of the subsurface in 2D [van Avendonk et al. 2001, Zelt and Smith 1992] and 3D [Eberhart-Phillips and Bannister 2002, Hole 1992, Rawlinson and Sambridge 2003]. The 3D inverse methods are becoming more common place, as they allow the insertion of complex survey geometry and minimise the impact of out-of-plane effects that 2D methods may experience [Zelt and Zelt 1998].

In theory, the quality of a solution model is relative to the quality and resolution of the dataset. Hence, for this study, a model of exceptionally high resolution and accuracy should be expected. However, this is not necessarily the case as the limitations of the tomography code and inversion strategy substantially reduced the resolution of the solution model. Would a forward modelling method have resulted in a more robust solution? Does forward modelling overcome the limitations of inverse modelling? The following discussion intends to critically contrast the two types of modelling, and determine whether a forward modelling step can complement an inverse modelling strategy. Two key aspects are addressed here, the method assumptions and the non-uniqueness.

\section{Method assumptions}

Both types of modelling are affected by their ray-tracing assumptions. Many modelling methods are based on the assumption that the earth can be approximated as being isotropic and linear (i.e. having slowly varying velocity gradients). However, the linearity assumption, which may be sufficient for earthquake tomography, cannot satisfy active seismic data because of the heterogeneity of crustal velocity structure [Rawlinson and Sambridge 2003]. Additionally, modelling methods generally fail to resolve sharp and discontinuous structures such as faults and lithology contrasts, which may lead to erroneous results [Watanabe et al. 1996].

Conversely, more pervasive and complex structures, such as the interface between continental and oceanic lithospheres and the Moho velocity discontinuity, are modelled as an interface. This simplification is used for the convenience of defining reflecting interfaces to allow for the inversion of reflection phases. This results in an illusion of high resolution of the solution model and a geologically unrealistic model sharpness [Zelt et al. 2003]. Finally, since the seismic ray samples physical properties along its propagation path, the model's robustness will depend on the method's ability to accurately parameterise that raypath (e.g. node grids, interface smoothness).

\section{Non-uniqueness}

A key aspect of modelling in a wider sense is the inherent non-uniqueness of the solution model, meaning that multiple models will have a satisfactory fit to the data. This is illustrated in chapter 5 by the similarity of RMS traveltime residual reduction between the objective and the subjective solution models. This hinders considerably the credibility of any proposed model and, therefore, justification for the choice of the preferred model needs to be supplied. This can be done, for example, by analysis the RMS traveltime residuals of the solution models. 
Regardless of the size of the dataset, the inverse method will make the model converge towards any possible local minima in the model space. This means that, without structural knowledge of the model area, finding a geologically realistic solution by forward modelling is virtually impossible, especially for large datasets [Zelt 1999]. Therefore, for both modelling types, there is a need for subjectivity at the onset of modelling.

The most efficient way to reduce this non-uniqueness is to include geological information. In inversion modelling, this will narrow the convergence possibilities to a local minimum that is geologically plausible. Hence, the solution model of the inverse method will be dependent on the choice of the starting model. This is also valid for forward modelling in that the solution model will depend on the knowledge and theories of the modeller. However, the inclusion of inappropriate a priori information will lead to incorrect model structure [Zelt et al. 2003].

Another way of reducing the non-uniqueness in inverse modelling is to restrain the model's variation by apply smoothing and/or damping parameters to the inversion process. However, this reduces the model's resolution and results in a smoother, more conservative solution model. This resolution loss is not valid in forward modelling as a geologically sensible solution can easily be conserved throughout modelling. More geological information may be resolved by forward modelling because of the possibility of including isolated, yet robust picks that would be downweighted by an inverse method. However, forward modelling can easily become the arbitrary adjustment of the model in any necessary way to reduce the data misfit. One significant advantage of inverse modelling is its time efficient capability of generating alternative models. In forward modelling, time constraints and the time-consuming nature of trial-and-error modelling do not allow for an extensive exploration of the model space [Zelt 1999].

Inverse modelling is a powerful tool to model subsurface structure provided that the input observations are from conventional and well identified seismic phases and that the modelled structures are simple. This is also its main disadvantage. Given the geometry of the crustal root underlying the Southern Alps, only back-scattered rays can give coverage from the deepest part of the thickened crust [Scherwath et al. 2003]. Also, the subsurface structure (both crustal and sedimentary) of the central South Island is complex and heterogeneous. Hence, the associated traveltime picks are difficult to identify and cannot be dealt with by inverse modelling and the solution model will be incomplete and/or will include spurious results. Inverse modelling would be widely preferred over forward modelling if the integrity and expertise of the modeller could be included. This has, alas, not yet been achieved.

The inversion method used in this project, FMTOMO, provided a geologically reasonable solution model. However, the conservativeness of the preferred solution model suggests that forward modelling may have yielded a more detailed and sharper solution model. The inability to reach a suitable solution model with a dense dataset of excellent quality highlights the limitations of inverse modelling and tomography in general. Nonetheless, useful and complementary knowledge can be derived from both modelling types. Therefore, the consecutive use of both inverse and forward modelling, as done by Scherwath et al. [2003], may prove to be beneficial and should be the preferred methodology if the time constraints allow for it.

\subsection{Summary of the findings - conclusions}

A 3D seismic traveltime tomography method is used in this research project to investigate the evolution of the continental collision zone between the lines 01 and 02 in the central South Island. The features observed in the proposed model are consistent with geological evidence as well as with results from previous studies. These features are described hereafter: 
- Normal crustal velocities $(5.5 \mathrm{~km} / \mathrm{s}$ close to the surface and $6.3 \mathrm{~km} / \mathrm{s}$ at the bottom of the crust) on either side of the collision zone starting about $100 \mathrm{~km}$ to the northwest and $80 \mathrm{~km}$ to the southeast of the Alpine fault surface trace.

- Lower velocities $(5.7 \mathrm{~km} / \mathrm{s})$ intruding in the basement under the South Westland Basin in the Australian plate to depth of $20 \mathrm{~km}$, which is consistent with the downward flexure of the Australian plate [Scherwath et al. 2003].

- A high velocity body $(6.3 \mathrm{~km} / \mathrm{s})$ is located in the upper $10 \mathrm{~km}$ of the upper-crust, immediately above the thickened crust between the West Coast and the Main Divide of the Southern Alps. This has been interpreted to be a drier, more rigid, schist body [EberhartPhillips and Bannister 2002, Wannamaker et al. 2002]. Its location is thought to extent $60 \mathrm{~km}$ northwest of that found in previous studies [Eberhart-Phillips and Bannister 2002].

- A zone of lower velocities $(5.8 \mathrm{~km} / \mathrm{s}$ reaching $8 \mathrm{~km}$ depth) is observed in the uppermost crust, it is interpreted as a back-shearing structure through which metamorphic fluids, generated in the thickened part of crust, escape towards the surface. This weaker zone is modelled with much more resolution than previous coarser-scale 3D tomography [Eberhart-Phillips and Bannister 2002] and fine scale explosion seismic studies [Stern et al. 2001].

- A zone of reduced velocities $(5.9-6.1 \mathrm{~km} / \mathrm{s})$ is observed to the bottom of the thickened crust to the southeast of the Alpine fault. This LVZ is consistent with the AFZ [Scherwath et al. 2003, Stern et al. 2001] and is thought to be weakened by high fluid pressure.

Other features were directly observable from the proposed model. They include the evolution of anisotropy of the upper-mantle and that of the geometry of the Moho:

1. The upper-mantle velocities seem to increase from $7.8 \mathrm{~km} / \mathrm{s}$ under line 01 to $8.3 \mathrm{~km} / \mathrm{s}$ under line 02 suggesting a reduction of the upper-mantle anisotropy towards the south. However, the short wavelength of the velocity structure under line 02 suggests that this feature may be a modelling artefact.

2. The Moho interface appears to vary smoothly between line 02 (42 km depth) and line 01 (35 km depth). However, given the few interface inversions steps that were performed, this is dependent on the interface interpolation rather than to the inversion process itself.

Furthermore, an apparent flexural signature in the Australian plate is observed along line 01. A flexural analysis yielded a flexural parameter, $\alpha$, of about $89 \mathrm{~km}$, an elastic thickness, Te, of $14 \mathrm{~km}$ and a flexural rigidity, $D$, of $1.5 .10^{23} \mathrm{~N} . \mathrm{m}$. These results are consistent with previous results along line 02 Harrison [1999].

The tomography method used in this project has proven to be complementary in that it has brought out features that were not seen by regional scale passive seismic tomography nor local scale explosion seismic. However, the interface inversion process remains to be perfected in the software. Nonetheless, the velocity inversion is satisfactory and the resulting 3D crustal velocity model of the central South Island will be used as reference model for the microearthquake source relocation procedure of the Southern Alps Microearthquake Borehole Array (SAMBA) project. 


\section{Appendix A}

\section{Traveltime picks datasets breakdown}

This Appendix presents the detailed breakdown of the traveltime pick datasets used for this projec. The total traveltime pick dataset (Section A.3) is composed of the author's picks of the cross-line West Coast dataset (Section A.1) as well as two additional picks from other source (Section A.2), they are:

1. The in-line T1 pick dataset from van Avendonk et al. [2004] (Section A.2.1)

2. The in-line T2 pick dataset from Scherwath et al. [2003] (Section A.2.2)

\section{A.1 Author's picks, cross-line West Coast}

\section{A.1.1 Traveltime picks}

A total of 98,884 traveltime picks were picked by the author. The phase breakdown for each dataset is summarised in Table A.1. To prevent the overshadowing of a sparse dataset by a dense one, regardless of their robustness, the datasets were decimated so that the spatial density of the picks matches that of the least dense dataset [Zelt 1999]. In this case, the onshore dataset is the least dense one with a maximum of a pick every $400 \mathrm{~m}$.

\begin{tabular}{c|c|c|c|c} 
Phases & $01 \mathrm{~W} \rightarrow \mathrm{T} 2$ & $02 \mathrm{~W} \rightarrow \mathrm{T} 1$ & $03 \mathrm{~W} \rightarrow \mathrm{T} 1 \& \mathrm{~T} 2$ & $\mathrm{TOTAL}$ \\
\hline $\mathrm{Pg}$ & 4,551 & 4,252 & 27,299 & 36,102 \\
$\mathrm{PlP}$ & 5,580 & 11,094 & $\mathrm{X}$ & 16,674 \\
$\mathrm{PmP}$ & 12,270 & 14,170 & $\mathrm{X}$ & 26,440 \\
$\mathrm{Pn}$ & 9,518 & 10,150 & $\mathrm{X}$ & 19,668 \\
\hline TOTAL & 31,919 & 39,666 & 27,299 & 98,884
\end{tabular}

Table A.1: The onshore-offshore seismic traveltime picks dataset picked by the author for this study arranged by sub-dataset and phase.

The dataset offers a reasonably even coverage of the upper-crust and the upper-mantle velocity structure and the lower-crust and the Moho boundary geometry in between T1 and T2. As much as $75 \%$ of the $\mathrm{Pg}$ traveltime picks originate from the source line $03 \mathrm{~W}, 53 \%$ of the picks constrain the crust ( $36 \%$ of $\mathrm{Pg}, 17 \%$ of $\mathrm{PlP}$ ) and $47 \%$ of them constrain the Moho and the upper-mantle (27\% of PmP, $20 \%$ of Pn).picks 


\section{A.2 Additional picks}

A total of 65,164 additional in-line picks from T1 [van Avendonk et al. 2004] and T2 [Scherwath et al. 2003] are added onto this project's dataset. The breakdown of the additional dataset is summarised in Table A.2.

\begin{tabular}{|c|c|c|c|c|c|c|c|c|c|}
\hline Seismic & \multicolumn{4}{|c|}{ v. Avendonk } & \multicolumn{4}{|c|}{ Scherwath } & TOTAL \\
\hline Phases & $\mathrm{OO}$ & $\mathrm{OB}$ & $\mathrm{ON}$ & Total & $\mathrm{OO}$ & OB & $\mathrm{ON}$ & Total & PICKS \\
\hline $\mathrm{Pg}$ & 8,396 & 2,058 & 3,721 & 14,175 & 3,976 & 755 & 1,629 & 6,360 & 20,535 \\
\hline $\mathrm{PlP}$ & 12,383 & 692 & 3,231 & 16,306 & 193 & $\mathrm{X}$ & 1,233 & 1,426 & 17,732 \\
\hline $\mathrm{PmP}$ & 9,783 & 1,528 & 2,564 & 13,875 & 4,566 & $\mathrm{X}$ & 439 & 5,005 & 18,880 \\
\hline $\mathrm{Pn}$ & 3,167 & 69 & X & 3,236 & 4,781 & $\mathrm{X}$ & $\mathrm{X}$ & 4,781 & 8,017 \\
\hline TOTAL & 33,729 & 4,347 & 9,516 & 47,592 & 13,516 & 755 & 3,301 & 17,572 & \\
\hline PICKS & & 47,592 & & & & 7,572 & & & 65,164 \\
\hline
\end{tabular}

Table A.2: The additional seismic traveltime picks dataset for this study arranged by authorial source, seismic component and phase. The additional picks originate from van Avendonk et al. [2004] and Scherwath et al. [2003]. OO Onshore-Offshore $\boldsymbol{O B}$ Ocean Bottom ON Onshore.

\section{A.2.1 van Avendonk et al. [2004], in-line T1}

Firstly, 47.592 picks from line 01 are received from Harm van Avendonk (30\% of $\mathrm{Pg}, 34 \%$ of $\mathrm{PlP}, 29 \%$ of $\mathrm{PmP}$ and $7 \%$ of $\mathrm{Pn})$. All phases are well represented throughout the onshoreoffshore dataset (25\% of $\mathrm{Pg}, 37 \%$ of $\mathrm{PlP}, 29 \%$ of $\mathrm{PmP}$ and $9 \%$ of $\mathrm{Pn}$ ). In the ocean-bottom dataset there are significantly less $\mathrm{PlP}$ and $\mathrm{Pn}$ picks (16\% and $1.6 \%$, respectively) than $\mathrm{Pg}$ or $\mathrm{PmP}$ (47.4\% and 35\%, respectively), resulting in a limited constraining of the lower-crust boundary geometry and upper-mantle velocity structure under the offshore stations of line 01W. Furthermore, there is no Pn pick in the onshore dataset due to offsets inferior to the cross-over distance (39\% of $\mathrm{Pg}, 34 \%$ of $\mathrm{PlP}$ and $27 \%$ of $\mathrm{PmP}$ ). This results in an unconstrained upper-mantle velocity structure under the onshore stations of line $01 \mathrm{~W}$.

\section{A.2.2 Scherwath et al. [2003], in-line T2}

Also, 17,572 picks from line 02 are received from Martin Scherwath (36\% of Pg, 9\% of PlP, 28\% of $\mathrm{PmP}$ and $27 \%$ of $\mathrm{Pn}$ ). In the onshore-offshore dataset PlP is significantly under represented (less than $1.5 \%$ of PlP, $29.5 \%$ of $\mathrm{Pg}, 34 \%$ of $\mathrm{PmP}$ and $35 \%$ of $\mathrm{Pn}$ ). The lower-crustal boundary under line $02 \mathrm{~W}$ is therefore lightly constrained. There are only $755 \mathrm{Pg}$ picks in the oceanbottom dataset, implying that, there are no constraints underneath the offshore stations of line 02W. There are no Pn picks in the onshore dataset $49 \%$ of $\mathrm{Pg}, 38 \%$ of PlP and $13 \%$ of $\mathrm{Pn})$, hence, there are no constraints for the upper-mantle velocity structure under the onshore stations of line $02 \mathrm{~W}$. 


\section{A.3 Total pick dataset}

The three datasets sum up to 164,048 traveltime picks and the breakdown of the dataset is summarised in Table A.3. The picks of the author represent $60 \%$ of the final dataset whereas the in-line datasets represent only $29 \%$ and $11 \%$, respectively. Except for Pn (17\% of the dataset), all phases are reasonably evenly represented (34\% of $\mathrm{Pg}, 21 \%$ of PIP and $28 \%$ of $\mathrm{PmP}$ ) enabling an adequate sampling of the features of interest within the model domain.

\begin{tabular}{c|c|c|c|c} 
Phases & Brikke & v. Avendonk & Scherwath & TOTAL \\
\hline Pg & 36,102 & 14,175 & 6,360 & 56,637 \\
PIP & 16,674 & 16,306 & 1,426 & 34,406 \\
PmP & 26,440 & 13,875 & 5,005 & 45,320 \\
Pn & 19,668 & 3,236 & 4,781 & 27,685 \\
\hline TOTAL & 98,884 & 47,592 & 17,572 & 164,048
\end{tabular}

Table A.3: The total seismic traveltime picks dataset for this study arranged by authorial source and phase.

\section{A.3.1 Pick uncertainties}

One value of pick uncertainty was assigned on a receiver gather per receiver gather basis due to reasons discussed in Chapter 6. The traveltimes uncertainties are presented in Table A.4 with the corresponding receiver and shot line. The West Coast cross-line dataset was processed for this project and includes the following:

- Receivers along T1 recording shots of line $02 \mathrm{~W}$

- Receivers along T2 recording shots of line $01 \mathrm{~W}$

- Receivers along T1 and T2 recording shots from line 03W

Consequently, the '-' marks in Table A.4 indicate in-line receiver gathers that were not processed for the project. Conversely, a traveltime uncertainty of '0.00' indicates a receiver gather that was processed, but whose information was discarded due to low SNR. 


\begin{tabular}{|c|c|c|c|}
\hline \multirow{2}{*}{$\begin{array}{l}\text { Receiver } \\
\text { Number }\end{array}$} & \multicolumn{3}{|c|}{ Offshore shot lines } \\
\hline & $01 \mathrm{~W}$ & $02 \mathrm{~W}$ & 03W \\
\hline \multicolumn{4}{|c|}{ T1 Receivers } \\
\hline SP01 & - & 0.00 & 0.00 \\
\hline 0028 & - & 0.20 & 0.10 \\
\hline 0048 & - & 0.30 & 0.15 \\
\hline 0072 & - & 0.20 & 0.10 \\
\hline 0096 & - & 0.15 & 0.10 \\
\hline 0120 & - & 0.10 & 0.10 \\
\hline 0144 & - & 0.20 & 0.10 \\
\hline 0172 & - & 0.15 & 0.10 \\
\hline 0192 & - & 0.15 & 0.10 \\
\hline 0216 & - & 0.00 & 0.00 \\
\hline SP03 & - & 0.10 & 0.10 \\
\hline 0288 & - & 0.15 & 0.15 \\
\hline 0304 & - & 0.10 & 0.10 \\
\hline 0336 & - & 0.15 & 0.00 \\
\hline SP04 & - & 0.20 & 0.10 \\
\hline 0380 & - & 0.20 & 0.10 \\
\hline 0408 & - & 0.15 & 0.10 \\
\hline 0432 & - & 0.15 & 0.10 \\
\hline 0460 & - & 0.10 & 0.20 \\
\hline 0480 & - & 0.10 & 0.10 \\
\hline 0500 & - & 0.10 & 0.10 \\
\hline 0532 & - & 0.15 & 0.10 \\
\hline 0552 & - & 0.15 & 0.10 \\
\hline 0564 & - & 0.10 & 0.15 \\
\hline 0576 & - & 0.15 & 0.10 \\
\hline SP06 & - & 0.20 & 0.10 \\
\hline 0600 & - & 0.20 & 0.10 \\
\hline 0604 & - & 0.10 & 0.10 \\
\hline 0624 & - & 0.30 & 0.00 \\
\hline 0632 & - & 0.00 & 0.00 \\
\hline 0644 & - & 0.10 & 0.10 \\
\hline 0660 & - & 0.20 & 0.15 \\
\hline 0668 & - & 0.00 & 0.00 \\
\hline 0684 & - & 0.20 & 0.15 \\
\hline SP07 & - & 0.10 & 0.10 \\
\hline 0708 & - & 0.15 & 0.10 \\
\hline 0720 & - & 0.15 & 0.10 \\
\hline 0728 & - & 0.15 & 0.10 \\
\hline 0744 & - & 0.10 & 0.00 \\
\hline 0756 & - & 0.15 & 0.10 \\
\hline
\end{tabular}

Table A.4: Table of the traveltime pick uncertainties for the receiver gathers processed for this study. The receiver and shot line nomenclatures are that of the SIGHT project and the values are in seconds. Part 1 of 5. 


\begin{tabular}{l||l|l|l|l}
\multicolumn{2}{c||}{ Receiver } & \multicolumn{3}{l}{ Offshore shot lines } \\
Number & 01W & $02 \mathrm{~W}$ & $03 \mathrm{~W}$ \\
\hline \hline \multicolumn{3}{c}{ T1 Receivers } \\
\hline SP08 & - & 0.07 & 0.10 \\
0780 & - & 0.15 & 0.10 \\
0792 & - & 0.15 & 0.10 \\
0804 & - & 0.10 & 0.10 \\
0816 & - & 0.15 & 0.10 \\
0828 & - & 0.10 & 0.10 \\
0840 & - & 0.10 & 0.10 \\
0852 & - & 0.10 & 0.10 \\
0864 & - & 0.10 & 0.15 \\
0904 & - & 0.10 & 0.10 \\
0912 & - & 0.10 & 0.10 \\
0924 & - & 0.10 & 0.10 \\
0936 & - & 0.10 & 0.10 \\
0944 & - & 0.10 & 0.10 \\
0960 & - & 0.10 & 0.10 \\
SP10 & - & 0.10 & 0.15 \\
0984 & - & 0.10 & 0.15 \\
0996 & - & 0.00 & 0.00 \\
1008 & - & 0.10 & 0.15 \\
1020 & - & 0.15 & 0.15 \\
1036 & - & 0.10 & 0.10 \\
SP11 & - & 0.10 & 0.10 \\
1052 & - & 0.10 & 0.10 \\
1072 & - & 0.10 & 0.10 \\
1084 & - & 0.10 & 0.00 \\
1096 & - & 0.10 & 0.20 \\
1112 & - & 0.10 & 0.00 \\
1124 & - & 0.10 & 0.15 \\
1136 & - & 0.10 & 0.05 \\
1156 & - & 0.20 & 0.12 \\
1184 & - & 0.30 & 0.00 \\
1196 & - & 0.00 & 0.00 \\
1204 & - & 0.00 & 0.00 \\
1216 & - & 0.00 & 0.00 \\
1224 & - & 0.20 & 0.10 \\
1236 & - & 0.00 & 0.00 \\
1240 & - & 0.20 & 0.10 \\
1248 & - & 0.15 & 0.15 \\
& - & 0.00 & 0.00 \\
1284 & - & 0.15 & 0.15 \\
\hline
\end{tabular}

Table A.4: Table of the traveltime pick uncertainties for the receiver gathers processed for this study. The receiver and shot line nomenclatures are that of the SIGHT project and the values are in seconds. Part 2 of 5. 


\begin{tabular}{|c|c|c|c|}
\hline \multirow{2}{*}{$\begin{array}{l}\text { Receiver } \\
\text { Number }\end{array}$} & \multicolumn{3}{|c|}{ Offshore shot lines } \\
\hline & $01 \mathrm{~W}$ & $02 \mathrm{~W}$ & $03 \mathrm{~W}$ \\
\hline \multicolumn{4}{|c|}{$\begin{array}{ll}\text { T1 Receivers }\end{array}$} \\
\hline 1308 & - & 0.15 & 0.15 \\
\hline 1320 & - & 0.00 & 0.00 \\
\hline 1324 & - & 0.12 & 0.15 \\
\hline 1328 & - & 0.00 & 0.00 \\
\hline 1332 & - & 0.10 & 0.10 \\
\hline 1336 & - & 0.15 & 0.20 \\
\hline 1344 & - & 0.10 & 0.15 \\
\hline 1360 & - & 0.10 & 0.15 \\
\hline 1372 & - & 0.10 & 0.20 \\
\hline SP14 & - & 0.10 & 0.20 \\
\hline 1396 & - & 0.10 & 0.20 \\
\hline 1404 & - & 0.10 & 0.15 \\
\hline 1416 & - & 0.20 & 0.10 \\
\hline 1428 & - & 0.00 & 0.05 \\
\hline 1440 & - & 0.10 & 0.15 \\
\hline 1452 & - & 0.20 & 0.10 \\
\hline 1464 & - & 0.20 & 0.10 \\
\hline SP15 & - & 0.12 & 0.15 \\
\hline 1488 & - & 0.10 & 0.30 \\
\hline 1500 & - & 0.00 & 0.00 \\
\hline SP16 & - & 0.15 & 0.10 \\
\hline \multicolumn{4}{|c|}{ T2 Receivers } \\
\hline 2000 & 0.00 & - & 0.00 \\
\hline 2024 & 0.00 & - & 0.05 \\
\hline SP21 & 0.20 & - & 0.10 \\
\hline 2072 & 0.15 & - & 0.15 \\
\hline 2096 & 0.20 & - & 0.15 \\
\hline 2120 & 0.30 & - & 0.10 \\
\hline 2144 & 0.00 & - & 0.00 \\
\hline SP22 & 0.30 & - & 0.20 \\
\hline 2196 & 0.20 & - & 0.15 \\
\hline 2216 & 0.20 & - & 0.15 \\
\hline 2240 & 0.00 & - & 0.00 \\
\hline 2264 & 0.15 & - & 0.10 \\
\hline 2288 & 0.20 & - & 0.10 \\
\hline SP23 & 0.15 & - & 0.10 \\
\hline 2336 & 0.15 & - & 0.15 \\
\hline 2360 & 0.10 & - & 0.10 \\
\hline 2384 & 0.15 & - & 0.15 \\
\hline 2404 & 0.15 & - & 0.10 \\
\hline 2432 & 0.10 & - & 0.20 \\
\hline
\end{tabular}

Table A.4: Table of the traveltime pick uncertainties for the receiver gathers processed for this study. The receiver and shot line nomenclatures are that of the SIGHT project and the values are in seconds. Part 3 of 5. 


\begin{tabular}{l||l|l|l|l}
\multicolumn{1}{l|}{ Receiver } & \multicolumn{3}{|c}{ Offshore shot lines } \\
Number & $01 \mathrm{~W}$ & $02 \mathrm{~W}$ & $03 \mathrm{~W}$ \\
\hline \hline \multicolumn{4}{c}{ T2 Receivers } \\
\hline 2456 & 0.10 & - & 0.10 \\
2480 & 0.30 & - & 0.10 \\
2500 & 0.30 & - & 0.10 \\
2528 & 0.10 & - & 0.10 \\
2552 & 0.15 & - & 0.10 \\
2572 & 0.10 & - & 0.10 \\
SP24 & 0.10 & - & 0.10 \\
2628 & 0.10 & - & 0.10 \\
2648 & 0.10 & - & 0.15 \\
2672 & 0.10 & - & 0.20 \\
2688 & 0.10 & - & 0.00 \\
2720 & 0.10 & - & 0.10 \\
2744 & 0.10 & - & 0.10 \\
2756 & 0.10 & - & 0.10 \\
2768 & 0.20 & - & 0.07 \\
2780 & 0.10 & - & 0.05 \\
2792 & 0.10 & - & 0.10 \\
2808 & 0.00 & - & 0.10 \\
2820 & 0.07 & - & 0.15 \\
2832 & 0.10 & - & 0.10 \\
2840 & 0.20 & - & 0.10 \\
2852 & 0.10 & - & 0.10 \\
2864 & 0.15 & - & 0.15 \\
2876 & 0.15 & - & 0.15 \\
2888 & 0.15 & - & 0.05 \\
SP25 & 0.10 & - & 0.20 \\
2912 & 0.10 & - & 0.20 \\
2920 & 0.15 & - & 0.15 \\
2936 & 0.10 & - & 0.10 \\
2948 & 0.15 & - & 0.10 \\
2960 & 0.00 & - & 0.00 \\
2972 & 0.10 & - & 0.15 \\
2996 & 0.10 & - & 0.20 \\
3008 & 0.10 & - & 0.10 \\
3020 & 0.10 & - & 0.10 \\
3028 & 0.20 & - & 0.10 \\
3040 & 0.10 & - & 0.30 \\
3052 & 0.10 & - & 0.20 \\
3064 & 0.10 & - & 0.00 \\
3076 & 0.15 & - & 0.10 \\
& & &
\end{tabular}

Table A.4: Table of the traveltime pick uncertainties for the receiver gathers processed for this study. The receiver and shot line nomenclatures are that of the SIGHT project and the values are in seconds. Part 4 of 5. 


\begin{tabular}{l||c|c|c|c}
\multicolumn{1}{l||}{ Receiver } & \multicolumn{3}{c}{ Offshore shot lines } \\
Number & $01 \mathrm{~W}$ & $02 \mathrm{~W}$ & $03 \mathrm{~W}$ \\
\hline \hline \multicolumn{4}{c}{ T2 Receivers } \\
\hline 3092 & 0.15 & - & 0.10 \\
3104 & 0.00 & - & 0.00 \\
3116 & 0.10 & - & 0.10 \\
3128 & 0.10 & - & 0.10 \\
3140 & 0.10 & - & 0.10 \\
3152 & 0.10 & - & 0.10 \\
3156 & 0.15 & - & 0.10 \\
SP26 & 0.15 & - & 0.10 \\
3184 & 0.10 & - & 0.10 \\
3188 & 0.10 & - & 0.10 \\
3208 & 0.00 & - & 0.00 \\
3220 & 0.10 & - & 0.10 \\
3232 & 0.10 & - & 0.10 \\
3240 & 0.15 & - & 0.15 \\
3284 & 0.20 & - & 0.10 \\
3320 & 0.10 & - & 0.15 \\
3328 & 0.10 & - & 0.15 \\
3340 & 0.15 & - & 0.15 \\
3376 & 0.15 & - & 0.00 \\
3384 & 0.20 & - & 0.15 \\
3396 & 0.00 & - & 0.15 \\
3408 & 0.00 & - & 0.15 \\
3456 & 0.30 & - & 0.15 \\
3484 & 0.00 & - & 0.15 \\
3500 & 0.20 & - & 0.50 \\
3528 & 0.20 & - & 0.10 \\
3536 & 0.20 & - & 0.15 \\
3548 & 0.20 & - & 2.00 \\
3560 & 0.20 & - & 0.20 \\
SP27 & 0.30 & - & 0.10 \\
& & &
\end{tabular}

Table A.4: Table of the traveltime pick uncertainties for the receiver gathers processed for this study. The receiver and shot line nomenclatures are that of the SIGHT project and the values are in seconds. Part 5 of 5. 


\section{Appendix B}

\section{Dataset consistency}

The seismic picks dataset originates from three authorial sources wherein different geometry and nomenclature conventions are applied. This Appendix presents several consistency steps that are taken to reduce the subjectivity and enhance the coherency of the dataset.

\section{B.1 Offshore sources and receivers}

\section{Positioning}

\section{Offshore shots}

The land acquisition report of the SIGHT project [Scherwath et al. 1996] provides the latitudes and longitudes (datum World Geodetic System of 1984 (WGS84)) of every hundredth airgun shot. For an easier management of the coordinates, the location of every hundredth shot are converted to New Zealand Map Grid (NZMG) easting and northing (datum New Zealand Geodetic Datum of 1949 (NZGD49)) with the Unix command cs2cs. The location of in-between shots are interpolated. The coordinates are converted back to latitudes and longitudes (WGS84) with the Unix command cs2cs, and with the coordinate conversion function of Microsoft Excel. The difference between the two conversions is nil. The locations of the shots of $01 \mathrm{~W}$ have an average difference of $4.10^{-4}$ and $6.10^{-4}$ degrees in the latitude and longitude, respectively compared to that used by van Avendonk et al. [2004], contributing to an error of $\pm 49 \mathrm{~m}$ and $\pm 50 \mathrm{~m}$ in the northing and easting, respectively. The locations of the shots of $02 \mathrm{~W}$ are converted into offset using the formula from Vincenty [1975] (equation B.1) and compared with the geometry convention of Scherwath [2002]. The average difference is of $\pm 10 \mathrm{~m}$. The Vincenty's formula is used to calculate the great circle distance, $d$, from latitudes and longitudes (WGS84) between a base point $\left(\phi_{s}, \lambda_{s}\right)$ and a forepoint $\left(\phi_{f}, \lambda_{f}\right): d=r . \Delta \hat{\sigma}$, where $r$ is the radius of the Earth $(6371 \mathrm{~km})$, and $\Delta \hat{\sigma}$ the spherical angular difference defined as follows:

$$
\Delta \hat{\sigma}=\arctan \left\{\frac{\sqrt{\left(\cos \phi_{f} \sin \Delta \lambda\right)^{2}+\left(\cos \phi_{s} \sin \phi_{f}-\sin \phi_{s} \cos \phi_{f} \cos \Delta \lambda\right)^{2}}}{\sin \phi_{s} \sin \phi_{f}+\cos \phi_{s} \cos \phi_{f} \cos \Delta \lambda}\right\}
$$

With $\Delta \lambda$ being the difference between the longitudes of the points, $\left(\lambda_{s}-\lambda_{f}\right)$. The differences are deemed insignificant. The coordinate values from the Microsoft Excel coordinate conversion function are used for the rest of the study. 


\section{OBS and OBH}

The latitudes and longitudes of the deployment and retrieval positions are given in the cruise report of the SIGHT project [Holbrook and Davey 1996]. A log entry reports a storm on the last few days of the deployment of the ocean bottom instruments. Therefore, it is arguable that instruments may have shifted from their deployment location. Hence the retrieval position of the instruments are used. However, several instruments have no recorded retrieval position (instruments number 26, A2, A4, 20, 19), their deployment location was used. The difference between the deployment and the retrieval locations is of $\pm 500 \mathrm{~m}$ in the easting and/or northing.

The latitude and longitude values are converted to NZMG easting and northing with the Unix command cs2cs. Then these values are converted back to latitudes and longitude using the coordinate conversion functions of Microsoft Excel. The difference is nil. The location of the instruments are compared to that used by van Avendonk et al. [2004] and to the geometry convention of Scherwath [2002]. The differences are negligible. As a matter of consistency, the values of latitude and longitude resulting from the Microsoft Excel coordinate conversion function are considered for the rest of the study.

\section{Bathymetry}

In the same way as for their location, the depth to seabed under the offshore shots is interpolated from the hundredth shot value from the land acquisition report [Scherwath et al. 1996]. The latitudes and longitudes of the offshore shots and receivers are sent to the National Institute of Weather and Atmospheric research (NIWA) where a grid of $250 \mathrm{~m}$ resolution of the New Zealand sea floor is used to get bathymetry at those locations. The resulting dataset is compared with the interpolated depths to basement. The comparison are summarised in Table B.1. The interpolated depth are considered for the rest of the study as they are recorded at the time of the survey.

\begin{tabular}{cccccc} 
Shot Line & $01 \mathrm{~W}$ & $12 \mathrm{~W}$ & $02 \mathrm{~W}$ & $23 \mathrm{~W}$ & $03 \mathrm{~W}$ \\
\hline Mean $(\mathrm{m})$ & -2.5 & 26.9 & -2.3 & -0.3 & -3.5 \\
St Dev $(\mathrm{m})$ & 63 & 45.6 & 68.1 & 39.4 & 54.3 \\
\hline
\end{tabular}

Table B.1: Table of the mean and standard deviation of the bathymetry of the offshore shots in metres.

\section{B.2 Land sources and receivers}

\section{Positioning}

This category includes the land shots, the land receivers for the land shots and the land receivers for the offshore airgun shots. The position, both latitude/longitude and NZMG easting/northing, of these stations is given in the land acquisition report [Scherwath et al. 1996]. The latitude and longitude values are converted into NZMG easting and northing with the Unix command cs2cs and compared to the values in the report. The mean differences, along with the standard deviation, are summarised in Table B.2. 


\begin{tabular}{ccccc} 
Components & Land Rec T1 & Land Rec T2 & Land Shots & Onoff Land Rec \\
\hline Northing $(\mathrm{m})$ & $1.99 \pm 0.24$ & $2.44 \pm 0.19$ & $2.15 \pm 0.25$ & $2.03 \pm 0.49$ \\
Easting $(\mathrm{m})$ & $0.24 \pm 0.36$ & $0.27 \pm 0.51$ & $0.21 \pm 0.41$ & $0.27 \pm 0.32$ \\
\hline
\end{tabular}

Table B.2: Table of the differences in location (NZMG easting and northing) of the land receivers of $T 1$ and $T 2$, the land shots and onshoreoffshore land receivers. The values represent the mean difference and standard deviation between the initial coordinate values and those issued from the Unix conversion.

The NZMG coordinate are converted back into latitudes and longitudes with the Microsoft Excel coordinate conversion function and compared against the geometry conventions of van Avendonk et al. [2004] and Scherwath [2002]. The differences are negligible. The latitude and longitude conversion from the Microsoft Excel function is used for the rest of the study.

\section{Elevation}

The elevation of the land stations [Scherwath et al. 1996] are compared against elevation values estimated from a Digital Elevation Model (DEM) file with the Generic Mapping Tool (GMT) command grdtrack [Wessel and Smith 1998]. The DEM file of the central South Island has a resolution of $25 \mathrm{~m}$. The difference are negligible and the initial values of elevation are considered for the rest of the study.

\section{B.3 MCS stack offset}

To verify the consistency of the offset of the MCS stack, the initial bathymetry profiles of the offshore shot lines [Scherwath et al. 1996] is correlated to the seabed depth sampled from the stacks. Lateral translation is necessary for lines $02 \mathrm{~W}$ and $03 \mathrm{~W}(27 \mathrm{~km}$ to the southeast and $31 \mathrm{~km}$ to the northeast, respectively), and the resulting mean difference and standard deviation between the two bathymetries is summarised in Table B.3.

\begin{tabular}{rccc} 
Shot Line & $01 \mathrm{~W}$ & $02 \mathrm{~W}$ & $03 \mathrm{~W}$ \\
\hline Mean $(\mathrm{m})$ & 13 & 1 & 6 \\
Std Dev $(\mathrm{m})$ & 57 & 80 & 34 \\
\hline
\end{tabular}

Table B.3: Table showing the vertical difference of the correlation of the initial bathymetry and the one sampled from the stacks. 


\section{Appendix C}

\section{Model parameters calibration}

This Appendix details the calibration tests carried out for the determination of model parameters used for the checkerboard testing. Unless otherwise stated, six inversion iterations are performed. A total of six parameters were investigated in three modelling steps:

1. The damping and smoothing factor (Section C.1)

2. The velocity disturbance's amplitude of the node spacing of the velocity grid (Section C.2)

3. The traveltime uncertainty and the number of inversion iterations (Section C.3)

\section{C.1 Damping and smoothing factors}

The damping and smoothing factors control the reference model's perturbation and the solution model's roughness, respectively. The adequate values for the damping and smoothing factors are assessed qualitatively [Rawlinson and Sambridge 2003] in that the preferred values will result in a solution model for which the trade-off between smearing and velocity amplitude recovery is satisfactory.

The node spacing of this checkerboard model is about $8 \mathrm{~km}$, the checkerboard patterns are $32 \mathrm{~km}$ in size (4 nodes) and they have a maximum amplitude of $2.5 \mathrm{~km} / \mathrm{s}$ in the crust (both upperand old oceanic crusts) and $2.0 \mathrm{~km} / \mathrm{s}$ in the upper-mantle (top left plot in Figure C.1 a, left plots in Figure C.1 b and c). A hundred models were computed with individual combinations of values for damping and smoothing (values between 5 and 50 for each parameters).

The solution model with damping and smoothing values of 35 and 30, respectively, produced the best reconstruction of the checkerboard model (top right plot, as compared to the bottom left plot, in Figure C.1 a, right plots in Figures C.1 b and c). Results of this checkerboard test indicate a velocity amplitude recovery of up to $60 \%$ throughout the crust (Layer 2), about $25 \%$ in the lower crust (Layer 3) and down to $10 \%$ in the upper-mantle. Increasing the damping factor results in limiting the smearing and improves the recovery of the pattern's shape. However, it decreases the velocity amplitude recovery. Increasing the smoothing factor results in reducing the recovery of the velocity amplitudes. The smoothing factor has a less pronounced effect than the damping factor as the solution model with the smoothing factor increased to 100 (bottom right plot in Figure C.1 a) shows no improvement from the one with a smoothing value of 30 (top right plot in Figure C.1 a). 

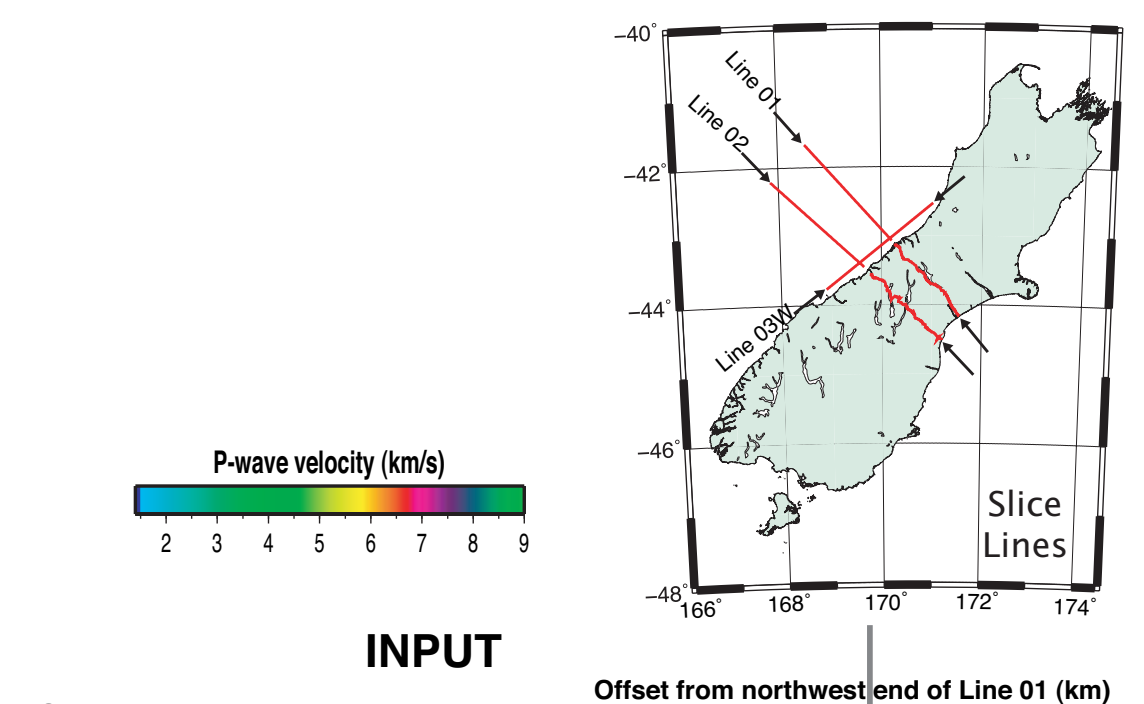

\section{SOLUTION}
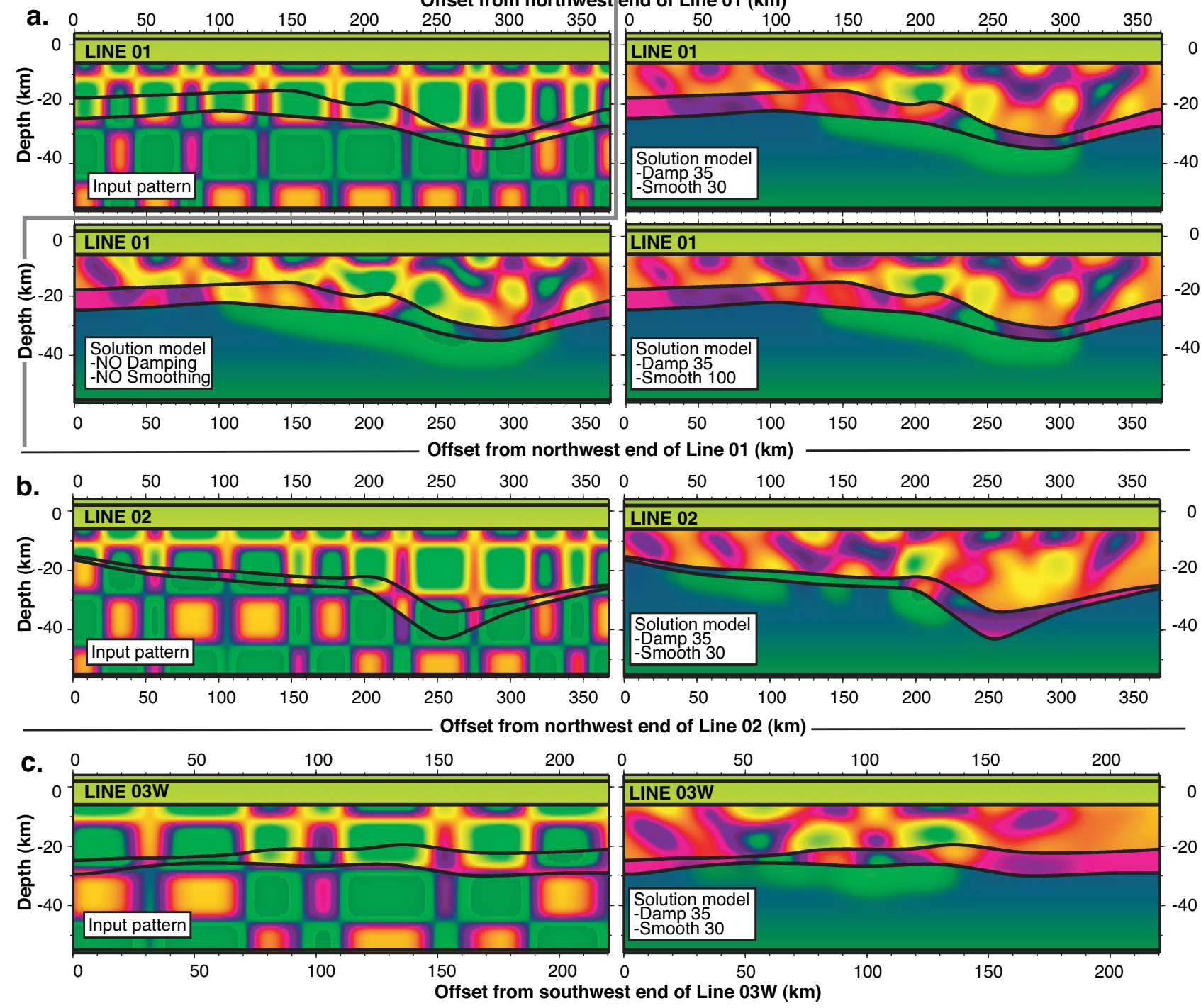

Figure C.1: Results of calibration checkerboard tests for the values of damping and smoothing parameters. The node spacing is $8 \mathrm{~km}$. a. Cross section along line 01 with the input synthetic model (top left plot) and the solution model (top right plot) with damping and smoothing to 35 and 30, respectively. The bottom left plot shows the solution model without damping or smoothing applied and the bottom right plot shows the solution model with the smoothing to a value of 100. b. Cross section along line 02 with the input synthetic model (left plot) and the solution model (right plot) with damping and smoothing to 35 and 30, respectively. c. Cross section along line $03 \mathrm{~W}$ with the input synthetic model (left plot) and the solution model (right plot) with damping and smoothing to 35 and 30, respectively. 


\section{C.2 Amplitude and node spacing}

Additional checkerboard tests are computed to investigate the effect of node spacing and the recovery of different velocity amplitudes. Node spacing govern the trade-off between the resolution of the solution model and the computing time. Two node spacings $(3 \mathrm{~km}$ and $8 \mathrm{~km})$ and two velocity amplitudes $(0.5$ and $1 \mathrm{~km} / \mathrm{s})$ are tested. The pattern size is kept at $32 \mathrm{~km}$ as previous studies have suggested the existence of structures of these dimensions in the area [Scherwath et al. 2003, van Avendonk et al. 2004]. Values of 35 and 30 for damping and smoothing are applied here. The results of this test are shown in Figure C.2.

Velocity amplitude and pattern recovery of $65 \%$ in the crust and $15 \%$ in the upper-mantle is observed for solution models with a node spacing of $8 \mathrm{~km}$ (Figure C.2 c and d). The recovery in the lower crust is less than $10 \%$, however. Patterns of $1 \mathrm{~km} / \mathrm{s}$ amplitude (Figure C.2 d) are better recovered (70\%) than those of $0.5 \mathrm{~km} / \mathrm{s}(60 \%)$ (Figure C.2 c). Significant smearing and a reduced velocity and pattern recovery (15-20\%) is observed for solution models with a node spacing of $3 \mathrm{~km}$ (Figure C.2 a and b). Recovery in the old oceanic crust increases to $30 \%$ with a node spacing of $3 \mathrm{~km}$ and a velocity amplitude of $1 \mathrm{~km} / \mathrm{s}$ (Figure C.2 b); however, the recovery of the upper-mantle is of less than $5 \%$. Models with a node spacing of $3 \mathrm{~km}$ have a computing time of over 42 hours for 6 inversion iterations on an Apple MacBook $2.4 \mathrm{GHz}$ Intel Core Duo 2 and 2GB RAM, as opposed to 6 hours with a $8 \mathrm{~km}$ node spacing. Furthermore, the size of the resolved structures with a $8 \mathrm{~km}$ node spacing (about $30 \mathrm{~km}$ wavelength) and a velocity disturbance of $1 \mathrm{~km} / \mathrm{s}$ corresponds to the expected velocity structure and variation in the region [Scherwath et al. 2003, van Avendonk et al. 2004]. Therefore, a node spacing of $8 \mathrm{~km}$ and $1 \mathrm{~km} / \mathrm{s}$ of velocity disturbance are preferred for the rest of the synthetic modelling.

\section{C.3 Traveltime uncertainty and number of iterations}

The effect of traveltime uncertainty on the solution model is investigated by varying the standard deviation of the introduced Gaussian noise. A velocity amplitude of $1 \mathrm{~km} / \mathrm{s}$, node spacing of $8 \mathrm{~km}$, values of damping and smoothing of 35 and 30, respectively, are used here. Values of 0,100 and $200 \mathrm{~ms}$ of standard deviation of Gaussian noise are tested. A noise content of $0 \mathrm{~ms}$ is unrealistic, yet it allows to assess the recovery ability of the model based solely on the raypath distribution.

In the solution model, amplitude recoveries of $85 \%, 70 \%$ and $60 \%$ are observed in the crust for standard deviation of the Gaussian noise of $0 \mathrm{~ms}$ (Figure C.3 b), $100 \mathrm{~ms}$ (Figure C.3 c) and $200 \mathrm{~ms}$ (Figure C.3 d), respectively. The recovery in the old oceanic crust remains of the order of $50 \%$. That of the upper-mantle is of about $20 \%$ with the horizontal width of the disturbed zone reducing from $330 \mathrm{~km}$ in Figure C.3 b to $290 \mathrm{~km}$ in Figure C.3 d. A value for standard deviation of Gaussian noise of $100 \mathrm{~ms}$ is preferred for the rest of the synthetic tests as this is an adequate value to represent the noise content of active source seismic traveltimes [Zelt 1999]. Furthermore, eleven iterations of tomography inversion were necessary to bring the global traveltime residual down to the level of the standard deviation of the Gaussian noise. 


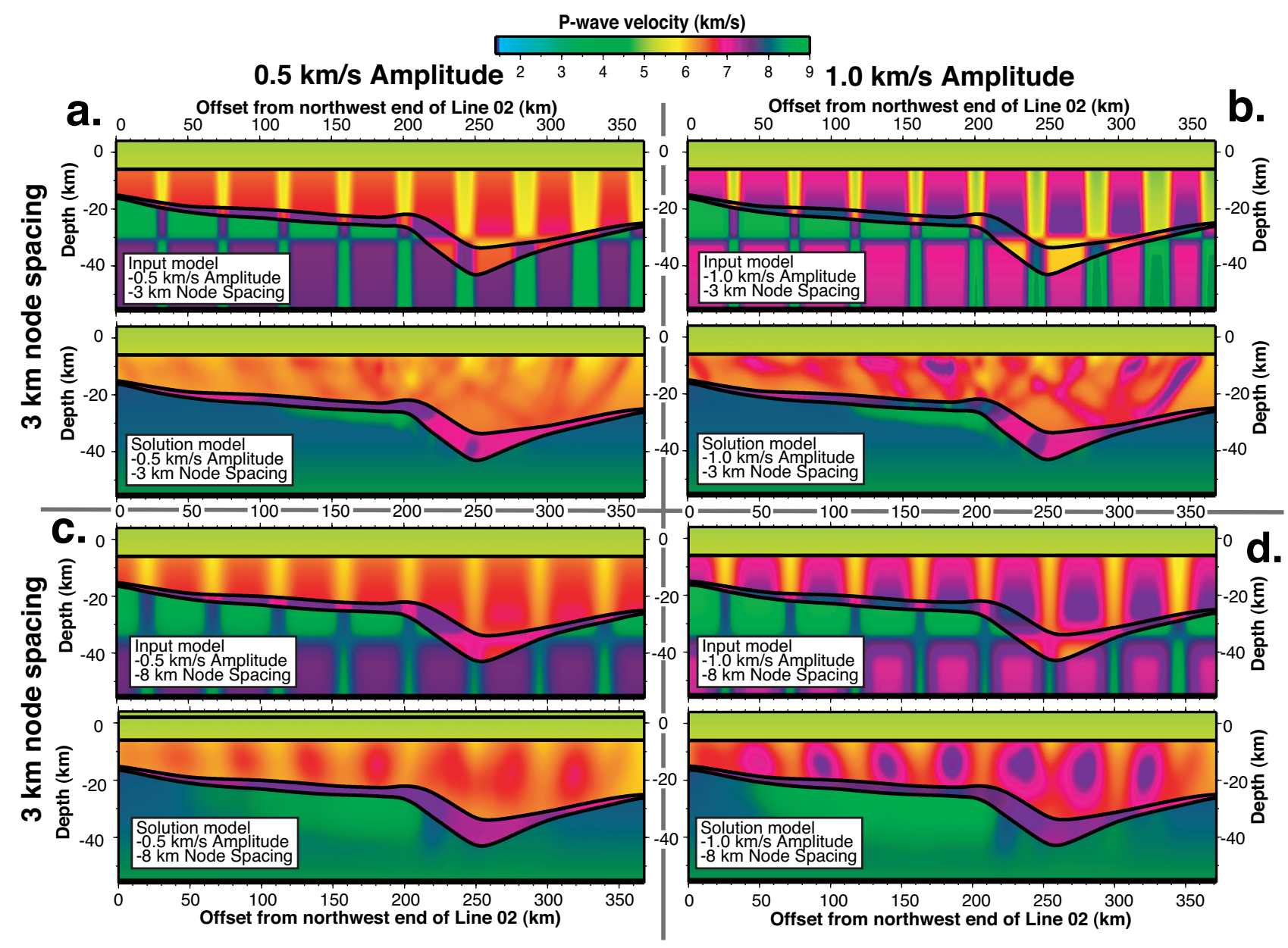

Figure C.2: Results of calibration checkerboard tests assessing the recovery with varying velocity amplitude and node spacings. Values for damping and smoothing of 35 and 30, respectively, are applied. All plots represent cross sections along line 02. $\boldsymbol{a}$. Input (top plot) and solution model (bottom plot) with $0.5 \mathrm{~km} / \mathrm{s}$ velocity amplitude and $3 \mathrm{~km}$ node spacing. $\boldsymbol{b}$. Input (top plot) and solution model (bottom plot) with $1.0 \mathrm{~km} / \mathrm{s}$ velocity amplitude and $3 \mathrm{~km}$ node spacing. $\boldsymbol{c}$. Input (top plot) and solution model (bottom plot) with $0.5 \mathrm{~km} / \mathrm{s}$ velocity amplitude and $8 \mathrm{~km}$ node spacing. d. Input (top plot) and solution model (bottom plot) with $1.0 \mathrm{~km} / \mathrm{s}$ velocity amplitude and $8 \mathrm{~km}$ node

spacing. 

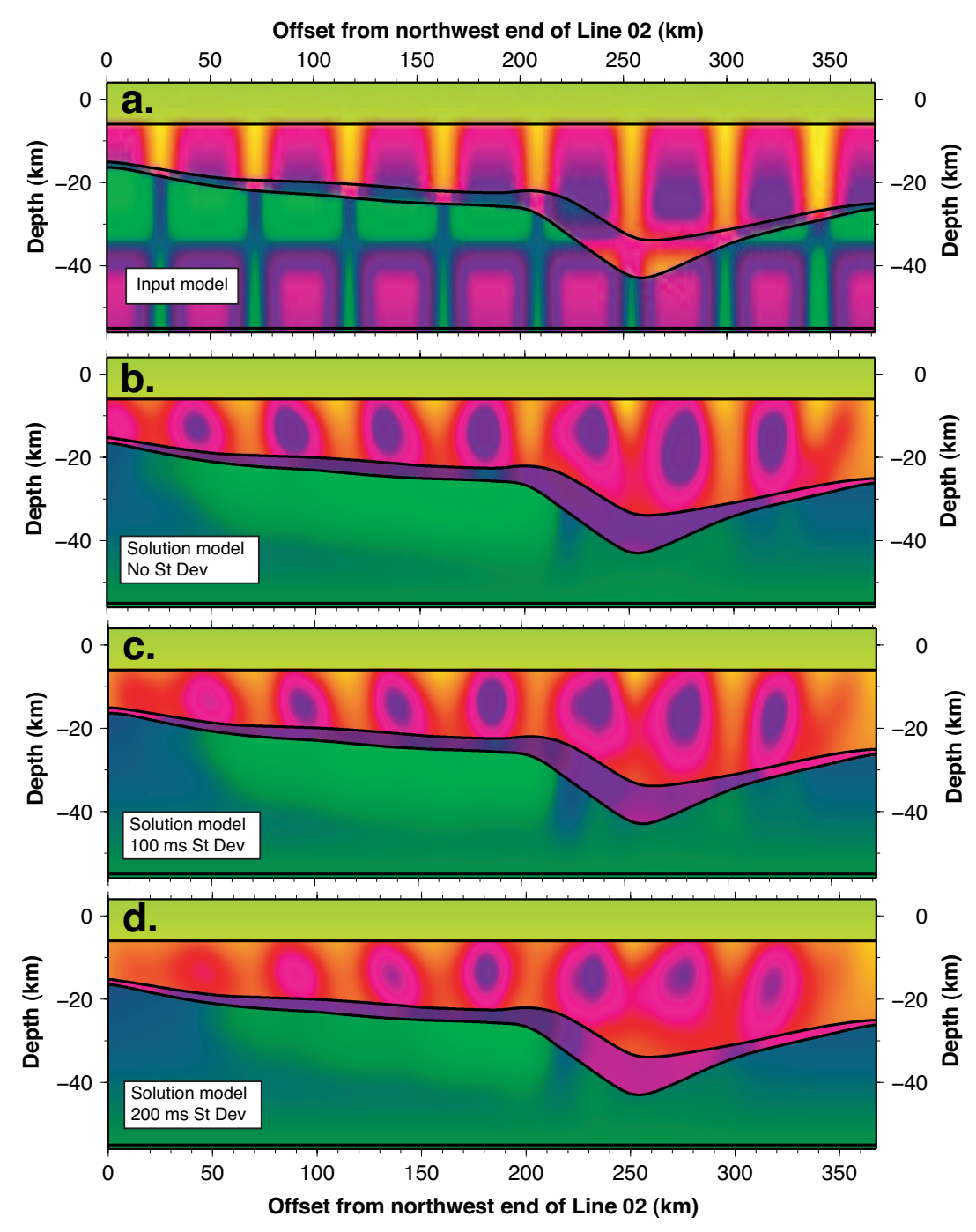

Figure C.3: Results of calibration checkerboard tests assessing the effect of the standard deviation of the traveltimes on the model resolution and number of iterations. A node spacing of $8 \mathrm{~km}$, a velocity amplitude of $1 \mathrm{~km} / \mathrm{s}$ and values for damping and smoothing of 35 and 30, respectively, are used here. The plots represent cross sections along line 02. a. Plot of the input model for this checkerboard test. b. Plot of the solution model excluding standard deviation of Gaussian noise. $c$. Plot of the solution model including a standard deviation of Gaussian noise of $100 \mathrm{~ms}$, similar to that found in active source traveltimes. $\boldsymbol{d}$. Plot of the solution model including a standard deviation of Gaussian noise of $200 \mathrm{~ms}$. 


\section{Appendix D}

\section{Final inversion schemes}

The Matlab [MathWorks 2002] programs that are described in this Appendix are written with the help of Mark Henderson.

\section{D.1 Reference model interpolation}

\section{D.1.1 Interface boundaries}

The lower-crustal and Moho boundaries, which are present in the two published models [Scherwath et al. 2003, van Avendonk et al. 2004], are interpolated throughout the model space. A surface is estimated from the observations using the method of least square collocation [Krarup 1970]. Each interface is modelled by a set of parameters:

- Correlation distance $(\lambda)$ : A characteristic distance over which the surface is expected to undulate in two dimensions and over which the surface is highly correlated.

- Amplitude parameter $(\alpha)$ : A characteristic amplitude for the undulations away from some baseline. This is the standard deviation of the random process.

The correlation distance is defined along two axes: parallel and perpendicular to the Alpine fault. A smaller correlation factor perpendicular to the Alpine fault effectively means that we expect more variation in the perpendicular direction more than parallel to it. A crosscorrelation factor of $95 \%$ between the two interfaces (lower crust and Moho) ensures that they do not overlap during the interpolation and that surfaces vary sympathetically. The values of these parameters are summarised in Table D.1. These values were chosen for the satisfactory interpolation they produced.

\section{D.1.2 Velocity structure}

The velocity structure within the three layers also needs to be interpolated: the three layers are the upper-crust, the lower-crust and the upper-mantle. Here, the problem is more complicated, as the value of the digitised surfaces of equal velocity do not match between the two transects. To model this, an average velocity gradient is estimated from the observations. The interpolation uses a random walk process as a collocated feature. This process effectively tries 


\begin{tabular}{c|c|c|c} 
& \multicolumn{2}{|c|}{$\lambda(\mathrm{km})$} & $\alpha$ \\
& $/ /$ & $\perp$ & $(\mathrm{km})$ \\
\hline L. crust & 75 & 50 & 10 \\
Moho & 75 & 50 & 14
\end{tabular}

Table D.1: Table of the interface interpolation parameters for the lowercrust and Moho interfaces. The parameters are the correlation factor $(\lambda)$ in two dimensions (parallel (//) and perpendicular $(\perp)$ to the Alpine fault) and the amplitude parameter $(\alpha)$.

to reduce the first order derivative of the interpolated surface, while maintaining an adequate fit to the data.

The correlation factor $(\lambda)$ includes three dimensions in this case: the depth dimension as well as the ones mentioned above. The values of the parameters are summarised in Table D.2. The smaller values of correlation factor for the upper-crust mean that we expect significantly more velocity variation in the perpendicular and vertical directions. The larger perpendicular correlation factors for the lower-crust and the upper-mantle reflect the limitation of data coverage in these layers. Again, the values are chosen for the satisfactory result of the interpolation.

\begin{tabular}{c|c|c|c|c} 
& \multicolumn{3}{|c|}{$\lambda(\mathrm{km})$} & $\alpha$ \\
& $/ /$ & $\perp$ & $\mathrm{z}$ & $(\mathrm{km} / \mathrm{s})$ \\
\hline U. crust & 10 & 2 & 2 & 0.1 \\
L. crust & 10 & 10 & 2 & 0.1 \\
U. mantle & 10 & 10 & 2 & 0.1
\end{tabular}

Table D.2: Table of the velocity interpolation parameters for the uppercrust, lower-crust and upper-mantle layers. The parameters are the correlation factor $(\lambda)$ in three dimensions (parallel $(/ /)$, perpendicular $(\perp)$ from the Alpine fault and depth $(z))$ and the amplitude parameter $(\alpha)$.

\section{D.2 Additional inversion features}

\section{D.2.1 Down-weighting scheme}

Scatter of observations due to mistaken picks and unmodelled sediment refraction cause the model to behave badly without outlier detection. Hence, an aberrant observation detection mechanism, such as that described here, is necessary in order for the model to converge towards a realistic solution.

The outliers can be discarded manually, however this may take a considerable amount of time depending on the size of the dataset. An automated scheme may prove significantly more practical and effective. Each observation is compared to the standard deviation of the dataset, if the observation is aberrant, it is down-weighted.

In this case we use a fourth order exponential function to determine the amount of downweighting for a given traveltime residual (Figure D.1): 


$$
W=e^{-\frac{x^{4}}{2 d^{4}}}
$$

The advantage of using this function as opposed to the usual Gaussian function is that a steeper cut-off enables more radical down-weighting of outlying observations. Observations with a traveltime residual of $\pm 0.35 \mathrm{~s}$ are weighed at $80 \%$. Observations with residuals of $0.45 \mathrm{~s}$ and $0.8 \mathrm{~s}$ are down-weighed by more than $\pm 50 \%$ and $\pm 90 \%$, respectively.

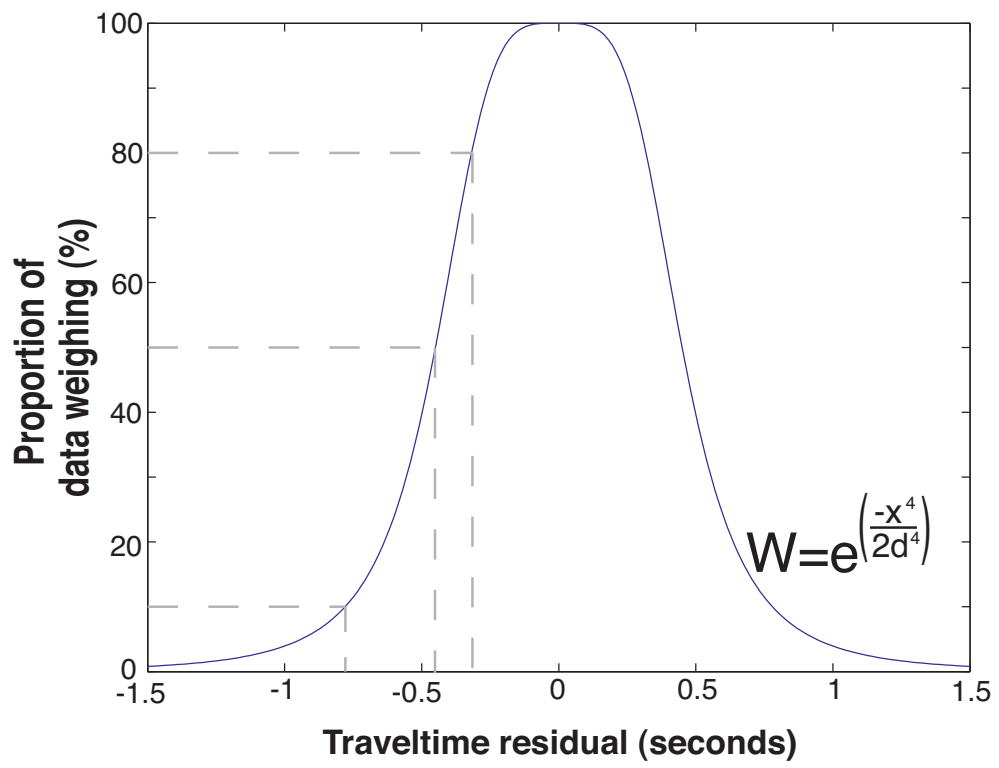

Figure D.1: Plot of the down-weighting function. The grey dashed line represent the amount of traveltime residual that is weighed at 80,50 and $10 \%$.

\section{D.2.2 Station term estimation}

This step evaluates the observations that are likely to get modelled in a subsequent iteration once the model reaches a more stable solution, as well as which features may never be determined through modelling. The station terms are considered well constrained when there are many observations at a station.

This scheme is a balancing act between the station terms, the de-weighting scheme and the actual body of the model. If the station terms are unrestrained then the model would not change because the station terms have corrected for most of the variations. However, if the station terms are disregarded, estimation errors and unaccounted variations due to basins and topography will permeate into the model.

As can be seen on Figure D.2, the station terms get smaller as the final inversion process progresses. Before the last inversion (after iteration 10, red line on Figure D.2), most station terms are centered around 0 . The smallness of the station terms indicate the accuracy of the static corrections calculated in Chapter 3 as well as suggests the 3D reference model is reasonably realistic. 


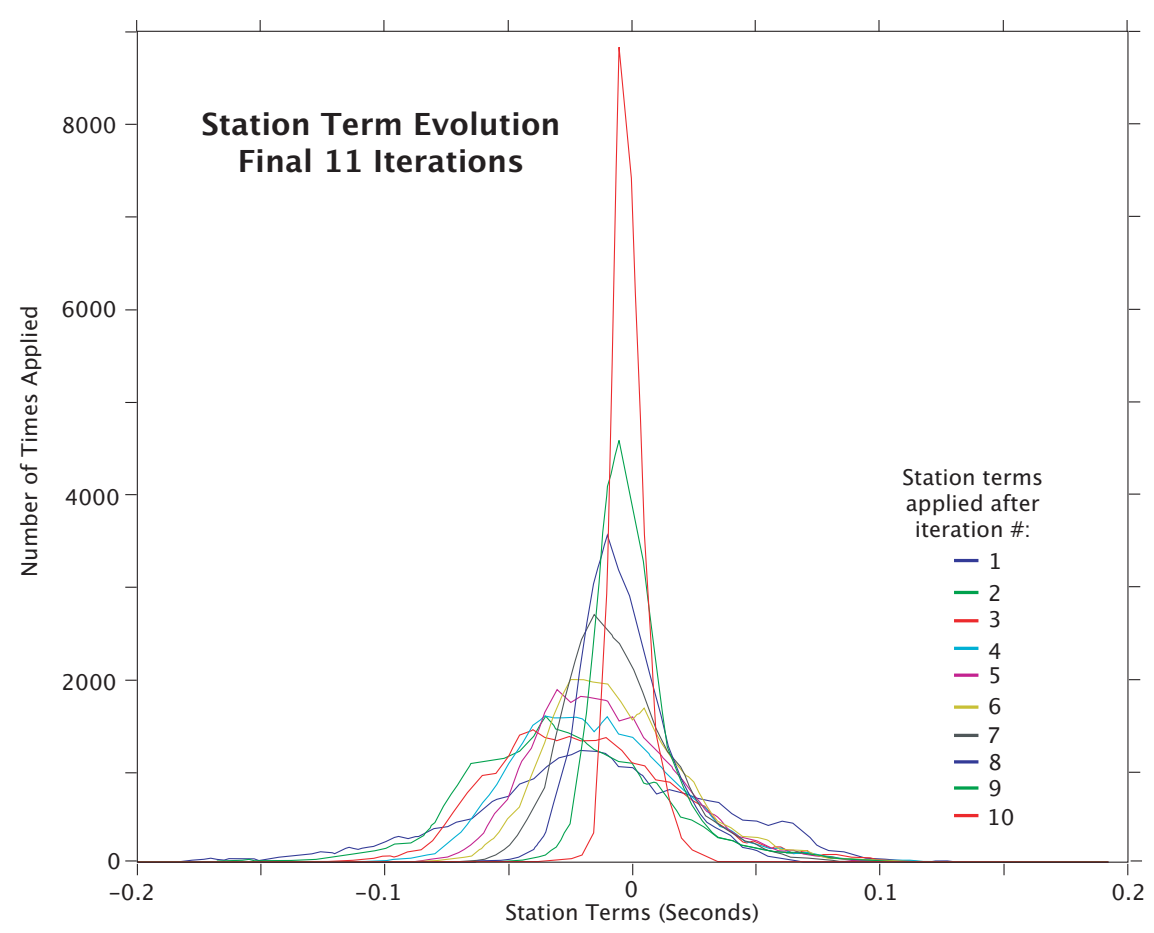

Figure D.2: Plot of the evolution of the station terms throughout the inversion process. Each solid line represent the station terms applied on the traveltimes after each iteration. The iteration plotted are the 11 final ones, that calculated the upper-mantle velocity structure.

\section{D.2.3 Down-weighting strategy}

The down-weighting strategy follows the following steps after each iteration:

1. Estimation of station terms without constraints

2. Estimation the Median Absolute Deviation (MAD) from the observed and estimated times to assess the true spread of the measurements due to error. Effectively, a delay time is estimated at each station (source $i$ and receiver $j$ ) and the MAD is calculated as follows:

$$
M A D=\operatorname{median}_{i}\left(\left|X_{i}-\operatorname{median}_{j}\left(X_{j}\right)\right|\right)
$$

3. Use MAD value to calculate down-weighting of measurements

4. Use down-weighted measurements to estimate station terms. This time the station terms are modelled as having a value of zero but with a standard variation of $0.1 \mathrm{~s}$.

5. Estimated station terms are used to adjust original measurements. Note that $0.1 \mathrm{~s}$ standard deviation causes little change in measurements.

6. Down-weighting from step 3. used to adjust uncertainties in model input files. 


\section{Appendix E}

\section{Solution model input files}

This Appendix includes two main input files that are used to produce the preferred solution model:

1. grid3dg.in This file (Figure E.1) is used to parameterise the model space in terms of its bounds, its propagation and inversion nodes (including velocity and interface nodes). This files also constructs the reference model in terms of the velocity structure and interface geometry. This involves the specification of a set of external 3D velocity and $2 \mathrm{D}$ interface files (*.vel and ${ }^{*}$.xy, respectively).

2. obsdata.in This file (Figure E.2) reads in the source file to produce the dataset of observed traveltimes. This is where the seismic phases are linked to the interfaces. The path signatures of each of the four phases used in the inversion are shown. 


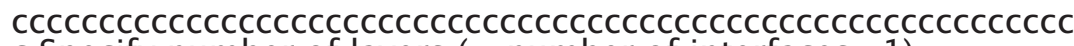
c Specify number of layers (= number of interfaces -1 )

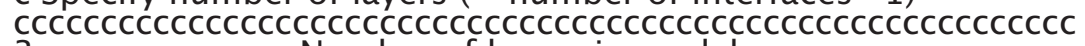
3 c: Number of layers in model

$1 \quad$ c: Number of velocity grid types (1 or 2)

0.03

c: Pinchout distance $(\mathrm{km})(>=0.0)$

$\begin{array}{ll}\text { vgrids.in } & \text { c: Output velocity grid file } \\ \text { interfaces.in } & \text { c: Output interface grid file }\end{array}$

145678 C: Seed for random number generation (int)

1.00

c: Minimum permitted velocity $(\mathrm{km} / \mathrm{s})$

cCCCCCCCCCCCCCCCCCCCCCCCCCCCCCCCCCCCCCCCCCCCCCCCCCCCCCCCCCC

c Set 3-D grid size and location. Note that all layer

c velocity grids have the same spatial dimension, but can

c have different node densities. Interface grids have the

c same node distribution.

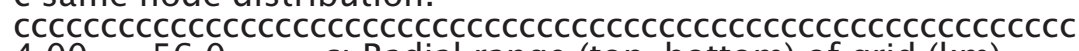
$4.00-56.0 \quad$ C: Radial range (top-bottom) of grid (km)

$-41.5 \quad-44.54 \quad$ C: Latitudinal range $(\mathrm{N}-\mathrm{S})$ of grid (degrees)

$167.5172 .06 \quad$ c: Longitudinal range (E-W) of grid (degrees) $6371.0 \quad$ c: Earth radius

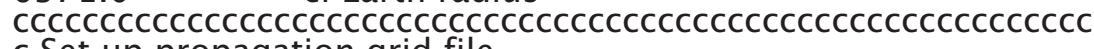
c Set up propagation grid file

cCCCCCCCCCCCCCCCCCCCCCCCCCCCCCCCCCCCCCCCCCCCCCCCCCCCCCCCCCCCCC

propgrid.in c: Name of propagation grid file

$205763 \quad$ C: Number of points in rad lat, long

42 c: Refine factor \& no. of local cell's

$0.01 \quad$ C: Cushion factor for prop grid $(<<1)$

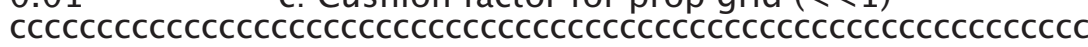
cCCCCCCCCCCCCCCCCCCCCCCCCCCCCCCCCCCCCCCCCCCCCCCCCCCCCCCCCCCCCC c First, set up the velocity grids

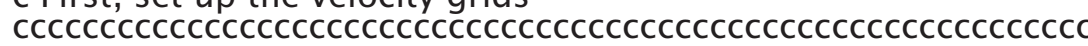
cCCCCCCCCCCCCCCCCCCCCCCCCCCCCCCCCCCCCCCCCCCCCCCCCCCCCCCCCCCCCC c Set velocity grid values for layer 1

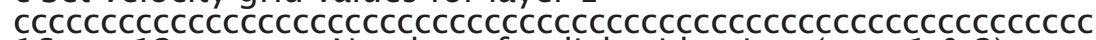
$\begin{array}{ll}16 & 12 \\ 43 & 12 \\ 47 & 12 \\ 0 & \end{array}$
c: Number of radial grid points (type $1 \& 2$ )
$\mathrm{P}$
c: Number of grid points in theta $(\mathrm{N}-\mathrm{S})$
C: Number of grid points in phi (E-W)
: Use model (0) or constant gradient (1)
VelUcrust.vel
c: Use P or $\mathrm{S}$ velocity model

$\begin{array}{ll}3.1 & 4.0 \\ 5.8 & 5.0\end{array}$

c: Velocity at origin $(\mathrm{km} / \mathrm{s})$ (option 1$)$

c: Velocity at maximum depth $(\mathrm{km} / \mathrm{s})$ (option 1$)$

c Optionally apply random structure to layer 1

cCCCCCCCCCCCCCCCCCCCCCCCCCCCCCCCCCCCCCCCCCCCCCCCCCCCCCCCCCCCCC

$0 \quad$ c: Add random structure $(0=$ no, $1=$ yes $)$

0.7 C: Standard deviation of Gaussian noise

$1 \quad$ C: Add a priori model covariance $(0=$ no, $1=y e s)$ ?

0.3

c: Diagonal elements of covariance matrix

cccccccceccccccccccccccccccccccccccccccccccccccccccc c Optionally apply checkerboard to layer 1

cCCCCCCCCCCCCCCCCCCCCCCCCCCCCCCCCCCCCCCCCCCCCCCCCCCCCCCCCCCCCC

$0 \quad$ C: Add checkerboard $(0=$ no, $1=$ yes $)$

1 c: Maximum perturbation of vertices

$4 \quad$ c: Checkerboard size $(\mathrm{N} \times \mathrm{N} \times \mathrm{N})$

$1 \quad$ c: Use spacing $(0=$ no, $1=$ yes $)$

cccccccccccccccccccccccccccccccccccccccccccccccccccccccc c Optionally, apply spikes to layer 1

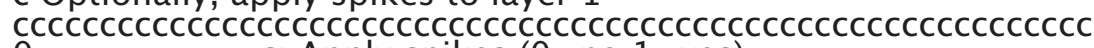

$0 \quad$ C: Apply spikes $(0=$ no, $1=$ yes $)$

$1.40 \quad$ C: Number of spikes
1.40

$-30.0-33.1 \quad 140.0 \quad$ c: Coordinates of spike 1

Figure E.1: The input file grid3dg.in that parameterises the model space. Part 1 of 4 


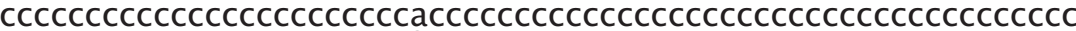
c Set velocity grid values for layer 2

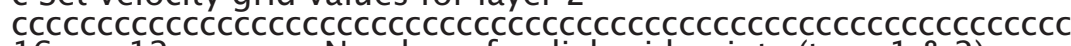

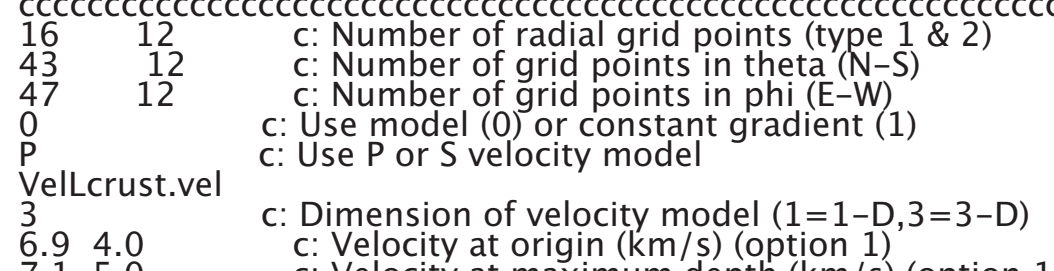
7.15 .0 c: Velocity at maximum depth $(\mathrm{km} / \mathrm{s})$ (option 1$)$ cccccccccccccccccccccccccccccccccccccccccccccccccccccc c Optionally apply random structure to layer 2

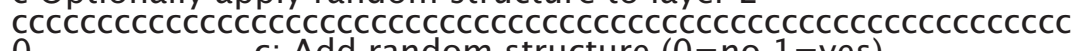
0 c: Add random structure $(0=$ no, $1=$ yes $)$

$0.7 \quad$ C: Standard deviation of Gaussian noise

$1 \quad$ c: Add a priori model covariance $(0=$ no, $1=y e s)$ ?

$0.3 \quad$ c: Diagonal elements of covariance matrix

cccccccccccccccccccccccccccccccccccccccccccccccccccccccc c Optionally apply checkerboard to layer 2

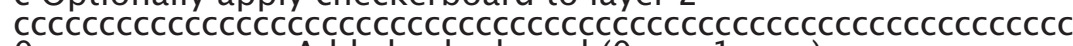
$0 \quad$ c: Add checkerboard $(0=$ no, $1=$ yes $)$

1 c: Maximum perturbation of vertices

$4 \quad$ c: Checkerboard size $(\mathrm{N} \times \mathrm{N} \times \mathrm{N})$

$1 \quad$ c: Use spacing $(0=$ no, $1=$ yes $)$

cccccccccccccccccccccccccccccccccccccccccccccccccccccccc c Optionally, apply spikes to layer 2

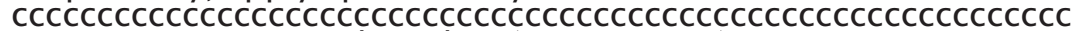

$0 \quad$ c: Apply spikes $(0=$ no, $1=$ yes $)$

$140 \quad$ c: Number of spikes

$1.40 \quad$ c: Amplitude of spike 1

$-30.0-33.1 \quad 140.0 \quad$ c: Coordinates of spike 1

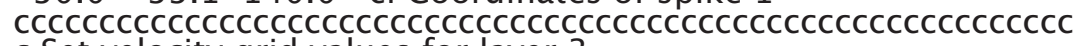
c Set velocity grid values for layer 3

cCCCCCCCCCCCCCCCCCCCCCCCCCCCCCCCCCCCCCCCCCCCCCCCCCCCCCCCCCCCCC

$\begin{array}{lll}16 & 12 & \text { C: Number of radial grid points (type } 1 \text { \& 2) }\end{array}$

$43 \quad 12 \quad$ c: Number of grid points in theta $(N-S)$

$0 \quad$ c: Use model (0) or constant gradient (1)

VelMantle.vel

C: Use P or $S$ velocity model

$\begin{array}{ll}3 & \text { c: Dimension of velocity model }(1=1-\mathrm{D}, 3=3-\mathrm{D})\end{array}$

$5.14 .0 \quad$ C: Velocity at origin $(\mathrm{km} / \mathrm{s})$ (option 1)

$5.85 .0 \quad$ C: Velocity at maximum depth $(\mathrm{km} / \mathrm{s})($ option 1$)$

ccccccccccceccceccccccccccccccccccccccccccccccccccccccccc c Optionally apply random structure to layer 3

cCCCCCCCCCCCCCCCCCCCCCCCCCCCCCCCCCCCCCCCCCCCCCCCCCCCCCCCCCCCCC

$0 \quad$ c: Add random structure $(0=$ no, $1=$ yes $)$

$0.7 \quad$ C: Standard deviation of Gaussian noise

$1 \quad$ C: Add a priori model covariance $(0=$ no, $1=y e s)$ ?

0.3

c: Diagonal elements of covariance matrix

cccccccccccccccccccccccccccccccccccccccccccccccccccccccc c Optionally apply checkerboard to layer 3

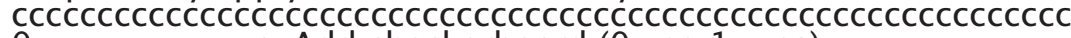

0 c: Add checkerboard $(0=$ no, $1=$ yes $)$

$1 \quad$ c: Maximum perturbation of vertices

$4 \quad$ C: Checkerboard size $(\mathrm{N} \times \mathrm{N} \times \mathrm{N})$

$1 \quad$ c: Use spacing $(0=$ no, $1=$ yes $)$

ccccccccccccccccccccccccccccccccccccccccccccccccccccccc c Optionally, apply spikes to layer 3

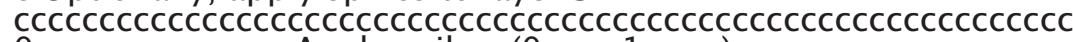

$0 \quad$ C: Apply spikes $(0=$ no, $1=$ yes)

$1 \quad c$ : Number of spikes

$1.40 \quad$ C: Amplitude of spike 1

$\begin{array}{llll}-30.0 & -33.1 & 140.0 & \text { c: Coordinates of spike } 1\end{array}$

Figure E.1: grid3dg.in continued. Part 2 of 4 


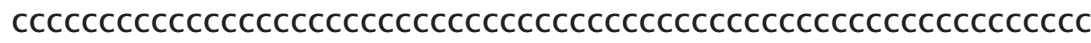
 c Now, set up the interface grids

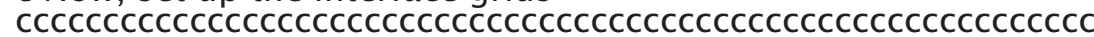

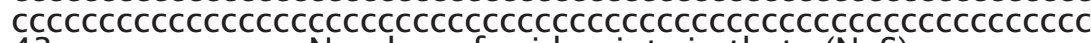
$43 \quad$ C: Number of grid points in theta $(\mathrm{N}-\mathrm{S})$

$47 \quad$ C: Number of grid points in phi (E-W)

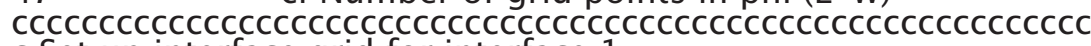
c Set up interface grid for interface 1

cCCCCCCCCCCCCCCCCCCCCCCCCCCCCCCCCCCCCCCCCCCCCCCCCCCCCCCCCCCCCC 0 c: Obtain grid from external file $(0=$ no, $1=y e s)$

int1.z C: External interface grid file (option 1)

$\begin{array}{ll}3.9 & \text { C: Height of NW grid point (option } 0) \\ 3.9 & \text { C: Height of NE grid point (option } 0)\end{array}$

$3.9 \quad$ C: Height of NE grid point (option 0)

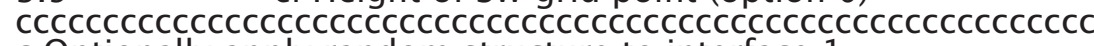
c Optionally apply random structure to interface 1

cCCCCCCCCCCCCCCCCCCCCCCCCCCCCCCCCCCCCCCCCCCCCCCCCCCCCCCCCCCCCC

0 C: Add random structure $(0=$ no, $1=$ yes)

$2.00 \quad$ C: Standard deviation of Gaussian noise

$1 \quad$ c: Add a priori model covariance $(0=$ no, $1=y e s)$ ?

0.3

c: Diagonal elements of covariance matrix

cccccccccccccccccccccccccccccccccccccccccccccccccccc c Optionally apply checkerboard to interface 1

cCCCCCCCCCCCCCCCCCCCCCCCCCCCCCCCCCCCCCCCCCCCCCCCCCCCCCCCCCCCCC

0 C: Add checkerboard $(0=$ no, $1=$ yes $)$

$5.00 \quad$ c: Maximum perturbation of vertices

$2 \quad$ c: Checkerboard size $(\mathrm{N} \times \mathrm{N})$

$1 \quad$ c: Use spacing $(0=$ no, $1=$ yes $)$

cCCCCCCCCCCCCCCCCCCCCCCCCCCCCCCCCCCCCCCCCCCCCCCCCCCCCCCCCCCCCC c Optionally, apply spikes to interface 1

cCCCCCCCCCCCCCCCCCCCCCCCCCCCCCCCCCCCCCCCCCCCCCCCCCCCCCCCCCCCCC

$0 \quad$ c: Apply spikes $(0=$ no, $1=$ yes $)$

2 c: Number of spikes

$-5.00 \quad$ C: Amplitude of spike 1

$-42.1146 .4 \quad$ c: Coordinates of spike 1

5.00

$-41.4146 .4$

c: Amplitude of spike 2

c: Coordinates of spike 2

cccccccccccccccccccccccccccccccccccccccccccccccccccccc c Set up interface grid for interface 2

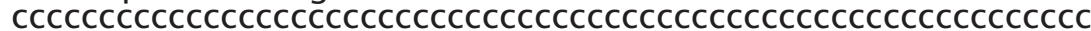

1

LCsurf.z

$-55.0$

$-55.0$

c: Obtain grid from external file $(0=$ no, $1=y e s)$

c: External interface grid file (option 1)

$-55.0$

c: Height of NE grid point (option 0 )

C: Height of SW grid point (option 0 )

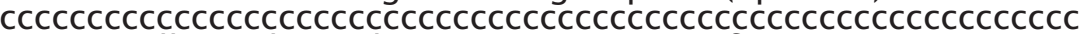
c Optionally apply random structure to interface 2

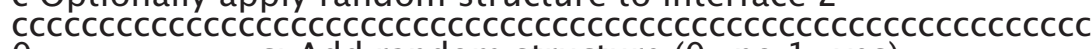
0

2.00

1
$0.3 \quad$ C: Add a priori model covariance $(0=$ no, $1=y e s) ?$
cccccccccccccccccccccccccccccccccccccccccccccccccccc

C: Add random structure $(0=$ no, $1=$ yes $)$

c: Standard deviation of Gaussian noise c Optionally apply checkerboard to interface 2

cCCCCCCCCCCCCCCCCCCCCCCCCCCCCCCCCCCCCCCCCCCCCCCCCCCCCCCCCCCCCC

0 c: Add checkerboard $(0=$ no, $1=$ yes)

$5.00 \quad$ C: Maximum perturbation of vertices

2 c: Checkerboard size $(\mathrm{N} \times \mathrm{N})$

$1 \quad$ C: Use spacing $(0=$ no, $1=$ yes $)$

ccccccccccccccccccccccccccccccccccccccccccccccccccccc c Optionally, apply spikes to interface 2

cCCCCCCCCCCCCCCCCCCCCCCCCCCCCCCCCCCCCCCCCCCCCCCCCCCCCCCCCCCCCC

0 C: Apply spikes $(0=$ no, $1=$ yes $)$

$2 \quad$ c: Number of spikes

$-5.00 \quad$ C: Amplitude of spike 1

$-42.1 \quad 146.4 \quad$ c: Coordinates of spike 1

5.00

C: Coordinates of spik
Amplitude of spike 2

-41.4 146.4 c: Coordinates of spike 2

Figure E.1: grid3dg.in continued. Part 3 of 4 


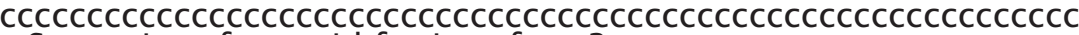
c Set up interface grid for interface 3

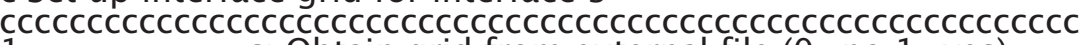
1

$\begin{array}{ll}\text { Msurf.z } & \text { C: External interface grid file (option } \\ 3.9 & \text { c: Height of NW grid point (option } 0)\end{array}$

c: Obtain grid from external file $(0=$ no, $1=$ yes $)$

$3.9 \quad$ C: Height of NE grid point (option 0 )

$3.9 \quad$ c: Height of SW grid point (option 0)

cccccccccccccccccccccccccccccccccccccccccccccccccccc c Optionally apply random structure to interface 3

cCCCCCCCCCCCCCCCCCCCCCCCCCCCCCCCCCCCCCCCCCCCCCCCCCCCCCCCCCCCCC

$0 \quad$ c: Add random structure $(0=$ no, $1=$ yes $)$

$2.00 \quad$ C: Standard deviation of Gaussian noise

1.3

c: Add a priori model covariance $(0=$ no, $1=y e s)$ ?

0.3

c: Diagonal elements of covariance matrix

c Optionally apply checkerboard to interface 3

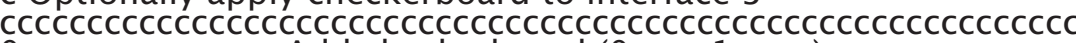

0 c: Add checkerboard $(0=$ no, $1=$ yes $)$

$5.00 \quad$ C: Maximum perturbation of vertices

$2 \quad$ c: Checkerboard size $(\mathrm{N} \times \mathrm{N})$

c: Use spacing $(0=$ no, $1=$ yes $)$

ccccccccccccccccccccccccccccccccccccccccccccccccccccc c Optionally, apply spikes to interface 3

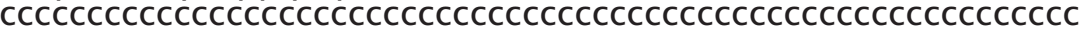

0 C: Apply spikes $(0=$ no, $1=$ yes $)$

2 c: Number of spikes

$-5.00 \quad$ C: Amplitude of spike 1

-42.1
5.00 $\quad$ c: Amplitude of spike 2 . Coordinates of 1

5.00

$-41.4146 .4$

c: Coordinates of spike 2

cccccccecccccccccccccccccccccccccccccccccccccccccccccccc c Set up interface grid for interface 4

cCCCCCCCCCCCCCCCCCCCCCCCCCCCCCCCCCCCCCCCCCCCCCCCCCCCCCCCCCCCCC

$0 \quad$ c: Obtain grid from external file $(0=$ no, $1=y e s)$

int1.z c: External interface grid file (option 1)

$-55.0 \quad$ c: Height of NW grid point (option 0 )

$-55.0 \quad$ c: Height of NE grid point (option 0)

$-55.0 \quad$ C: Height of SW grid point (option 0 )

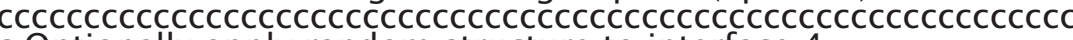
c Optionally apply random structure to interface 4

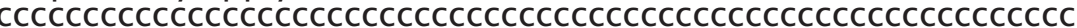

$0 \quad$ c: Add random structure $(0=$ no, $1=y e s)$

$2.00 \quad$ C: Standard deviation of Gaussian noise

$1 \quad$ c: Add a priori model covariance $(0=$ no, $1=y e s)$ ?

$0.3 \quad$ c: Diagonal elements of covariance matrix

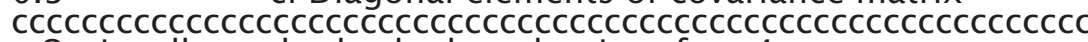
c Optionally apply checkerboard to interface 4

cCCCCCCCCCCCCCCCCCCCCCCCCCCCCCCCCCCCCCCCCCCCCCCCCCCCCCCCCCCCCC

$0 \quad$ c: Add checkerboard $(0=$ no, $1=$ yes $)$

$5.00 \quad$ c: Maximum perturbation of vertices

2 c: Checkerboard size $(\mathrm{N} \times \mathrm{N})$

$1 \quad$ c: Use spacing $(0=$ no, $1=$ yes $)$

c Optionally, apply spikes to interface 4

0
0

2 c: Number of spikes

$-5.00 \quad$ C: Amplitude of spike 1

$-42.1146 .4 \quad$ c: Coordinates of spike 1

$5.00 \quad$ c: Amplitude of spike 2

$-41.4146 .4 \quad$ c: Coordinates of spike 2

Figure E.1: grid3dg.in continued. Part 4 of 4 


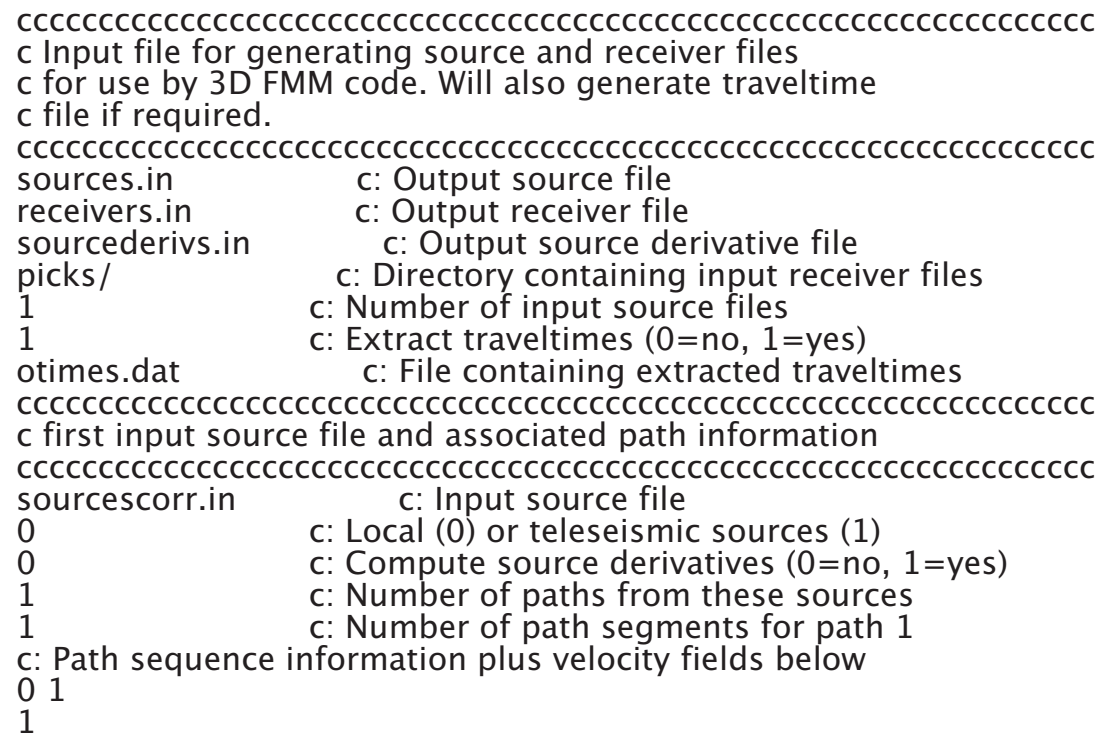

2 c: Number of path segments for path 1 c: Path sequence information plus velocity fields below

$\begin{array}{llll}0 & 2 & 2 & 1 \\ 1 & & 1\end{array}$

(PIP)

$4 \quad$ c: Number of path segments for path 1 c: Path sequence information plus velocity fields below $\begin{array}{llllllll}0 & 2 & 2 & 3 & 3 & 2 & 2 & 1\end{array}$

\section{$(\mathrm{PmP})$}

5 c: Number of path segments for path 1 c: Path sequence information plus velocity fields below

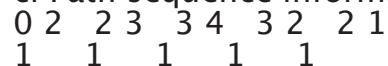

$(\mathrm{Pn})$

Figure E.2: The input file obsdata.in that produce the observed dataset and defines the path signatures. 


\section{Appendix F}

\section{Participatory software development}

Several corrections to the tomography software's source code have been applied throughout this research project. The purpose of this Appendix is to offer suggestions for possible future software development of FMTOMO. The following guidelines aim to make this package more user-friendly, complete and, hence, more popular:

1. Additional data in the user's manual. The description of essential files (frechet.in and modeset.in) is not present in the user's manual. A flowchart of the interaction of the different components of the software would greatly help the user to understand the software package.

2. Graphical interface for input model files. A simple and interactive graphical interface would be extremely useful to prevent the omission of input parameters and/or parameter blocks.

3. Source and receiver files creation module. This automated step would help the creation of the the input source and receiver files.

4. External file input for sedimentary structures. The role of sediments and the effect of the velocity field of the uppermost crust on the model cannot be underestimated. Being able to include such data in the reference model would be a great advantage to the resolution of the solution model.

5. Enhanced node definition of the upper-crust. Brittle processes in the upper-most crust may result in structures of finer size than at greater depth. A node spacing set to recover structures at greater depth would not be able to recover such finer structures. A finer node spacing closer to the surface down to a user-specified depth would, hence, be beneficial.

6. Tighter nodal connection To compensate for the non-interpolating nature of the cubic B-splines a tension factor could be added for a enhanced representation of the nodal field.

7. Universality of input and output file format. The files defining the velocity and interface grids change format after a velocity or interface inversion has been run, respectively. This involves another conversion step to be able to use the grid of a solution model as a reference one for a later inversion run.

8. Extremum velocities. For the velocity structure not to be unrealistic, an additional parameter defining the minimum and maximum velocities allowed for a given layer is necessary. The same can be done for an interface in terms of its depth. 
9. Output files cataloguing switch. In order to keep a trace and/or follow the progress of an inversion run, a copy of model plots and the associated output files (especially the calculated model times) after each iterations is necessary.

10. Decimation parameter. This parameter would enable the user to reduce the size of a traveltime dataset for test runs. This would make the testing steps substantially more time-efficient.

11. Syn-processing modification. As the inversion run progresses, so must the damping and smoothing parameters. A module with various inversion schemes would be a useful tool for this purpose.

12. Varying velocity gradient. Enabling the specfication of various velocity gradient active within specific depth ranges for the user to perform first break tomography by using a $1 \mathrm{D}$ velocity reference model.

13. Model alignment module. Survey geometries are not necessarily aligned north-south and east-west. The model domain should be rotatable such that the smallest amount of nodes are used, and the area that is not sampled by seismic rays is minimised.

14. De-weighting module. Such a module would enable the user to de-weight aberrant observations. It would include a user-specified residual threshold, a set of decaying functions to choose from (e.g. linear, exponential) and an occurrence factor (apply de-weighting every $\mathrm{n}^{\text {th }}$ iteration).

15. Statistical plotting module. A graph-plotting supplement would prove useful to visually examine the evolution of the global residual of the model as well as key statistical values (RMS traveltime residual, variance, $\chi^{2}$ misfit).

16. Corresponding ray plotting. Enabling the plotting of seismic rays that pass exclusively through the chosen $2 \mathrm{D}$ section.

17. 3D velocity structure generation module. This module would assist the user in the construction of a readable 3D velocity model from the input of a series of $1 \mathrm{D}$ or $2 \mathrm{D}$ velocity models (e.g. for use in Mayavi). This would involve different options of interpolation schemes that would connect the input models between each other.

18. Floating reflector module. This module would enable the inversion of isolated interfaces within the model space. This would require the input of a set of observations and the definition of an isolated interface.

19. Matching module. Onshore-offshore datasets are extensive and much time can be spent book-keeping. This module could output files that would facilitate the matching of ray numbers with pick files to locate outlying observations, for example.

20. Error detection module. A module that would perform simple checks on the solution model to verify for any outliers and/or error in the dataset could save the user a lot of time. 


\section{References}

Adams, C. J. D., 1979. Age and origin of the Southern Alps. In: Walcott, R. I., Creswell, M. M. (Eds.), The Origin of the Southern Alps. Vol. 18 of Roy. Soc. NZ. Bull. pp. 73-78.

Allis, R. G., Henley, R. W., Carman, A. F., 1979. Thermal regime beneath the Southern Alps. In: Walcott, R. I., Creswell, M. M. (Eds.), The Origin of the Southern Alps. Vol. 18 of Roy. Soc. NZ Bull. pp. 79-85.

Allis, R. G., Shi, Y., 1995. New insights to temperature and pressure beneath the central Southern Alps, New Zealand. NZ J. Geol. Geophys. 38(4), 585-592.

Amos, C. B., Burbank, D. W., Nobes, D. C., Read, S. A. L., 2007. Geomorphic constraints on listric thrust faulting: implications for active deformation in the MacKenzie Basin, South Island, New Zealand. J. Geophys. Res. 112, B03S11, doe:10.1029/2006JB004291.

Atkins, R., Hicks, S., 1979. Geophysical models along Ashburton River, Canterbury, New Zealand. NZ. J. Geol. Geophys. 22, 673-677.

Baldock, G., 2004. High resolution crustal and upper mantle structure adjacent to a continental transform, south island, new zealand. Master's thesis, Institute of Geophysics, Victoria University of Wellington.

Baldock, G., Stern, T., 2005. Width of mantle deformation across a continental transform: Evidence from upper mantle (Pn) seismic anisotropy measurements. Geology 33 (9), 741744.

Bassett, D., Sutherland, R., Henrys, S., Stern, T., Scherwath, M., Benson, A., Toulmin, S., Henderson, M., 2010. Three-dimensional velocity structure of the northern Hikurangi margin, Raukumara, New Zealand: Implications for the growth of continental crust by subduction erosion and tectonic underplating. Geoch. Geophys. Geol. 11 (10), Q10013.

Beaumont, C., Kamp, P. J., Hamilton, J., Fullsack, P., 1996. The continental collision zone, South Island, New Zealand: Comparison of geodynamical and observations. J. Geophys. Res. 10 (B2), 3333-3359.

Beavan, J., Ellis, S., Wallace, L., Denys, P., 2007. Kinematic constraints from GPS on oblique convergence of the Pacific and Australian plates, central South Island, New Zealand. In: Okaya, D., Stern, T., Davey, F. (Eds.), A continental plate boundary: Tectonics at South Island, New Zealand. Vol. 175 of AGU Geophysical Monograph Series. pp. 75-94.

Beavan, J., Haines, J., 2001. Contemporary horizontal velocity and strain rate fields of the Pacific-Australian plate boundary zone through New Zealand. J. Geophys. Res. 106(B1), 741-770. 
Beavan, J., Moore, M., Pearson, C., Henderson, M., Parsons, B., Bourne, S., England, P., Walcott, R., Blick, G., Darby, D., Hodgkinson, K., 1999. Crustal deformation during 19941998 due to oblique continental collision in the central Southern Alps, New Zealand, and implications for seismic potential of the Alpine fault. J. Geophys. Res. 104 (B11), 2523325255.

Bevc, D., 1997. Flooding the topography: Wave-equation datuming of land data with rugged acquisition topography. Geophysics 62(5), 1558-1569.

Bishop, D. J., 1992. Extensional tectonism and magmatism during the middle Cretaceous to Paleocene, North Westland, New Zealand. NZ. J. Geol. Geophys. 35, 81-91.

Blythe, A., 1998. Active tectonics and Ultrahigh-pressure rocks. In: Liou, B., J.G., H. (Eds.), When continents collide: Geodynamics and geochemistry of ultrahigh-pressure rocks. Kluwer Academic Publishers, pp. 141-160.

Bossiere, G., 1991. Petrology of pseudotachylites from the Alpine fault of New Zealand. Tectonoph. 196 (1-2), 173-193.

Bourguignon, S., 2009. Lithospheric deformation at the South Island oblique collision, New Zealand. Ph.D. thesis, Institute of Geophysics, Victoria University of Wellington.

Bourguignon, S., Savage, M. K., Stern, T., 2007. Crustal thickness and Pn anisotropy beneath the Southern Alps oblique collision, New Zealand. In: Okaya, D., Stern, T., Davey, F. (Eds.), A continental plate boundary: tectonics at South Island, New Zealand. Vol. 175 of AGU Geophysical Monograph Series. pp. 115-122.

Bourguignon, S., Stern, T., Savage, M. K., 2006. Crust and mantle thickening beneath the southern portion of the Southern Alps, New Zealand. Geophys. J. Int. 168(2), 681-690.

Brikke, N. E. A., 2007. Seismic velocity structure of the shallow part of the Alpine fault and gravity study of the basement features in the Whataroa River flood plain, central Westland, South Island. GradDipSci dissertation.

Brown, L., Wilson, D., 1988. Stratigraphy of the late Quaternary deposits of the northern Canterbury Plains, New Zealand. NZ. J. Geol. Geophys 31, 305-335.

Campbell, F. M., Kaiser, A., Horstmeier, H., Green, A. G., Ghisetti, F., Gorman, A., Finnemore, M., Nobes, D. C., 2010. Processing and preliminary interpretation of noisy high resolution seismic reflection/refraction data across the active Ostler fault zone, South Island, New Zealand. J. Appl. Geophys. 70(4), 332-342.

Cande, S. C., Stock, J. M., 2004. PacificAntarcticAustralia motion and the formation of the Macquarie Plate. Geophys. J. Int. 157 (1), 399-414.

Chang, X., Liu, Y., Wang, H., Li, F., Chen, J., 2002. 3-D tomographic static correction. Geophysics 67(4), 1275-1285.

Chetwin, E., 1998. Active faulting and subsurface structure in the McKenzie Basin: an investigation using gravity and seismic modelling. BSc dissertation.

Christensen, N., Okaya, D., 2007. Compressional and shear wave velocities in South Island, New Zealand rocks and their application to the interpretation of seismological models of the New Zealand crust. In: Okaya, D., Stern, T., Davey, F. (Eds.), A continental plate boundary: tectonics at South Island, New Zealand. Vol. 175 of AGU Geophysical Monograph Series. pp. $123-155$. 
Cotton, C., 1956. Coastal history of southern Westland and northern Fiordland. Trans. R. Soc. NZ. 83, 483-488.

Cox, M., 1999. Static corrections for seismic reflection surveys. Society of Exploration Geophysicists, Tulsa, Okla.

Cox, S., Barrell, D., 2007. Geology of the Aoraki area. Vol. 15 of 1:250000 Geological map. GNS Science.

Cox, S. C., Craw, D., Page Chamberlain, C., 1997. Structure and fluid migration in a late Cenozoic duplex system forming the main divide in the central Southern Alps, New Zealand. NZ. J. Geol. Geophys. 40, 359-373.

Cox, S. C., Findlay, R. H., 1995. The Main Divide fault zone and its role in formation of the Southern Alps, New Zealand. NZ. J. Geol. Geophys. 38, 489-499.

Cox, S. C., Sutherland, R., 2007. Regional geological framework of South Island, New Zealand, and its significance for understanding the active plate boundary. Geophysical Monogrpah Series, AGU 175, 19-46.

Davey, F., Eberhart-Phillips, D., Kohler, M. D., Bannister, S., Caldwell, G., Henrys, S., Scherwath, M., Stern, T., van Avendonk, H. J., 2007. Geophysical structure of the Southern Alps orogen, South Island, New Zealand. In: Okaya, D., Stern, T., Davey, F. (Eds.), A continental plate boundary: Tectonics at South Island, New Zealand. Vol. 175 of AGU Geophysical Monograph Series. pp. 47-73.

Davey, F., Henyey, T., Holbrook, W., Okaya, D., Stern, T., Melhuish, A., Henrys, S., Anderson, H., Eberhart-Phillips, D., McEvilly, T., Uhrhammer, R., Wu, F., Jiracek, G., Wannamaker, P., Caldwell, G., Christensen, N., 1998. Preliminary results from a geophysical study across a modern continent-continent collisional plate boundary - the Southern Alps, New Zealand. Tectonoph. 288, 221-235.

Davey, F., Henyey, T., Kleffmann, S., Melhuish, A., Okaya, D., Stern, T., Woodward, D., 1995. Crustal reflections from the Alpine Fault Zone, South Island, New Zealand. NZ. J. Geol. Geophys. 38, 601-604.

de Kool, M., Rawlinson, N., Sambridge, M., 2006. A practical grid-based method for tracking multiple refraction and reflection phases in three-dimensional heterogeneous media. Geophys. J. Int. 167, 253-270.

de Vel, O. Y., 1984. Development of a software package for the determination of automatic non-surface consistent static corrections: Application to the New Zealand southern Taranaki graben. Tech. Rep. 199, GNS Science.

DeMets, C., Gordon, R., Argus, D., Stein, S., 1990. Current plate motions. Geophys. J. Int. $101,425-478$.

DeMets, C., Gordon, R., Argus, D., Stein, S., 1994. Effect of revisions to the geomagnetic reversal time scale on estimates of current plate motions. Geophys. Res. Let. 21, 2191-2194, doi: 10.1029/94GL02118.

Diamond, S. O. C. N., 1981. Mikonui no1 well completion report. Tech. rep., New Zealand Geologcal Survey Open-File Petroleum.

Doo, W., Hsu, S., Tsai, C., Yeh, Y., Chang, C., 2008. New insights on the structures and age of northwestern West Philippine Basin. AGU, fall meeting 2008, T31C-2027. 
Eberhart-Phillips, D., 1995. Examination in central Alpine fault region, South Island, New Zealand. NZ. J. Geol. Geophys. 38, 571-578.

Eberhart-Phillips, D., Bannister, S., 2002. Three-dimensional crustal structure in the Southern Alps region of New Zealand from inversion of local earthquakes and active source data. J. Geophys. Res. 107(B10), 2262.

Evison, F. F., 1971. Seismicity of the Alpine fault, New Zealand. In: Collins, B., Fraser, R. (Eds.), Recent crustal movements. Vol. 9 of Roy. Soc. NZ. Bull. pp. 161-165.

Field, B., Browne, G., 1993. A subsiding platform adjacent to a plate boundary transpression zone: Neogene of Canterbury, New Zealand. In: South Pacific sedimentary basins, sedimentary basins of the world. Vol. 2. pp. 271-278.

Forsyth, P., 2001. Geology of the Waitaki area. Vol. 19 of 1:250000 Geological map. GNS Science.

Fuis, G., Kohler, M. D., Scherwath, M., ten Brink, U., van Avendonk, H. J., Murphy, J. M., 2007. Comparison between the transpressional plate boundaries of South Island, New Zealand, and southern California, USA: The Alpine and the San Andreas fault systems. In: Okaya, D., Stern, T., Davey, F. (Eds.), A continental plate boundary: Tectonics at South Island, New Zealand. Vol. 175 of AGU Monograph Series. pp. 307-327.

Gair, H., 1959. The Tertiary geology of the Paeroa district, south Canterbury. NZ J. Geol. Geophys. 2, 265-296.

Gair, H., 1978. Mid and south Canterbury and north Otago. In: From the geology of New Zealand. Vol. 2. Government Printers, Wellington, pp. 510-516.

Garrick, R., Hatherton, T., 1973. Seismic velocity studies in the Southern Alps, New Zealand. NZ. J. Geol. Geophys. 16 (4), 973-995.

Ghisetti, F., Gorman, A., Sibson, R., 2007. Surface breakthrough of a basement fault by repeated seismic slip episodes: The Ostler fault, South Island, New Zealand. Tectonics 26, TC6004, doi:10.1029/2007TC002146.

Godfrey, N. J., Davey, F., Stern, T., Okaya, D., 2001. Crustal structure and thermal anomalies of the Dunedin region, South Island, New Zealand. J. Geophys. Res. 106(B12), 30,835-30,848.

Grapes, R. H., 1995. Uplift and exhumation of Alpine schist, Southern Alps, New Zealand: Thermobarometric constraints. NZ J. Geol. Geophys. 38(4), 525-533.

Greenhalgh, S., Emerson, D., 1986. Elastic properties of coal measure rocks from the Sydney Basin, New South Wales. Expl. Geophys. 17, 157-163.

Greenroyd, C., Yu, J., Melhuish, A., Ravens, J., Davey, F., Maslen, G., the SIGHT working group, 2003. New Zealand South Island GeopHysical Transect (SIGHT): Marine active-source seismic component - a processing summary.

Harrison, A., 1999. Multi-channel seismic and flexural analysis of Westland Sedimentary Basin, South Island, New Zealand. Ph.D. thesis, Institute of Geophysics, Victoria University of Wellington.

Hatherton, T., 1969. Geophysical anomalies over the eu- and miogeosynclinical systems of California and New Zealand. Geol. Soc. Am. Bull. 80, 213-230. 
Hawkes, P., Mound, D., 1984. Drilling completion report Clipper-1, PPL 38202, offshore Canterbury, South Island, New Zealand. Tech. rep., New Zealand Geological Survey Open-File Petroleum.

Henderson, R. D., 1998. The Southern Alps experiment or why is the West Coast as wet as the West Coast is? NZ. Alp. J., 106-109.

Henrys, S. A., Woodward, D. J., Okaya, D., Yu, J., 2004. Mapping the Moho beneath the Southern Alps continent-continent collision, New Zealand, using wide-angle reflections. Geophys. Res. Lett. 31, L17602.

Hicks, S., 1989. Structure of the Canterbury Plains, New Zealand, from gravity modelling. Tech. rep., GNS Science.

Holbrook, S., Davey, F., 1996. South Island GeopHysical Transect (SIGHT): Marine activesource seismic component. Cruise report EW-9601A R/V Ewing. Lyttleton to Port Chalmers, New Zealand. Feb. 8 - March 7, 1996.

Hole, J., 1992. Nonlinear high-resolution three-dimensional seismic traveltime tomography. J. Geophys. Res. 97 (7), 6553-6562.

Hyvönen, T., Tiira, T., Korja, A., Heikkinen, P., Rautioaho, E., the SVEKALAPKO seismic tomography working group, 2007. A tomographic crustal velocity model of the central Fennoscandian Shield. Geophys. J. Int. 168, 1210-1226.

Ibbitt, R. P., Henderson, R. D., Copeland, J., Wratt, D. S., 2000. Simulating mountain runoff with meso-scale weather model rainfall estimates: A New Zealand experience. J. Hydro. 239(1-4), 19-32.

Ingham, M., Brown, C., 1998. A magnetotelluric study of the Alpine fault, New Zealand. Geophys. J. Int. 135 (2), 542-552.

Ingham, M. R., 1995. Electrical structure along a transect of the central South Island, New Zealand. NZ J. Geol. Geophys. 38(4), 559-563.

Jiracek, G., Gonzalez, V., Caldwell, G., Wannamaker, P., Kilb, D., 2007. Seismogenesis, electrically conductive, and fluid zones at continental plate boundaries in New Zealand, Himalaya, and California, USA. In: Okaya, D., Stern, T., Davey, F. (Eds.), A continental plate boundary: Tectonics at South Island, New Zealand. Vol. 175 of AGU Monograph Series. pp. 347-369.

Jongens, R., 2006. Gneissic rocks of the Bonar Range, central Westland, New Zealand. NZ. J. Geol. Geophys. 49, 281-286.

Jung, H., Mo, W., Green, H. W., 2009. Upper mantle seismic anisotropy resulting from pressureinduced slip transition in olivine. Nature Geosciences 2, 73-77.

Kamp, P. J., 1986. The mid-Cenozoic Challenger Rift system of western New Zealand and its implications for the age of Alpine fault inception. Geol. Soc. Am. Bull. 97, 255-281.

Kamp, P. J., Tippett, J., 1993. Dynamics of Pacific Plate crust in the South Island (New Zealand) zone of oblique continent-continent convergence. J. Geophys. Res. 98 (B9), 1610516118.

Katz, H. R., Kliewer, G., 1970. Petroleum developments in southwest Pacific region during 1969. Am. Assoc. Petr. Geol. Bull. 54. 
King, P., 2000. Tectonic reconstruction of New Zealand: 40Ma to the present. NZ. J. Geol. Geophys. 43, 611-638.

Kleffmann, S., 1999. Crustal structure studies of a transpressional plate boundary - the central South Island of New Zealand. Ph.D. thesis, Institute of Geophysics, Victoria University of Wellington.

Kleffmann, S., Davey, F., Melhuish, A., Okaya, D., Stern, T., 1998. Crustal structure in the central South Island, New Zealand, from the Lake Pukaki seismic experiment. NZ. J. Geol. Geophys. 41, 39-49.

Kohler, M. D., Eberhart-Phillips, D., 2002. Three-dimensional lithospheric structure below the New Zealand Southern Alps. J. Geophys. Res. 107(B10), ESE-6.

Krarup, T., 1970. The method of Least Square Collocation. Studia Geophysica et Geodaetica 14 (2), 107-109.

Laake, A., Zaghloul, A., 2009. Estimation of static corrections from geologic and remote-sensing data. The Leading Edge 28(2), 192-196.

Lacombe, C., Butt, S., McKenzie, G., Schons, M., Bornard, R., 2009. Correcting for watercolumn variations. The Leading Edge 28(2), 198-201.

Langdale, S., 1996. Late Tertiary deformation in Cannington Basin, south Canterbury: Evidence from seismic and gravity data. BSc dissertation, Institute of Geophysics, Victoria Univeristy of Wellington.

Langdale, S., Stern, T., 1998. Late Tertiary deformation in Cannington Basin, south Canterbury, New Zealand: Evidence from seismic and gravity data. NZ. J. Geol. Geophys. 41, $247-257$.

Leckie, D., 1994. Canterbury Plains, New Zealand-implications for sequence stratigraphic models. Am. Assoc. Petr. Geol. Bull. 78(8), 1240-1256.

Lee, E., Wu, F. T., Huang, B., Liang, W., Wang, C., Rawlinson, N., Okaya, D. A., 2008. Joint local/teleseismic tomographic inversion in Taiwan using TAIGER and other data. In: AGU, fall meeting. pp. T33E-06.

Leitner, B., Eberhart-Phillips, D., Anderson, H., Nabelek, J., 2001. A focused look at the Alpine fault New Zealand: Seismicity, focal mechanisms, and stress observations. J. Geophys. Res. 106 (B2), 2193-2220.

Li, P., Zhou, H.-W., Yan, Z., He, Y., 2009. Deformable layer tomostatics: 2D examples in western China. The Leading Edge 28(2), 206-210.

Little, T., Holcombe, R., Ilg, B., 2002. Ductile fabrics in the zone of active oblique convergence near the Alpine fault, New Zealand: Identifying the neotectonic overprint. J. Stru. Geol. 24, $193-217$.

Little, T. A., Cox, S., Vry, J. K., Batt, G., 2005. Variations in exhumation level and uplift rate along oblique-slip Alpine fault, central Southern Alps, New Zealand. Geol. Soc. Am. Bull. 117, 707-723.

Long, D. T., Cox, S., Bannister, S., Gerstenberger, M. C., Okaya, D., 2003. Upper crustal structure beneath the eastern Southern Alps and the MacKenzie Basin, New Zealand, derived from reflection data. NZ. J. Geol. Geophys. 46(1), 21-39. 
Luetgert, J.H., 1992. MacRay interactive two-dimensional seismic raytracing for the MacIntosh. Open file report.

MathWorks, 2002. Matlab statistics toolbox user's guide.

Meissinger, D., 2004. SEG-Y floating point confusion. CSEG recorder, 36-39.

Melhuish, A., Holbrook, S., Davey, F., Okaya, D., Stern, T., 2005. Crustal and upper mantle seismic structure of the Australian Plate, South Island, New Zealand. Tectonoph. 395, 113135.

Molnar, P., Anderson, H., Audoine, E., Eberhart-Phillips, D., Gledhill, K. R., Klosko, E. R., McEvilly, T. Okaya, D., Savage, M. K., Stern, T., Wu, F., 1999. Continuous deformation versus faulting through the continental lithosphere of New Zealand. Science 286, 526-629.

Mouyen, M., Cattin, R., Masson, F., 2008. Coulomb stress change due to seismic cycle in western Taiwan over the last 270 years. In: AGU, fall meeting. pp. T33E-03.

Nathan, S., 1977. Cretaceous and lower Tertiary stratigraphy of the coastal strip between Buttress Point and Ship Creek, South Westland, New Zealand. NZ. J. Geol. Geophys. 20 (4), 615-654.

Nathan, S., Anderson, H., Cook, R., Herzer, R., Hoskins, R., Raine, J., Smale, D., 1986. Cretaceous and Cenozoic sedimentary basins of the West Coast region, South Island, New Zealand. In: NZ. Geol. Sur. Basin Studies. Vol. 1.

Norris, R., 1979. A geometrical study of finite strain and bending in the South Island. In: Walcott, R., M.M., C. (Eds.), The Origin of the Southern Alps. Vol. 18 of Roy. Soc. NZ. Bull. pp. 21-28.

Norris, R., Cooper, A., 1995. Origin of small-scale segmentation and transpressional thrusting along the Alpine fault, New Zealand. Geol. Soc. Am. Bull. 107 (2), 231-240.

NZ Petroleum Exploration Co., L., 1971. Harihari no1 well completion report. Tech. rep., New Zealand Geological Survey Open-File Petroleum Report.

NZ Petroleum Exploration Co., L., 1972. The geology of Waiho no1 exploratory well. Petroleum Prospecting Licence no376 (Westland area). Tech. rep., New Zealand Geological Survey Open-File Petroleum Report.

Okaya, D., 2009. Joint passive/controlled source seismic experiment across Taiwan. EOS, Trans. AGU 90 (34), 289-290.

Okaya, D., Christensen, N., Stanley, D., Stern, T., 1995. Crustal anisotropy in the vicinity of the Alpine Fault Zone, South Island, New Zealand. NZ. J. Geol. Geophys. 38, 579-583.

Okaya, D., Henrys, S., Stern, T., 2002. Double-sided onshore-offshore seismic imaging of a plate boundary: "Super-gathers" across South Island, New Zealand. Tectonoph. 355, 247-263.

O'Keefe, B., 2008. Microseismicity of the central Alpine fault region, New Zealand. Master's thesis, Institute of Geophysics, Victoria University of Wellington.

Pearson, C. F., Beavan, J., Darby, D. J., Blick, G. H., Walcott, R., 1995. Strain distribution across the Australian-Pacific plate boundary in the central South Island, New Zealand, from 1992 GPS and earlier terrestrial observations. J. Geophys. Res. 100(B11), 22071-22082. 
Petit, J., Jouzel, J., Raynaud, D., Barkov, N., Barnola, J., Basile, I., Bender, M., Chappellaz, J., Davis, M., Delaygue, G., Delmotte, M., Kotlaykov, V., Legrand, M., Lipenkov, V., Lorius, C., Pepin, L., Ritz, C., Saltzman, E., Stievenard, M., 1999. Climate and atmospheric history of the past 420,000 years from the Vostok ice core, Antarctica. Nature 399, 429-436.

Pulford, A. K., 2002. Crustal structure and lithospheric doming: Aspects of deformation along an obliquely convergent plate boundary. Ph.D. thesis, Institute of Geophysics, Victoria University of Wellington.

Rajasekaran, S., McMechan, G. A., 1996. Tomographic estimation of spatial distribution of statics. Geophysics 61(4), 1198-1208.

Rattenbury, M., 1986. Late low-angle thrusting and the Alpine fault, central Westland, New Zealand. NZ. J. Geol. Geophys. 29 (437-446), 437-446.

Rattenbury, M., 1987. Timing of mylonitisation west of the Alpine fault, central Westland, New Zealand. NZ. J. Geol. Geophys. 30, 287-297.

Rattenbury, M., 1991. The Fraser complex: high-grade metamorphic, igneous and mylonitic rocks in central Westland, New Zealand. NZ. J. Geol. Geophys. 34, 23-33.

Ravens, J., 1999. Globe Claritas, seismic processing manual. Tech. rep., GNS Science.

Rawlinson, N., 2005. FMTOMO - fast marching tomography package: Instruction manual. Tech. rep., Research School of Earth Sciences, Australian National University.

Rawlinson, N., Kennett, B. L. N., 2008. Teleseismic tomography of the upper mantle beneath the southern Lachlan Orogen, Australia. Physics of the Earth and Planetary Interiors 167, $84-97$.

Rawlinson, N., Kennett, B. L. N., Heintz, M., 2006a. Insights into the structure of the upper mantle beneath the Murray Basin from 3D teleseismic tomography. Australian Journal of Earth Sciences 53, 595-604.

Rawlinson, N., Reading, A. M., Kennett, B. L. N., 2006b. Lithospheric structure of Tasmania from a novel form of teleseismic tomography. J. Geophys. Res. 111, B02301.

Rawlinson, N., Sambridge, M., 2003. Seismic traveltime tomography of the crust and lithosphere. Advances in Geophysics 46, 81-197.

Rawlinson, N., Sambridge, M., 2005. The fast marching method: an effective tool for tomographic imaging and tracking multiple phases in complex layered media. Expl. Geophys. 36, $341-350$.

Rawlinson, N., Urvoy, M., 2006. Simultaneous inversion of active and passive source datasets for 3D seismic structure with application to Tasmania. Geophys. Res. Letters 33, L24313.

Sambridge, M., Gudmundsson, O., 1998. Tomographic systems of equations with irregular cells. J. Geophys. Res. 103(B1), 773-781.

Sambridge, M., Rickwood, P., Rawlinson, N., Sommacal, S., 2007. Automatic differentiation in geophysical inverse problems. Geophys. J. Int. 170, 1-8.

Savage, M. K., Duclos, M., Marson-Pidgeon, K., 2007. Seismic anisotropy in South Island, New Zealand. In: Okaya, D., Stern, T., Davey, F. (Eds.), A continental plate boundary: Tectonics at South Island, New Zealand. Vol. 175 of AGU Geophysical Monograph Series. pp. 95-114. 
Scherwath, M., 2002. Lithospheric structure and deformation in an oblique continental collision zone, South Island, New Zealand. Ph.D. thesis, Institute of Geophysics, Victoria University of Wellington.

Scherwath, M., Okaya, D., Stern, T., Henrys, S., Kleffmann, S., Davey, F., 1996. SIGHT’96 Seismic land data acquisition report.

Scherwath, M., Stern, T., Davey, F., Davies, R., 2006. Three-dimensional lithospheric deformation and gravity anomalies associated with oblique continent collision in South Island, New Zealand. Geophys. J. Int. 167, 906-916.

Scherwath, M., Stern, T., Davey, F., Okaya, D., Holbrook, W., Davies, R., Kleffmann, S., 2003. Lithospheric structure across oblique continental collision in New Zealand from wide-angle P-wave modelling. J. Geophys. Res. 108 (B12), 2566.

Scherwath, M., Stern, T., Melhuish, A., Molnar, P., 2002. Pn anisotropy and distributed upper mantle deformation associated with a continental transform fault. Geophys. Res. Letters $29(8)$.

Scholz, C., Rynn, J. M., Weed, R. W., Frohlich, C., 1973. Detailed seismicity of the Alpine Fault Zone and Fiordland region, New Zealand. Geol. Soc. Am. Bull. 84(10), 3297-3316.

Schuster, G. T., Zhou, M., 2006. A theoretical overview of model based and correlation-based redatuming methods. Geophysics 71(4), SI103-SI110.

Sethian, J. A., 1996. A fast marching level set method for monotonically advancing fronts. Proc. Nat. Acad. Sci. 93, 1591-1595.

Seward, A. M., 2008. Modelling Pn wave speeds beneath the central North Island, New Zealand. Ph.D. thesis, Institute of Geophysics, Victoria University of Wellington.

Sherriff, R. E., Geldart, L. P., 1995. Exploration Seismology. Cambridge University Press.

Sibson, R., 1977. Fault rocks and fault mechanisms. J. Geol. Soc. London 133, 191-213.

Sibson, R. H., White, S. H., Atkinson, B. K., 1979. Fault rock distribution and structure within the Alpine Fault Zone: a preliminary account. In: Walcott, R. I., Creswell, M. M. (Eds.), The Origin of the Southern Alps. Vol. 18 of Roy. Soc. NZ. Bull. pp. 55-65.

Sircombe, K., 1993. Analysis of the South Westland Basin, New Zealand. Master's thesis, School of Earth Sciences, University of Waikato.

Sircombe, K., Kamp, P. J., 1998. The South Westland Basin: seismic stratigraphy basin geometry and evolution of a foreland basin with the Southern Alps collision zone, New Zealand. Tectonoph. 300, 359-387.

Smith, E. G., Stern, T., O'Brien, B., 1995. A seismic velocity profile across the central South Island, New Zealand. NZ. J. Geol. Geophys. 38, 565-570.

Stagpoole, V., 1997. A geophysical study of the northern Taranaki Basin, New Zealand. Ph.D. thesis, Institute of Geophysics, Victoria University of Wellington.

Stein, S., Wysession, M., 2003. An introduction to Seismology, Earthquake and Earth structure. Blackwell Publishing.

Stern, T., 1995. Gravity anomalies and crust loading at and adjacent to the Alpine fault, New Zealand. NZ. J. Geol. Geophys. 38, 593-600. 
Stern, T., Davey, F., Delisle, G., 1991. Lithospheric flexure induced by the load of Ross Archipielago, southern Victoria Land, Antarctica. In: Thomson, M., Crame, J., Thomson, J. (Eds.), Geological Evolution of Antarctica. Cambridge University Press, pp. 323-328.

Stern, T., Kleffmann, S., Okaya, D., Scherwath, M., Bannister, S., 2001. Low seismic wave speeds and enhanced fluid pressure beneath the Southern Alps of New Zealand. Geology 29 (8), 679-682.

Stern, T., McBride, J., 1998. Seismic exploration of continental strike-slip zones. Tectonoph. $286,63-78$.

Stern, T., Molnar, P., Okaya, D., Eberhart-Phillips, D., 2000. Teleseismic P-wave delays and modes of shortening the mantle lithosphere beneath South Island, New Zealand. J. Geophys. Res. 105 (B9), 21615-21631.

Stern, T., Okaya, D., Kleffmann, S., Scherwath, M., Henrys, S., Davey, F., 2007. Geophysical exploration and dynamics of the Alpine Fault Zone. In: Okaya, D., Stern, T., Davey, F. (Eds.), A continental plate boundary: Tectonics at South Island, New Zealand. Vol. 175 of AGU Geophysical Monograph Series. pp. 207-233.

Stern, T., Okaya, D., Scherwath, M., 2002. Structure and strength of a continental transform from onshore-offshore seismic profiling of South Island, New Zealand. Earth Planets Space 54, 1011-1019.

Stern, T., Stratford, W., Seward, A., Henderson, M., Savage, M., Smith, E., Benson, A., Greve, S., Salmon, M., 2010. Crust-mantle structure of the central North Island, New Zealand, based on seismological observations. J. Volc. Geoth. Res. 190, 58-74.

Stock, J., Molnar, P., 1987. Revised history of early Tertiary plate motion in the south-west Pacific. Nature 325, 495-499.

Suggate, R., 1963. The Alpine Fault. Trans. Roy. Soc. NZ. (Geol.) 2 (7), 105-129.

Suggate, R., 1990. Late Pliocene and Quaternary glaciations of New Zealand. Quat. Sc. Rev. 9, 175-197.

Suggate, R., Almond, P., 2005. The Last Glacial Maximum (LGM) in western South Island, New Zealand: Implications for the global LGM and MIS2. Quat. Sc. Rev. 24 (16-17), 19231940.

Sutherland, R., 1995. The Australia-Pacific boundary and Cenozoic plate motions in the SW Pacific: Some constraints from GEOSAT data. Tectonics 14, 819-831.

Sutherland, R., 1996. Transpressional development of the Australia-Pacific boundary through southern South Island, New Zealand: Constraints from Miocene-Pliocene sediments, Waiho no1 borehole, South Westland. NZ. J. Geol. Geophys. 42, 295-301.

Sutherland, R., Berryman, K., Norris, R., 2006. Quaternary slip rates and geomorphology of the Alpine fault: Implications for kinematics and seismic hazard in southwest New Zealand. Geol. Soc. Am. Bull. 118 (3/4), 464-474.

Sutherland, R., Eberhart-Phillips, D., Harris, R. A., Stern, T., Beavan, J., Ellis, S., Henrys, S., Cox, S., Norris, R., Berryman, K., Townend, J., Bannister, S., Pettinga, J., Leitner, B., Wallace, L., Little, T., Cooper, A., Yetton, M., Stirling, M., 2007. Do great earthquakes occur on the Alpine fault in central South Island, New Zealand? In: Okaya, D., Stern, T., Davey, F. (Eds.), A continental plate boundary: Tectonics at South Island, New Zealand. Vol. 175 of AGU Geophysical Monograph Series. pp. 235-251. 
Sutherland, R., Nathan, S., Turnbull, M., 1995. Pliocene-Quaternary sedimentation and Alpine fault related tectonics in the lower Cascade Valley, South Westland, New Zealand. NZ. J. Geol. Geophys. 38(4), 431-450.

Taylor, L., 1997. The South Island Geophysical Transect: forward modelling and high resolution data. DipAppSci dissertation, Institute of Geophysics, Victoria University of Wellington.

Tippett, J., Hovius, N., 2000. Geodynamic processes in the Southern Alps, New Zealand. In: Summerfield, M. A., Wiley, J. (Eds.), Geomorphology and global tectonics. Hoboken, N. J.

Tippett, J., Kamp, P. J., 1993. Fission track analysis of the late Cenozoic vertical kinematics of continental Pacific crust, South Island, New Zealand. J. Geophys. Res. 98 (B9), 16119-16148.

Upton, P., Caldwell, G., Chamberlain, D., Craw, D., James, Z., Jiracek, G., Koons, P. O., Wannamaker, P., 2000. Fluids in a backthrust regime, Southern Alps, New Zealand. J. Geochem. Expl. 69-70, 517-521.

Upton, P., Mueller, K. J., Koons, P. O., Powell, L., 2003. Reorganization of strain in response to erosional forcing at intermediate scales: Puli Embayment, Western Taiwan. Eos Trans. AGU 84 (46).

van Avendonk, H. J., Harding, A., Orcutt, J., Holbrook, S., 2001. Hybrid shortest path and ray bending method for traveltime and raypath calculations. Geophysics 66, 648-653.

van Avendonk, H. J., Holbrook, S., Okaya, D., Austin, J., Davey, F., Stern, T., 2004. Continental crust under compression: a seismic refraction study of South Island Geophysical Transect I, South Island, New Zealand. J. Geophys. Res. 109, B06302.

Vincenty, T., 1975. Direct and inverse solutions of geodetics on the ellipsoid with application of nested equations. National Geodesic Survey Review XXII, 176.

Vry, J., Powell, R., Golden, K. M., Petersen, K., 2010. The role of exhumation in metamorphic dehydration and fluid production. Nature Geoscience 3, 31-35.

Vry, J., Storkey, A. C., Harris, C., 2001. Role of fluids in the metamorphism of the Alpine fault Zone, New Zealand. J. Metamorph. Geol. 19, 21-31.

Walcott, R., 1979. Plate motion and shear strain rates in the vicinity of the Southern Alps. R. Soc. NZ. Bull. 18, 5-12.

Walcott, R., 1984. The kinematics of the plate boundary zone through New Zealand: A comparison of short- and long-term deformation. Geophys. J. Roy. Astron. Soc. 79(2), 613-633.

Walcott, R., 1998. Modes of oblique compression: Late Cenozoic tectonics of the South Island of New Zealand. Rev. Geophys. 36 (1), 1-26.

Wallace, L. M., Beavan, J., McCaffrey, R., Berryman, K., Denys, P., 2007. Balancing the plate motion budget in the South Island, New Zealand using GPS, geological and seismological data. Geophys. J. Int. 168 (1), 332-352.

Wannamaker, P., Jiracek, G., Stodt, J., Caldwell, T., Gonzalez, V., McKnight, J., A.D., P., 2002. Fluid generation and pathways beneath an active compressional orogen, the New Zealand Southern Alps, inferred from magneto-telluric data. J. Geophys. Res. 107(B6).

Watanabe, T., T., H., Sassa, K., 1996. Seismic traveltime tomography in anisotropic heterogeneous media. J. Appl. Geophys. 35, 133-143. 
Watts, A. B., 2001. Isostasy and flexure of the lithosphere. Cambridge University Press.

Wellman, H., 1953. Data for the study of recent and late Pleistocene faulting in the South Island of New Zealand. NZ. J. Sc. \& Techn. 34B, 270-288.

Wellman, H., 1956. Structural outline of New Zealand. NZ. Geol. Sur. Bull. 121.

Wellman, H., 1979. An uplift map for the South Island of New Zealand, and a model for the uplift of the Southern Alps. R. Soc. NZ. Bull. 18, 13-20.

Wells, A., Yetton, M., Duncan, R., Stewart, G., 1999. Prehistoric dates of the most recent Alpine fault earthquakes, New Zealand. Geology 27 (11), 995-998.

Wessel, P., Smith, W., 1998. New, improved version of generic mapping tool released. EOS, Trans. AGU 79(47), 579.

White, S. H., Green, P. F., 1986. Tectonic development of the Alpine Fault Zone, New Zealand: A fission-track study. NZ. J. Geol. Geophys. 14(2), 124-127.

Wightman, R., Little, T., 2007. Deformation of the Pacific Plate above the Alpine fault ramp and its relationship to expulsion of metamorphic fluids: An array of backshears. In: Okaya, D., Stern, T., Davey, F. (Eds.), A continental plate boundary: Tectonics at South Island, New Zealand. Vol. 175 of AGU monograph Series. pp. 177-205.

Woodward, D., 1979. The crustal structure of the Southern Alps, New Zealand, as determined by gravity. Roy. Soc. NZ. Bull. 18, 95-98.

Woodward, D., 1987. Downhole seismic survey at Orton and Hinds, south Canterbury. In: Seismic surveys for groundwater in Canterbury, New Zealand 1985-86. A case study. Research report no217. GNS Science.

Woodward, D., 1989. Seismic survey at Orton, south Canterbury. Tech. Rep. 225, GNS Science.

Woodward, D., 1991. Inversion of seismic refraction data. Tech. Rep. 114, GNS Science.

Woodward, D., Kicinski, J., 1987. Minisosie seismic surveys at Hinds and Orton, south Canterbury. In: Seismic surveys for groundwater in Canterbury, New Zealand 1985-86. A case study. Research report no217.

Wu, F., Davey, F., Okaya, D., 2007. Taiwan and South Island, New Zealand: A comparison of continental collision. In: Okaya, D., Stern, T., Davey, F. (Eds.), A continental plate boundary: Tectonics at South Island, New Zealand. Vol. 175 of AGU Geophysical Monograph Series. pp. 329-346.

Young, D., 1968. The Fraser fault in central Westland, New Zealand, and its associated rocks. NZ. J. Geol. Geophys. 11 (2), 291-311.

Zelt, B., Sain, K., Naumenko, J., Sawyer, D., 2003. Assessment of crustal velocity models using seismic refraction and reflection tomography. Geophys. J. Int. 153, 609-626.

Zelt, C., 1999. Modelling Strategies and model assessment for wide-angle seismic traveltime data. Geophys. J. Int. 139, 183-204.

Zelt, C., Smith, R., 1992. Seismic traveltime inversion for 2D crustal velocity structure. J. Geophys. Res. 108, 16-34. 
Zelt, C., Zelt, B., 1998. Study of out-of-plane effects in the inversion of refraction/wide-angle reflection traveltimes. Tectonoph. 286, 209-221.

Zhou, H.-W., 2006. Multiscale deformable-layer tomography. Geophysics 71(3), R11-R19.

Zhu, X., Sixta, D. P., Angstman, B. G., 1992. Tomostatics: turning-ray tomography + static corrections. The Leading Edge 11(12), 15-23.

Zhu, X., Valasek, P., Roy, B., Shaw, S., Howell, J., Whitney, S., Whitmore, N. D., Anno, P., 2008. Recent applications of turning-ray tomography. Geophysics 73(5), VE243-VE254. 